\title{
A QUANTITATIVE RISK MANAGEMENT FRAMEWORK FOR DUST AND HYBRID MIXTURE EXPLOSIONS
}

\author{
by \\ Meftah Ali Abuswer \\ Submitted in partial fulfilment of the requirements \\ for the degree of Doctor of Philosophy
}

at

Dalhousie University

Halifax, Nova Scotia

July 2012

(C) Copyright by Meftah Ali Abuswer, 2012 


\section{DALHOUSIE UNIVERSITY}

\section{PROCESS ENGINEERING AND APPLIED SCIENCE}

The undersigned hereby certify that they have read and recommend to the Faculty of Graduate Studies for acceptance a thesis entitled "A QUANTITATIVE RISK MANAGEMENT FRAMEWORK FOR DUST AND HYBRID MIXTURE EXPLOSIONS" by Meftah Ali Abuswer in partial fulfilment of the requirements for the degree of Doctor of Philosophy.

Dated: July 03, 2012

External Examiner:

Research Supervisor:

Examining Committee:

Departmental Representative: 


\title{
DALHOUSIE UNIVERSITY
}

DATE: July 03, 2012

\begin{abstract}
AUTHOR: Meftah Ali Abuswer
TITLE: $\quad$ A QUANTITATIVE RISK MANAGEMENT FRAMEWORK FOR DUST AND HYBRID MIXTURE EXPLOSIONS

DEPARTMENT OR SCHOOL: $\quad$ Process Engineering and Applied Science

DEGREE: PhD CONVOCATION: October $\quad$ YEAR: 2012
\end{abstract}

Permission is herewith granted to Dalhousie University to circulate and to have copied for non-commercial purposes, at its discretion, the above title upon the request of individuals or institutions. I understand that my thesis will be electronically available to the public.

The author reserves other publication rights, and neither the thesis nor extensive extracts from it may be printed or otherwise reproduced without the author's written permission.

The author attests that permission has been obtained for the use of any copyrighted material appearing in the thesis (other than the brief excerpts requiring only proper acknowledgement in scholarly writing), and that all such use is clearly acknowledged.

Signature of Author 


\section{DEDICATION PAGE}

To Father and Mother 


\section{TABLE OF CONTENTS}

LIST OF TABLES viii

LIST OF FIGURES X xii

$\begin{array}{ll}\text { ABSTRACT Xvii } & \text { x }\end{array}$

LIST OF ABBREVIATIONS AND SYMBOLS USED X xiii

ACKNOWLEDGMENTS Xxiv

CHAPTER 1 INTRODUCTION 1

1.1 THESIS OVERVIEW

1.2 DEFINITIONS and TERMINOLOGY 4

1.3 SCOPE OF RESEARCH AND OBJECTIVES 5

1.4 Qualitative AND Quantitative Risk ANALYSIS 6

1.5 Dust And Hybid MiXture Explosions 8

1.5.1 Dust and hybrid mixture explosions in the process industries $\quad 10$

$\begin{array}{lll}\text { 1.5.2 Dust explosibility } & 11\end{array}$

1.5.3 Domino effect 12

1.5.4 Illustrative case histories of dust and hybrid mixture explosions 13

1.6 LEGISLATION AND DUST EXPLOSIONS 14

1.6.1 U.S. Occupational Safety \& Health Administration (OSHA) 15

1.6.2 National Fire Protection Association (NFPA) 15

1.7 Dust and Hybrid Mixture Explosion Prevention, Mitigation, AND CONTROL 16

$\begin{array}{lll}\text { 1.7.1 The risk management process } & 17\end{array}$

1.8 Original CONTRIBUtions OF THE RESEARCH 25

$\begin{array}{lll}\text { CHAPTER } 2 \text { BACKGROUND } & 26\end{array}$

$\begin{array}{lll}2.1 & \text { INTRODUCTION } & 26\end{array}$

2.2 QuAntitative Risk Assessment ReSEARCH 26 
2.3.2 Quantitative Risk Assessment methodology for industrial processes handling dust

2.3.3 Dust explosion prevention and mitigation approach based on inherent safety

2.3.4 Computational Fluid Dynamics modeling (CFD) 36

2.3.5 Fault Tree Analysis 37

CHAPTER 3 QUANTITATIVE RISK MANAGEMENT FRAMEWORK 41

3.1 QRMF Methodology 41

3.1.1 Hazard identification 43

3.1.2 Risk analysis 43

3.1.3 Risk estimation $\quad 54$

3.1.4 Risk evaluation 58

3.1.5 Risk control 59

$\begin{array}{lll}\text { 3.1.6 Residual risk control } & 61\end{array}$

3.2 QRMF IMPLEMENTATION $\quad 61$

CHAPTER 4 EXPERIMENTAL AND SIMULATION WORK 65

4.1 EXPERIMENTAL WORK

4.1.1 Apparatus 65

4.1.2 Procedure 66

$\begin{array}{lll}\text { 4.1.3 Tested dust materials } & 67\end{array}$

4.2 Dust Explosion Simulation Code(DESC) 70

4.2.1 Simulation preparation $\quad 70$

$\begin{array}{lll}\text { 4.2.2 Validation and simulations } & 73\end{array}$

$\begin{array}{lll}\text { CHAPTER } 5 & \text { CASE STUDIES } & 78\end{array}$

5.1 The IMPERIAL SUgar REFINERY DUST EXPLOSION 78

$\begin{array}{lll}5.1 .1 & \text { Refinery description } & 78\end{array}$ 
$\begin{array}{lll}\text { 5.1.2 Explosion causes } & 79\end{array}$

$\begin{array}{lll}\text { 5.1.3 Explosion event } & 81\end{array}$

5.1.4 Applying the QRMF to the Imperial Sugar refinery 82

5.2 Semabla Grain Storage Hybrid Mixture Explosion 125

5.2.1 Semabla installation description 125

$\begin{array}{lll}\text { 5.2.2 Explosion causes } & 126\end{array}$

$\begin{array}{lll}\text { 5.2.3 Explosion event } & 127\end{array}$

5.2.4 Explosion consequences 128

5.2.5 Applying the QRMF to the Semabla grain storage silo 128

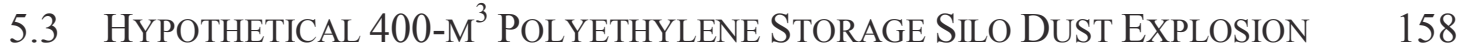

CHAPTER 6 CONCLUSIONS AND RECOMMENDATIONS 164

$\begin{array}{lll}6.1 & \text { CONCLUSIONS } & 164\end{array}$

$\begin{array}{lll}6.2 & \text { RECOMMENDATIONS } & 167\end{array}$

$\begin{array}{ll}\text { REFERENCES } & 168\end{array}$

$\begin{array}{lll}\text { Appendix A Industries with combustible dusts } & 175\end{array}$

Appendix B Examples of dust explosion incidents 180

Appendix C Process Safety Management elements 184

Appendix D Probit correlations for variety of explosions and their transformation 186

Appendix E Severity of consequences and hazard probability ratings 189

$\begin{array}{lll}\text { Appendix F } & \text { Explosibility parameters of different dust materials, used in } \\ & \text { DESC simulations } & 191\end{array}$

Appendix G Elsevier license, terms and conditions 194 


\section{LIST OF TABLES}

Table 1.1 Features of qualitative and quantitative research.

Table 1.2 Explosibility parameters and risk components.

Table $1.3 \quad$ The explosibility rank.

Table 1.4 NFPA publications relevant to combustible dust hazard controls.

Table $1.5 \quad$ Key inherent safety principles.

Table 1.6 A hierarchical view of various means of preventing and mitigating dust explosions.

Table 3.1

Fatal accident rates in Australian industry.

Table 3.2

The decision matrix risk assessment technique.

Table 3.3

Inherent safety checklist.

Table 4.1 20-L explosibility data for polyethylene/hybrid mixture samples.

Table 4.2 20-L explosibility data for icing sugar powder.

Table 4.3 20-L explosibility data for granulated sugar powder.

Table 4.4 DESC scenario input data for $400 \mathrm{~m}^{3}$ polyethylene silo geometry.

Table 4.5 The percent error of dust explosion $\mathrm{P}_{\max }$ between the experimental and DESC of different materials in 20-L chamber.

Table 4.6 Comparison between different materials at different explosion volumes in terms of DESC $\mathrm{P}_{\max }$ and $\mathrm{t}_{\max }$.

Table 5.1 The number of injured, deceased, and uninjured workers at the Imperial Sugar refinery explosion.

Table 5.2 Opening pressures values of pressure panels and their sizes in the Imperial Sugar refinery.

Table 5.3 DESC scenario input data for Imperial Sugar refinery geometry.

Table 5.4

Estimated Probit damage percentages caused by explosion 
overpressure of incident outcome cases at Module $(2,1)$.

Table 5.5 Estimated Probit damage percentages caused by explosion overpressure of incident outcome cases at Module $(2,2)$.

Table 5.6 Estimated Probit damage percentages caused by explosion overpressure of incident outcome cases at Module $(2,3)$.

Table 5.7 Estimated Probit damage percentages caused by explosion overpressure of incident outcome cases at Module $(2,4)$.

Table 5.8 Failure rates of the explosion basic events at the Imperial Sugar refinery.

Table 5.9 Individual risk calculations for the first floor, Module $(2,1)$.

Table 5.10 Individual risk calculations for the second floor, Module $(2,2)$.

101

Table 5.11 Individual risk calculations for the third floor, Module $(2,3)$.

101

Table 5.12 Individual risk calculations for the fourth floor, Module $(2,4)$.

102

Table 5.13 Estimated number of fatalities at each frequency of the incident outcome cases.

104

Table 5.14 Cumulative frequency data for F-N curve of the Imperial Sugar refinery explosion.

Table 5.15 Summary of the individual risk results for the Imperial Sugar refinery explosion, before applying the QRMF.

Table 5.16 Applying inherent safety principles on the units, and wrong actions that contributed to the Imperial Sugar refinery explosion.

Table 5.17 Opening pressure values of pressure panels and their sizes in the Imperial Sugar refinery, after applying the QRMF.

Table 5.18 Estimated Probit damage percentages caused by explosion overpressure of incident outcome cases in the simulated refinery.

Table 5.19 The estimated failure rate of the explosion's basic events at the Imperial Sugar refinery before and after applying the QRMF.

Table 5.20 Individual risk calculations after applying the QRMF for the first floor.

Table 5.21 Individual risk calculations after applying the QRMF for the second floor. 
Table 5.22 Individual risk calculations after applying the QRMF for the third floor

Table 5.23 Individual risk calculations after applying the QRMF for the fourth floor

Table 5.24 Summary of the individual risk results for the Imperial Sugar refinery explosion.

Table 5.25 The number of injured, deceased and uninjured people at the storage grain silo explosion.

Table 5.26 Opening pressure values of pressure panels and their sizes in the Semabla storage silo.

Table 5.27 DESC scenario input data for Semabla silo geometry.

Table 5.28 Estimated Probit damage percentages caused by explosion overpressure of incident outcome cases at Module $(2,1)$.

Table 5.29 Individual risk calculations for the Semabla silo, Module (4,1).

Table 5.30 Cumulative frequency data for the F-N curve of the Semabla explosion.

Table 5.31 Cumulative frequency data for F-N curve of the Semabla explosion.

Table 5.32 Summary of the individual risk results for the Semabla explosion, before applying the QRMF.

Table 5.33 Applying inherent safety principles to the units and wrong actions that contributed to the Semabla explosion.

Table 5.34 Opening pressures values of pressure panels and their sizes in the Semabla storage silo.

Table 5.35 Estimated Probit damage percentages caused by explosion overpressure of incident outcome cases in the simulated Semabla grain silo, after applying the QRMF.

Table 5.36 Estimated failure rate of the explosion's basic events at Semabla, before and after applying the QRMF.

Table 5.37 Individual risk calculations for the Semabla silo, Module $(4,1)$.

Table 5.38 Summary of the individual risk results for the Semabla storage silo explosion. 
Table 5.39 Potential dust explosion scenarios for case study.

Table A.1 Industries with more frequent and/or high consequence combustible dust explosions / fires.

Table A.2 Industries that may have combustible dusts.

Table B.1 Illustrative examples of dust explosion incidents, 1911-2004.

Table C.1 Process Safety Management elements.

Table D.1 Probit correlations for a variety of exposures (the causative variable is representative of the magnitude of the exposure).

Table D.2 Transformation from percentages to Probits.

Table E.1 Criticality rating (or severity of consequences ratings) for the decision matrix risk assessment technique.

Table E.2 Frequency rating (or hazard probability ratings) for the decision matrix risk assessment technique.

Table F.1 Explosibility parameters of polyethylene dust, -200 mesh (Sample no. A).

Table F.2 Explosibility parameters of polyethylene dust, -70 mesh (Sample no. B).

Table F.3 Explosibility parameters of polyethylene dust, -200 mesh + $1 \%$ hexane (Sample no. C).

Table F.4 Explosibility parameters of corn starch (maize) dust (provided by GexCon). 


\section{LIST OF FIGURES}

$\begin{array}{lll}\text { Figure } 1.1 & \text { Thesis overview. } & 3\end{array}$

Figure 1.2 Overview of the QRM framework process. 7

$\begin{array}{lll}\text { Figure 1.3 The domino effect in dust explosions. } & 13\end{array}$

Figure 1.4 The risk management process. 18

Figure 1.5 Inherent safety is not an isolated change but, rather, part of a package of improvements needed by the process industries. 21

$\begin{array}{lll}\text { Figure 2.1 The SCAP algorithm. } & 28\end{array}$

Figure 2.2 Overview of the QRA tool. 31

Figure 2.3 Illustration of a fictional industrial facility, divided into groups of modules. 32

Figure 2.4 A systematic approach to loss prevention. 34

$\begin{array}{lll}\text { Figure 2.5 The fire triangle. } & 35\end{array}$

$\begin{array}{lll}\text { Figure 2.6 The fire triangle for dust. } & 35\end{array}$

Figure 2.7 The explosion pentagon. 35

Figure $2.8 \quad 3 \mathrm{D}$ plot showing flame propagation inside a typical module. 36

Figure 2.9 A Relex architect platform sample with fault tree data displayed.

Figure 3.1 A Quantitative Risk Management Framework for dust and hybrid mixture explosion prevention based on the hierarchy of controls.

Figure 3.2 General dust and hybrid mixture explosion FTA flowchart. 46

Figure 3.3 HSE framework for tolerability of risk. 59

Figure 3.4 An inherent safety-based management of change protocol. 63

Figure 3.5 Flowchart for implementation of conceptual risk management framework for dust and hybrid mixture explosions. 64

Figure 4.1 Experimental, validation, and simulation link 66

$\begin{array}{lll}\text { Figure 4.2 Scheme of Siwek 20-L sphere. } & 67\end{array}$ 
Figure 4.3 KSEP pressure-time curve during polyethylene (-200 mesh) dust explosion in a $20-\mathrm{L}$ chamber.

Figure 4.4 Part of a DESC Excel spreadsheet.

Figure 4.5 A silo geometry at CASD (Computer Aided Scenario Design) window.

Figure 4.6 DESC run manager window.

Figure 4.7 DESC simulation of an icing sugar explosion in a 20-L spherical chamber.

Figure 4.8 DESC simulation of an icing sugar explosion in a $1-\mathrm{m}^{3}$ spherical chamber.

Figure 4.9 DESC simulation of a granulated sugar explosion in a 20-L spherical chamber.

Figure 4.10 DESC simulation of a granulated sugar explosion in a $1-\mathrm{m}^{3}$ spherical chamber.

Figure 4.11 DESC simulation of an icing sugar explosion in a $400-\mathrm{m}^{3}$ cylindrical silo without explosion vents.

Figure 4.12 DESC simulation of a granulated sugar explosion in a $400-\mathrm{m}^{3}$ cylindrical silo without explosion vents.

Figure 4.13 DESC simulation of $48-\mu \mathrm{m}$ polyethylene explosion in a $20-\mathrm{L}$ spherical chamber.

Figure 5.1 Granulated sugar supply and discharge through the silos.

Figure 5.2 Packing buildings: first floor plan.

Figure 5.3 CASD image (3D front view) of the Imperial Sugar refinery with the pressure relief panels (PPs).

Figure 5.4 CASD image (3D back view) and grid cells of the Imperial Sugar refinery with the pressure relief panels (PPs).

Figure 5.5 Side view of the module distributions of the Imperial Sugar refinery geometry.

Figure 5.6 DESC representation of interconnected $3700-\mathrm{m}^{3}$ silos and the monitoring points (M1 - M80) at the Imperial Sugar refinery.

Figure 5.7 DESC pressure simulation from a plane view of the first floor, Module $(2,1)$, of the Imperial Sugar refinery explosion. 
Figure 5.8 DESC pressure simulation from a plane view of the second floor, Module (2,2), of the Imperial Sugar refinery explosion.

Figure 5.9 DESC pressure simulation from a plane view of the third floor, Module (2,3), of the Imperial Sugar refinery explosion.

Figure 5.10 DESC pressure simulation from a plane view of the fourth floor, Module $(2,4)$, of the Imperial Sugar refinery explosion.

Figure 5.11 DESC pressure/time simulation at the monitor points on the first floor, Module $(2,1)$, of the Imperial Sugar refinery explosion.

Figure 5.12 DESC pressure/time simulation at the monitor points on the second floor, Module $(2,2)$, of the Imperial Sugar refinery explosion.

Figure 5.13 DESC pressure/time simulation at the monitor points on the third floor, Module $(2,3)$, of the Imperial Sugar refinery explosion.

Figure 5.14 DESC pressure/time simulation at the monitor points on the fourth floor, Module $(2,4)$, of the Imperial Sugar refinery explosion.

Figure 5.15 Fault Tree Analysis flowchart of the Imperial Sugar refinery explosion.

Figure 5.16 The estimated social risk F-N curve for the Imperial Sugar refinery before the explosion.

Figure 5.17 DESC pressure simulation from a plane view of the first floor, Module $(2,1)$, of the Imperial Sugar refinery explosion, after applying the QRMF.

Figure 5.18 DESC pressure simulation from a plane view of the second floor, Module (2,2), of the Imperial Sugar refinery explosion, after applying the QRMF.

Figure 5.19 DESC pressure simulation from a plane view of the third floor, Module (2,3), of the Imperial Sugar refinery explosion, after applying the QRMF.

Figure 5.20 DESC pressure simulation on a plane view of the fourth floor, Module $(2,4)$, of the Imperial Sugar refinery explosion after applying the QRMF.

Figure 5.21 DESC pressure/time simulation at monitor points on the first floor, Module $(2,1)$, of the Imperial Sugar refinery explosion, after applying the QRMF.

Figure 5.22 DESC pressure/time simulation at monitor points on the second 
floor, Module $(2,2)$, of the Imperial Sugar refinery explosion, after applying the QRMF.

Figure 5.23 DESC pressure / time simulation at the monitor points in the third floor, Module $(2,3)$, of the Imperial Sugar refinery explosion, after applying the QRMF.

Figure 5.24 DESC pressure/time simulation at monitor points on the fourth floor, Module $(2,4)$, of the Imperial Sugar refinery explosion, after applying the QRMF.

Figure 5.25 Fault Tree Analysis flowchart of the Imperial Sugar refinery explosion.

Figure 5.26 HSE frameworks for tolerability of risk.

Figure 5.27 View of the Semabla cells and warehouse-A storage units before the explosion.

Figure 5.28 The Semabla identification of storage cells.

Figure 5.29 A view of the Semabla silo and warehouse-A storage facilities after the explosion.

Figure 5.30 CASD image (3D view) of the Semabla storage silo with the pressure relief panels (PPs).

Figure 5.31 Module distribution: a side view of the Semabla silo geometry.

Figure 5.32 DESC pressure simulation of the Semabla silo explosion geometry (top view).

Figure 5.33 DESC pressure simulation of the Semabla silo explosion geometry (side view).

Figure 5.34 A plane view of the Semabla silo geometry in Blaye, France.

Figure 5.35 DESC pressure/time simulation at monitor points in Modules $(4,1)$ and $(4,2)$ of the Semabla storage silo explosion.

Figure 5.36 Fault Tree Analysis flowchart of the Semabla silo explosion.

Figure 5.37 Social risk F-N curves for the Semabla explosion.

Figure 5.38 DESC pressure simulation from a plane view of the Semabla storage silo explosion, after applying the QRMF at $3.228 \mathrm{~s}$.

Figure 5.39 DESC pressure simulation from a plane view of the Semabla storage silo explosion, after applying the QRMF at $12.378 \mathrm{~s}$. 
Figure 5.40 DESC pressure/time simulation at the monitor points in Modules $(4,1)$ and $(4,2)$ of the Semabla storage silo explosion, after applying the QRMF.

Figure 5.41 Fault Tree Analysis flowchart of the Semabla explosion after application of the QRMF.

Figure 5.42 HSE frameworks for tolerability of risk.

Figure 5.43 DESC simulation of Scenario 1.

Figure 5.44 DESC simulation of Scenario 2.

Figure 5.45 DESC simulation of Scenario 3.

Figure 5.46 DESC simulation of Scenario 4.

Figure 5.47 DESC simulation of Scenario 5.

Figure 5.48 DESC simulation of Scenario 6. 


\section{ABSTRACT}

Dust and hybrid mixture explosions continue to occur in industrial processes that handle fine powders and flammable gases. Considerable research is therefore conducted throughout the world with the objective of both preventing the occurrence and mitigating the consequences of such events. In the current work, research has been undertaken to help advance the field of dust explosion prevention and mitigation from an emphasis on hazards to a focus on risk. Employing the principles of quantitative risk assessment (QRA) of dust and hybrid mixture explosions, a methodological framework for the management of these risks has been developed.

The Quantitative Risk Management Framework (QRMF) is based on hazard identification via credible accident scenarios for dust explosions, followed by probabilistic Fault Tree Analysis (FTA) (using Relex - Reliability Excellence - software) and consequence severity analysis, represented by maximum explosion pressure, (using DESC - Dust Explosion Simulation Code - software). Identification of risk reduction measures in the framework is accomplished in a hierarchical manner by considering inherent safety measures, passive and active engineered devices, and procedural measures.

Dust explosion tests to determine icing and granulated sugar dust explosibility characteristics have been achieved in a 20-L Siwek chamber, and, accordingly, DESC fuel files were built and DESC was validated.

Three industrial case studies are presented to show how the QRMF could have been helpful in reducing dust and hybrid mixture explosion risk at the Imperial Sugar refinery, the Semabla grain storage silo, and a hypothetical $400-\mathrm{m}^{3}$ polyethylene storage silo. DESC simulations and Probit equation determined the destructive percentage of each pressure zone in the simulations, followed by probabilistic FTA that were achieved for the first two case studies, before and after applying the framework. Detailed individual and societal risks calculations were made and F-N (Frequency of occurrence - Number of fatalities) curves plotted for the two processes. The polyethylene silo case study is presented to show how inherent safety measures can be helpful in reducing dust and hybrid mixture explosion risk.

The framework showed significant risk reduction to the point where the residual risks are acceptable for the both processes. 


\section{LIST OF ABBREVIATIONS AND SYMBOLS USED}

\begin{tabular}{ll} 
& \multicolumn{1}{c}{ Abbreviations } \\
ADF & annual damage friction \\
AFR & annual fatalities rate \\
AIT & auto ignition temperature \\
ALARP & as low as reasonably practicable \\
ARAMIS & Accidental Risk Assessment Methodology for Industries \\
AWCBC & Association of Workers' Compensation Boards of Canada \\
BDD & binary decision diagram \\
CASD & Computer Aided Scenario Design \\
CCF & common Cause Failure model \\
CCOHS & Canadian Centre for Occupational Health and Safety \\
CCPS & Center for Chemical Process Safety \\
CFD & computational fluid dynamic \\
CPI & chemical process industries \\
CPQRA & Chemical Process Quantitative Risk Analysis \\
CSB & Chemical Safety Board \\
DESC & Dust Explosion Simulation Code (software) \\
DMRA & decision matrix risk assessment \\
ESC & equivalent social cost \\
ESD & event sequence diagram \\
ETA & Event Tree Analysis \\
F & Frequency (y ${ }^{-1}$ ) \\
\end{tabular}




$\begin{array}{ll}\text { FAR } & \text { fatal accident rate } \\ \text { FEDI } & \text { Fire and Explosion Damage Index } \\ \text { F\&EI } & \text { Fire and Explosion Index } \\ \text { FIBC } & \text { flexible intermediate bulk container } \\ \text { FMEA } & \text { Failure Modes and Effects Analysis } \\ \text { F-N } & \text { cumulative frequences of an event versus number of fatalities } \\ \text { FT } & \text { fault tree } \\ \text { FTA } & \text { Fault Tree Analysis } \\ \text { G } & \text { Toxic Damage Index estimation factor } \\ \text { HAZOP } & \text { Hazard and Operability Analysis } \\ \text { HEPI } & \text { Human Error Probability Index } \\ \text { HIRA } & \text { Hazard Identification and Ranking Analysis system } \\ \text { HRSDC } & \text { Human Resources and Skills Development Canada } \\ \text { HSE } & \text { Health and Safety Executive } \\ \text { HSL } & \text { Health and Safety Laboratory (UK) } \\ \text { IET } & \text { Institute of Engineering and Technology } \\ \text { ISIR } & \text { individual - specific individual risk } \\ \text { LFL } & \text { lower flammable limit } \\ \text { LOC } & \text { lowest oxidant concentration } \\ \text { LOPA } & \text { Layer of Protection Analysis } \\ \text { LSIR } & \text { location - specific individual risk } \\ \text { MAXCRED } & \text { Maximum Credibility Accident Analysis } \\ \text { MCAA } & \text { Maximum Credible Accident Analysis } \\ \text { MCS } & \text { Minimal Cut Set (for FTA) } \\ & \\ & \end{array}$




\begin{tabular}{ll} 
MEC & minimum explosible concentration \\
MIE & minimum ignition energy \\
MIT & minimum dust cloud ignition temperature \\
MOC & management of change \\
MSHA & Mine Safety and Health Administration (USA) \\
N & number of fatalities \\
NFPA & National Fire Protection Association \\
NIOSH & National Institute for Occupational Safety and Health (USA) \\
NORA & National Occupation Research Agenda \\
NS OH\&S & Nova Scotia Occupational Health and Safety \\
OH\&S & Occupational Health and Safety \\
OSHA & Occupational Safety \& Health Administration (USA) \\
PP & pressure panel \\
PRA & Probabilistic Risk Assessment (software) \\
PROFAT & Probabilistic Fault Tree Analysis \\
PSM & Process Safety Management \\
QRA & Quantitative Risk Assessment \\
QRAS & Quantitative Risk Assessment System (software) \\
QRM & quantitative risk management \\
QRMF & Quantitative Risk Management Framework \\
Relex & Reliability Excellence (software) \\
ROD & Rate of Death \\
TDI & Toxic Damage Index \\
\hline
\end{tabular}


TORAP Tool for Rapid Risk Assessment in Petroleum Refinery and Petrochemical Industries (software)

$\begin{array}{ll}\text { SCAP } & \text { management based on a safety credible accident, probabilistic algorithm } \\ \text { SDOF } & \text { single degree of freedom } \\ \text { SMS } & \text { safety management system } \\ \text { SWIFT } & \text { structured what if technique } \\ \text { WIFT } & \text { What If Technique } \\ \text { WP } & \text { work packages }\end{array}$

Symbols

$\mathrm{C}_{\mathrm{m}} / \mathrm{C}_{\mathrm{p}} \quad$ cost of module as fraction of platform cost

$\mathrm{D}_{\mathrm{F}} \quad$ platform damage friction

$\mathrm{D}_{\mathrm{m}} \quad$ fraction of module damaged

$(\mathrm{dP} / \mathrm{dt})_{\mathrm{m}} \quad$ maximum rate of pressure rise due to an explosion test (bar/s)

$(\mathrm{dP} / \mathrm{dt})_{\max }$ maximum rate of pressure rise (bar/s)

$\mathrm{f}_{\mathrm{i}} \quad$ frequency of incident outcome, case $\mathrm{i}\left(\mathrm{yr}^{-1}\right)$

$\mathrm{F}_{\mathrm{S}} \quad$ frequency of scenarios $\left(\mathrm{y}^{-1}\right)$

$\mathrm{H} \quad$ hours of work per year

k constant

K turbulent Kinetic energy

$\mathrm{K}_{1}, \mathrm{~K}_{2} \quad$ probit correlation causative variables

$\mathrm{K}_{\mathrm{st}} \quad$ dust deflagration index (dust cloud explosion violence) (bar $\bullet \mathrm{m} / \mathrm{s}$ )

L liter

$\mathrm{m}^{3} \quad$ cubic meter

ms milliseconds 


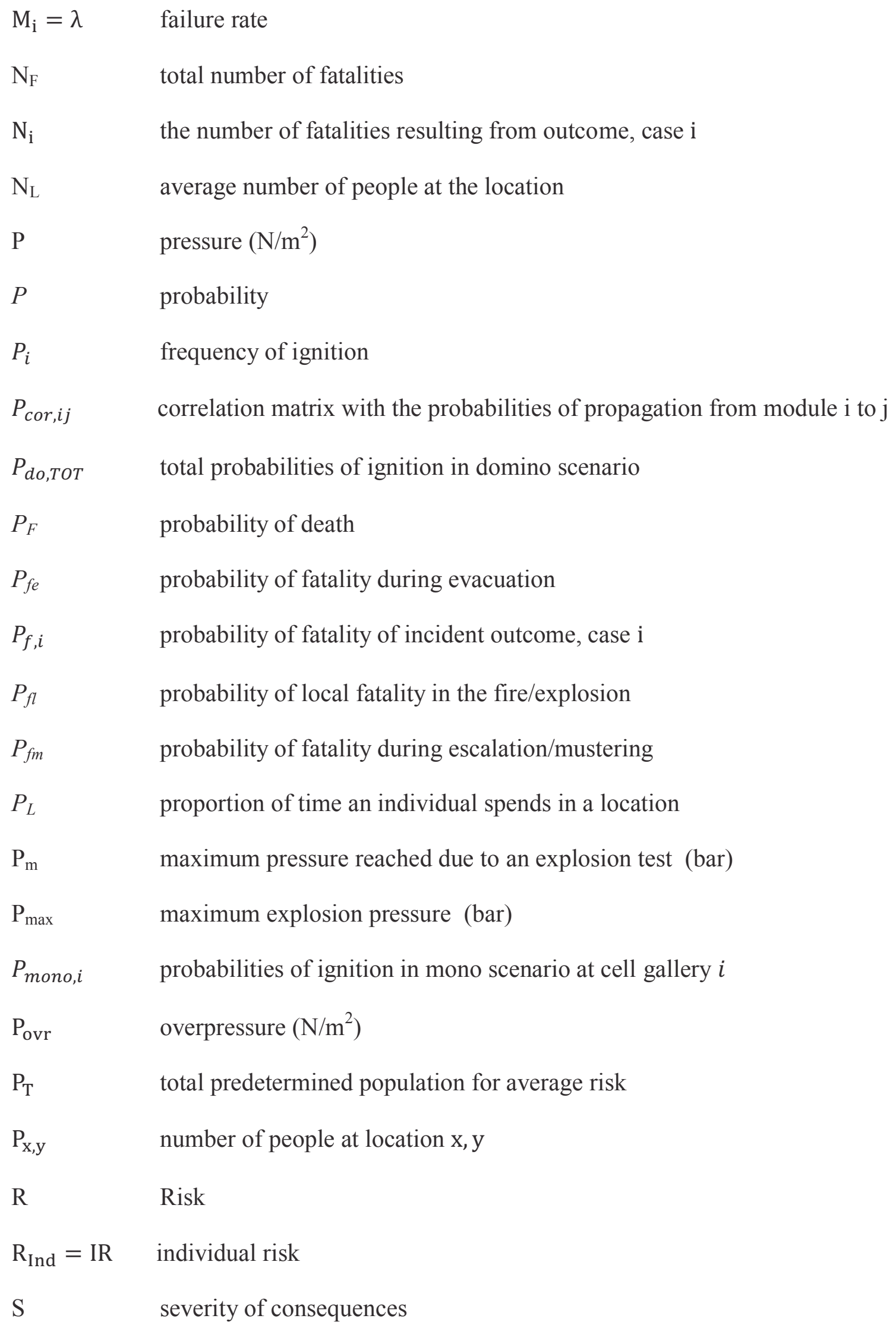




$\begin{array}{ll}\mathrm{t} & \text { time }(\mathrm{s}) \\ \mathrm{t}_{\exp } & \text { total explosion time } \\ \mathrm{V} & \text { 20-L chamber volume }\left(\mathrm{m}^{3}\right) \\ \mathrm{Y} & \text { probit variable (unit-less) } \\ \mu \mathrm{m} & \text { microns }\left(10^{-6} \text { meters }\right)\end{array}$




\section{ACKNOWLEDGMENTS}

I am sincerely and heartily grateful to my supervisor, Dr. Paul Amyotte, who was endlessly helpful and offered generous support and guidance. The thesis would have not have been possible or completed without his help. My deepest gratitude also goes to Dr. Faisal Khan and Dr. Michael Pegg for their technical guidance and support as my supervisory committee. In addition, I would like to thank the Libyan Ministry of Higher Education for the scholarship, and the Natural Sciences and Engineering Research Council of Canada for their financial support. It is also an honor for me to thank Trygve Skjold from GexCon, Norway, for his help and guidance in using the DESC software. Finally, I owe sincere and heartfelt gratitude to my father (Ali Abuswer), my mother (Halima Abufanas), my wife and children, and my siblings for their moral support and encouragement. 


\section{CHAPTER 1 INTRODUCTION}

\subsection{Thesis OVerview}

This first chapter provides basic information about industrial dust and hybrid mixture explosions. It describes the explosion pentagon and discusses the importance of dust characteristics and their influence on the likelihood and severity of dust explosions. As well, the main parameters affecting dust explosibility (such as dust particle size and moisture) are reviewed and an overview of secondary dust explosions is given. The chapter also discusses hybrid mixtures and details their effect on dust explosion severity and likelihood. In addition, dust and hybrid mixture risk management is introduced and some reasons why process industries use quantitative and not qualitative risk assessment are investigated. The chapter also includes illustrative case histories of well-known explosions and provides information on industrial safety agencies and their standards and legislation.

The main goal of this work is to investigate the management of dust and hybrid mixture explosions in the process industries. This goal is approached through the building of a framework whose steps are sequentially arranged for maximum effectiveness. The framework uses specific methodologies to analyze risk consequences: Dust Explosion Simulation Code (DESC) software and likelihood Fault Tree Analysis (FTA).

The second chapter provides important background information related to dust and hybrid mixture explosions, investigating the work of other researchers and then comparing it with the developed framework. Chapter 2 also reviews various methodologies and tools that deal with dust explosion prevention and mitigation.

Chapter 3 consists of two main sections. The first is the framework methodology section, which presents the developed risk management framework steps. It explains in detail the developed conceptual framework, which is a quantitative risk management framework (QRMF) to prevent and mitigate dust and hybrid mixture explosions during industrial 
processing. This section also identifies risk reduction measures in the framework in a hierarchical manner by considering inherent safety measures, passive and active engineered safety add-on devices, and procedural safety measures. The second section of Chapter 3 demonstrates the implementation of the conceptual framework. It shows the methodology flowchart and includes all the steps and the framework's logic gates.

Chapter 4 provides details of the experimental work performed to validate and build the fuel file of the DESC software, DESC preparation, and some DESC simulations for validation. This chapter consists of: (1) experimental work performed in the dust explosion laboratory at Dalhousie University, using the Siwek 20-L chamber to identify dust characteristics for icing sugar, granulated sugar, and polyethylene; and (2) DESC simulations of the above materials at $20-\mathrm{L}, 1-\mathrm{m}^{3}$, and $400-\mathrm{m}^{3}$ geometries, and a comparison of the experimental and simulation results.

Chapter 5 reviews three case studies of dust and hybrid mixture explosions; two occurred in the past (the dust explosion at the Imperial Sugar Company at Port Wentworth, Georgia, in 2008, and the Semabla grain silo explosion at Blaye, France in 1997). The third case study is a hypothetical dust explosion in a $400-\mathrm{m}^{3}$ polyethylene storage silo. DESC was used to simulate the explosion accidents, and a probit model has been used to estimate the severity of the consequences and calculate the probability of the analyzed basic events. As well, in this chapter, Relex (Reliability Excellence) FTA software was used to determine the overall probability of each top event. Total risk has been estimated, and risk evaluation (to judge the proper safeguards) has been applied. Finally, some appropriate safeguards have also been used, and the results (both before and after applying the framework) have been compared.

Chapter 6 provides conclusions and recommendations for future work. The appendices offer supporting documentation. Figure 1.1 summarizes the overview given above. 


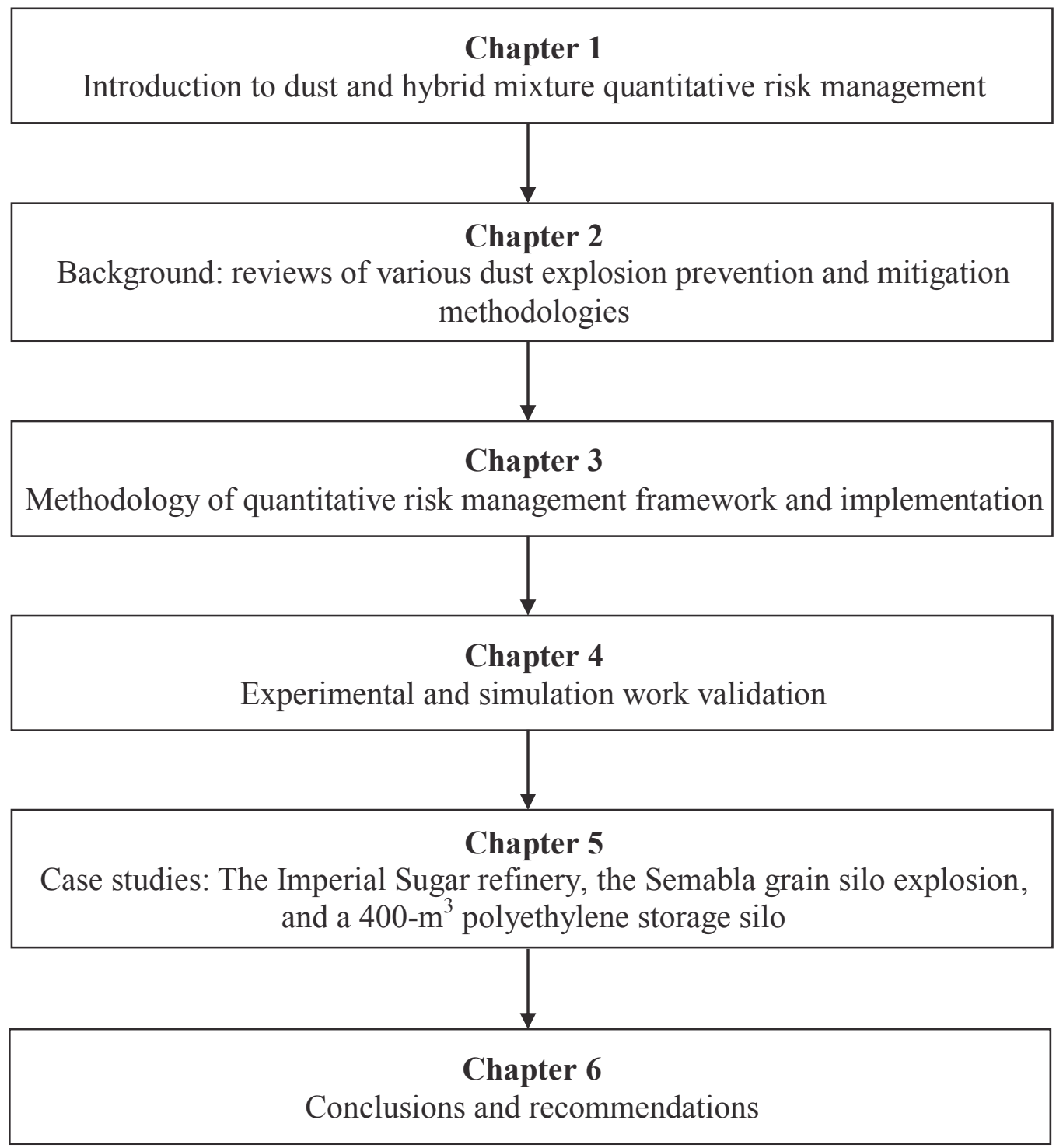

Figure 1.1 Thesis overview. 


\subsection{Definitions and Terminology}

As the area of industrial safety and risk management has evolved, a specialized terminology has developed. The following terms and definitions have come into use:

Hazard: "The potential of a machine, equipment, process, material or physical factor in the working environment to cause harm to people" (Wilson \& McCutcheon, 2003).

Risk: "The possibility of human injury or death, production and/or property loss, and/or environmental damage created by a hazard. The significance of a risk is a function of the probability of an unwanted incident and the severity of the consequences" (Wilson \& McCutcheon, 2003).

Hazard identification: "A systematic procedure for finding all of the hazards associated with unit operations and equipment. It is a process of determining what, why, and how things can happen" (Rogers, 2000).

Risk assessment: "A series of logical steps to enable a systematic examination of the hazards associated with unit operations and equipment" (Rogers, 2000).

Risk estimation: "Determination of the frequency at which the identified hazards could occur and give rise to specific levels of severity" (Rogers, 2000).

Risk evaluation: "Comparison of the risk estimated with criteria in order to decide whether a risk is acceptable or whether the unit operations and/or equipment design must be modified in order to reduce the risk" (Rogers, 2000).

Residual risk: "The remaining level of risk, after all actions have been taken to reduce the probability and consequences of a risk" (Rogers, 2000).

Risk management: "The systematic application of management policies, procedures and practices to the tasks of identifying, analyzing, monitoring, and controlling risk" (Rogers, 2000). 


\subsection{Scope of Research ANd OBJectives}

There is an urgent need in the process industry to develop a tool that combines various safety methodologies, software, procedures, etc., to prevent dust and hybrid mixture explosions. Unfortunately, few published papers in the explosion area deal with dust/hybrid mixture explosion risk assessment, mainly due to the complex nature of these phenomena (Markowski, 2007).

Consequently, this research has been developed with the following scope, motivation, and objective to cover the industrial problem of dust and hybrid mixture explosions:

i. Scope: The development of a quantitative risk management framework:

- For dust and hybrid mixture explosion prevention and mitigation.

- Explicitly incorporating hierarchy of controls principles via DESC and FTA

\section{ii. Motivation:}

- Protection of people, assets, production, and environment.

- Promotion of a hierarchical approach to loss prevention.

- Inherent safety focus within research group.

\section{iii. Objective:}

- To manage the risks of any expected dust or hybrid mixture explosion in industrial complexes (large-scale).

This research uses the Computational Fluid Dynamics (CFD) modeling technique, which is represented in DESC software, to assess accidental consequences arising from dust explosions, and the FTA technique to estimate dust explosion frequencies in process industries. The research goals are:

- To develop a conceptual framework and an implementation flowchart to facilitate management of the dust and hybrid mixture hazard. 
- To develop a Fault Tree Analysis flowchart that identifies the likelihood of any expected dust or hybrid mixture explosion for a given scenario.

- To use DESC for the prediction of dust and/or hybrid mixture explosion consequences for industrial-scale process units.

- To simulate different (large-scale) industrial dust explosions as case studies to analyze the severity of consequences of different scenarios.

The thesis uses QRA (Quantitative Risk Assessment), which includes both explosion likelihood and consequences. These are the key features of the framework, together with explicit consideration of the hierarchy of safety controls. Figure 1.2 shows an overview of the QRMF (Quantitative Risk Management framework) for explosion prevention.

However, the question arises as to why the framework uses quantitative and not qualitative risk analysis. The answer is simple - while qualitative risk analysis has the ability to identify and control hazardous events in many instances, quantitative risk analysis is the better method when the risk is excessive and safeguards are required (Grossel, 2001)

\subsection{Qualitative And Quantitative Risk Analysis}

As shown in Table 1.1, risk analysis can be divided into two major approaches: qualitative risk analysis and quantitative risk analysis. Qualitative risk analysis is more subjective and gives data in the form of words, while quantitative risk analysis is more objective, explains what is observed, and produces more efficient data.

In their comprehensive and comparative study of three risk analysis and assessment techniques (qualitative, quantitative, and a hybrid of quantitative and qualitative), Marhavilas et al. (2011) revealed that the most frequently used technique was the quantitative one (at 66\%), and that its major use was in the industrial field.

Dust and hybrid mixture explosion prevention and mitigation is the main objective of this thesis, and the following sections provide basic information and an overall description of the subject. 


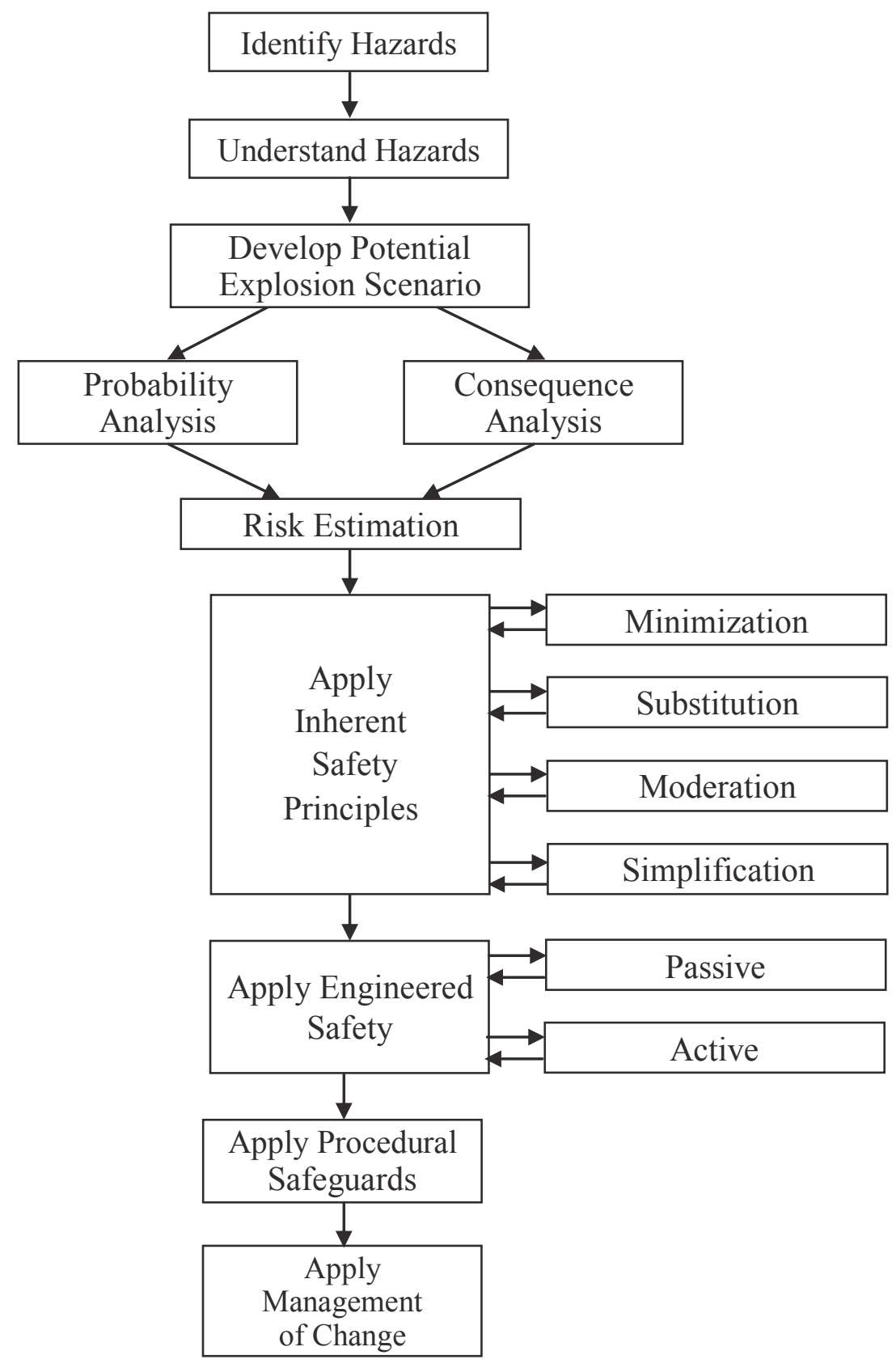

Figure 1.2 Overview of the QRM framework process. 
Table 1.1 Features of qualitative and quantitative research (James, 2007).

\begin{tabular}{|c|c|}
\hline Qualitative & Quantitative \\
\hline $\begin{array}{l}\text { "All research ultimately has } \\
\text { a qualitative grounding." } \\
\text { - Donald Campbell }\end{array}$ & $\begin{array}{l}\text { "There's no such thing as qualitative } \\
\text { data. Everything is either } 1 \text { or } 0 . " \\
\text { - Fred Kerlinger }\end{array}$ \\
\hline $\begin{array}{l}\text { The aim is a complete and detailed } \\
\text { description. }\end{array}$ & $\begin{array}{l}\text { The aim is to classify features, count } \\
\text { them, and construct statistical } \\
\text { models in an attempt to explain } \\
\text { what is observed. }\end{array}$ \\
\hline $\begin{array}{l}\text { Researcher may only know roughly in } \\
\text { advance what he/she is looking for. }\end{array}$ & $\begin{array}{l}\text { Researcher knows clearly in } \\
\text { advance what he/she is looking for. }\end{array}$ \\
\hline $\begin{array}{l}\text { Recommended during earlier phases of } \\
\text { research projects. }\end{array}$ & $\begin{array}{l}\text { Recommended during latter phases } \\
\text { of research projects. }\end{array}$ \\
\hline The design emerges as the study unfolds. & $\begin{array}{l}\text { All aspects of the study are carefully } \\
\text { designed before data is collected. }\end{array}$ \\
\hline $\begin{array}{l}\text { Data is in the form of words, pictures or } \\
\text { objects. }\end{array}$ & $\begin{array}{l}\text { Data is in the form of numbers and } \\
\text { statistics. }\end{array}$ \\
\hline $\begin{array}{l}\text { Subjective - individual interpretation of } \\
\text { events is important (e.g., uses participant } \\
\text { observation, in-depth interviews, etc.). }\end{array}$ & $\begin{array}{l}\text { Objective - seeks precise } \\
\text { measurement and analysis of target } \\
\text { concepts (e.g., uses surveys, } \\
\text { questionnaires, etc.). }\end{array}$ \\
\hline $\begin{array}{l}\text { Qualitative data is more "rich" and time- } \\
\text { consuming, and less able to be } \\
\text { generalized. }\end{array}$ & $\begin{array}{l}\text { Quantitative data is more efficient } \\
\text { and able to test hypotheses, but may } \\
\text { lack contextual detail. }\end{array}$ \\
\hline $\begin{array}{l}\text { Researcher tends to become subjectively } \\
\text { immersed in the subject matter. }\end{array}$ & $\begin{array}{l}\text { Researcher tends to remain } \\
\text { objectively separated from the } \\
\text { subject matter. }\end{array}$ \\
\hline
\end{tabular}

\subsection{Dust ANd Hybrid Mixture Explosions}

According to British Standard Institute code BS2955:1958, dust is a material with a particle diameter of less than $76 \mu \mathrm{m}$ (Abbasi \& Abbasi, 2007), but the National Fire Protection Association code NFPA 654 defines dust as "any finely divided solid, $420 \mu \mathrm{m}$ 
or less in diameter", which is equivalent to a U.S. No. 40 standard sieve (Amyotte \& Eckhoff, 2010). A dust explosion can be defined as the rapid combustion of flammable particulates suspended in air (Abbasi \& Abbasi, 2007).

A hybrid mixture is a combination of a flammable gas and a combustible dust, where gas may be present in an amount less than its lower flammable limit (LFL) and also an amount of dust less than its minimum explosible concentration (MEC). Nevertheless, they may, in combination, create an explosible mixture (Amyotte \& Eckhoff, 2010). Eckhoff (2003) demonstrated that the addition of flammable gas to a dust cloud significantly increases the explosion violence. Likewise, Amyotte et al. (2010) showed experimentally the increased maximum explosion pressure $\left(\mathrm{P}_{\max }\right)$ and maximum rate of pressure rise in constant-volume $\left(\mathrm{K}_{\mathrm{St}}\right)$ for ethylene/polyethylene, hexane/polyethylene, and propane/polyethylene mixtures. The methane/coal dust system is the most dangerous and volatile hybrid mixture in underground coal mines. In addition, there are several examples of hybrid mixture formations in the process industries, such as the natural gas/fly ash system in fossil fuel-burning power plants and various hydrocarbon/resin combinations arising from the production of plastic powders (Amyotte et al., 2010).

To occur, dust and hybrid mixture explosions require the following five basic components: (i) fuel, (ii) oxidant, (iii) ignition source, (iv) mixing of the fuel and oxidant, and (v) confinement (Amyotte, Kahn, \& Dastidar, 2003). Most often, explosion events occur inside processing equipment (e.g., mills, bucket elevators, silos, cyclones, ducts, etc.) (Abbasi \& Abbasi, 2007).

In addition, one or more secondary explosions may occur following primary explosion pressure waves. These strong shock waves can suspend settled dust in the area, forming a dust cloud which can then be ignited by the released energy of the primary explosion (Abbasi \& Abbasi, 2007). Secondary explosions may actually be worse than the initial ones due to increases in the quantity and concentration of combustible dust/hybrid mixtures. Nonetheless, it is theoretically possible to prevent or mitigate a dust or hybrid mixture explosion by disabling at least one of the explosion pentagon elements. 
Practically, however, a number of different measures are usually implemented to minimize the risk of explosion to a tolerable level.

In responding to a query as to why dust explosions continue to happen, given our current level of knowledge about preventing them, Amyotte (2010) suggested that many people still believe in unicorns, meaning they still do not think scientifically. He outlined twelve basic and persistent false beliefs about dust explosions:

(i) Dust does not explode. (ii) Dust explosions only happen in coal mines and grain elevators. (iii) A lot of dust is needed to create an explosion. (iv) Gas explosions are much worse than dust explosions. (v) It's up to the explosibility testing lab to specify which particle size to test. (vi) Any amount of suppressant is better than none. (vii) There's no problem if dust is not visible in the air. (viii) Venting is the only/best solution to the dust explosion problem. (ix) The vocabulary of dust explosions is difficult to understand. (x) Dust explosion parameters are fundamental material properties. (xi) It makes sense to combine explosion parameters in a single index. (xii) It won't happen to me. (Amyotte, 2010)

\subsubsection{Dust and hybrid mixture explosions in the process industries}

Many industries handle combustible dust or hybrid mixtures during at least one of their processing stages. Therefore, dust and hybrid mixture explosions present an explosion hazard that can threaten processing plants and harm people as well as damage the environment, production, and/or processing equipment. Frank (2004) and Amyotte \& Eckhoff (2010) show that dust explosions occur in a wide range of industries and industrial applications involving numerous and varied products such as coal, grain, paper, foodstuffs, metals, rubber, pharmaceuticals, plastics, textiles, etc. Table A.1 (Appendix A) provides a list of common industries that have more frequent and or high consequence dust explosions, while Table A.2 (Appendix A) lists chemical industries that may have combustible dusts. The next sub-sections give basic knowledge to understand dust and hybrid mixture explosion phenomena. 


\subsubsection{Dust explosibility}

Identification of dust explosion hazards involves answering questions such as: (1) Can a given material yield dust explosions when dispersed as a cloud in air? and (2) What concentration of airborne dust is needed for an explosion? Finding the basic explosibility parameters, as described in Table 1.2, helps to answers these and other questions (Amyotte \& Eckhoff, 2010). Dust explosibility is different for each material and depends upon the dust's parameters. Some of these parameters influence the likelihood of occurrence, while others influence the severity of explosion (Dastidar et al., 2005).

Table 1.2 Explosibility parameters and risk components (Amyotte \& Eckhoff, 2010).

\begin{tabular}{|l|c|l|l|}
\hline Parameter & $\begin{array}{c}\text { Typical } \\
\text { Units }\end{array}$ & \multicolumn{1}{|c|}{ Description } & \multicolumn{1}{|c|}{$\begin{array}{c}\text { Risk } \\
\text { Component } \\
\text { Addressed }\end{array}$} \\
\hline $\mathrm{P}_{\max }$ & bar(g) & $\begin{array}{l}\text { Maximum explosion pressure in } \\
\text { constant-volume explosion }\end{array}$ & $\begin{array}{l}\text { Consequence } \\
\text { severity }\end{array}$ \\
\hline$(\mathrm{dP} / \mathrm{dt})_{\max }$ & $\mathrm{bar} / \mathrm{s}$ & $\begin{array}{l}\text { Maximum rate of pressure rise in } \\
\text { constant-volume explosion }\end{array}$ & $\begin{array}{l}\text { Consequence } \\
\text { severity }\end{array}$ \\
\hline $\mathrm{K}_{\mathrm{St}}$ & $\mathrm{bar} \cdot \mathrm{m} / \mathrm{s}$ & $\begin{array}{l}\text { Size- or volume-normalized maximum } \\
\text { rate of pressure rise in constant-volume } \\
\text { explosion }\end{array}$ & $\begin{array}{l}\text { Consequence } \\
\text { severity }\end{array}$ \\
\hline $\mathrm{MEC}$ & $\mathrm{g} / \mathrm{m}^{3}$ & $\begin{array}{l}\text { Minimum explosible (or explosive) } \\
\text { dust concentration }\end{array}$ & $\begin{array}{l}\text { Likelihood of } \\
\text { occurrence }\end{array}$ \\
\hline $\mathrm{MIE}$ & $\mathrm{mJ}$ & $\begin{array}{l}\text { Minimum ignition energy of dust cloud } \\
\text { (electric spark) }\end{array}$ & $\begin{array}{l}\text { Likelihood of } \\
\text { occurrence }\end{array}$ \\
\hline $\mathrm{MIT}$ & ${ }^{\circ} \mathrm{C}$ & $\begin{array}{l}\text { Minimum ignition temperature of dust } \\
\text { cloud }\end{array}$ & $\begin{array}{l}\text { Likelihood of } \\
\text { occurrence }\end{array}$ \\
\hline $\begin{array}{l}\text { MOC } \\
(\mathrm{LOC})\end{array}$ & volume & $\begin{array}{l}\text { Minimum (or limiting) oxygen } \\
\text { concentration in the atmosphere for } \\
\text { flame propagation in dust cloud }\end{array}$ & $\begin{array}{l}\text { Likelihood of } \\
\text { occurrence }\end{array}$ \\
\hline
\end{tabular}


Explosion strength and violence have been classified and ranked in terms of the dust $\mathrm{K}_{\mathrm{St}}$, as seen in Table 1.3. It is important to understand that each specific dust sample has just one $\mathrm{K}_{\mathrm{St}}$ value that is calculated from the maximum value of $(\mathrm{dP} / \mathrm{dt})$ over a sample of dust concentrations, and it is dependent on the explosion chamber volume, as shown in

Equation 1.1 (Amyotte \& Eckhoff, 2010):

$\mathrm{K}_{\mathrm{St}}=\mathrm{V}^{1 / 3}\left(\frac{\mathrm{dP}}{\mathrm{dt}}\right)_{\max }$

Where: $\mathrm{V}=$ the explosion chamber volume.

Table 1.3 The explosibility rank (OSHA, 2011).

\begin{tabular}{|c|c|}
\hline $\begin{array}{c}\text { Dust explosion } \\
\text { class }\end{array}$ & $\mathbf{K}_{\text {St }}$ (bar•m/s) \\
\hline St 0 & 0 \\
\hline St 1 & $>0$ and $\leq 200$ \\
\hline St 2 & $>200$ and $\leq 300$ \\
\hline St 3 & $>300$ \\
\hline
\end{tabular}

\subsubsection{Domino effect}

The expected first explosion could disturb settled dust lying nearby, building suitable conditions for a secondary dust explosion. Domino effect calculations can reveal the total risk by considering all the explosion consequences, as shown in Figure 1.3. 


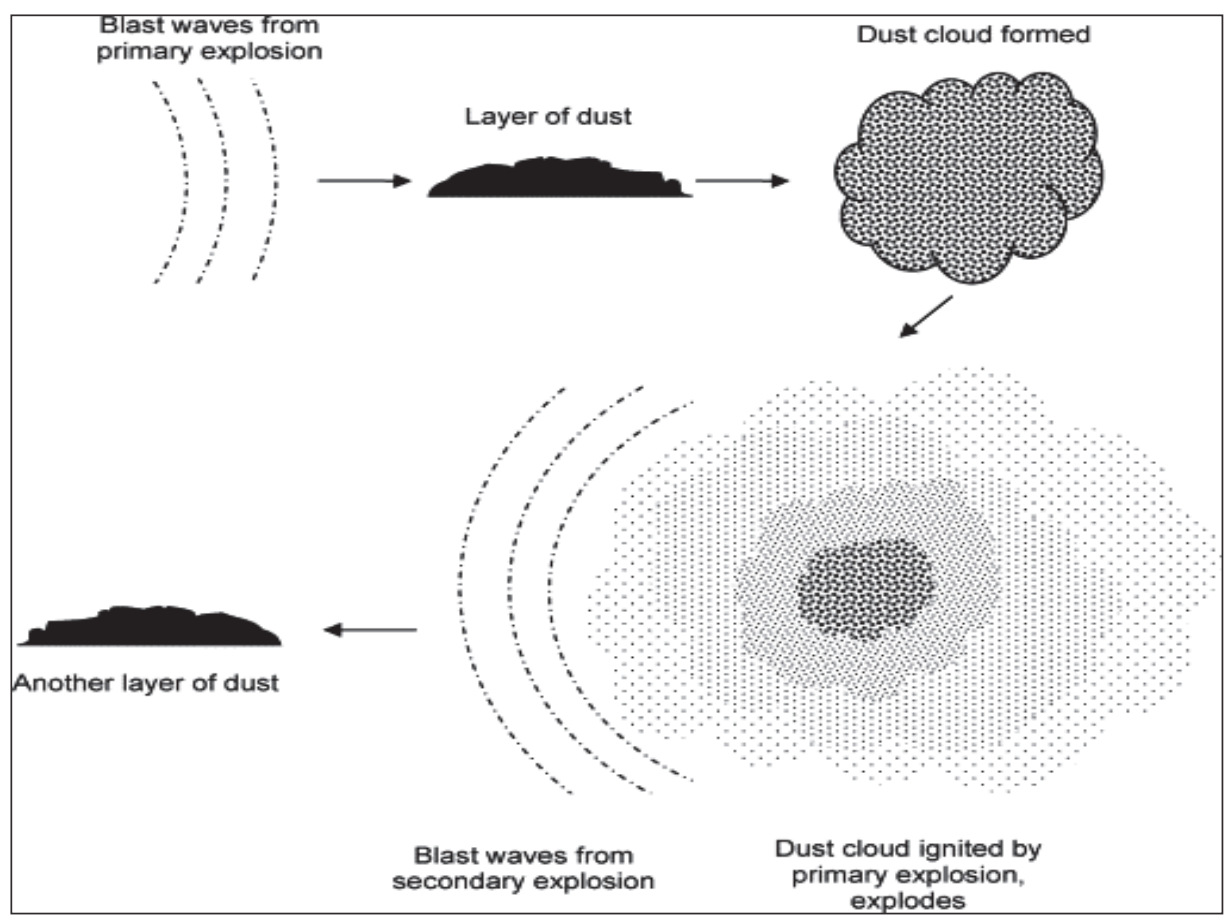

Figure 1.3 The domino effect in dust explosions (Abbasi \& Abbasi, 2007).

\subsubsection{Illustrative case histories of dust and hybrid mixture explosions}

Statistics and numerous literature reviews confirm that, since 1785, dust and hybrid mixture explosions have frequently occurred in industrial processes (Abbasi \& Abbasi, 2007). Every year, these explosions kill and cause severe injuries to hundreds of people, destroy assets, damage production, and contaminate the environment. For example, 43 people were killed in Iowa, USA, in a dust explosion accident which occurred in 1919 in a corn processing plant. A similar explosion happened five years later in another plant in the USA, resulting in the death of 42 workers. Other examples of dust explosions are: the Saskatchewan grain pools explosion accident in 1952 (6 killed and 14 injured); the grain silo explosion in Kampffmeyer, Austria, in 1960; the silicon powder grinding plant explosion at Bremanger, Norway, in 1972 (5 dead and 4 injured); the catastrophic explosion at the Harbin linen textile plant, China, in 1987 (58 dead and 177 injured); the dust explosion of the Daido Kako Enka fireworks factory in Moriya, Japan, in 1992 (3 
dead and 58 injured); the Blaye, France, hybrid mixture explosion in 1997 (11 killed); the mould fabrication station explosion in Massachusetts, USA, in 1999 (3 killed and 12 injured); the explosion at West Pharmaceutical (polyethylene dust) in 2003 at Kinston, North Carolina, USA (6 killed and 38 wounded) (CSB, 2004); the dust explosion at CTA Acoustics in Corbin, Kentucky, USA in 2003 (7 killed and 37 injured) (CSB, 2005); the lacquer dust explosion at Avon, Ohio, USA, in 2004; and the Imperial Sugar Company dust explosion in 2008 at Port Wentworth, Georgia, USA, resulting in 14 deaths and 38 injuries (Abbasi \& Abbasi, 2007). Over the past decade alone, dust explosion incidents have been responsible for hundreds of injuries and fatalities in North America as well as billions of dollars in property damage (Abbasi \& Abbasi, 2007). Table B.1 (Appendix B) provides a tabulated review of notable of dust explosion incidents between 1911 and 2004 (OSHA, 2007).

To avoid dust explosions and keep people, the environment, assets, and production safe from harm, countries have created their own agencies that are responsible for developing policies to manage risk. These policies encourage and force employers and employees to reduce or prevent risks in the workplace by following certain rules.

\subsection{Legislation AND DUSt EXPLOSions}

As industry has become increasingly complex, many countries have modified and developed their systems and methods, and have passed workplace legislation. Safety has become not just an industry but a government concern. For instance, in Canada, the Canadian health and safety system has multiple governance bodies and falls under federal and provincial statutes. Each province has its own legislation based on a federal code that enables legislation and regulation for the Canadian workplace (NOHSAC, 2007). Two of the main federal agencies are HRSDC (Human Resources and Skills Development Canada), which has federal responsibility for Occupational Health and Safety, and AWCBC (Association of Workers' Compensation Boards of Canada), which serves as a bridge between provincial workers' compensation boards. There are also ten provincial and three territorial agencies, each with their own Occupational Health and Safety 
$(\mathrm{OH} \& \mathrm{~S})$ legislation, such as the Nova Scotia Occupational Health and Safety (NS OH\&S) act (CCOHS, 2011).

\subsubsection{U.S. Occupational Safety \& Health Administration (OSHA)}

OSHA was created by the United States Department of Labor to set and enforce safety standards to protect people, assets, production, and the natural environment. For example, OHSA safety standard number 1910.109 is for explosives and blasting agents. The main duty of OSHA is to ensure a healthy and safe workplace, both inside facilities and in the surrounding area. OSHA is also responsible to ensure that workers have been adequately trained and know their rights (OSHA, 2007).

After the Bhopal toxic gas release tragedy in 1984, OSHA released, in 1992, their highly hazardous chemicals rule, called PSM (Process Safety Management) (Crowl \& Louvar, 2007). The PSM elements and components are listed in Table C.1 (Appendix C).

In addition, the National Institute for Occupational Safety and Health (NIOSH), works together with OSHA using concepts derived from NIOSH research, which is driven by the National Occupation Research Agenda (NORA). The Mine Safety and Health Administration (MSHA) is a U.S. agency which deals with the mining sector (NOHSAC, 2007).

\subsubsection{National Fire Protection Association (NFPA)}

NFPA is an international nonprofit organization whose responsibility is to reduce fire and explosion risks by providing safety codes and standards, research, training, and education. NFPA has developed over 300 codes and standards to minimize different kinds of fires and explosions (NFPA, 2011). For example, Table 1.4 shows combustible dust hazard control codes and standards that can help to prevent or minimize the risks associated with dust fires and explosions (Crowl \& Louvar, 2007). 
Table 1.4 NFPA publications relevant to combustible dust hazard controls (OSHA, 2007).

\begin{tabular}{|c|l|c|}
\hline $\begin{array}{c}\text { NFPA } \\
\text { Number }\end{array}$ & \multicolumn{1}{|c|}{ Title } & Edition \\
\hline 61 & $\begin{array}{l}\text { Standard for the Prevention of Fires and Dust Explosions in } \\
\text { Agricultural and Food Processing Facilities }\end{array}$ & 2002 \\
\hline 68 & Guide for Venting of Deflagrations & 2002 \\
\hline 69 & Standard on Explosion Prevention Systems & 2002 \\
\hline 70 & National Electrical Code & 2005 \\
\hline 77 & Recommended Practice on Static Electricity & 2000 \\
\hline 85 & Boiler and Combustion Systems Hazards Code & 2007 \\
\hline 86 & Standard for Ovens and Furnaces & 2007 \\
\hline 91 & $\begin{array}{l}\text { Standard for Exhaust Systems for Air Conveying of Vapors, } \\
\text { Gases, Mists, and Noncombustible Particulate Solids }\end{array}$ & 2004 \\
\hline 484 & Standard for Combustible Metals & 2004 \\
\hline 499 & $\begin{array}{l}\text { Recommended Practice for the Classification of Combustible } \\
\text { Dusts and of Hazardous (Classified) Locations for Electrical } \\
\text { Installations in Chemical Process Areas }\end{array}$ & 2006 \\
\hline 654 & $\begin{array}{l}\text { Standard for the Prevention of Fire and Dust Explosions from } \\
\text { the Manufacturing, Processing, and Handling of Combustible } \\
\text { Particulate Solids }\end{array}$ & $\begin{array}{l}\text { Standard for Prevention of Sulfur Fires and Explosions } \\
\text { Processing and Woodworking Facilities }\end{array}$ \\
\hline 664 & $\begin{array}{l}\text { Standard for the Prevention of Fires and Explosions in Wood } \\
\text { Prom }\end{array}$ & 2007 \\
\hline
\end{tabular}

\subsection{Dust and Hybid Mixture Explosion Prevention, Mitigation, AND CONTROL}

Actions to prevent and mitigate dust and hybrid mixture explosions involve breaking down the five basic components to prevent them from coming together in a specific process, thus disabling one or more elements of the explosion pentagon. Furthermore, it is important to evaluate dust characteristics - MIE, MIT, $\mathrm{P}_{\max }, \mathrm{K}_{\mathrm{St}}$, and MEC - in addition to considering the influence of dust explosion affecting factors (particle size and 
agglomeration, moisture, flammable gas content, inert content, etc.). In order to avoid primary or secondary dust explosions, proper housekeeping, following safety agency regulations, and limiting dust locations are very important. Also, there are many generally effective safety management methods and tools that can be applied to industrial processes that pose a threat of dust and/or hybrid mixture explosions.

\subsubsection{The risk management process}

Risk management is the complete process of understanding risk, risk assessment, and decision making to ensure that effective risk controls are in place and implemented. Risk management begins with actively identifying possible hazards, leading to ongoing management of those risks deemed to be acceptable. The major hazards that the chemical industry is concerned with are fire, explosion, and toxic release (Amyotte \& McCutcheon, 2006). Risk management consists of steps for identifying hazards and analyzing, evaluating, and controlling risks associated with the hazards. It proceeds as follows: hazard identification, risk analysis (frequency and consequence), risk estimation, risk control, and monitoring the residual risk by going over the steps again to identify whether any specific risk requires further attention. Amyotte and McCutcheon (2006) described the risk management process that controls risks associated with hazards, as shown in Figure 1.4. The following steps describe, in general, the risk management process:

\section{i) System Description}

This aspect of risk planning identifies the entire system component under study as well as the operating procedure, the hazardous materials, and the surrounding area (Wilson \& McCutcheon, 2003).

\section{ii) Review of Requirements}

This step involves a comprehensive system management review which looks at incident investigation, the overall project, compliance, insurance, and management direction. 


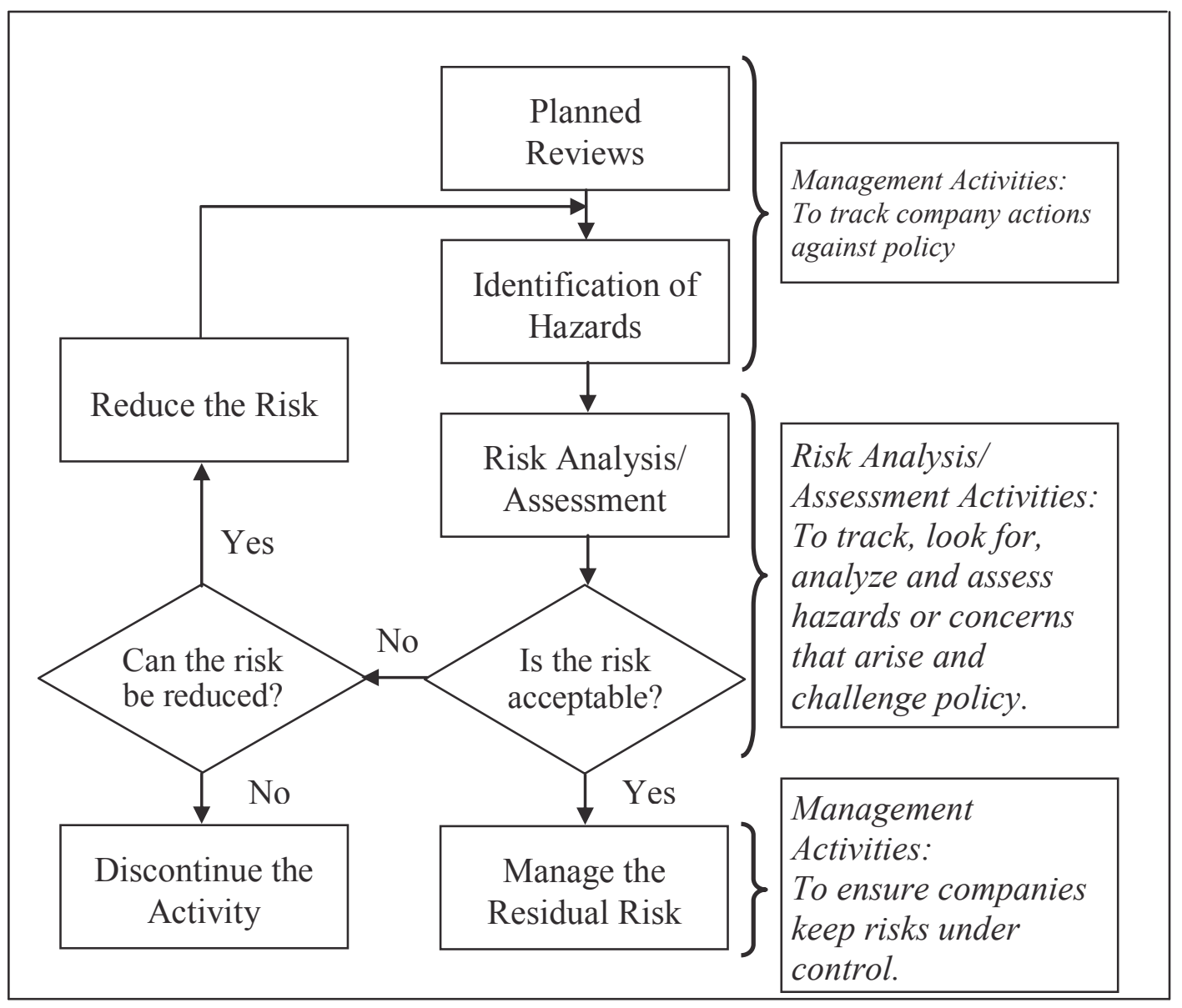

Figure 1.4 The risk management process (Amyotte \& McCutcheon, 2006).

\section{iii) Identification of Hazards}

This is the most important step that precedes any risk assessment work. Hazard identification pinpoints and characterizes the potential for hazardous events, focusing solely on what could go wrong. There are a variety of techniques that can be used to identify hazards in a system, such as the What If Technique (WIFT), Failure Modes and Effects Analysis (FMEA), Hazard and Operability Analysis (HAZOP), checklist, and Fault Tree Analysis (FTA). 


\section{iv) Risk Assessment}

Risk assessment looks at the possible causes of injuries or illness and their effects on people, and involves risk quantification and ranking. A risk assessment methodology should consider all risk factors, including unexpected parameters. Tweeddale (2003) explained that the relationship between risk management and risk assessment is similar to art's relationship to science, with risk assessment being the scientific tool for risk management.

Risk assessment's main use is providing answers to the following questions:

- What sorts of risk are there in this situation?

- Is this risk too high to be acceptable?

- What are the main components of this risk?

- What should we do about this risk?

- How can we reduce the risk most rapidly?

- How can we reduce the risk most cost-effectively?

- How can we keep this risk low?

- Are we managing this risk effectively at present?

- What do the exposed people need to know about the risk?

- What should those exposed people do in the event of the risk being realized?

Except for the second question (which requires risk magnitude, i.e., quantitative risk analysis), all of the above questions can be answered by qualitative analysis (Tweeddale, 2003).

Risk assessment consists of two main steps: risk analysis and risk evaluation.

\section{- Risk analysis and risk estimation}

Once hazards have been identified, there is a need to analyze any risks that may be present. Risk analysis is the determination of how often the event is likely to occur (frequency), and what the consequences would be if the event did occur (Wilson \& McCutcheon, 2003). There are several methods for determining risk frequency; two of the most popular are Fault Tree Analysis and Event Tree Analysis (ETA). Risk 
consequences can be quantified using, for instance, Computational Fluid Dynamics (CFD) simulations in explosion accidents to determine the maximum explosion pressure, followed by Probit equations to calculate deaths, injuries, and damage. Risk estimation is a critical process to quantify the risk. It combines the frequencies and consequences of events and is a very important process in risk management decisions (Wilson \& McCutcheon, 2003).

\section{- Risk evaluation}

Risk evaluation is the judgment and decision-making process, and addresses the question: Is the risk acceptable? (Wilson \& McCutcheon, 2003). If the answer is "Yes", no changes need to be made to the system; if the answer is "No", what do we need to do about it? and the above questions (in section 1.7.1, iv) must be answered.

\section{v) Risk Control}

Risk control is the action process to reduce risk. It produces risk reduction by decreasing the likelihood and/or consequences of the hazardous event. Risk control could include inherent changes in the process management by such means as minimization, substitution, moderation, and simplification. It could also involve engineered changes (passive or active) and/or procedural changes. The risk control step needs to reviews the entire process and applies the changes as necessary. If the risk or the residual risk is too high and changes cannot be safely made, the right decision is to discontinue the activity.

1. Inherent safety: In 1978, Trevor Kletz devised the theory of inherent safety. Since that time, inherent safety has recorded several applications in the process industry (Amyotte et al., 2009). Amyotte et al. (2003) defined inherent safety as a proactive approach in which hazards are eliminated or lessened so as to reduce risk without engineered (add-on) devices or procedural intervention. Therefore, inherent safer design costs less, as described in Figure 1.5. Inherent safety is more a problem-avoidance tool than a solving tool (Kletz \& Amyotte, 2010). 


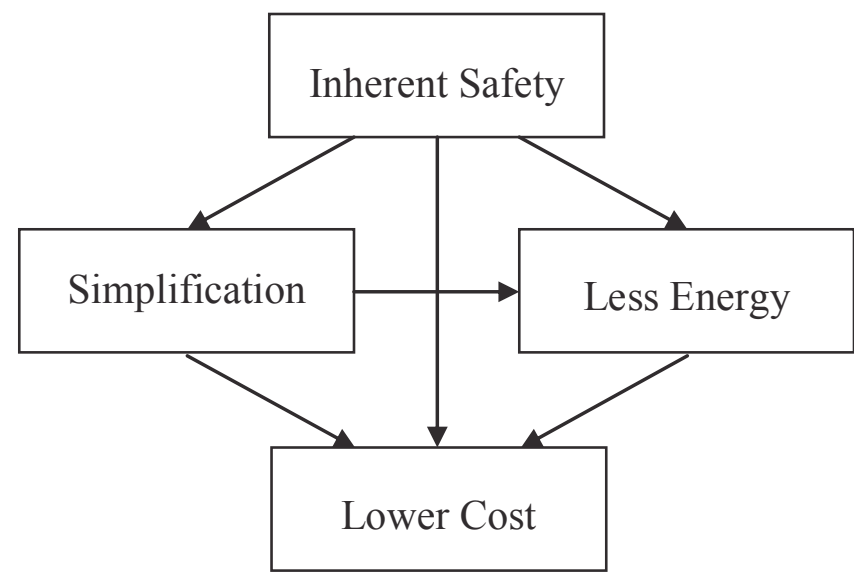

Figure 1.5 Inherent safety is not an isolated change, but, rather, part of a package of improvements needed by the process industries (Kletz \& Amyotte, 2010).

As seen in Table 1.5, inherent safety has four main principles: minimization, substitution, moderation, and simplification. It can reduce dust explosion consequences and likelihood when applied at the early project design cycle and solve problems at their root sources, as follows (Amyotte et al., 2009):

- start by minimizing the hazardous material of a given process whenever possible,

- substitute hazardous materials, processing routes, and/or procedures with others that are less hazardous,

- use process materials in their least hazardous form, and

- $\quad$ simplify process routes, equipment, and procedures as much as possible to minimize human error, maintenance, cost, etc.

Amyotte et al. (2007) emphasized that there is a reduced need to institute safety add-ons or different safety procedures if an inherent safety approach has been applied in a process industry. Kletz and Amyotte (2010) clarified the inherent safety strategy with the following analogies: Why raise lions if lambs can do what we need? Why build houses with tall stairs if we can have a one-story house or install staircases with frequent landings instead? However, in some cases, 
Table 1.5 Key inherent safety principles (Amyotte et al., 2009).

\begin{tabular}{|l|l|}
\hline \multicolumn{1}{|c|}{ Principle } & \multicolumn{1}{c|}{ Description } \\
\hline Minimization & $\begin{array}{l}\text { Use smaller quantities of hazardous materials when the use of such } \\
\text { materials cannot be avoided or eliminated. Perform a hazardous } \\
\text { procedure as few times as possible when the procedure is unavoidable. }\end{array}$ \\
\hline Substitution & $\begin{array}{l}\text { Replace a substance with a less hazardous material, or a processing } \\
\text { route with one that does not involve hazardous material. Replace a } \\
\text { hazardous procedure with one that is less hazardous. }\end{array}$ \\
\hline Moderation & $\begin{array}{l}\text { Use hazardous materials in their least hazardous forms or identify } \\
\text { processing options that involve less severe processing conditions. }\end{array}$ \\
\hline Simplification & $\begin{array}{l}\text { Design processes, processing equipment, and procedures to eliminate } \\
\text { opportunities for errors by eliminating excessive use of add-on safety } \\
\text { features and protective devices. }\end{array}$ \\
\hline
\end{tabular}

inherently safer design does not in itself reduce the threat to an acceptable level, and therefore engineered safety and procedural safety measures are needed.

2. Engineered safety: This refers to engineered safety add-on devices with special features that reduce the frequency and consequences of any existing hazard. Engineered safety devices are classified as passive or active.

- Passive engineered safety: These kinds of add-on devices do not have to be commissioned or initiated by other devices. Explosion relief vents are a good example of passive add-ons. They open to release explosion pressure when the pressure rises (Amyotte \& Eckhoff, 2010).

- Active engineered safety: These kinds of add-on devices have to be initiated by other detectors or sensors and require periodic checks and maintenance to be reliable. Inerting is an example of a dust and hybrid mixture explosion prevention/mitigation measure, which is adding $\mathrm{N}_{2}, \mathrm{CO}_{2}$, or rare gases to a dust cloud by an automatic explosion suppression process. However, inerting could also be an inherent safety measure (moderation), when adding solid inertants to a given fuel mixture to maximize MEC (Amyotte \& Eckhoff, 2010). 
3. Procedural safety: This is the weakest safety measure with respect to the above protective measures (Kletz \& Amyotte, 2010). Typically, its use is to eliminate ignition sources by, for example, requesting hot-work permitting (Amyotte \& Eckhoff, 2010).

The main difference between the above safety measures is that inherent safety measures look to remove the hazard at the outset of the project design, while the other two attempt to mitigate the effects.

The hierarchy of controls strategy places control methodologies in sequential order: inherent safety, passive engineered safety, active engineered safety, and procedural safety. An overall hierarchical view for dust explosions is given in Table 1.6. It is similar to the LOPA (Layers of Protection Analysis) concept, where inherently safer design acts as the core of the layers (Kletz \& Amyotte, 2010).

In general, risk management is an iterative process. After a risk has been evaluated, the next decision is whether or not the risk needs to be reduced. After it has been reduced, it is necessary to re-estimate the risk. A decision can then be made as to whether the measures taken have reduced the risk to an acceptable level. It is also essential to check that the measures used to reduce the risk have themselves not introduced any new hazards. 
Table 1.6 A hierarchical view of various means of preventing and mitigating dust explosions (Amyotte \& Eckhoff, 2010).

\begin{tabular}{|c|c|c|}
\hline \multicolumn{2}{|c|}{ EXPLOSION PREVENTION } & \multirow{2}{*}{ EXPLOSION MITIGATION } \\
\hline $\begin{array}{c}\text { Preventing } \\
\text { Explosible Dust Clouds }\end{array}$ & $\begin{array}{c}\text { Preventing } \\
\text { Ignition Sources }\end{array}$ & \\
\hline $\begin{array}{l}\text { Process design to prevent } \\
\text { undesired generation of } \\
\text { dust clouds and particle } \\
\text { size reduction and } \\
\text { segregation } \\
\text { Inherent Safety - } \\
\text { Minimization, Substitution, } \\
\text { Moderation, Simplification }\end{array}$ & $\begin{array}{l}\text { Smouldering combustion } \\
\text { in dust, dust fires } \\
\text { Procedural Safety - may } \\
\text { also involve aspects of } \\
\text { Inherent Safety or } \\
\text { Engineered Safety }\end{array}$ & $\begin{array}{l}\text { Good housekeeping (dust } \\
\text { removal/cleaning) } \\
\text { Mitigation with respect to } \\
\text { secondary dust explosions; } \\
\text { prevention with respect to primary } \\
\text { dust explosions } \\
\text { Inherent Safety - Minimization }\end{array}$ \\
\hline $\begin{array}{l}\text { Keeping dust concentration } \\
\text { outside explosible range } \\
\text { Inherent Safety - } \\
\text { Minimization }\end{array}$ & $\begin{array}{l}\text { Other types of open } \\
\text { flames (e.g. hot work) } \\
\text { Procedural Safety - may } \\
\text { also involve aspects of } \\
\text { Inherent Safety or } \\
\text { Engineered Safety }\end{array}$ & $\begin{array}{l}\text { Explosion-pressure resistant } \\
\text { construction } \\
\text { Inherent Safety - Simplification }\end{array}$ \\
\hline $\begin{array}{l}\text { Inerting of dust cloud by } \\
\text { adding inert dust } \\
\text { Inherent Safety - } \\
\text { Moderation }\end{array}$ & $\begin{array}{l}\text { Hot surfaces (electrically } \\
\text { or mechanically heated) } \\
\text { Procedural Safety - may } \\
\text { also involve aspects of } \\
\text { Inherent Safety or } \\
\text { Engineered Safety }\end{array}$ & $\begin{array}{l}\text { Explosion isolation (sectioning) } \\
\text { Inherent Safety - Moderation (e.g., } \\
\text { unit segregation, product choke, } \\
\text { etc.) if not using mechanical } \\
\text { devices. If mechanical devices are } \\
\text { used to isolate plant sections, } \\
\text { classification would be Engineered } \\
\text { Safety - Passive in the case of } \\
\text { physical barriers, or Engineered } \\
\text { Safety - Active in the case of } \\
\text { isolation valves. }\end{array}$ \\
\hline $\begin{array}{l}\text { Intrinsic inerting of dust } \\
\text { cloud by combustion gases } \\
\text { Engineered Safety - Active }\end{array}$ & $\begin{array}{l}\text { Heat from mechanical } \\
\text { impact (metal sparks and } \\
\text { hot-spots) } \\
\text { Procedural Safety - may } \\
\text { also involve aspects of } \\
\text { Inherent Safety or } \\
\text { Engineered Safety }\end{array}$ & $\begin{array}{l}\text { Explosion venting } \\
\text { Engineered Safety - Passive }\end{array}$ \\
\hline \multirow{2}{*}{$\begin{array}{l}\text { Inerting of dust cloud by } \\
\mathrm{N}_{2}, \mathrm{CO}_{2} \text { and rare gases } \\
\text { Engineered Safety - Active }\end{array}$} & \multirow{2}{*}{$\begin{array}{l}\text { Electric sparks and arcs } \\
\text { and electrostatic } \\
\text { discharges } \\
\text { Procedural Safety - may } \\
\text { also involve aspects of } \\
\text { Inherent Safety or } \\
\text { Engineered Safety }\end{array}$} & $\begin{array}{l}\text { Automatic explosion suppression } \\
\text { Engineered Safety - Active }\end{array}$ \\
\hline & & $\begin{array}{l}\text { Partial inerting of dust cloud by } \\
\text { inert gas } \\
\text { Engineered Safety-Active }\end{array}$ \\
\hline
\end{tabular}




\subsection{Original Contributions of The Research}

Few studies in the dust and hybrid mixture explosion area have dealt with explosion risk assessment and management. The current work ${ }^{1}$ attempts to provide an extensive Quantitative Risk Management Framework (QRMF) for dust and hybrid mixture explosion prevention/mitigation. Based on the hierarchy of controls (inherent, engineered, and procedural safety), the framework can effectively help industrial managers and safety engineers prevent and mitigate dust and hybrid mixture explosions in the process industries.

The primary contribution of this research is to provide of an extensive and robust framework that gathers together the concepts of three risk management methodologies: the SCAP (Safety, Credible, Accident, and Probabilistic) algorithm methodology for safety management (Khan et al., 2001), the QRA tool for the external safety of industrial plants with a dust explosion hazard (van der Voot et al., 2007), and a dust explosion prevention/mitigation approach based on inherent safety (Amyotte et al., 2003)), a CFD tool (DESC software), and probability analysis software (Relex).

The novel idea of the current work includes the use of concepts drawn from previous methodologies, formulated into two main steps. The first step is the creation of a new combined safety management framework, and the second step is the use of DESC and FTA to assess explosion consequences and likelihood, respectively. No prior work has hitherto been undertaken to formulate such a framework. This is the first time that DESC, a newly developed Fault Tree Analysis, and Relex software have been integrated to analyze and simulate dust/hybrid mixture explosions.

\footnotetext{
${ }^{1}$ A portion of this work was presented at the $8^{\text {th }}$ ISHPMIE in Japan, and was awarded the honor of being the best paper. The work has since been published in JLPP, referenced as Abuswer et al. (2011).
} 


\section{CHAPTER 2 BACKGROUND}

\subsection{INTRODUCTION}

To date, while many researchers have tried to model or predict dust cloud structures and flame propagation as a first step to mitigating or even preventing dust explosions, there is still a lack of findings that can provide a real explanation of those hazards (Eckhoff, 2005). Other research has tried to develop robust process management procedures, techniques, tools, and frameworks with the intention of mitigating or preventing dust explosion accidents, but there is still more work to be done.

\subsection{Quantitative Risk Assessment Research}

Many researchers have derived models, developed methodologies, or predicted frameworks to mitigate and prevent process industry explosions. However, there is scant published research in the dust and hybrid explosion prevention area, mainly due to the complex nature of these phenomena (Markowski, 2007). In the late 1990s, Khan and Abbasi (1998b) developed the software package MAXCRED (Maximum Credible Accident Analysis) to conduct rapid quantitative risk studies and comprehensive risk analyses of the petrochemical industry. Its five main modules (data collecting, accident scenario generation, consequence analysis, graphics, and documentation) make MAXCRED a flexible tool for risk assessment, as it does not require other packages for data analysis or graphic support (Khan \& Abbasi, 1998a). A few years later, Khan \& Abbasi (2001) developed another computer program called TORAP (Tool for Rapid Risk Assessment in Petroleum Refinery and Petrochemical Industries), which is used for conducting rapid risk assessment in the chemical process industry (CPI) and is capable of handling many types of industrial fires and explosions. This software methodology includes four main steps: accident scenario generation, consequence analysis, checking for a higher degree of accidents, and characterization of worst case scenarios. Papazoglou et al. (2003) developed a methodology for integrating a Quantitative Risk Assessment 
model and a safety management system (SMS) for chemical installations. Bernatik \& Libisova (2004) explained the importance of Quantitative Risk Assessment in the operation of six large old gasholders in an area of high population density in the Czech Republic. Pula et al. (2005) revised several fire consequence models for offshore Quantitative Risk Assessment. Gowland (2006) explained the principles of LOPA (Layer of Protection Analysis) and how it can be used within ARAMIS (Accidental Risk Assessment Methodology for Industries). ARAMIS, which accommodates LOPA, has several modules that can be used to simplify Quantitative Risk Assessment. Attwood et al. (2006) explained the development of a quantitative model that can predict accident frequency on offshore platforms. Their quantitative model focuses on the important factors that can affect the accident process, such as workers' opinions regarding safety.

Creating a communication bridge among managers, engineers and risk analysts was the main goal of Groen et al. (2006). They developed QRAS (Quantitative Risk Assessment System) software, which is used for modeling and risk analysis. The model consists of risk scenarios in the form of event sequence diagram (ESD), fault tree (FT), common cause failure model (CCF), and binary decision diagram (BDD), where BDD compares results with a Probabilistic Risk Assessment (PRA) software tool. The system starts with definitions of a functional hybrid system hierarchy and a mission timeline, which together represent a high-level model.

\subsection{Dust Explosion Prevention Tools}

Each one of the selected tools below can provide a different safety methodology to manage, assess, or analyze risks associated with dust or hybrid mixture releases.

\subsubsection{SCAP}

SCAP is a methodology for safety management based on feedback from a credible accident probabilistic fault tree analysis system (Khan, et al., 2001). It is an algorithm 
methodology developed by Khan \& Husain in 2001. Figure 2.1 shows the steps involved in SCAP.

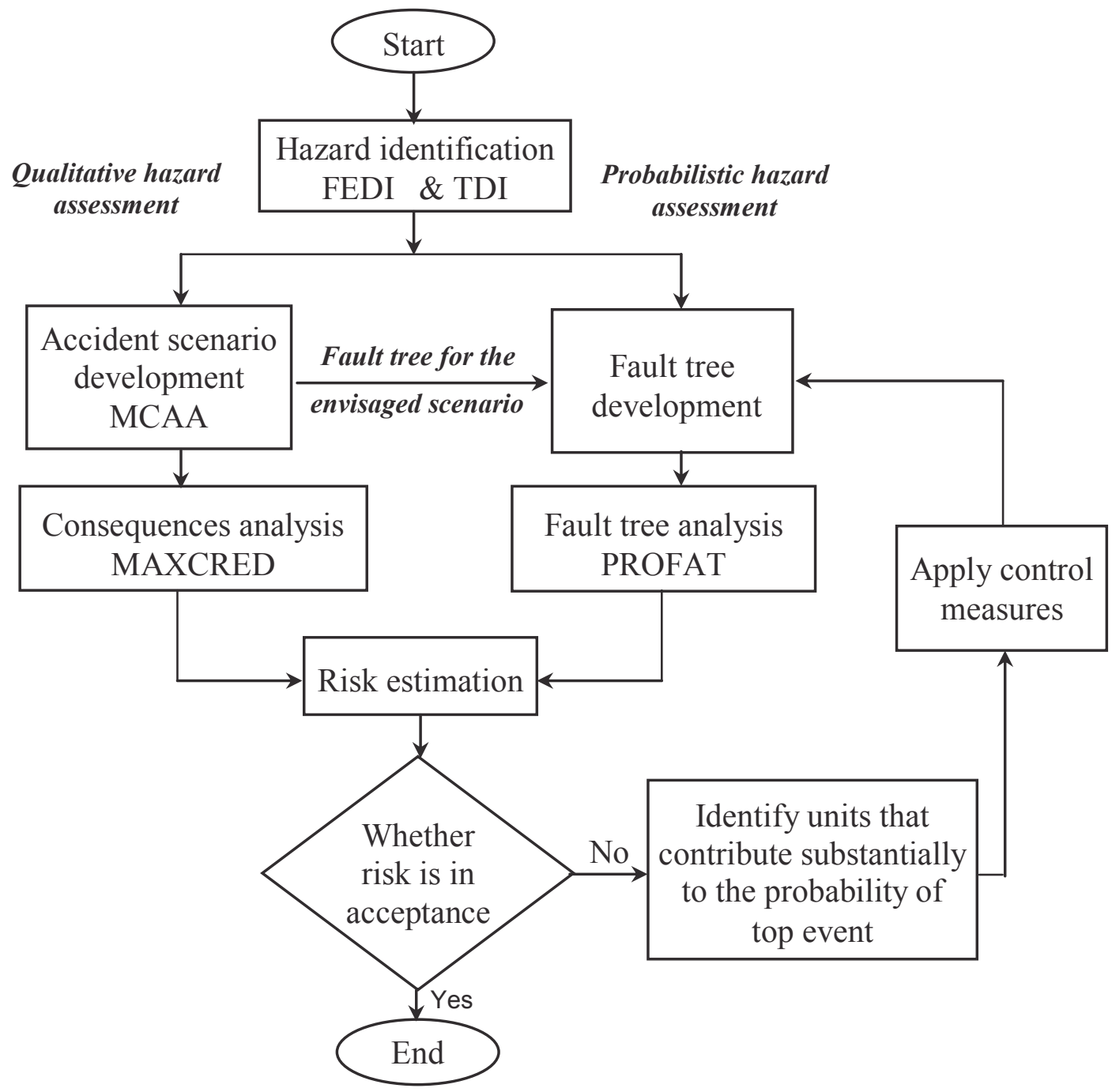

Figure 2.1 The SCAP algorithm (Khan \& Husain, 2001). 
The steps involved in SCAP include:

i) Hazard identification

- FEDI (Fire and Explosion Damage Index) estimation involves the following steps:

- classifying units into five categories (storage units, units involving operation, units involving chemical reactions, transportation units, and hazard units, e.g., furnace or boiler),

- evaluation of energy factors,

- assignment of penalties, and

- estimation of damage potential.

- TDI (Toxic Damage Index) represents fatal toxic load over an area. TDI is based on transport phenomena, empirical models, the physical state, chemical toxicity, operational conditions, and the location condition (Khan \& Husain, 2001). $\mathrm{G}$ is the TDI estimation factor, which takes into account the following (Khan \& Husain, 2001):

- accedental release of super-heated liquid from a unit, some of which could flash to vapors, and some of which could form a liquid pool,

- gas dispersed directly to the surroundings of a unit which could be toxic,

- liquefied gas that could cause the same result as the dispersed gas, and

- toxic gases that could be released from pyrophoric solids.

- $\quad$ HIRA (the Hazard Identification and Ranking Analysis System) enables computation of FEDI and TDI, and serves the following purposes (Khan \& Husain, 2001):

- considers the impacts of process units, parameters, and hazard identification,

- provides reliable quantitative results, and

- uses penalties derived from tested models of thermodynamics and transport phenomena. 
ii) Quantitative hazard assessment branch: MCAA (Maximum Credible Accident Analysis) and MAXCRED software were developed by Khan and Abbasi (1998). This step forecasts the probability of one or more types of accidents occurring in a unit. MCAA is used to assess risks in process industries; it provides possible accident scenarios and their consequences. In turn, MAXCRED takes MCAA results as inputs to provide risk assessment. MAXCRED's modules consist of scenario generation, consequence analysis, domino scenarios, documentation, and graphics (Khan \& Husain, 2001).

iii) PROFAT (Probabilistic Fault Tree Analysis) is an automated tool developed by Khan et al. in 1999 to perform analytical simulation, and is a development of FTA. Key steps of PROFAT (Khan \& Husain, 2001) are:

- fault tree development for individual or a combination of units,

- Boolean matrix creation to solve computer memory allocation problems,

- findings of minimum cut sets and optimizations,

- probability analysis, and

- improvement of index estimation.

\subsubsection{Quantitative Risk Assessment methodology for industrial processes handling dust}

A recent initiative from the organization TNO of the Netherlands (van der Voort et al., 2007) illustrates an interesting approach to incorporating dust explosion probability and consequence severity considerations into a Quantitative Risk Assessment tool. Figure 2.2 provides an overview of the QRA tool. This research used the accident that took place in Semabla, a grain storage facility, in 1997 in Blaye, France, as a case study. The accident occurred because of the propagation of a series of dust explosions in a storage silo building, which caused complete destruction of most of the cells in the building and killed 11 people. These fatalities were caused because of the effects of the debris throw and the grain outflow (van der Voort et al., 2007). 


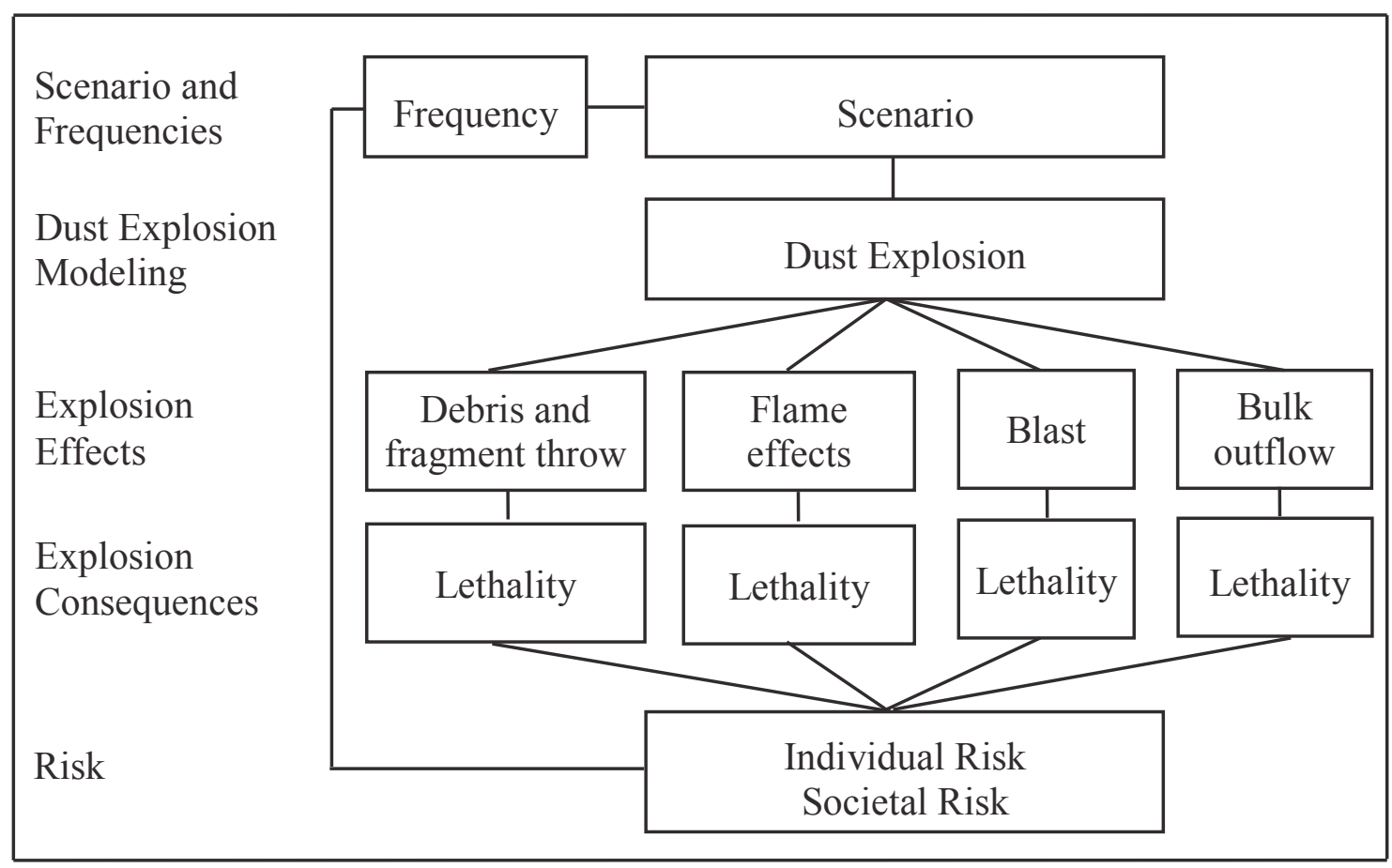

Figure 2.2 Overview of the QRA tool (van der Voort et al., 2007).

The authors explained their modeling as follows:

\section{i) Scenarios and frequencies}

The first step in the modeling was dividing an industrial plant into groups of modules, as shown in Figure 2.3, based on their size, shape, and constructional properties. The second step was finding the relevant explosion scenarios with their probabilities of occurrence, including both a mono scenario, which is the participation of one module, and a domino scenario, which is the participation of all modules in the group. The probabilities of ignition in mono $\left(P_{\text {mono }, i}\right)$ and domino $\left(P_{\text {do,TOT }}\right)$ scenarios are calculated using Equations 2.1 and 2.2 respectively.

$$
\begin{aligned}
& P_{\text {mono }, i}=P_{i} \prod_{j}\left(1-P_{\text {cor }, i j}\right) \\
& P_{\text {do,Tot }}=\sum_{i}\left(P_{i}-P_{\text {mono }, i}\right)
\end{aligned}
$$

Where $\quad P_{i}=$ frequency of ignition 


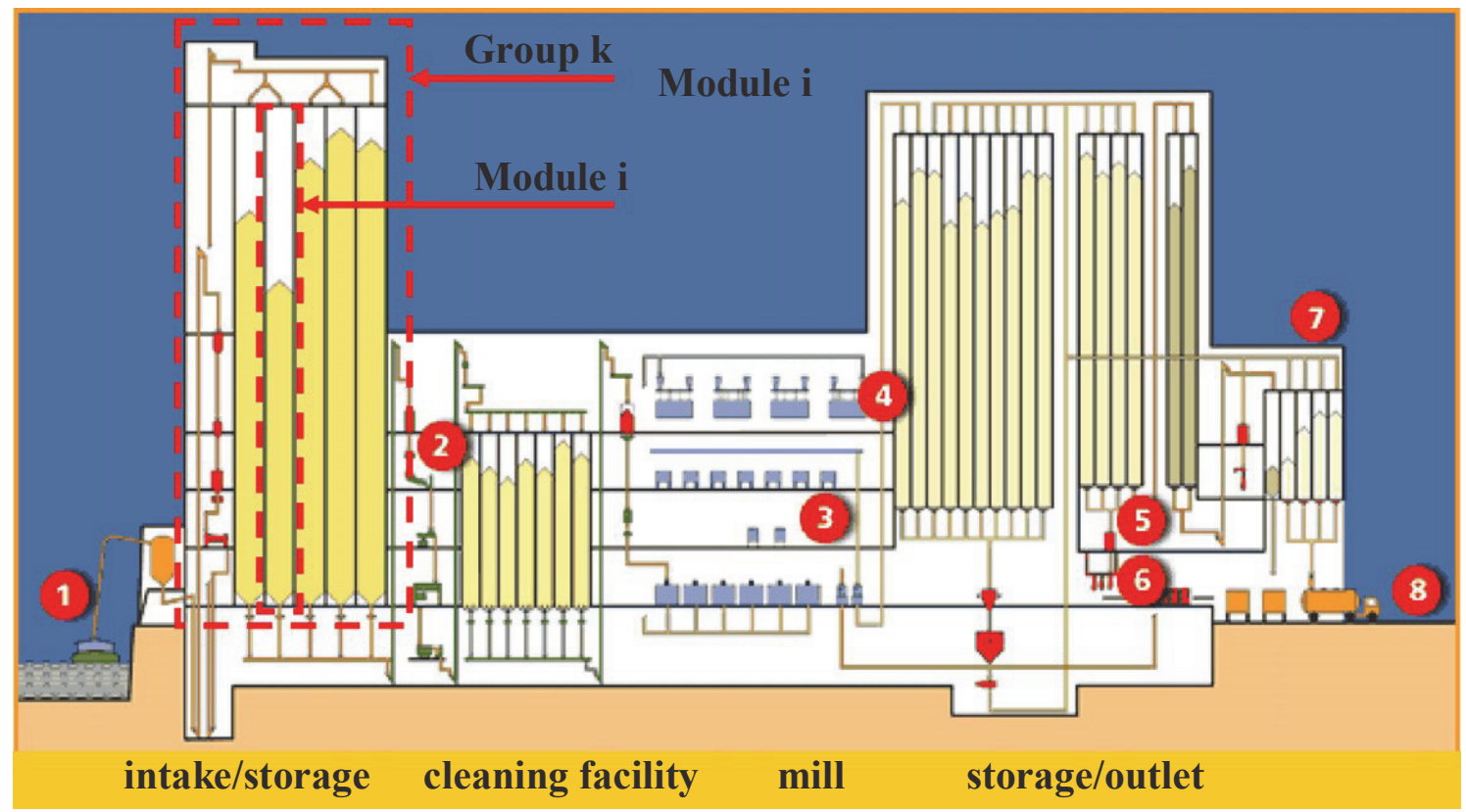

Figure 2.3 Illustration of a fictional industrial facility, divided into groups of modules (van der Voort et al., 2007).

$$
\begin{aligned}
P_{c o r, i j}= & \text { correlation matrix with the probabilities of propagation } \\
& \text { from module } \mathrm{i} \text { to } \mathrm{j}(\mathrm{Pcor}, \mathrm{ij})
\end{aligned}
$$

ii) Dust explosion modeling

Dust explosion modeling is divided into three main parts (van der Voort et al., 2007):

- The initial phase: The module was initially determined based on ignition type, cloud properties, and geometry.

- Module strength: Knowledge about constructional strength is essential to mitigate explosion effects (e.g., blast and debris throw). The QRA tool determines constructional strength based on SDOF (single degree of freedom) calculations.

- Model for pressure relief and acceleration of module parts: This is the module developed to predict the process of pressure venting after module failure by using eight developed differential equations.

iii) Explosion effects and consequences 
The authors developed their module to quantify the effects and consequences of an explosion by considering the following:

- blast and flame effects,

- outflow of bulk material, and

- throw of fragments and debris.

iv) Individual and societal risk

The probability of lethality due to a dust explosion depends on the number of unprotected people in the explosion area. The QRA tool considered four types of objects unprotected people, vehicles, domestic houses, and office buildings - that would be affected by the explosion.

\subsubsection{Dust explosion prevention and mitigation approach based on inherent safety}

Amyotte et al. (2003) developed a systematic approach to loss prevention (shown in Figure 2.4) that incorporates the inherent safety principles (i.e., minimize, substitute, moderate, and simplify). The authors designed their approach based on various previous heuristics work, including the following methodologies (Amyotte et al., 2003):

- The fire triangle, which represents the simple concept of fire elements (fuel, oxidant and ignition source), as shown in Figure 2.5.

- The fire triangle for dusts, which shows the fuel requirements for dusts in the fire triangle (as illustrated in Figure 2.6). Dusts have to be combustible, airborne, and within their explosible concentrations.

- The explosion pentagon, which expands the basic fire triangle to include fuel/oxidant mixing and confinement of the mixture, as shown in Figure 2.7.

- Worldwide guides and standards providing further advice on engineering measures and on where explosion protection is required. 


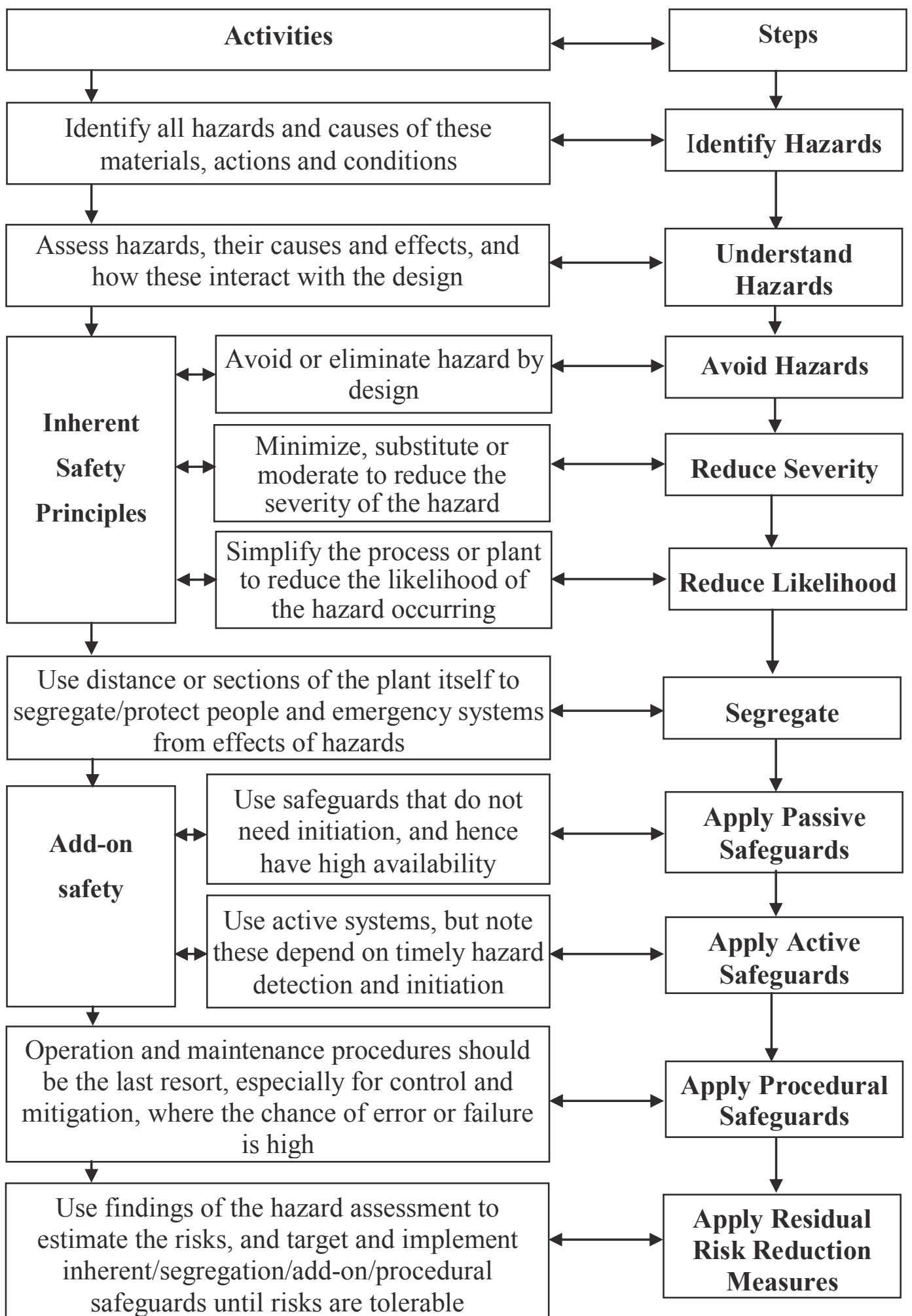

Figure 2.4 A systematic approach to loss prevention (Amyotte et al., 2003). 


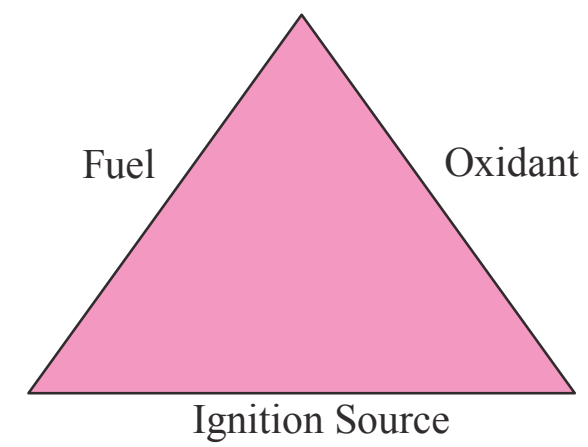

Figure 2.5 The fire triangle (Amyotte \& Eckhoff, 2010).

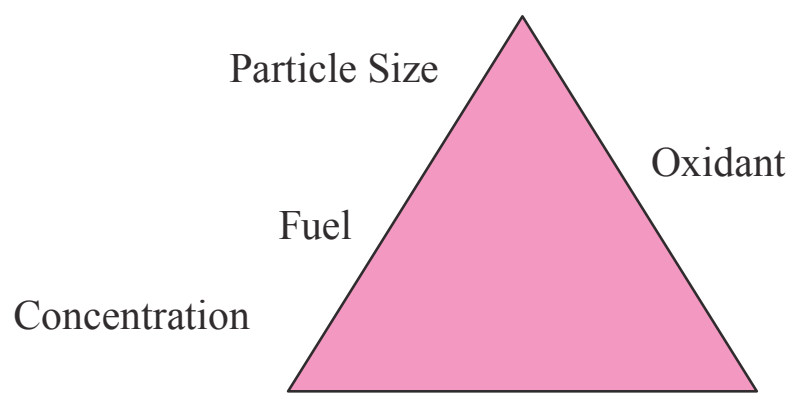

Ignition Source

Figure 2.6 The fire triangle for dust (Amyotte \& Eckhoff, 2010).

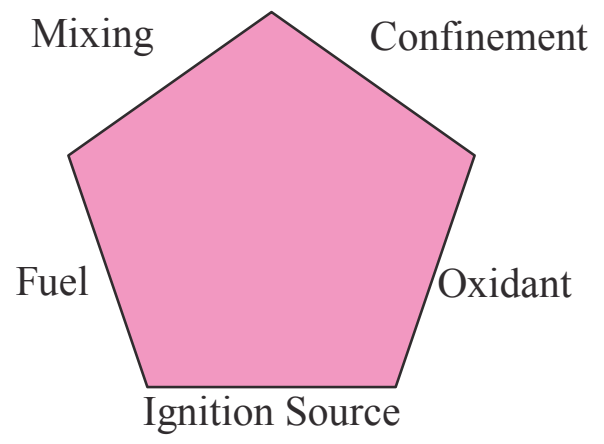

Figure 2.7 The explosion pentagon (Amyotte \& Eckhoff, 2010). 
The developed systematic approach is based on the hierarchy of controls, assembled from three different methodologies: inherent safety, engineered safety, and procedural safety.

\subsubsection{Computational Fluid Dynamics modeling (CFD)}

While Computational Fluid Dynamics modeling of gas explosions has been underway for a number of years, CFD is a relatively new approach in the field of dust explosions. The most comprehensive package available at present is Dust Explosion Simulation Code, which has been developed by GexCon of Norway. The main purpose of the DESC project was to develop a simulation tool based on CFD that could predict the potential consequences of industrial dust explosions in complex geometries (Skjold, 2007). As described by Skjold (2007), DESC can be helpful as a plant design tool for the optimization of mitigation measures such as explosion barriers, vents and suppression systems; Figure 2.8 shows a DESC explosion simulation in an industrial complex.

The DESC project deals with the complex nature of the dust explosion phenomenon and seeks a balance between sufficiently accurate models, robust and efficient numerical schemes, simplified user input, and emphasis on a risk assessment approach (Skjold, 2007).

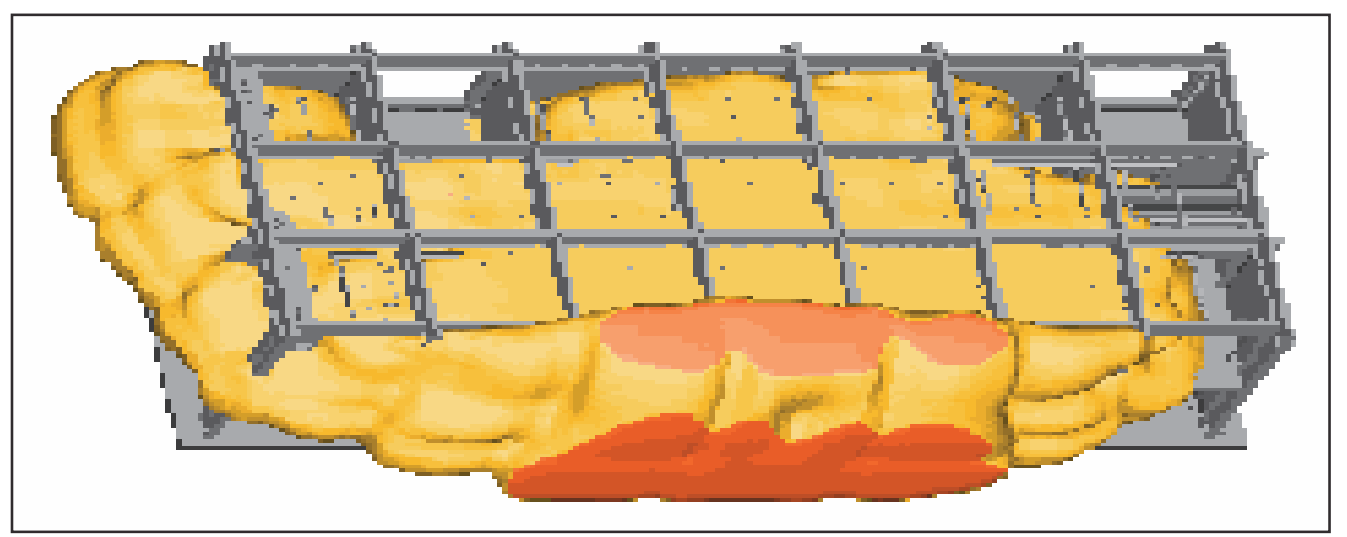

Figure 2.8 3D plot showing flame propagation inside a typical module (GexCon, 2009). 
There are seven work packages (WPs) in the project, and each one was executed by several research groups; turbulent flow measurements, measurements of burning velocities and flame speeds, dust dispersion phenomena, combustion model, development of the CFD code, validation of the CFD code, software package and explosion results (Skjold, 2007).

DESC capabilities have been addressed by GexCon (2009). The software shows numerous advantages when used in dust explosion simulations. For instance, DESC is able to: plot 2D and 3D simulations, and achieve fast-acting pressure panels, as well as simulate large-scale industrial processes, most kinds of dust encountered in industry, pressure development and flame propagation, and dust lifting. It can also predict blast waves.

\subsubsection{Fault Tree Analysis}

Commonly, when Quantitative Risk Assessment is required in industrial processes, Fault Tree Analysis (FTA) and Event Tree Analysis (ETA) are used to estimate the likelihood of occurrence. These methods extensively analyze and investigate the unwanted event diagrammatically, logically, and independently. In the developed QRM framework, FTA has been chosen to calculate explosion likelihood.

Bell Telephone Laboratories developed FTA in 1961 to evaluate a ballistic missile launch control system. In 1965, Haasl at Boeing expanded the use of the FTA technique to other missile systems, and then a year later Boeing started using FTA in civil aircraft design. In 1975, the U.S. Nuclear Regulatory Commission approved FTA as an essential technique in nuclear safety studies. Recently, FTA has been widely employed in various chemical process industries (CCPS, 2000).

Basically, FTA technology uses a combination of the Boolean logic gates "AND" and "OR" in the analysis. Equations 2.3 and 2.4 show the probability calculations for each gate:

The failure probability equation of the "OR" gate is: 


$$
\begin{aligned}
& P=1-\prod_{i=1}\left(1-P_{i}\right) \\
& \text { where: } \quad P=\text { total failure probability } \\
& \qquad P_{i}=\text { the probability of } \mathrm{i}-\mathrm{th} \text { component }
\end{aligned}
$$

The failure probability equation of the "AND" gate is:

$$
P=\prod_{i=1} P_{i}
$$

The developed QRMF uses Relex software to calculate frequencies and probabilities. The advanced features of Relex Fault Tree Analysis software are that it supports quantitative analyses, is user-friendly, provides computational flexibility, and quickly determines the minimal cut sets by incorporating a Minimal Cut Set (MCS) engine (Misra, 2008). Figure 2.9 shows the Relex architect platform.

When no realistic data is available or no failure has occurred in the past, mathematical tools, such as those of Freeman (2011), can generate reliable new data. Freeman (2011) developed twelve tools to estimate failure ratios of any event that has no failure history. The author classified the tools into two categories: best guess methods and confidence limit methods. The methods deal with a variety of possible assumptions, such as assuming that the failure has actually happened, hypothesis testing, uniform probability distribution, exponential distribution, and/or binomial failure limits. However, a minimum ten-year period of historical data is needed to estimate the event failure rate.

Two methods, presented in Equations 2.5 and 2.6, have been chosen to calculate the failure rate $\left(M_{i}\right)$ during number of years of operation $(\mathrm{n})$, which is at least 10 years:

- The 'best guess method' assumes that the event has actually happened:

$$
M_{i}=\lambda=k / n
$$

where $\quad k$ is a constant and has been found between 0.24 and 0.51 .

- The 'confidence limit method' is recommended for explosion initiation test estimates: 


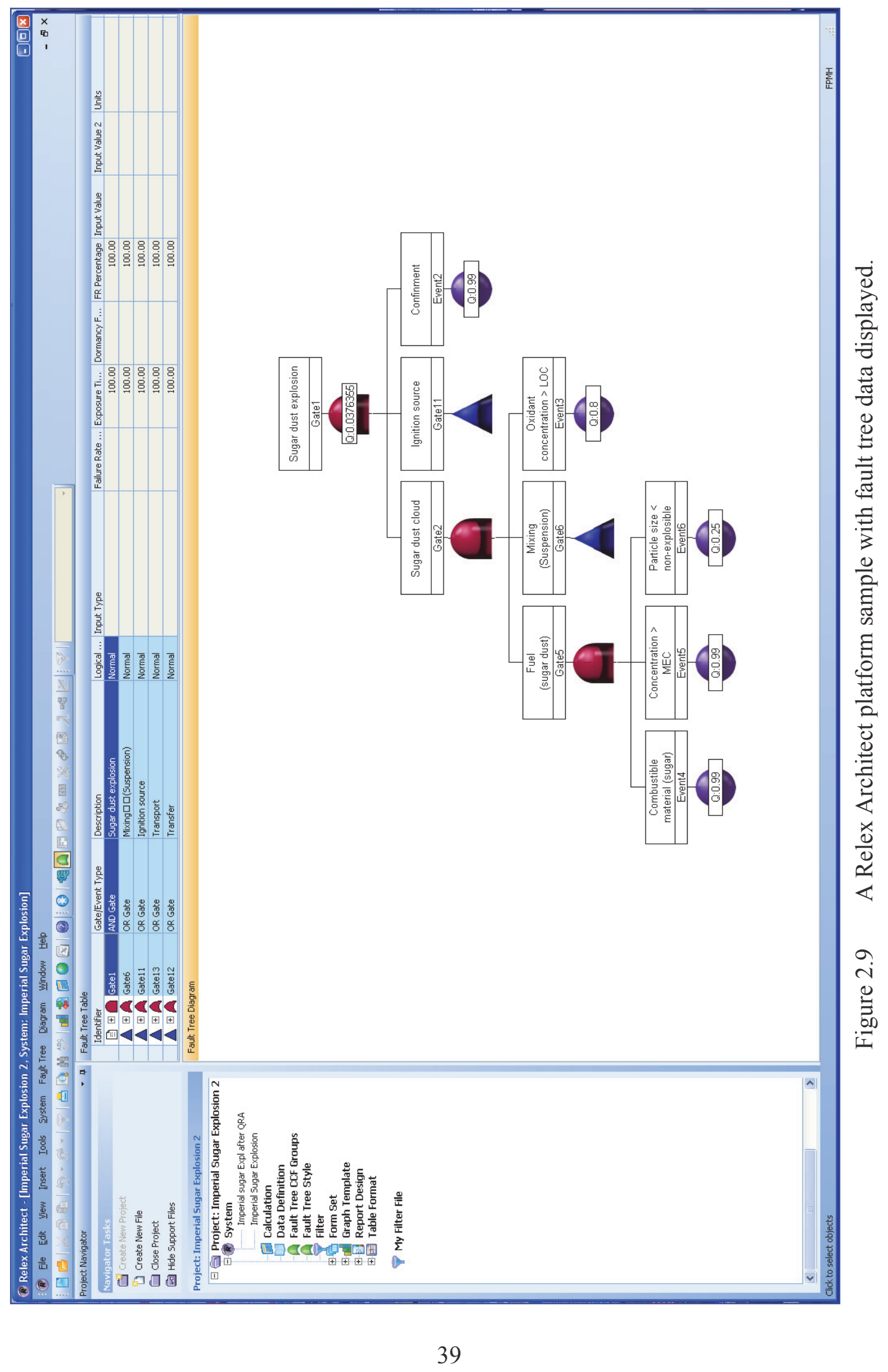




$$
M_{i}=\lambda=1-0.5^{1 / \mathrm{n}}
$$

The best guess method has been recommended for Chemical Process Quantitative Risk Analysis (CPQRA), as the event is physically possible and more than ten years of history are available. If the best guess answer is intolerable, the confidence limit method is recommended to estimate the failure rate of devices with no failure history. Equations 2.5 and 2.6 are also recommended for explosion safety studies (Freeman, 2011).

Crowl and Louvar (2007) defined the failure probability (unreliability) $P$ by Equation 2.7:

$$
\begin{gathered}
P(t)=1-e^{-\lambda t} \\
\text { where: } \quad t=\text { time period } \geq 10 \text { years }
\end{gathered}
$$




\section{CHAPTER 3 QUANTITATIVE RISK MANAGEMENT FRAMEWORK}

\subsection{QRMF Methodology}

Wilson and McCutcheon (2003) define risk as the possibility of injury, loss, or environmental damage created by a hazard, with the significance of risk being a function of the probability (likelihood) of an unwanted incident and the severity of its consequences. Risk therefore arises from a hazard - i.e., the potential for a machine, process, material, piece of equipment, or physical factor in the working environment to cause harm to people, the environment, assets, or production. Risk management is the complete process of understanding risk, risk assessment, and decision making to ensure effective risk controls are in place and implemented. Risk management begins with actively identifying possible hazards, leading to the ongoing management of those risks deemed to be acceptable (Wilson \& McCutcheon, 2003).

As previously mentioned, this research has focused on the QRM of dust and hybrid mixture explosions with the development of a methodological framework for the management of these risks. This framework is shown in a conceptual format in Figure 3.1. The following sub-sections provide details on key components of the framework.

The Quantitative Risk Management approach is proposed to assess and analyze dust and hybrid mixture risks, together with the likelihood and the severity of consequences, and then to provide tools based on a hierarchy of controls to prevent or mitigate dust and hybrid mixture explosions.

The main goals of the QRMF:

- to preclude or mitigate dust and hybrid mixture explosions in process industries through a variety of safety methodologies avoiding any major changes in process design or procedure,

- to provide the optimal safety level in process industries handling dust or hybrid 


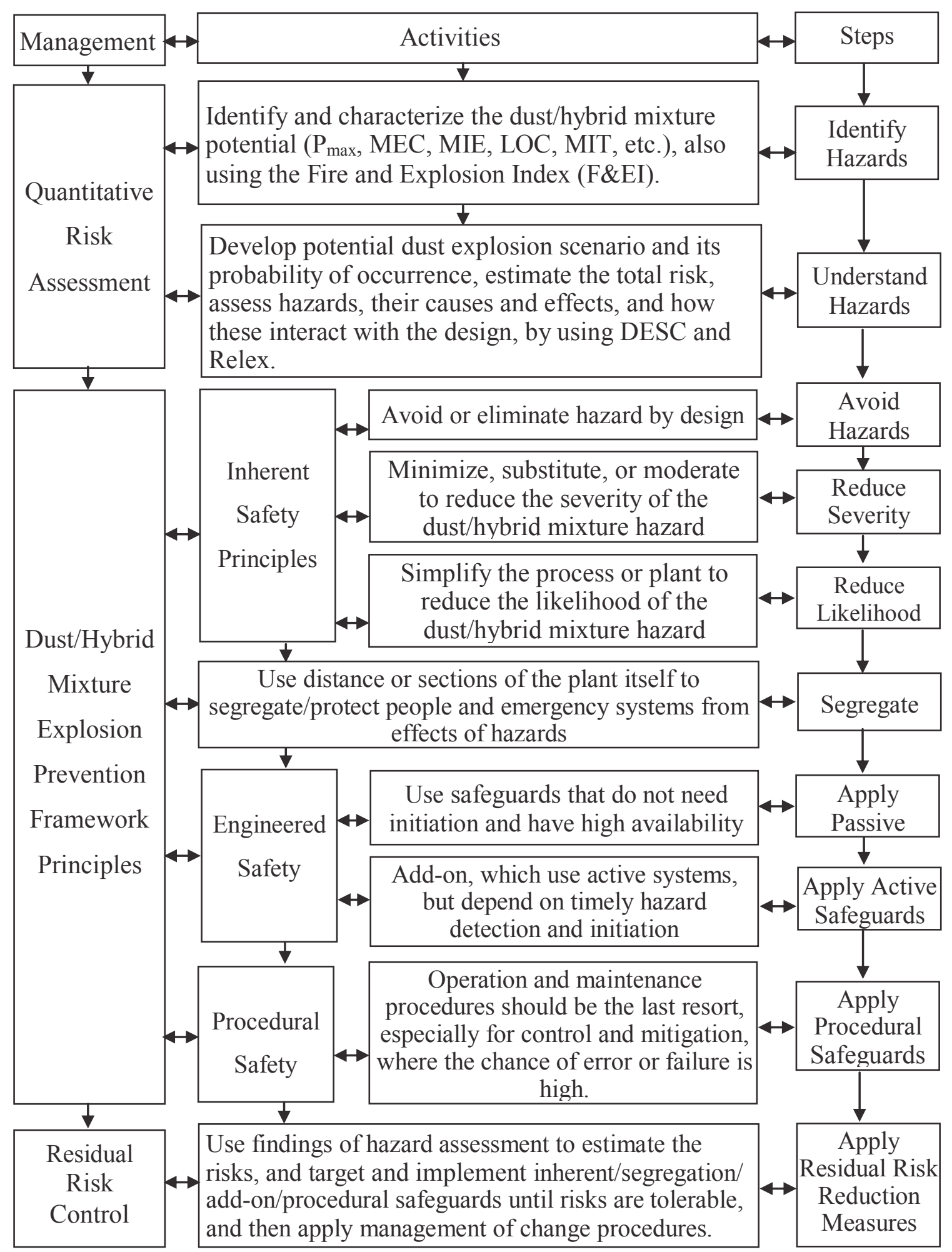

Figure 3.1 A Quantitative Risk Management Framework (QRMF) for dust and hybrid mixture explosion prevention based on the hierarchy of controls (Abuswer et al., 2011). 
mixtures that can be achieved by the hierarchy of controls,

- to provide a Quantitative Risk Management protocol based, in part, on tools developed for process risk reduction, and

- to provide a clearer and more complete picture of dust/hybrid mixture accident possibility scenarios through Relex and DESC analysis of accident scenarios.

The dust explosion prevention tools mentioned in section 2.3 have been modified for the proposed framework to aid dust explosion prevention in the process industries. The following tools are used: (1) the systematic approach to loss prevention, described in section 2.3.3 and shown in Figure 2.4, which is presented in the research framework as a general guide (i.e., using the same safety steps but with special tools for hazard identification and hazard understanding); (2) the SCAP methodology (section 2.3.1), which, by using DESC and Relex software, provides information on dust and hybrid mixture hazards; and (3) the QRA methodology, which is used for external safety (section 2.3.2), i.e., when appraising the external effects of a dust/hybrid mixture explosion. The framework can be summarized as follows.

\subsubsection{Hazard identification}

This step utilizes dust/hybrid mixture hazard identification, characterizes the dust/hybrid potential by screening their explosibility parameters $\left(\mathrm{P}_{\max }, \mathrm{MEC}, \mathrm{K}_{\mathrm{St}}, \mathrm{MIE}, \mathrm{MIT}, \mathrm{LOC}\right)$, and considers dust explosion affecting factors (particle size and agglomeration, moisture, flammable gas content, inert content, etc.).

\subsubsection{Risk analysis}

Once hazards have been identified, there is a need to analyze what risks may be present. An industrial plant should be divided into groups (k) of modules (i) as a first step, and then it should be determined how often an event, or incident, is likely to occur (frequency), and what the consequences in each group would be should the event occur. Total risk can be determined by the following equation (Woodruff, 2005):

$$
R=S * P
$$




$$
\text { where: } \quad \begin{aligned}
& R=\text { total risk } \\
& S=\text { severity of consequences } \\
& P=\text { likelihood of occurrence }
\end{aligned}
$$

Accordingly, to determine total risk, the severity of consequences and the likelihood of occurrence have to be calculated.

\section{i) Severity of consequences}

Determining dust/hybrid mixture incident consequences requires two steps. First, dust/hybrid mixture explosion scenarios should be created for areas threatened by a dust or hybrid mixture hazard. DESC software is able to anticipate and envisage explosions in the affected locations. DESC's main finding is the explosion overpressure $\left(\mathrm{P}_{\max }\right)$, which is the most important parameter needed to calculate damage. Second, using a Probit equation (3.2) (Mannan, 2005), the explosion magnitude, such as deaths, injuries, and structural damage, can be measured depending on the number of causative variables $\left(\mathrm{K}_{1}\right.$, $\mathrm{K}_{2}$ ). Table D.1 (Appendix D), shows the causative variables in the magnitude of the exposure; for structural damage, $\mathrm{K}_{1}=-23.8 \& \mathrm{~K}_{2}=2.92$.

$$
\begin{aligned}
& Y=K_{1}+K_{2} \ln \left(\mathrm{P}_{\mathrm{ovr}}\right) \\
& \text { where: } \quad \begin{array}{l}
Y=\text { Probit variable (unit-less) } \\
\\
\qquad\left(\mathrm{P}_{\mathrm{ovr}}\right)=\text { overpressure }\left(\mathrm{N} / \mathrm{m}^{2}\right) .
\end{array}
\end{aligned}
$$

The structural damage percentage $(P)$ can be transformed by using a Probit transformation table, Table D.2 (Appendix D), or using Equation 3.3 and the error function $(\operatorname{erf}(z))$ (equation 3.4).

$$
\begin{aligned}
& P=50\left[1+\frac{Y-5}{|Y-5|} \operatorname{erf}\left\{\frac{|Y-5|}{\sqrt{2}}\right\}\right] \\
& \operatorname{erf}(z)=\frac{2}{\sqrt{\pi}} \sum_{n=0}^{\infty} \frac{(-1)^{n} z^{2 n+1}}{n !(2 n+1)}=\frac{2}{\sqrt{\pi}}\left(z-\frac{z^{3}}{3}+\frac{z^{5}}{10}-\frac{z^{7}}{42}+\frac{z^{9}}{216}-\cdots\right)
\end{aligned}
$$




\section{ii) Likelihood of occurrence}

The proposed framework (QRMF) uses Fault Tree Analysis to identify the likelihood or probability of a dust or hybrid mixture explosion for a given scenario. FTA is an analytical tool that employs deductive reasoning to determine the occurrence of an undesired event by means of a series of "AND \& OR" logic gates. Figure 3.2, drawn with Relex software, shows the qualitative use of the developed FTA to depict all possible events that could lead to a dust/hybrid mixture explosion, from the top event to common basic events.

FTA can enable the determination of the frequency of accidents if reliable data is provided, and can also reveal various likely basic causes which can lead to the top event or accident. The top event probability or frequency is calculated from failure data of more simple events.

\section{- $\quad$ Dust explosion and hybrid mixture FTA flowchart}

As mentioned above, Figure 3.2 shows a diagrammatic analysis of the undesired top event in the fault tree and how it gathers all possible process industrial field events that could lead to a dust/hybrid mixture explosion. However, it can be modified by removing nonexistent events in any given process. This is described in the steps below, which address the main explosion elements, as follows:

1- Dust/hybrid mixture explosion: This is the top event of the diagram. It is the worst event that can occur and also the ultimate one. As such, it is the main target for analysis in order to determine the likelihood of its occurrence.

2- Ignition source: In the explosion pentagon, ignition source is usually the hardest element to avoid or control, as it can be anywhere and everywhere in industrial processes (i.e., it could be an electrical, mechanical, chemical, or even natural event). Abbasi \& Abbasi (2007) have listed some possible ignition sources, which have been used in the FTA flowchart; all that is required is to determine the probability of occurrence for each of them in order to calculate the total probability of the main ignition source element in the pentagon. 


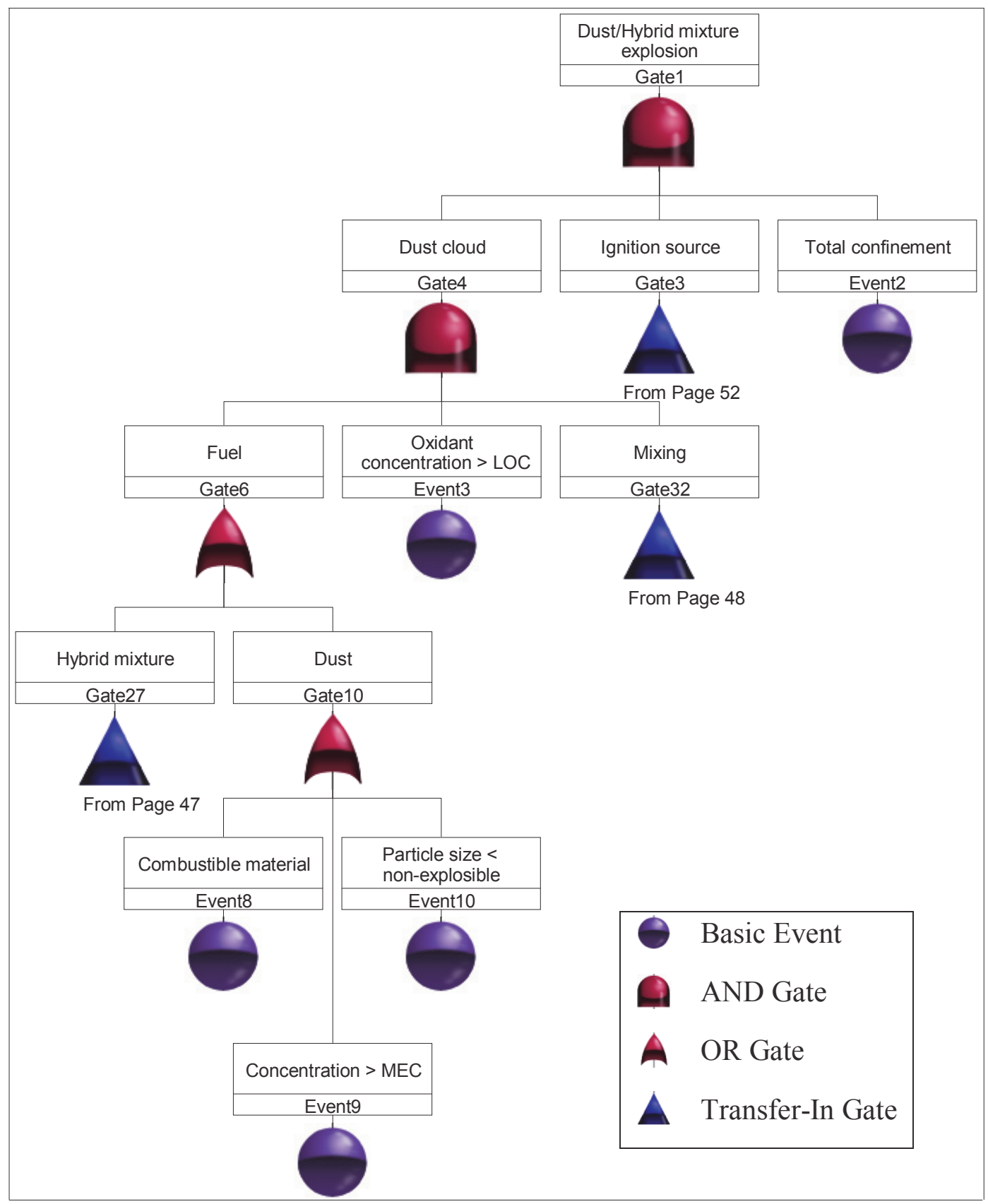

Figure 3.2 General dust and hybrid mixture explosion FTA flowchart. 


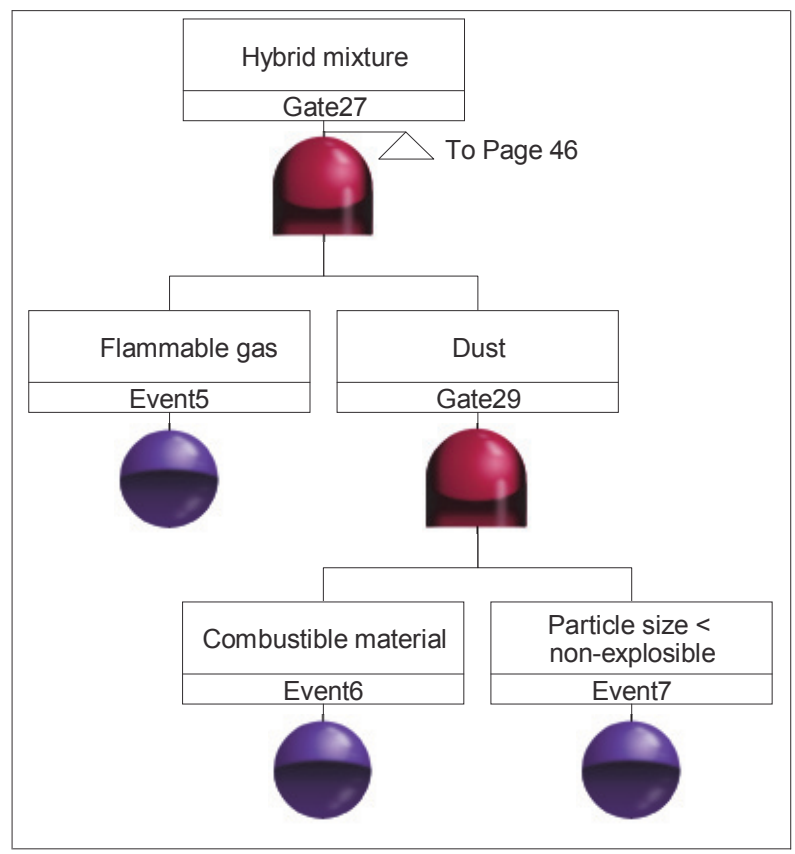




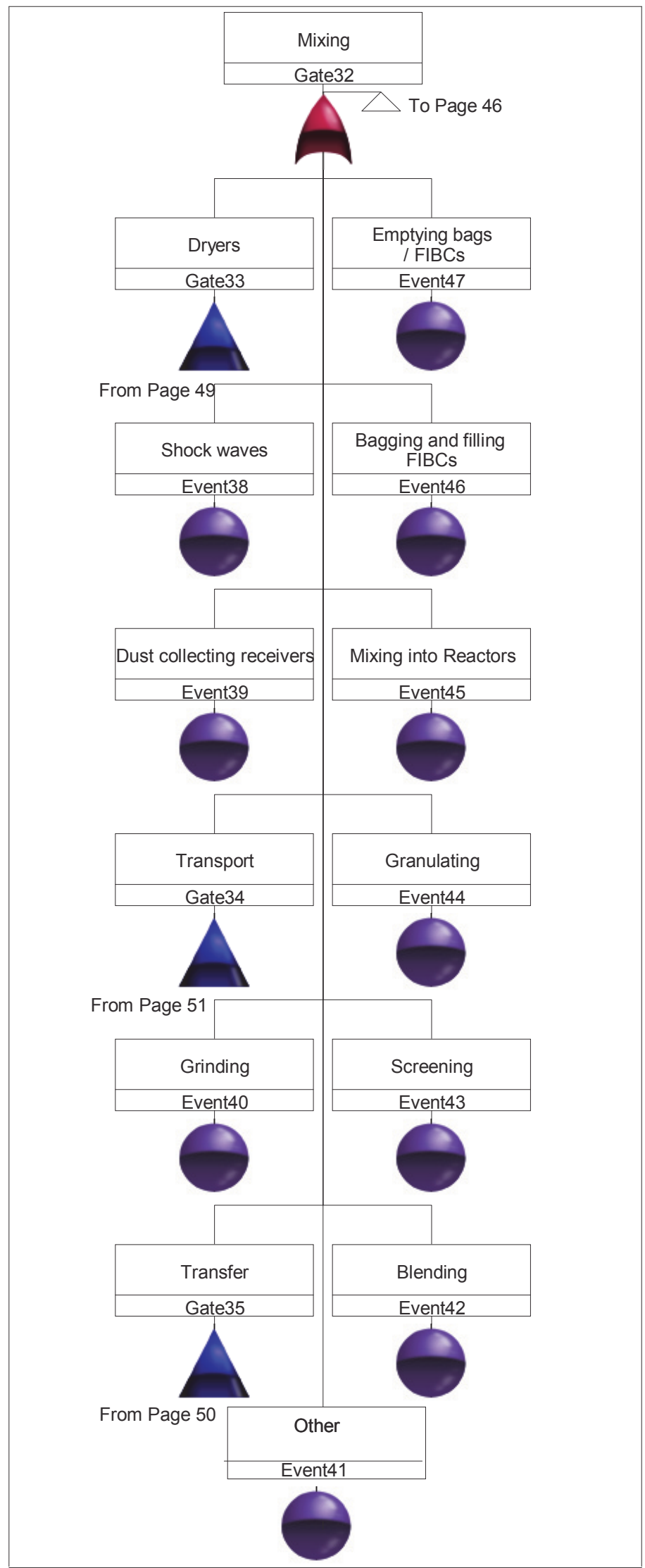




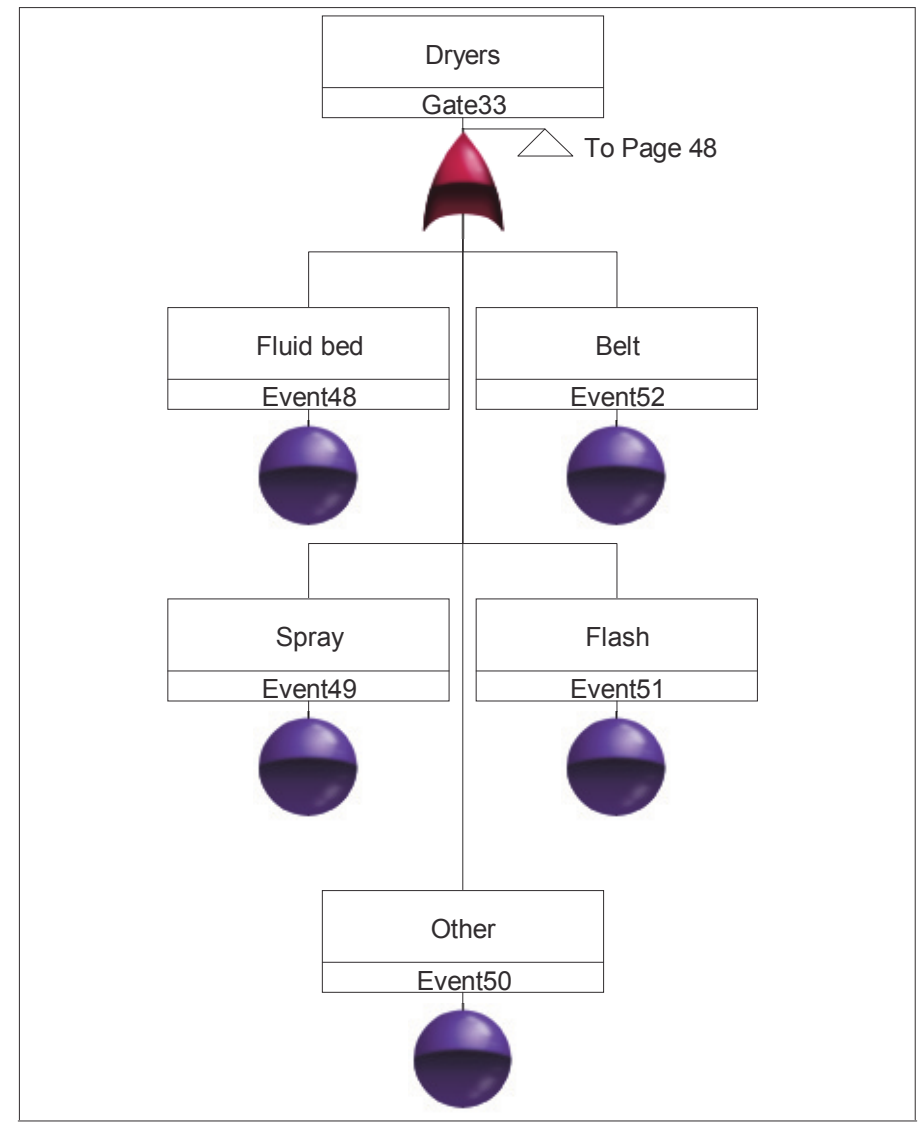




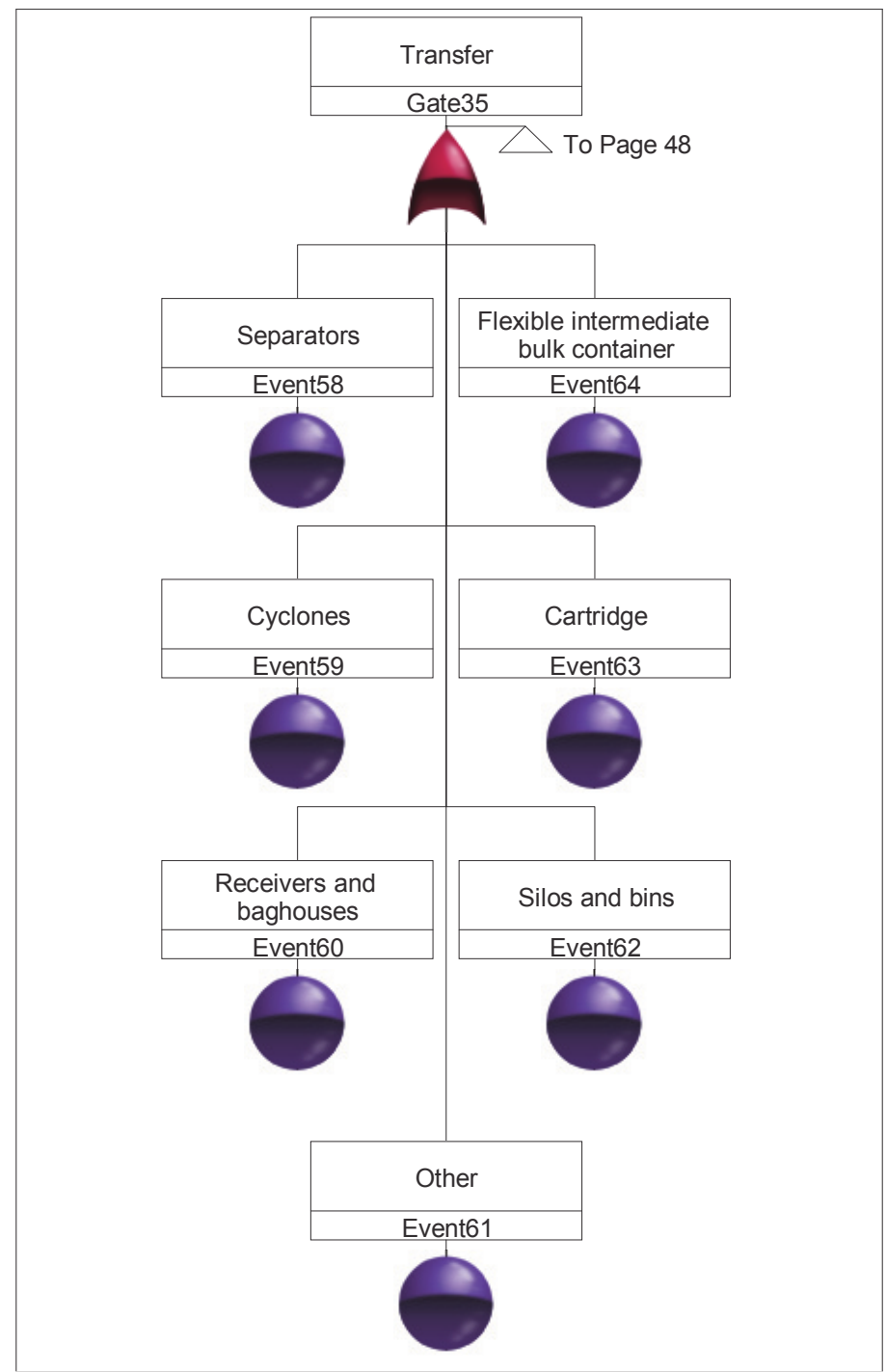




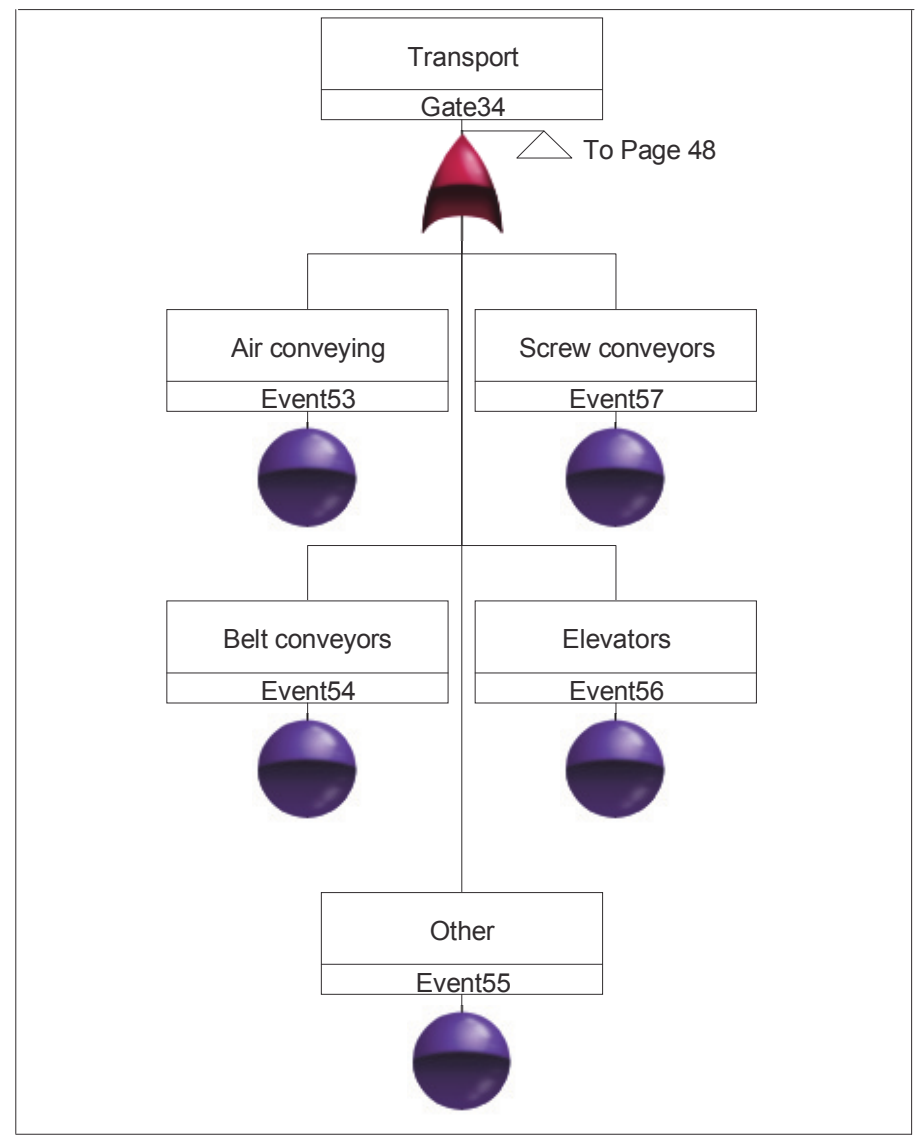




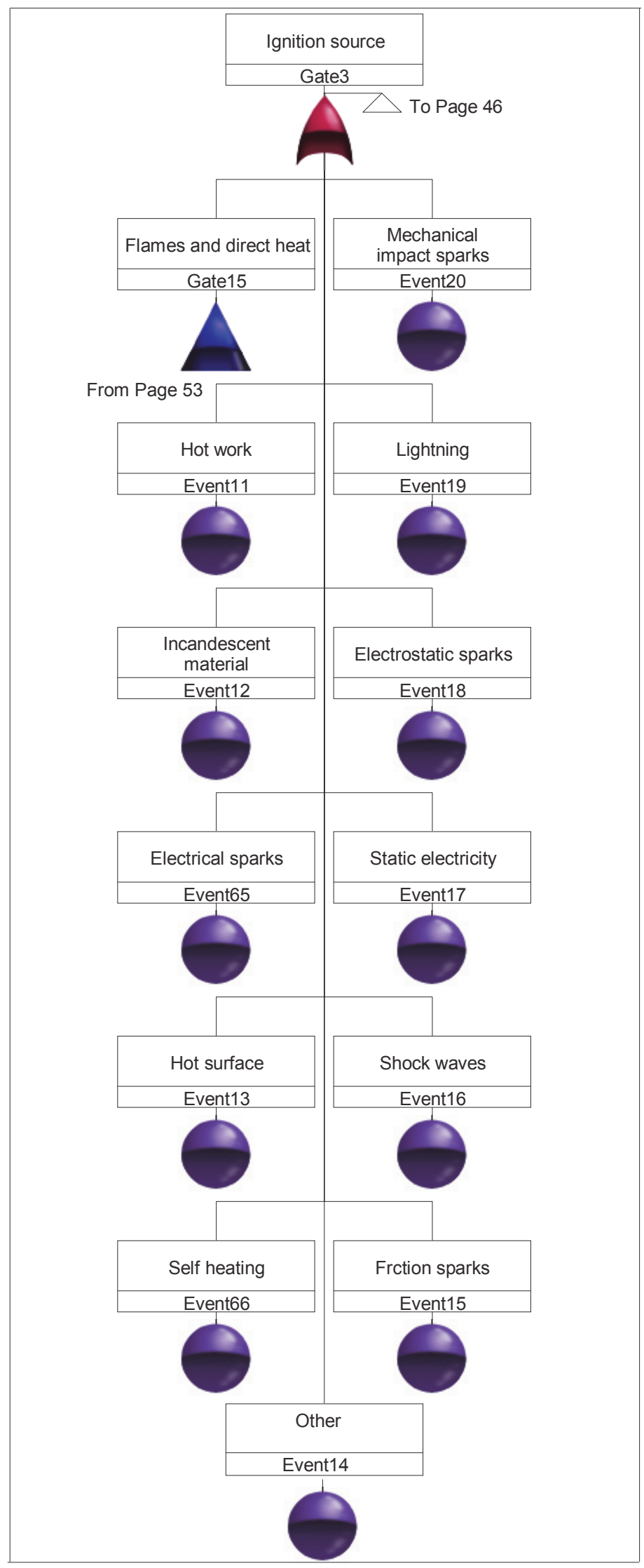




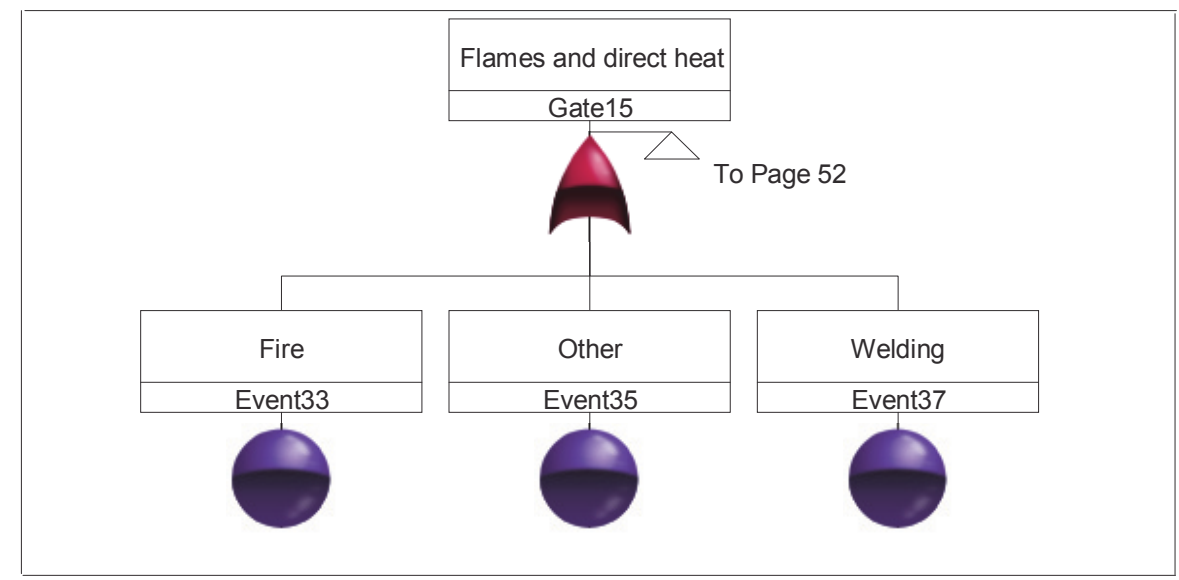

Industrial ignition sources can be one or more of the following: flames and direct heat (fire or welding), mechanical impact sparks, hot works, lightning, incandescent material, electrostatic sparks, electrical sparks, static electricity, hot surfaces, shock waves, self-heating, and friction sparks. There are also other known or unknown ignition sources.

3- Confinement: This refers to the probability of total or partial confinement, depending on where the explosion occurs.

4- Dust cloud: This consists of three main elements, and all three of these elements must be present to form a dust cloud:

- Fuel: this could be combustible dust with particle size within the explosible range and a concentration above the MEC (minimum explosible concentration), or it could be a hybrid mixture, which is a mixture of a small amount of flammable gas and combustible dust.

- Mixing: This is one of the five main principles of the explosion pentagon and is also the element that makes the dust airborne. Within the industrial process, suspension usually occurs when one or more of the following processes or pieces of equipment exist: dryers (fluid bed, spray, flash, or belt), emptying bags/FIBC (flexible intermediate bulk containers), dust collecting receivers, mixing into 
reactors, transport (pneumatic conveyors, belt conveyors, or elevators), granulating, grinding, screening, transfer (separators, flexible intermediate bulk containers, cyclones, silos and bins, receivers and bag houses, or cartridges), and/or blending. Suspension may also occur as a result of sudden shock waves or other events.

- Oxidant concentration: oxygen is one of the elements of the fire triangle and the explosion pentagon, whose concentration is fundamental in explosion control procedures. It affects the probability of occurrence and also affects the consequences of any possible explosion. Excess oxidants stimulate a swift and complete reaction, and vice-versa.

\subsubsection{Risk estimation}

Risk estimation is defined as a measure of human injury or death, production and/or property loss, and/or environmental damage created by a hazard. The significance of risk estimation is a function of the probability of an unwanted incident and the severity of the consequences (Wilson \& McCutcheon, 2003). There are three common ways to gauge risk: risk indices, individual risk $\left(\mathrm{R}_{\mathrm{Ind}}\right)$, and group (societal) risk. According to many studies, there are a variety of specific equations and definitions that address these kinds of measures, as follows (CCPS, 2000).

\section{i) Individual risks}

"Individual risk is defined formally (by the Institution of Chemical Engineering, UK) as the frequency at which an individual may be expected to sustain a given level of harm from the realization of specified hazards" (Khan, 1999). Individual risk could be determined in various ways, such as:

\section{- Location-specific individual risk (LSIR)}

LSIR calculates the risk at a particular location hypothetically; it is not a realistic method to calculate individual risk (Khan, 1999). It is shown in Equation 3.5. 


$$
\begin{aligned}
& L S I R=\sum F_{S} * P_{F} \\
& \qquad P_{F}=P_{f l}+P_{f m}\left(1-P_{f l}\right)+P_{f e}\left(1-P_{f m}\right)\left(1-P_{f l}\right)
\end{aligned}
$$

where: $\quad F_{S}=$ frequency of scenarios

$P_{F}=$ probability of death

$P_{f l}=$ probability of local fatality in the fire/explosion

$P_{f m}=$ probability of fatality during escalation/mustering

$P_{f e}=$ probability of fatality during evacuation.

- Individual-specific individual risk (ISIR)

ISIR calculates the risk at different locations, taking into account different lengths of time for workers, and is a more realistic measure (Khan, 1999), as shown in Equation 3.7.

$$
I S I R=L S I R * P_{L}
$$

where: $P_{L}=$ proportion of time an individual spends in a location.

- Average individual risk(IR)

The IR of exposed people in certain workplaces can be determined by Equation 3.8 (CCPS, 2000).

$$
I R_{x, y}=\frac{\sum_{x, y} I R_{x \cdot y, i} \mathrm{P}_{\mathrm{x}, \mathrm{y}}}{\sum_{x, y} \mathrm{P}_{\mathrm{x}, \mathrm{y}}}
$$

where: $\quad I R_{\text {avgi }}=$ average individual risk in the exposed population $\left(y r^{-1}\right)$.

$$
\begin{aligned}
I R_{x \cdot y, i} & =\text { individual risk at location } \mathrm{x}, \mathrm{y}\left(y r^{-1}\right) . \\
& =f_{i} p_{f, i} \\
f_{i} & =\text { frequency of incident outcome, case } i\left(y r^{-1}\right) \\
p_{f, i} & =\text { probability of fatality } \\
\mathrm{P}_{\mathrm{x}, \mathrm{y}} & =\text { number of people at location } x, y .
\end{aligned}
$$


Equation 3.9 calculates average individual risk of the total population whether they are inside the threatened facility or in nearby residences (CCPS, 2000).

$I R_{\text {avg } T}=\frac{\sum_{x, y} I R_{x . y} P_{x, y}}{P_{T}}$

where: $P_{T}=$ total predetermined population for average risk.

The acceptance of individual risk (IR) is quite different from one country to another; it depends on the country's regulations and rules e.g. the acceptance IR in the Netherlands is $10^{-5}$ per year, and $10^{-3}$ per year for societal risk, however the acceptance IR in UK is $10^{-4}$ per year, $10^{-3}$ per year for workers, and $10^{-6}$ per year for broadly accepted risk (Kauer, et al., 2002). The maximum acceptable individual risk range in the process industries is $5 * 10^{-5}$ to $5 * 10^{-6}$; however the maximum acceptable public individual risk range is $5 * 10^{-3}$ to $1 * 10^{-4}$ (CCPS, 2009).

ii) Risk Indices

- Fatal accident rate (FAR)

FAR is the number of fatalities per $10^{8}$ exposed hours, which is roughly the number of exposed hours at work in 1,000 working lifetimes. The typical FAR range is 1-30 for industries. FAR is more understandable that individual risk. Equation 3.10 calculates FAR from ISIR (Khan, 1999).

$$
F A R=\left(I S I R * 10^{8}\right) / H
$$

where: $H=$ hours of work per year.

Table 3.1 provides a list of fatal accident rates for selected industries in Australia. 
Table 3.1 Fatal accident rates in Australian industry (Cameron \& Raman, 2005).

\begin{tabular}{|l|c|}
\hline Industry category & FAR \\
\hline Mining (non-coal) & 27 \\
\hline Mining (coal) & 17 \\
\hline Agricultural, forestry & 11 \\
\hline Construction & 9 \\
\hline Chemicals, petroleum & 4 \\
\hline Other manufacturing & 3 \\
\hline
\end{tabular}

iii) Group (societal) risks

A societal risk is defined by the Institution of Chemical Engineering, UK, as the relationship between the frequency and the number of people suffering a given level of harm from the realization of specified hazards (Khan, 1999).

- F-N curve

F-N curve is a societal risk measure that displays cumulative frequencies (F) of an event versus number of fatalities $(\mathrm{N})$. The curve plots the F-N historical data and shows in which region (unacceptable, tolerable, or acceptable) they are. Also, it compares the historical data with QRA results, i.e., after application of the QRM protocol on given threatened plant (CCPS, 2000).

- $\quad$ Average Rate of Death (ROD)

ROD is a societal risk measure that is not related to any individual risk. It is determined by Equation 3.11 (CCPS, 2000):

$$
R O D=\sum_{i=1}^{n} f_{i} N_{i}
$$

where: $\mathrm{N}_{\mathrm{i}}=$ the number of fatalities resulting from outcome case $\mathrm{i}$.

- Equivalent societal cost (ESC): 
Multiple fatalities can be the outcome of a series of incidents or of one incident. ESC takes incident outcomes into account and shows which ones can cause the most severity. Equation 3.12 calculates the ESC (CCPS, 2000).

$$
E S C=\sum_{i=1}^{n} f_{i}\left(N_{i}\right)^{p}
$$

where: $p=$ risk aversion power factor $=2$ for chemical industries.

\subsubsection{Risk evaluation}

Risk evaluation is the stage at which values and judgments enter the decision process. This process addresses the question: Is the risk judged to be acceptable? (Wilson \& McCutcheon, 2003). If the answer is "Yes", no necessary changes need to be made to the system; the residual risk should be managed and the activity continued. However, if the answer is "No", the question remains: What should be done?

There are many risk criteria to evaluate risk, such as ALARP and DMRA.

\section{- ALARP (As Low As Reasonably Practicable)}

In order to reduce risk at working areas, and taking into account the concept of "reasonably practicable", the HSE (Health and Safety Executive) in 1974 developed ALARP principles as a simple method for its working staff. The principles are illustrated in Figure 3.3, which shows the unacceptable region (intolerable risk level), tolerable region, and acceptable region.

The HSE reported a tolerable individual and societal risk for workers from $1 * 10^{-6}$ /year to $1 * 10^{-3} /$ year and a tolerable risk for public from $1 * 10^{-6} /$ year to $1 * 10^{-4}$ / year (Mannan, 2005).

\section{- DMRA (Decision matrix risk-assessment)}

Marhavilas \& Koulouriotis. (2008) developed a systematic technique for risk estimation known as decision matrix risk assessment (DMRA). DMRA measures and categorizes risk in terms of its probability of occurrence and its severity of consequences by combining them in the same matrix, as shown in Table 3.2-a and Table 3.2-b. The 


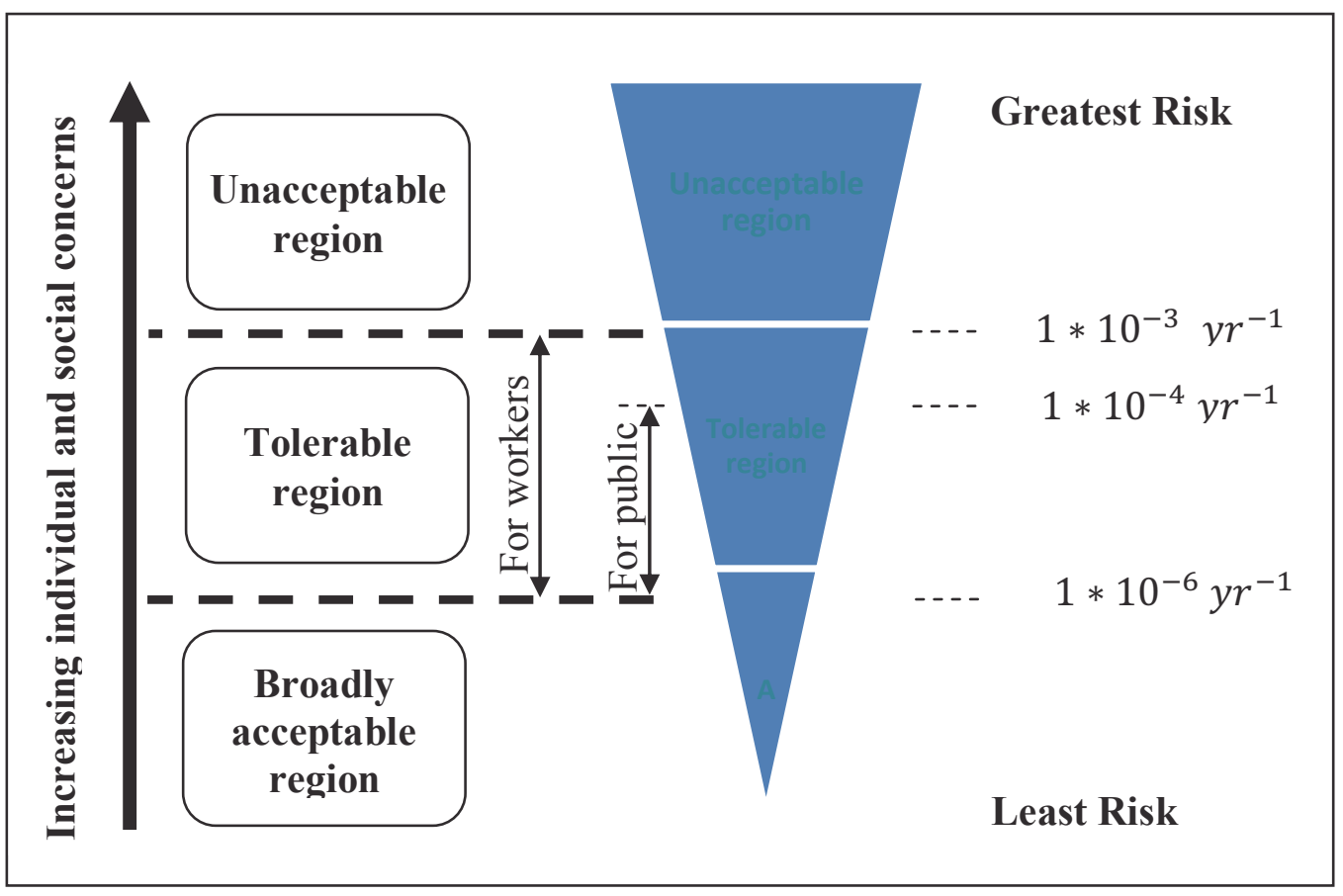

Figure 3.3 HSE framework for tolerability of risk (after (IET, 2010)).

authors have also developed two scales of values, each with six gradations; the first scale shows severity of consequences ratings, and the second scale shows frequency or hazard probability ratings as may be seen in Tables E.1 and E.2 in Appendix E (Marhavilas \& Koulouriotis, 2008).

\subsubsection{Risk control}

Risk control, as mentioned in Chapter 2, is the process of reducing risk by decreasing the likelihood and/or consequences of the hazardous event. This process needs to be reviewed, applying changes as necessary. If risk or residual risk is too high and changes cannot be made safely, the right decision is to discontinue the activity.

The quantitative risk management framework for dust and hybrid mixture explosion prevention is based on a hierarchy of controls, as shown in Figure 3.1, and gathers together three different methodologies - inherent safety, engineered safety, and procedural safety - to deal with dust and hybrid mixture hazards. The idea of the 
Table 3.2 The decision matrix risk assessment technique (Marhavilas \& Koulouriotis, 2008).

a) The risk matrix.

\begin{tabular}{|c|c|c|c|c|c|c|}
\hline \multirow{2}{*}{$\begin{array}{c}\text { Severity of } \\
\text { consquences } \\
\text { ratings (S) }\end{array}$} & \multicolumn{7}{|c|}{$\begin{array}{c}\text { Hazard probability ratings } \\
\text { (P) }\end{array}$} \\
\cline { 2 - 7 } & 6 & 5 & 4 & 3 & 2 & 1 \\
\hline 6 & 36 & 30 & 24 & 18 & 12 & 6 \\
\hline 5 & 30 & 25 & 20 & 15 & 10 & 5 \\
\hline 4 & 24 & 20 & 16 & 12 & 8 & 4 \\
\hline 3 & 18 & 15 & 12 & 9 & 6 & 3 \\
\hline 2 & 12 & 10 & 8 & 6 & 4 & 2 \\
\hline 1 & 6 & 5 & 4 & 3 & 2 & 1 \\
\hline
\end{tabular}

b) The decision making table.

\begin{tabular}{|l|l|c|}
\hline & Unacceptable & $18-36$ \\
\hline & Undesirable & $10-16$ \\
\hline & Acceptable with controls & $5-9$ \\
\hline & Acceptable & $1-4$ \\
\hline
\end{tabular}

framework is to apply the safety controls, starting with the most effective one (inherent safety) and moving to the least effective (with respect to inherent safety), which is procedural safety. When a safety control tool consists of one or more applicable principles, these principles should be applied in optimal sequence, as follows:

\section{i) Inherent safety}

- minimization

- substitution

- moderation, and

- simplification. 
ii) Engineered safeguards

- engineered safety - passive

- engineered safety - active

iii) Procedural safeguards

Amyotte et al. (2007) provide an illustrative example of a process safety and occupational safety checklist form, shown in Table 3.3. However, each company should have its own inherent safety-based checklist (Amyotte et al., 2007).

\subsubsection{Residual risk control}

Finally, the given process has to be extensively reviewed and monitored to make sure the applied changes do not affect the process parameters at any point in the whole system, a step which requires the application of the MOC (management of change) procedure. Figure 3.4 illustrates an inherent safety-based MOC protocol.

\subsection{QRMF IMPLEMENTATION}

Implementation of the conceptual framework, which is given in Figure 3.1, is undertaken by means of the flowchart shown in Figure 3.5. Topics of the developed QRMF include quantitative Fault Tree Analysis and the use of Probit models to express explosion consequences in terms of parameters other than overpressure. The case studies detailed in Chapter 5 emphasize QRMF applications using consequence analysis, DESC, FTA, and considerations related to the hierarchy of safety controls. 
Table 3.3 Inherent safety checklist (Amyotte et al., 2007).

\begin{tabular}{|c|c|}
\hline Guideword & Checklist Question \\
\hline \multirow{4}{*}{ Minimize } & - Is the storage of all hazardous gases, liquids, and solids minimized? \\
\hline & - Are just-in-time deliveries used when dealing with hazardous materials? \\
\hline & $\begin{array}{l}\text { - Are all hazardous materials removed or properly disposed of when they are no } \\
\text { longer needed or not needed in the next X days? }\end{array}$ \\
\hline & - Is shift rotation optimized to avoid fatigue? \\
\hline \multirow{4}{*}{ Substitute } & - Can a less toxic, flammable, or reactive material be substituted for use? \\
\hline & $\begin{array}{l}\text { - Is there an alternate way of moving product or equipment as to eliminate } \\
\text { human strain? }\end{array}$ \\
\hline & - Can a water-based product be used in place of a solvent- or oil-based product? \\
\hline & $\begin{array}{l}\text { - Are all allergenic materials, products, and equipment replaced with } \\
\text { nonallergenic materials, products, and equipment when possible? }\end{array}$ \\
\hline \multirow{4}{*}{ Moderate } & $\begin{array}{l}\text { - Can potential releases be reduced via lower temperatures or pressures, or } \\
\text { elimination of equipment? }\end{array}$ \\
\hline & $\begin{array}{l}\text { - Are all hazardous gases, liquids, and solids stored as far away as possible to } \\
\text { eliminate disruption to people, property, production, and environment in the } \\
\text { event of an incident? }\end{array}$ \\
\hline & $\begin{array}{l}\text {-When purchasing new equipment, are acceptable models available that operate } \\
\text { at lower speeds, pressures, temperatures, or volumes? }\end{array}$ \\
\hline & - Are workplaces designed such that employee seclusion is minimized? \\
\hline \multirow{4}{*}{ Simplify } & $\begin{array}{l}\text { - Are all manuals, guides, and instructional material clear and easy to } \\
\text { understand, especially those that are used in an emergency situation? }\end{array}$ \\
\hline & $\begin{array}{l}\text { - Are equipment and procedures designed such that they cannot be operated } \\
\text { incorrectly or carried out incorrectly? }\end{array}$ \\
\hline & $\begin{array}{l}\text { - Are machine controls located to prevent unintentional activation while } \\
\text { allowing easy access for stopping the machine? }\end{array}$ \\
\hline & $\begin{array}{l}\text { - Are all machines, equipment, and electrical installations easily isolated of all } \\
\text { sources of power? }\end{array}$ \\
\hline
\end{tabular}




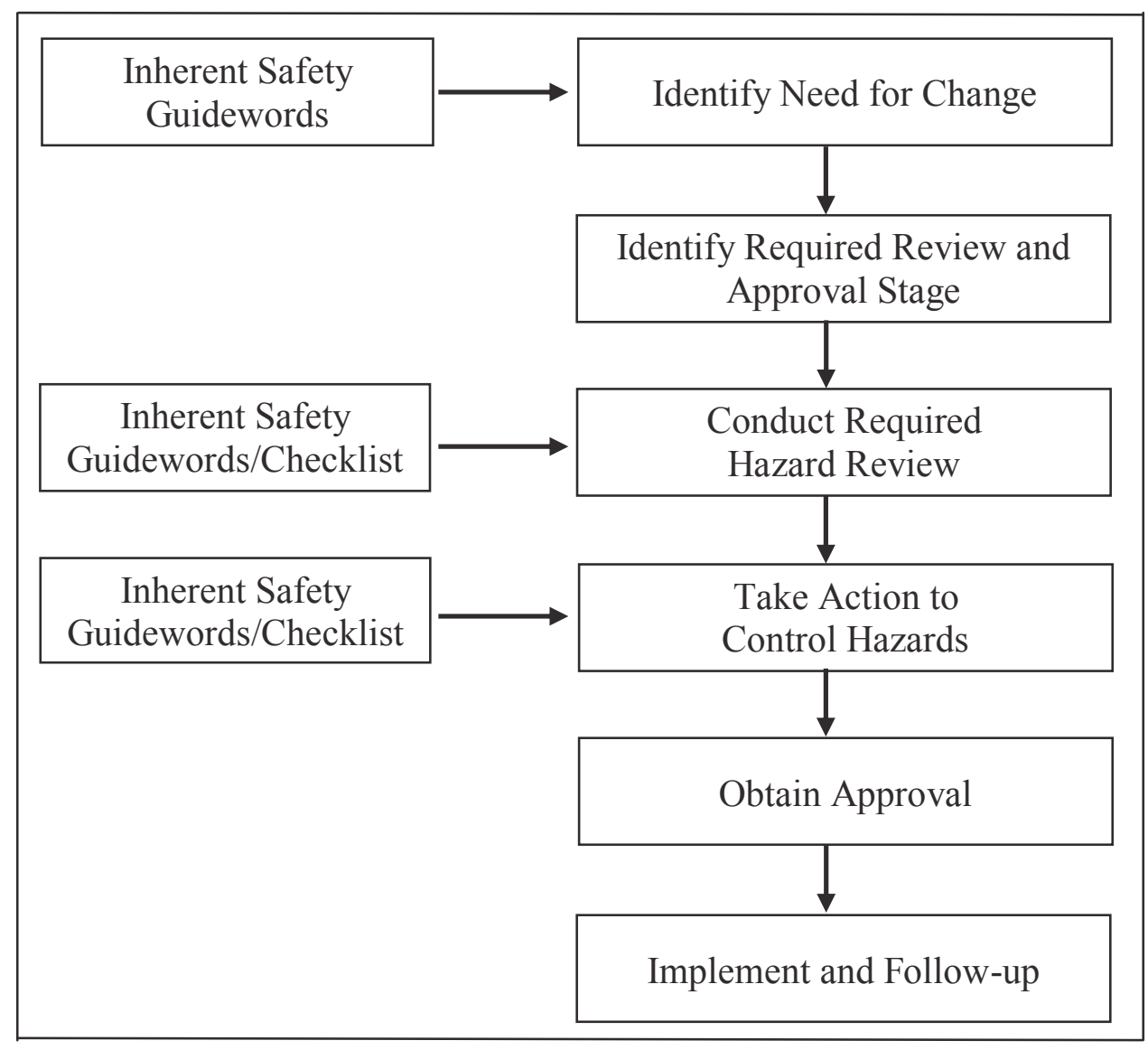

Figure 3.4 An inherent safety-based management of change protocol (Amyotte et al., 2007). 


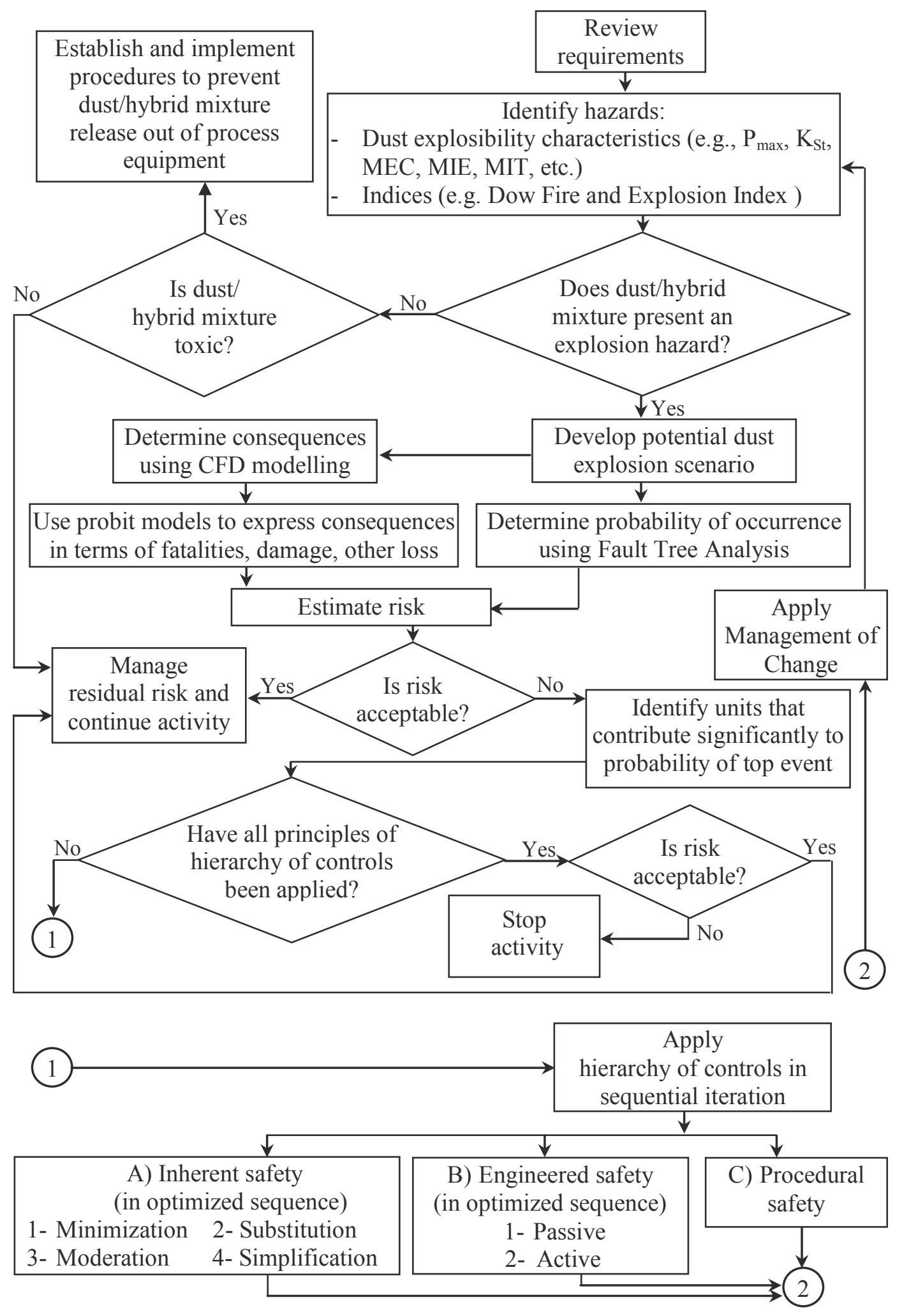

Figure 3.5 Flowchart for implementation of conceptual risk management framework for dust and hybrid mixture explosions. 


\section{CHAPTER 4 EXPERIMENTAL AND SIMULATION WORK}

\subsection{EXPERIMENTAL WORK}

This chapter presents a brief description of the experimental and simulation work performed in this research. A Siwek 20-L chamber was used to validate the DESC software and to prepare the DESC fuel files for the materials relevant to the case studies in Chapter 5. The overall aim of the experiments was to determine each material's explosion characteristics. Figure 4.1 describes, by means of a flow chart, the link used to validate DESC and then start simulations through the experimental work. The experimental data ( $\mathrm{P}_{\max }$ vs. dust concentration) is typically not sufficiently smooth to draw a curve that can extend through the entire data. Consequently, the data has to be smoothed in the DESC Excel spreadsheet. Once this step is done, the fuel file is produced and fed to the DESC software to run a new simulation on the 20-L geometry. If the result $\left(\mathrm{P}_{\max }\right)$ is almost the same as the experimental, continue run new other simulations on 1-

$\mathrm{m}^{3}$, and $400-\mathrm{m}^{3}$. If the result difference is more than $5 \%$, the Excel spreadsheet data has to be smoothed again (i.e., find another path for the curve to go through the experimental data), and continue until the desired results are obtained. The fuel file can then be fed to the case study geometry to start the aimed simulations.

\subsubsection{Apparatus}

The Siwek 20-L chamber is one of the most popular and important pieces of equipment used in dust explosion laboratories throughout the world to determine and evaluate dust explosibility and characteristics. Figure 4.2 illustrates the $20-\mathrm{L}$ chamber. The chamber is used for both dust and hybrid mixture testing. 


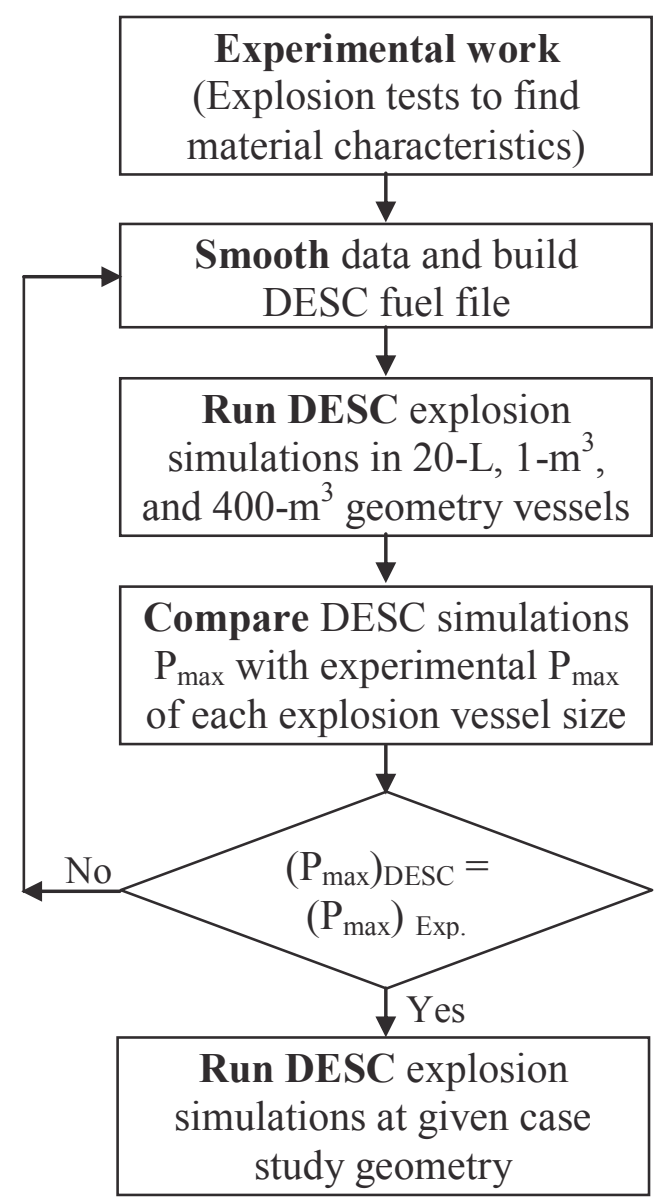

Figure 4.1 Experimental, validation, and simulation link

\subsubsection{Procedure}

The typical operating procedure was adhered to, as summarized below and described in detail by Kuhner, the equipment manufacture (Cesana \& Siwek, 1998). First, the compressed air amount entering the chamber was regulated to be released at $20 \mathrm{bar}(\mathrm{g})$. Then, in succession, a sample was weighed and placed into the dust container, the igniters were connected to the igniter leads, the chamber was closed, and the 20 -L vessel was evacuated until $0.4 \mathrm{bar}(\mathrm{g})$. The next step was inputting the testing parameter data (i.e., dust concentration $\left[\mathrm{g} / \mathrm{m}^{3}\right]$ and ignition energy [e.g., $\left.10 \mathrm{~kJ}\right]$ ) into the computer, after which the dust container was filled with weighed dust and compressed air until it reached 20 bar(g). Finally, the explosion button in the dust explosion program (KSEP) window was pressed to start the explosion process in the chamber. 


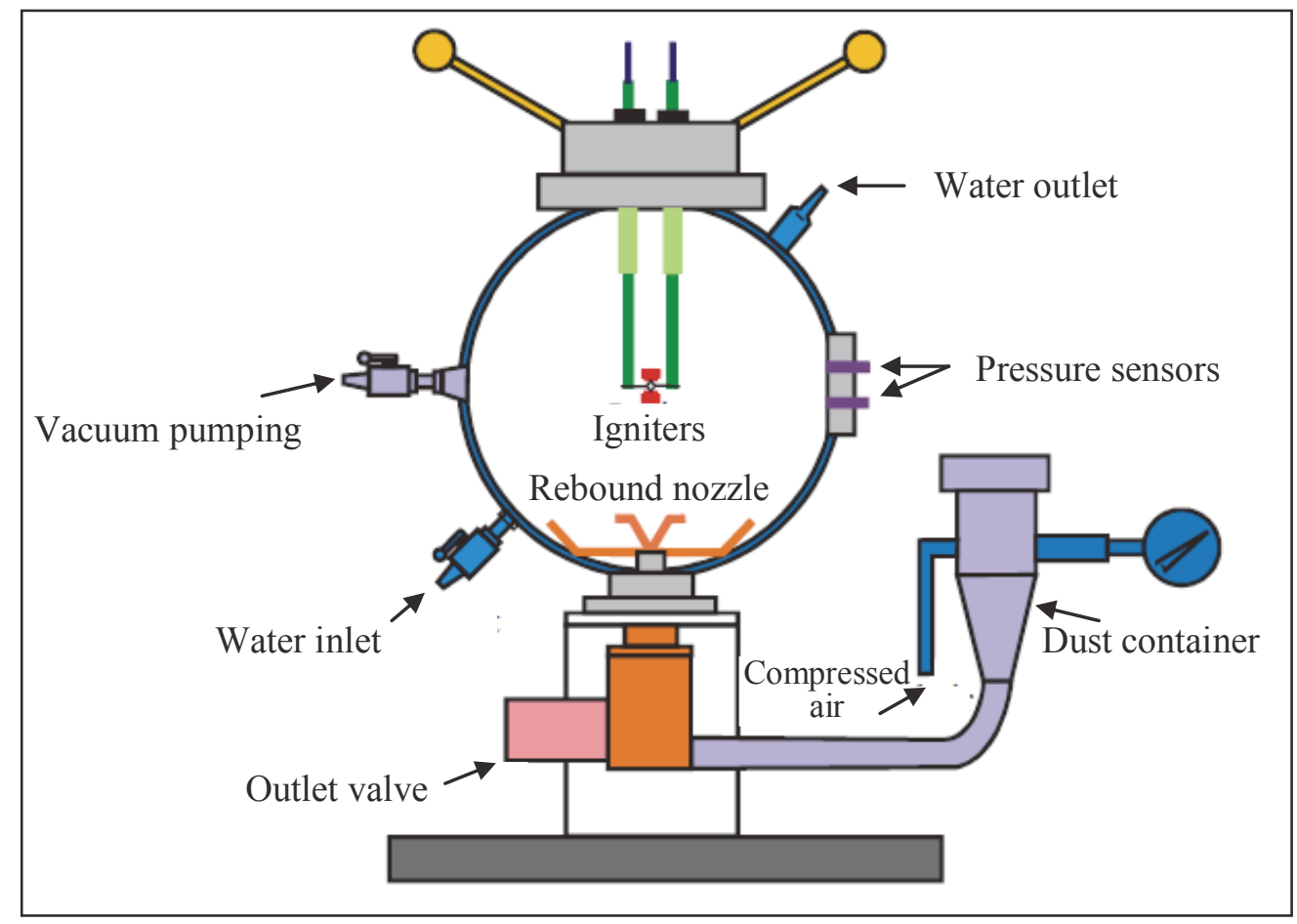

Figure 4.2 Schematic of Siwek 20-L sphere (Denkevits \& Dorofeev, 2004).

With the solenoid valve under the rebound nozzle open, the pressure difference between the two reservoirs carries the dust into the 20 -L chamber and disperses the dust/air mixture through the rebound nozzle. The computer fires the igniters after $60 \mathrm{~ms}$ of dust mixture dispersion. The pressure transducers send the explosion history to the KSEP program. For example, Figure 4.3 shows a typical pressure-time curve that was generated by the KSEP software. The figure indicates that the maximum pressure reached $\mathrm{P}_{\mathrm{m}}$ bar $(\mathrm{g})$ and the maximum rate of pressure rise $(\mathrm{dP} / \mathrm{dt})_{\mathrm{m}}(\mathrm{bar} / \mathrm{s})$ due to the given explosion test.

\subsubsection{Tested dust materials}

- Polyethylene dust

Tests involving polyethylene dust explosions have already been carried out by Abuswer et al. (2011). Their tests results are tabulated in Table 4.1, showing three different 


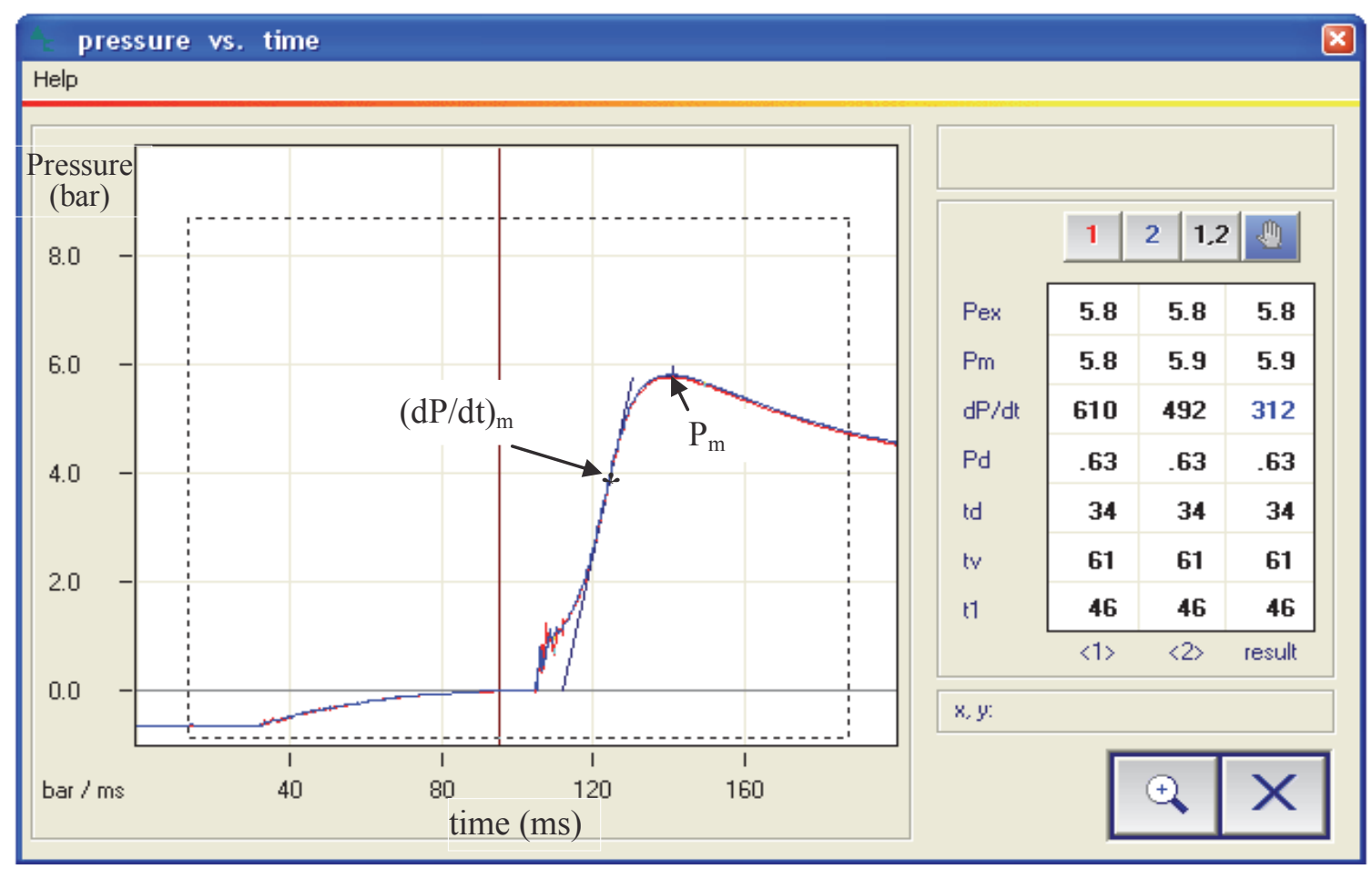

Figure 4.3 KSEP Pressure-Time curve during Polyethylene (- 200 mesh) dust explosion in 20-L chamber.

Table 4.1 20-L explosibility data for polyethylene/hybrid mixture samples (Abuswer et al., 2011).

\begin{tabular}{|c|c|c|c|c|c|c|}
\hline $\begin{array}{c}\text { Sample } \\
\text { No. }\end{array}$ & $\begin{array}{c}\text { Nominal } \\
\text { Mesh Size }\end{array}$ & $\begin{array}{l}\text { Volume Median } \\
\text { Diameter }[\mu \mathrm{m}]\end{array}$ & $\begin{array}{c}\text { Admixed } \\
\text { Hydrocarbon Gas }\end{array}$ & $\begin{array}{c}P_{\max } \\
{[\operatorname{bar}(g)]}\end{array}$ & $\begin{array}{c}\mathbf{K}_{\mathrm{St}} \\
{[\mathrm{bar} \cdot \mathbf{m} / \mathbf{s}]}\end{array}$ & Reference \\
\hline A & $\begin{array}{c}-200 \mathrm{mesh} \\
(<75 \mu \mathrm{m})\end{array}$ & 48 & N/A & 6.7 & 104 & $\begin{array}{l}\text { Amyotte et } \\
\text { al. (2009) }\end{array}$ \\
\hline B & $\begin{array}{l}-70 \text { mesh } \\
(<212 \mu \mathrm{m})\end{array}$ & 171 & N/A & 5.8 & 15 & $\begin{array}{l}\text { Amyotte et } \\
\text { al. (2008) }\end{array}$ \\
\hline $\mathrm{C}$ & $\begin{array}{c}-200 \text { mesh } \\
(<75 \mu \mathrm{m})\end{array}$ & 48 & $\begin{array}{l}1 \text { volume } \% \\
\text { hexane }\end{array}$ & 7.3 & 132 & $\begin{array}{l}\text { Amyotte et } \\
\text { al. (2009) }\end{array}$ \\
\hline
\end{tabular}

samples of polyethylene. The tests indicate particle size and flammable gas effects on the explosion. Tables F.1, F.2, and F.3 (Appendix F) show explosion characteristics data, for 
previous work done at the Dalhousie University dust explosion laboratory, of the samples $\mathrm{A}, \mathrm{B}$, and $\mathrm{C}$, respectively.

\section{- Sugar powder}

Following the 20-L test procedure outlined above, a sample of icing sugar and a sample of granulated sugar were tested. Tables 4.2 and 4.3 show the explosion characteristics data of icing sugar and granulated sugar, respectively; these are the typical data needed to build a fuel file in DESC for a given dust material. However, the $\mathrm{K}_{\mathrm{St}}$ data, listed in Tables 4.2 and 4.3, are not the actual $\mathrm{K}_{\mathrm{St}}$ for the materials; they are hypothetical values resulting from multiplying $(\mathrm{dP} / \mathrm{dt})_{\mathrm{m}}$ by the cubic root of the explosion chamber volume, and they are needed in the DESC fuel file calculations. The actual $\mathrm{K}_{\mathrm{St}}$ of any dust any material is calculated from Equation 1.1. The $\mathrm{K}_{\mathrm{St}}$ values indicate that the icing sugar (volume median diameter is $51 \mu \mathrm{m}$ ) is more hazardous than the granulated sugar. This shows the severity of consequences of the smaller particle size.

Table 4.2 20-L explosibility data for icing sugar powder.

\begin{tabular}{|c|c|c|c|c|}
\hline $\begin{array}{c}\text { Test } \\
\text { No. }\end{array}$ & $\begin{array}{c}\text { Concentration } \\
{\left[\mathbf{g} / \mathbf{m}^{\mathbf{3}}\right]}\end{array}$ & $\begin{array}{c}\mathbf{P}_{\mathbf{m}} \\
{[\mathbf{b a r}(\mathbf{g})]}\end{array}$ & $\begin{array}{c}(\mathbf{d P} / \mathbf{d t})_{\mathbf{m}} \\
{[\mathbf{b a r} / \mathbf{s}]}\end{array}$ & $\begin{array}{c}\mathbf{K}_{\mathbf{S t}} \\
{[\mathbf{b a r} \bullet \mathbf{m} / \mathbf{s}]}\end{array}$ \\
\hline 1 & 125 & 2.2 & 51 & 14 \\
\hline 2 & 250 & 4.3 & 71 & 19 \\
\hline 3 & 500 & 6.7 & 210 & 57 \\
\hline 4 & 750 & 7.2 & 344 & 93 \\
\hline 5 & 1000 & 7.0 & 305 & 83 \\
\hline 6 & 1250 & 6.6 & 237 & 64 \\
\hline 7 & 1500 & 6.1 & 166 & 45 \\
\hline
\end{tabular}


Table 4.3 20-L explosibility data for granulated sugar powder.

\begin{tabular}{|c|c|c|c|c|}
\hline $\begin{array}{c}\text { Test } \\
\text { No. }\end{array}$ & $\begin{array}{c}\text { Concentration } \\
{\left[\mathbf{g} / \mathbf{m}^{\mathbf{3}}\right]}\end{array}$ & $\begin{array}{c}\mathbf{P}_{\mathbf{m}} \\
{[\mathbf{b a r}(\mathbf{g})]}\end{array}$ & $\begin{array}{c}(\mathbf{d P} / \mathbf{d t})_{\mathbf{m}} \\
{[\mathbf{b a r} / \mathbf{s}]}\end{array}$ & $\begin{array}{c}\mathbf{K}_{\mathbf{S t}} \\
{[\mathbf{b a r} \cdot \mathbf{m} / \mathbf{s}]}\end{array}$ \\
\hline 1 & 125 & 1.7 & 22 & 6 \\
\hline 2 & 250 & 3.3 & 99 & 26 \\
\hline 3 & 500 & 6.3 & 178 & 48 \\
\hline 4 & 750 & 6.9 & 214 & 58 \\
\hline 5 & 1000 & 6.7 & 170 & 46 \\
\hline 6 & 1250 & 5.5 & 99 & 25 \\
\hline 7 & 1500 & 4.0 & 71 & 19 \\
\hline
\end{tabular}

\subsection{Dust Explosion Simulation Code (DESC)}

\subsubsection{Simulation preparation}

As DESC was used to estimate the consequences of the dust explosions of the given case studies, the primary step for the DESC simulation was preparing the fuel files. The files were produced by Excel spreadsheets (Figure 4.4) containing experimental data acquired in a 20-L Siwek chamber, along with other thermodynamic data (e.g., $\mathrm{K}_{\mathrm{St}}, \mathrm{P}_{\max }$, $[\mathrm{dP} / \mathrm{dt}]_{\max }$, particle density, particle size, and dust thermodynamic and physical properties) for each fuel material. All of this information was added to the working directory, to be read by the DESC simulation Run-Manager. Then, the explosion geometry in the DESC pre-processor CASD (Computer Aided Scenario Design) (Figure 4.5) was built for each case study and the required parameters, such as geometry monitor points, initial and boundary conditions, pressure relief panels, fuel information (name, composition and shape), and ignition source (position and strength in $\mathrm{kJ}$ ) were selected. Table 4.4 gives a general idea of the simulation input data. 


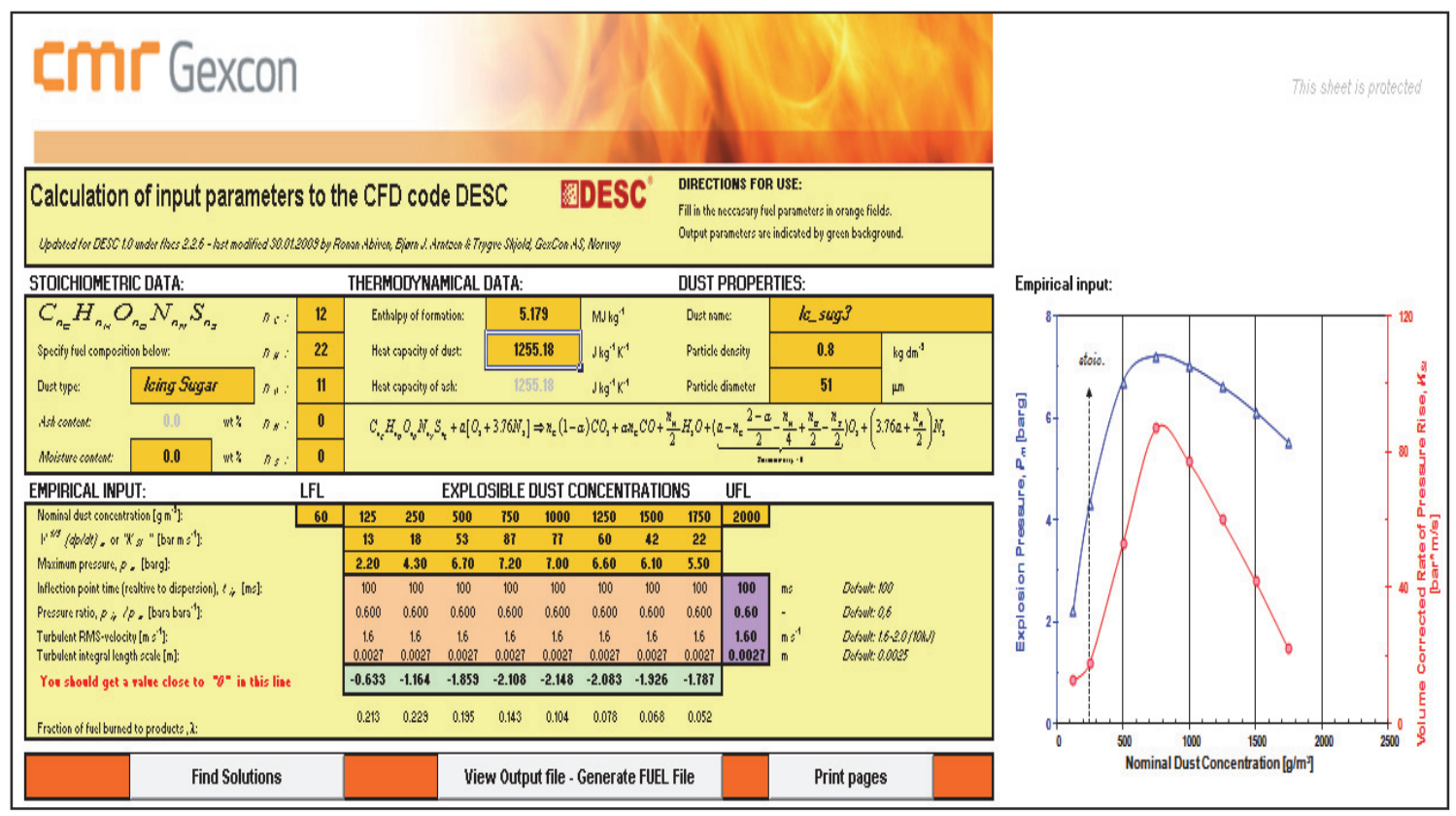

Figure 4.4 Part of a DESC Excel spreadsheet.

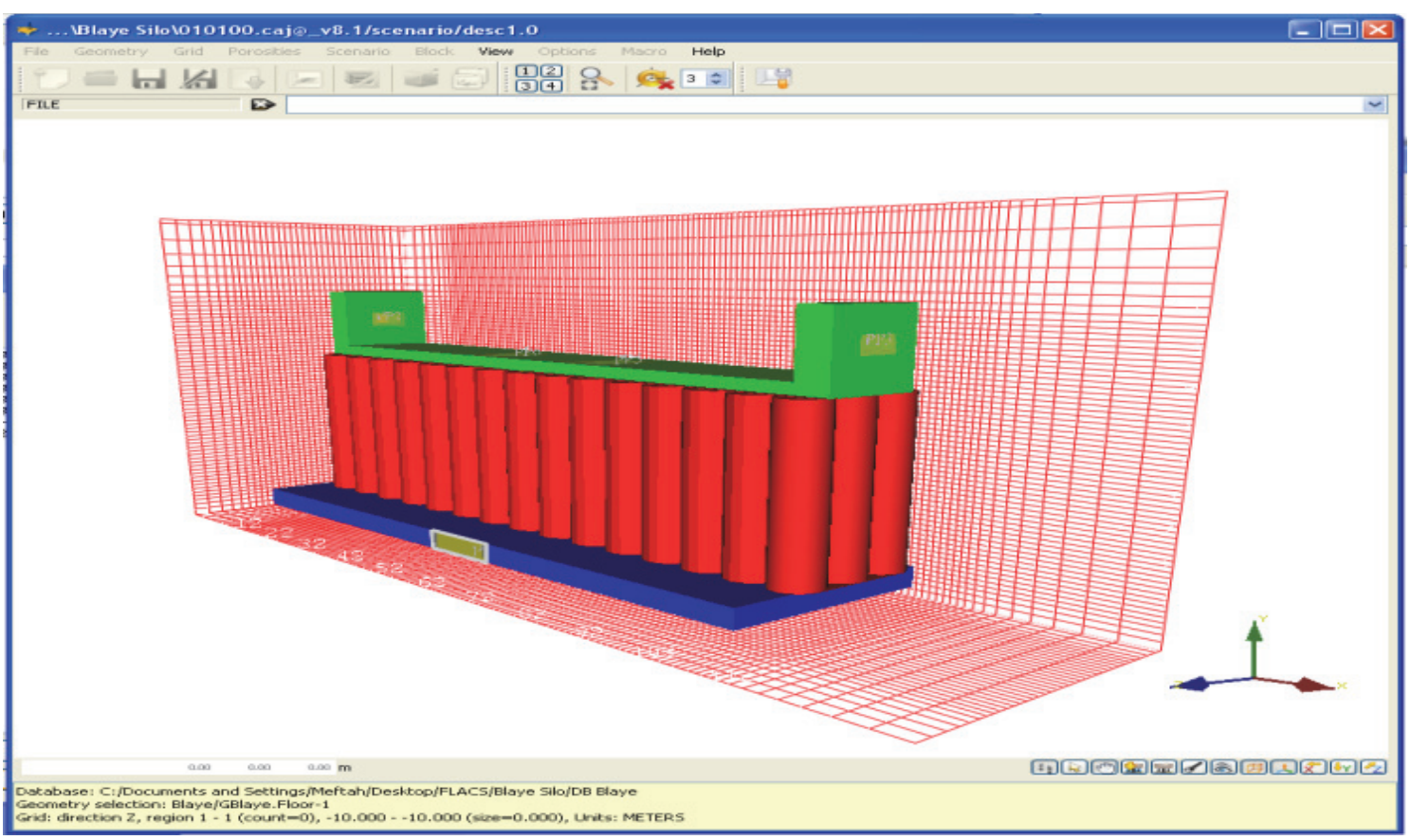

Figure 4.5 A silo geometry in CASD (Computer Aided Scenario Design) window. 
Table 4.4 DESC scenario input data for $400 \mathrm{~m}^{3}$ polyethylene silo geometry.

\begin{tabular}{|c|l|}
\hline No. & \multicolumn{1}{|c|}{ The scenario section } \\
\hline $\mathbf{1}$ & Simulation volume size $(\mathrm{x}, \mathrm{y}, \mathrm{z})=(30 \mathrm{~m}, 30 \mathrm{~m}, 34 \mathrm{~m})$ \\
\hline $\mathbf{2}$ & Grid cells $(\mathrm{x}, \mathrm{y}, \mathrm{z})=(25 \mathrm{~m}, 25 \mathrm{~m}, 75 \mathrm{~m})$ \\
\hline $\mathbf{3}$ & Fuel name is "MAIZE" \\
\hline 4 & Dust concentration $=500 \mathrm{~g} / \mathrm{m}^{3}$ \\
\hline $\mathbf{5}$ & Number of monitor points $=30$ \\
\hline $\mathbf{6}$ & Number of pressure panels $(\mathrm{PP})=6$ \\
\hline $\mathbf{7}$ & Ignition $=10 \mathrm{~kJ}$ \\
\hline
\end{tabular}

The simulations were run using the Run-Manager program (as seen in Figure 4.6), with each simulation process lasting from a few minutes to several hours, depending on geometries sizes. The DESC calculations and plotting curves were monitored while the programs were running. Simulations of the explosion temperatures, pressure and fuel consumption were developed and then displayed in 2-D and 3-D in the Flowvis program.

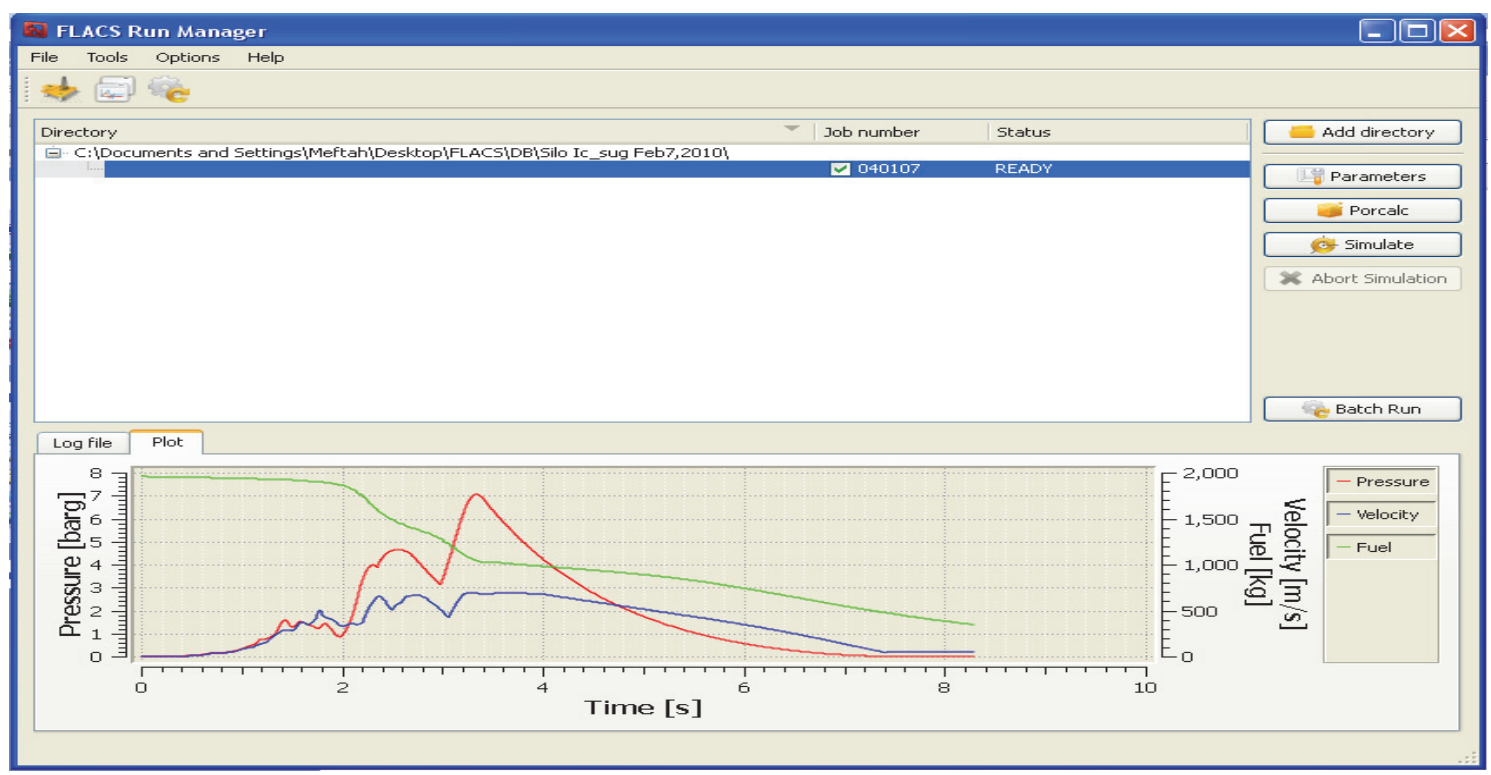

Figure 4.6 DESC run-manager window. 


\subsubsection{Validation and simulations}

Skjold (2007) discussed DESC validation work that was performed by GexCon. Such work was also performed by the Health and Safety Laboratory (HSL) in the UK, which involved a large-scale system of two interconnected vessels (Skjold, 2007).

DESC has been validated as the first step in the numerical research program on dust and hybrid mixture explosions. The maximum explosion pressures produced by DESC simulations in a 20-L chamber was compared with relevant experimental data for icing (powdered) sugar and granulated sugar, and 200-mesh polyethylene. The error percentages between experimental and predicted data for different materials were found to be less that 5\%, as shown in Table 4.5. Other DESC simulations were run for largerscale geometers of a $1-\mathrm{m}^{3}$ spherical vessel and a $400-\mathrm{m}^{3}$ cylindrical silo. The results showed the same maximum explosion pressure $\left(\mathrm{P}_{\max }\right)$ but different total explosion times $\left(t_{\text {exp }}\right)$ for each material, as can be seen in Table 4.6. The explosion period in larger vessels is of longer duration.

The next chapter shows, in detail, DESC simulations of case studies of the Imperial Sugar refinery explosion and the grain silo explosion in Blaye, as well as another hypothetical explosion in a $400-\mathrm{m}^{3}$ silo, to predict the consequences of polyethylene explosions

Table 4.5 The percent error of dust explosion $\mathrm{P}_{\max }$ between the experimental and DESC of different materials in 20-L chamber.

\begin{tabular}{|l|c|c|c|}
\hline \multirow{2}{*}{\begin{tabular}{c}
\multirow{2}{*}{$\begin{array}{c}\text { Dust } \\
\text { Material }\end{array}$} \\
\cline { 2 - 3 }
\end{tabular}} & \multicolumn{2}{|c|}{$\mathbf{P}_{\max }(\mathbf{b a r}(\mathbf{g}))$} & \multirow{2}{*}{$\begin{array}{c}\text { Percentage } \\
\text { Experimental }\end{array}$} \\
$\begin{array}{c}\text { DESC } \\
\text { Simulation }\end{array}$ & \\
\hline Icing Sugar & 7.2 & 7.4 & $2.7 \%$ \\
\hline $\begin{array}{l}\text { Granulated } \\
\text { Sugar }\end{array}$ & 6.9 & 7.0 & $1.4 \%$ \\
\hline Polyethylene & 6.7 & 6.5 & $3.0 \%$ \\
\hline
\end{tabular}


Table 4.6 Comparison between different materials at different explosion volumes in terms of DESC $P_{\max }$ and $t_{\max }$.

\begin{tabular}{|c|c|c|c|c|c|c|c|}
\hline \multicolumn{4}{|c|}{ 20-L Vessel } & \multicolumn{2}{|c|}{$1-m^{3}$ Vessel } & \multicolumn{2}{|c|}{$400-m^{3}$} \\
\hline \multicolumn{2}{|c|}{ Material } & $P_{\max }$ & $\mathbf{t}_{\text {exp }}$ & $\mathbf{P}_{\max }$ & $t_{\exp }$ & $\mathbf{P}_{\max }$ & $\mathbf{t}_{\text {exp }}$ \\
\hline \multirow{2}{*}{ Sugar } & Icing & 7.4 & 0.26 & 7.4 & 0.65 & 7.4 & 3.9 \\
\hline & Granulated & 7.0 & 0.28 & 7.0 & 0.69 & 7.0 & 4.2 \\
\hline \multicolumn{2}{|c|}{ Polyethylene } & 6.5 & 0.09 & 6.6 & 0.23 & 6.6 & 1.75 \\
\hline
\end{tabular}

Figures 4.7 and 4.8 show the DESC simulation results $\left(\mathrm{P}_{\max }\right.$ and $\left.\mathrm{t}_{\exp }\right)$ for icing sugar in $20-\mathrm{L}$ and $1-\mathrm{m}^{3}$ chambers. The highest explosion pressure attained in both simulations is 7.2 bar(g), which is within $3 \%$ of the experimental value. As shown in Figures 4.9 and 4.10, the peak overpressure for the granulated sugar in the $20-\mathrm{L}$ and $1-\mathrm{m}^{3}$ chambers was also the same: 6.9 bar(g). In each case (icing and granulated sugar), the explosions in the different-sized chambers have similar maximum explosion pressures but require more time to attain the peak overpressure in the larger $1-\mathrm{m}^{3}$ chamber (all with central ignition and a dust concentration of $500 \mathrm{~g} / \mathrm{m}^{3}$ ).

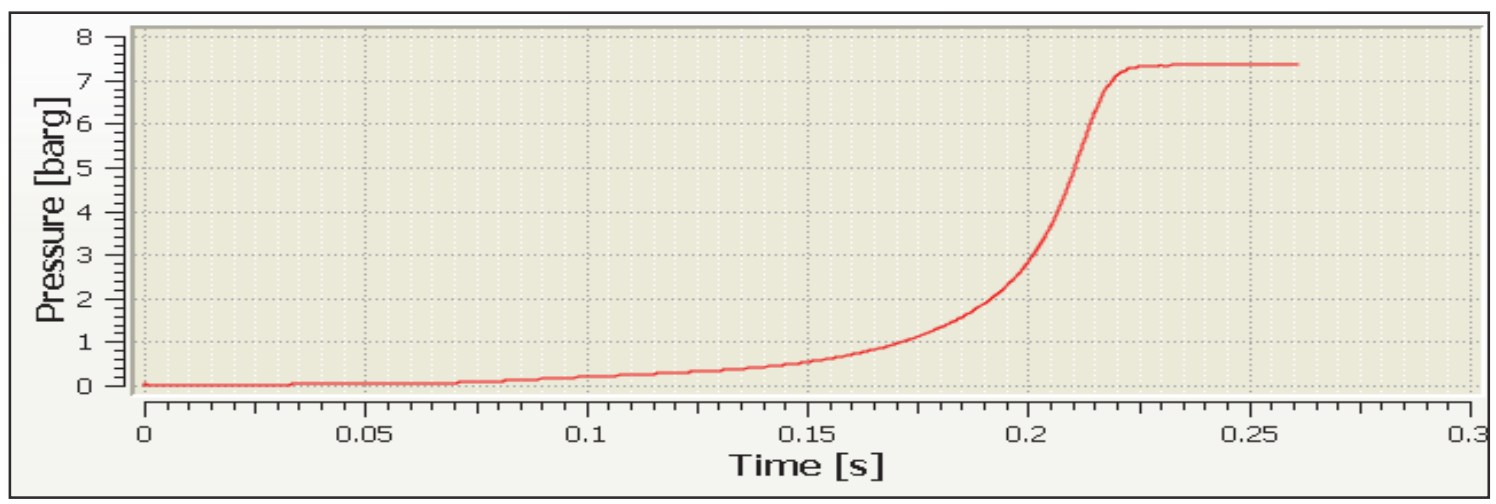

Figure 4.7 DESC simulation of icing sugar explosion in a 20-L spherical chamber 


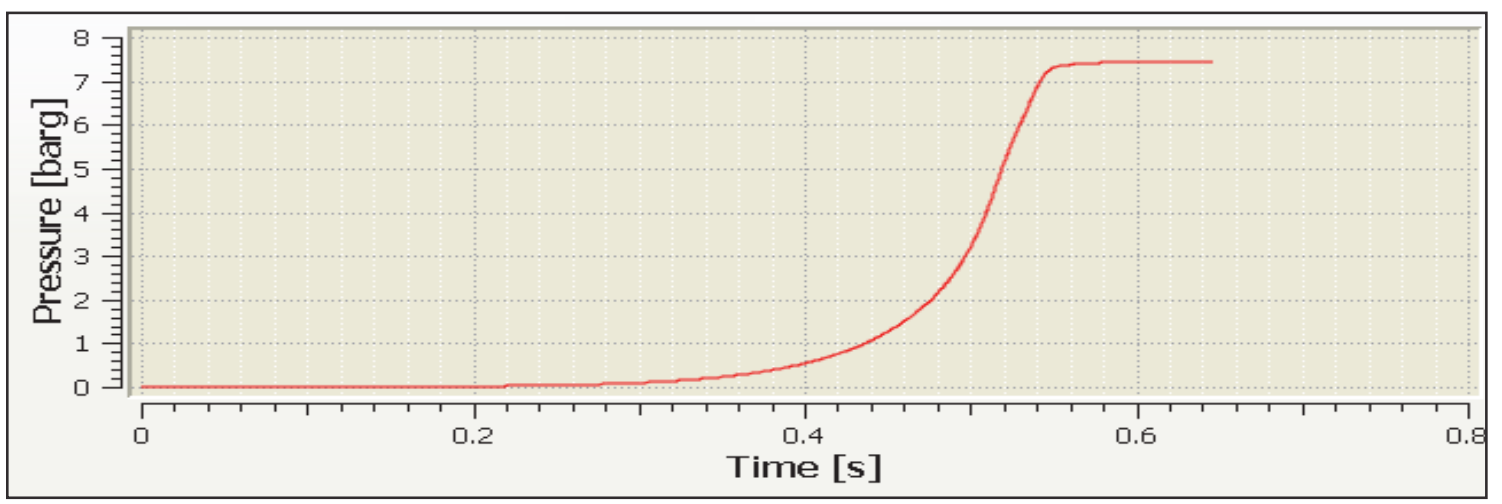

Figure 4.8 DESC simulation of icing sugar explosion in a $1-\mathrm{m}^{3}$ spherical chamber.

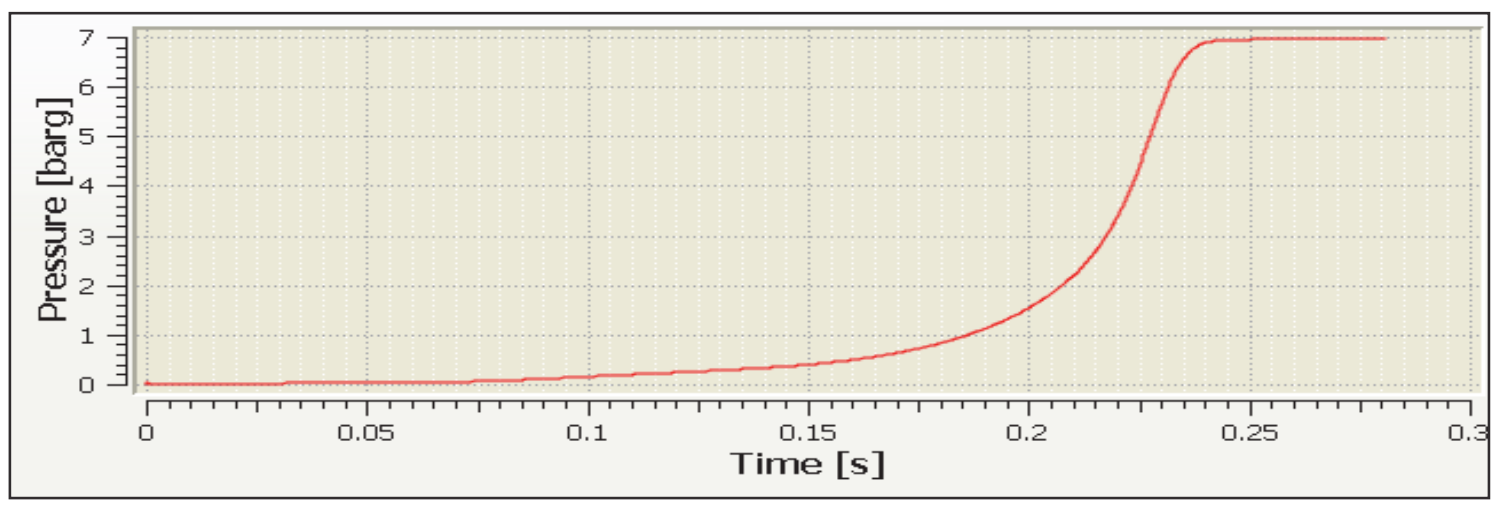

Figure 4.9 DESC simulation of granulated sugar explosion in a 20-L spherical chamber.

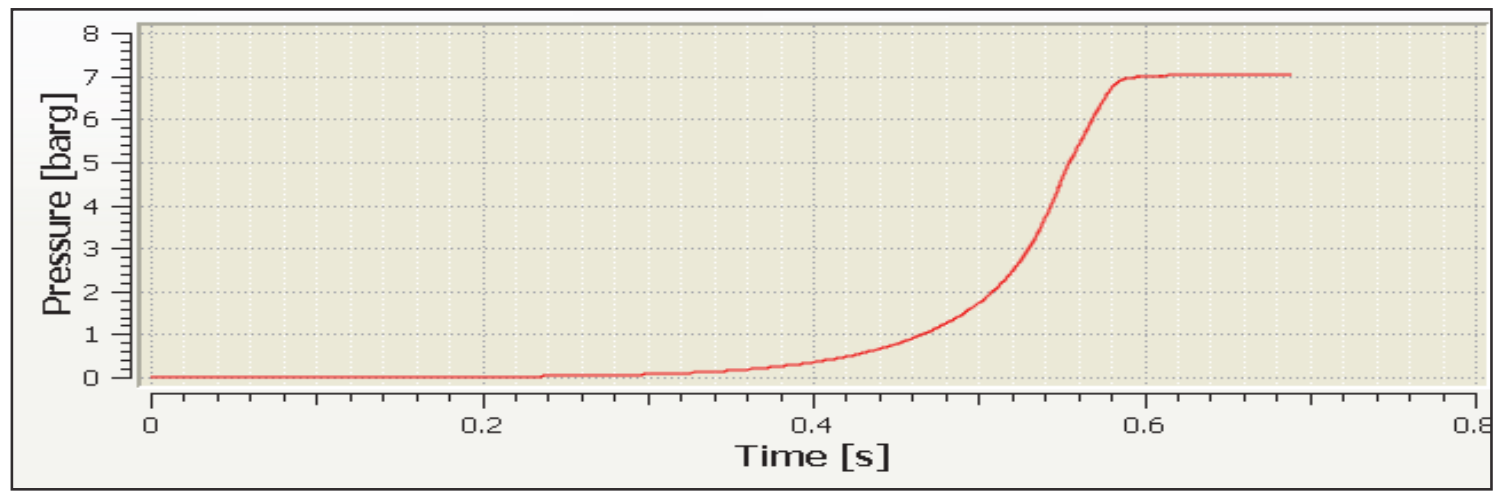

Figure 4.10 DESC simulation of granulated sugar explosion in a $1-\mathrm{m}^{3}$ spherical chamber. 
Similarly, more time is needed to reach the peak overpressure in an even larger volume, as shown in Figures 4.11 and 4.12 for a $400-\mathrm{m}^{3}$ storage silo.

Figure 4.13 shows simulation results obtained for explosions of a $48-\mu \mathrm{m}$ polyethylene sample in 20-L chambers (with central ignition and a dust concentration of $500 \mathrm{~g} / \mathrm{m}^{3}$ ).

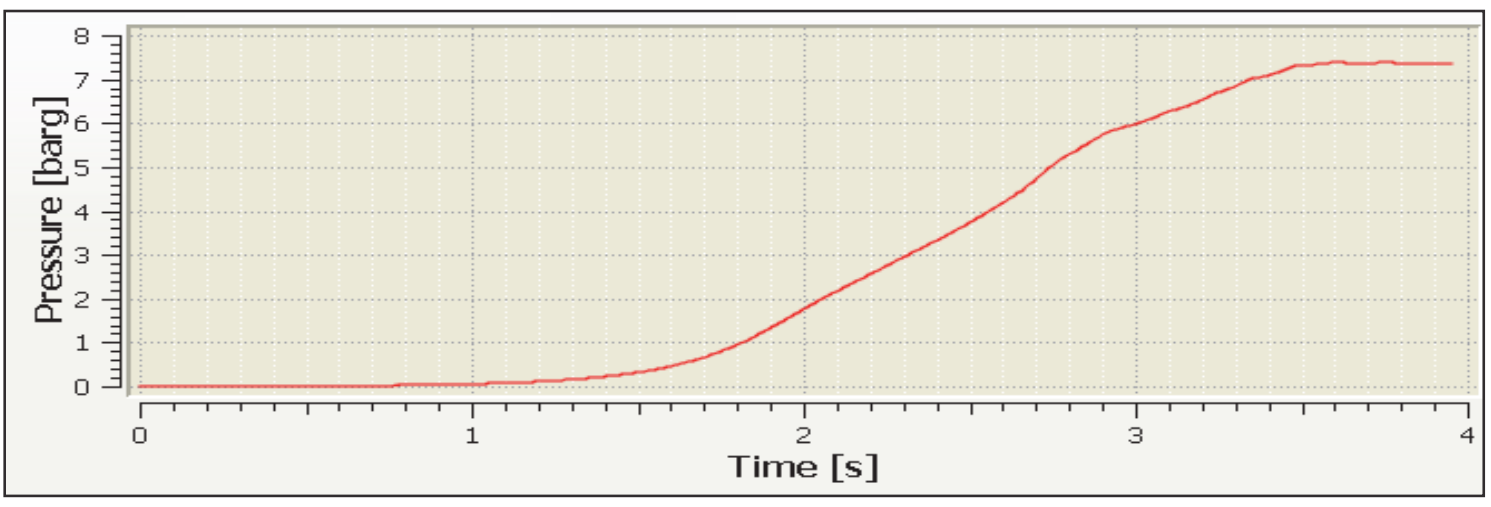

Figure 4.11 DESC simulation of icing sugar explosion in a $400-\mathrm{m}^{3}$ cylindrical silo without explosion vents.

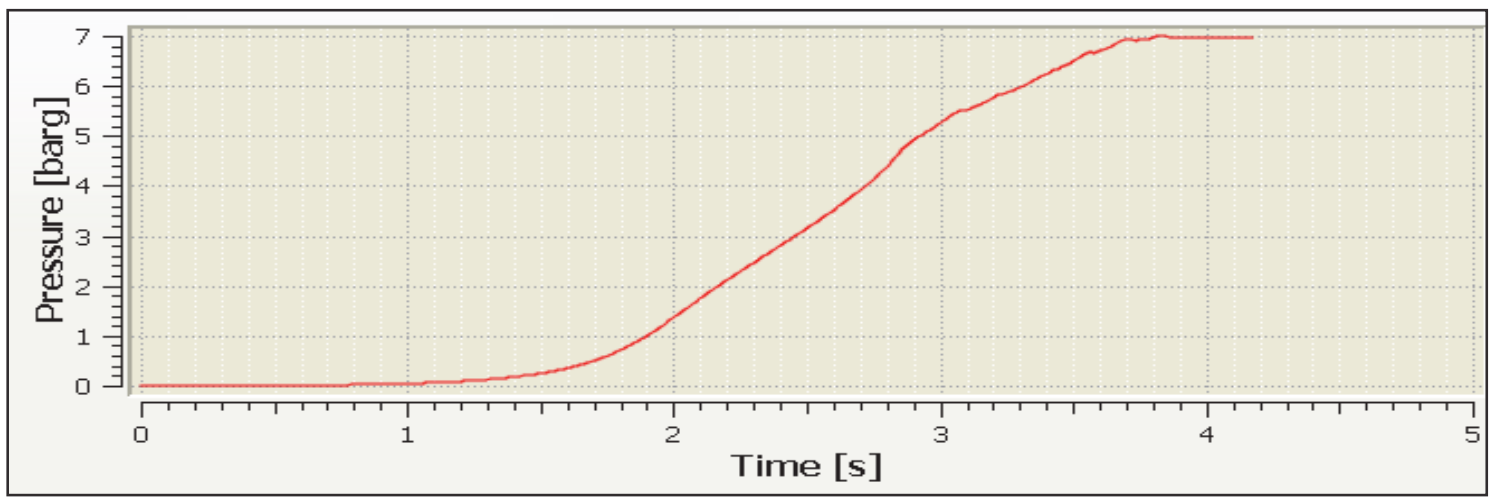

Figure 4.12 DESC simulation of a granulated sugar explosion in a $400-\mathrm{m}^{3}$ cylindrical silo without explosion vents. 


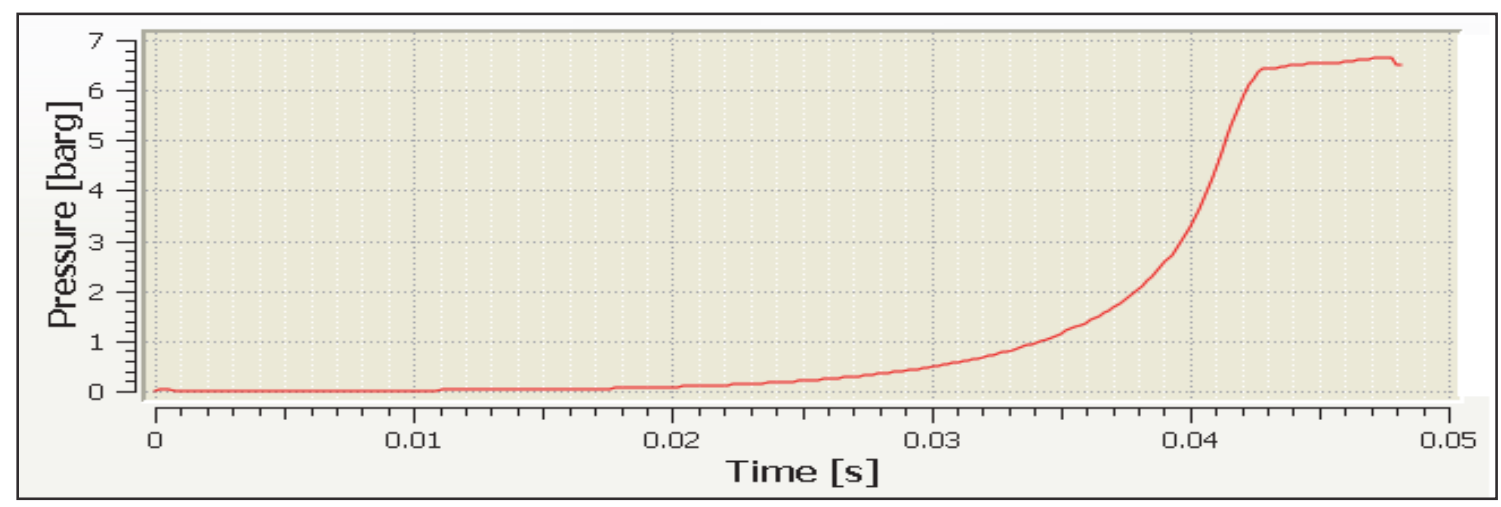

Figure 4.13 DESC simulation of 48- $\mu$ m polyethylene explosion in a 20-L spherical chamber (Amyotte et al., 2010). 


\section{CHAPTER 5 CASE STUDIES}

This chapter demonstrates the application of the framework to three case studies. Two of them occurred in the past: the dust explosion at the Port Wentworth Imperial Sugar refinery in Georgia, US, in 2008, and the hybrid mixture explosion at the grain silo at the Semabla company in Blaye, France, in 1997. However, the third case study was applied to a hypothetical dust explosion in a polyethylene $400-\mathrm{m}^{3}$ cylindrical silo. Each case study's geometry has, in the DESC pre-processor CASD, been built similar to its relevant real dimensions, and possible scenarios have then been simulated by DESC. Risk estimations (risk indices (ROD, FAR, ESC), individual risk, and societal risk) have been determined for each case study, before and after the framework was applied. Probit equations were used to estimate the severity of consequences, and Fault Tree Analysis was used to calculate the probabilities of the explosions.

In this research, the main changes in the case studies when applying the QRMF were in basic events in the Fault Tree Analysis, which consequently affected the risk estimation calculations. These case studies clearly show the framework's benefits in reducing the risks to acceptable or tolerable zones.

\subsection{The Imperial Sugar Refinery Dust EXPlOSION}

\subsubsection{Refinery description}

The Imperial Sugar refinery in Port Wentworth, Georgia, US is one of the largest sugar refineries and packaging complexes in the United States. It consists of three granulated sugar storage silos (32 $\mathrm{m}$ tall and $12.2 \mathrm{~m}$ in diameter) as shown in Figure 5.1 and Figure 5.2, a Bosch packing building (for granulated sugar, packaging machines, and packaging supplies), a south packing building (housing different kinds of manufactured sugar), and other facilities. The buildings are connected to each other by a complex transportation 


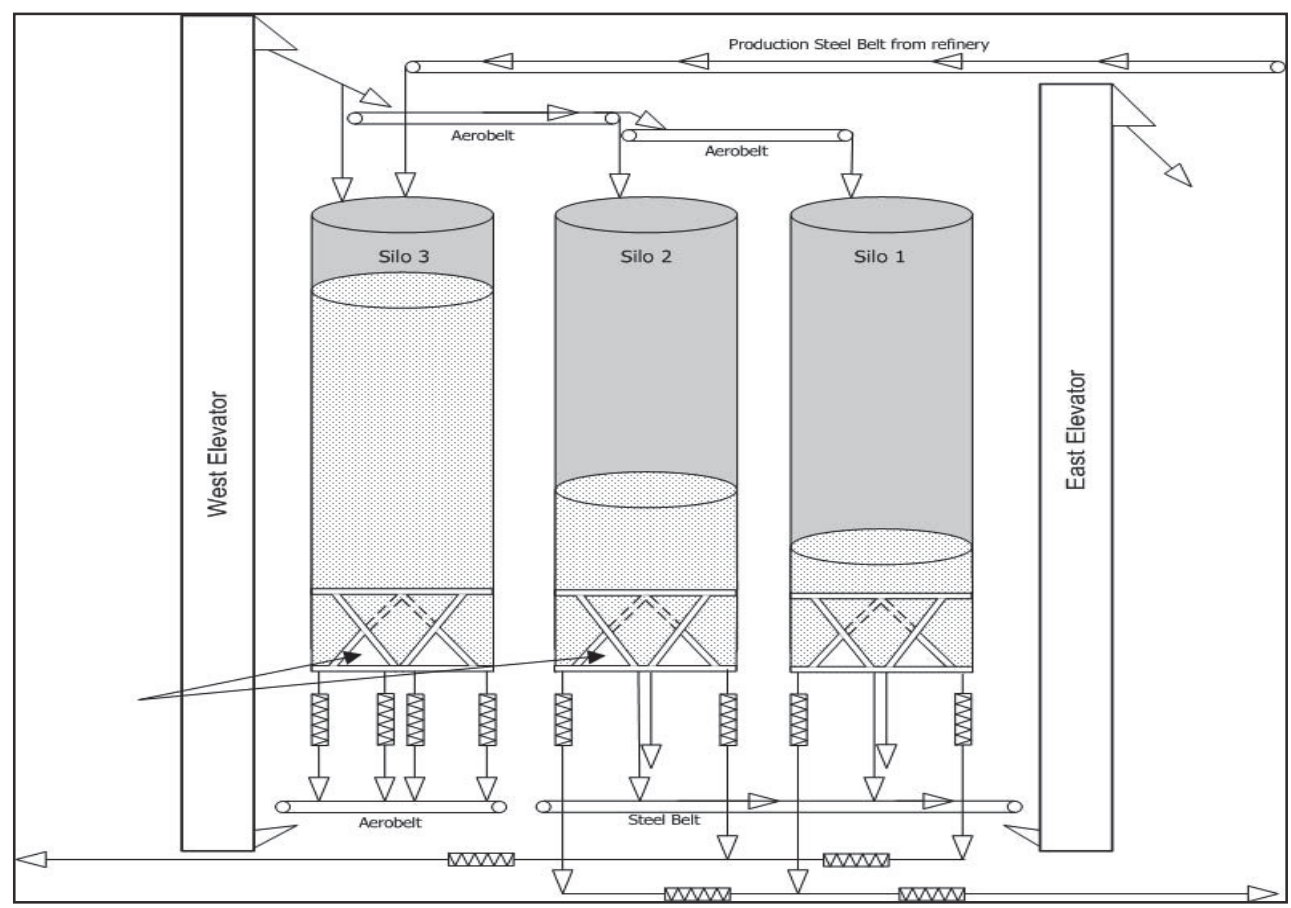

Figure 5.1 Granulated sugar supply and discharge through the silos (CSB, 2009).

system that consists of aero belts, packed elevators, screw conveyors, and conveyor belts. Granulated sugar from the refinery enters Silo no. 3 and is then transported to Silos no. 1 and 2 to start special processes (e.g., converting sugar to powdered sugar) and packaging procedures (CSB, 2009).

\subsubsection{Explosion causes}

Prior to the explosion at the Imperial Sugar refinery, the transportation system and hammer mills produced airborne sugar in the work areas, and the undersized dust collection system failed to decrease the concentration levels of the dust clouds. Furthermore, workers had used compressed air to clean the packaging machines. Over time, thick layers of sugar dust accumulated on elevated surfaces and in narrow places, in addition to the spilled sugar that built up, unnoticed, in crevices around the machines (CSB, 2009). In 2007, the company covered the conveyor belts with stainless steel panels to protect the sugar from contamination during the manufacturing process. However, with 


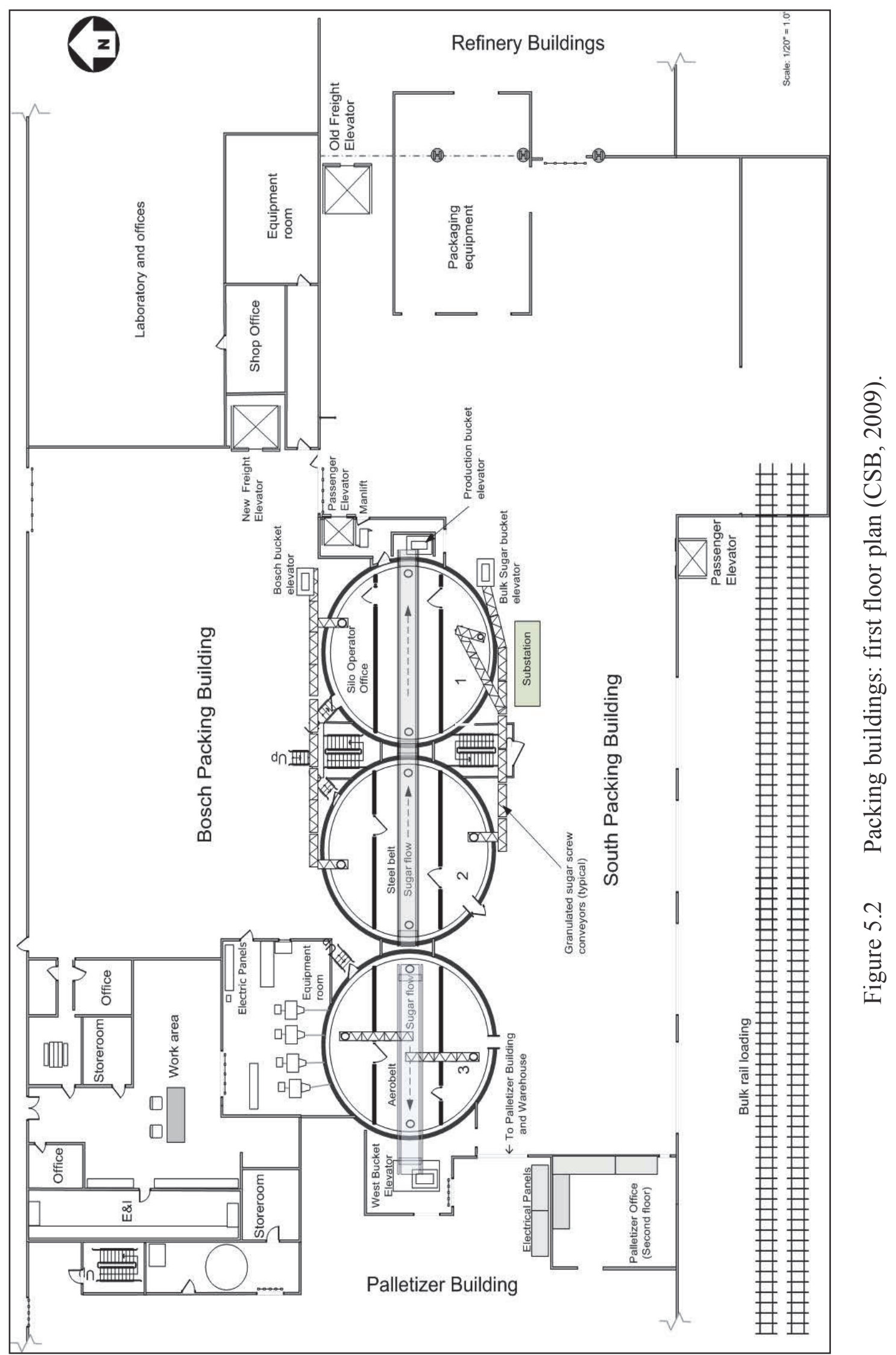


the movement of the belts and the absence of any kind of ventilation system inside the enclosure, the sugar dust concentration increased until it surpassed the MEC (CSB, 2009).

\subsubsection{Explosion event}

On February 7, 2008, an unknown ignition source inside the enclosed conveyor belts contacted the airborne dust, which was within the explosible concentration range, and a dust explosion took place in the packing building under the silos. The explosion's shock waves sent settled dust throughout the refinery into the air, and resulted in a secondary dust explosion, which caused a fire and the complete destruction of the refinery. The explosion killed 14 workers and injured 36 (CSB, 2009). Table 5.1 summarizes the fatalities, injuries, and number of workers on each floor of the refinery. The total number of workers at the refinery on the night of the accident was 135. All of the deceased were killed from injuries sustained from the structural damage or from severe burns.

Table 5.1 The number of injured, deceased, and uninjured workers at the Imperial Sugar refinery explosion.

\begin{tabular}{|c|c|c|c|c|c|c|c|}
\hline \multirow{2}{*}{$\begin{array}{c}\text { Floor } \\
\text { No. }\end{array}$} & \multirow{2}{*}{$\begin{array}{c}\text { Injured } \\
\text { No. }\end{array}$} & \multicolumn{3}{|c|}{ Deceased } & \multirow{2}{*}{$\begin{array}{c}\text { Uninjured } \\
\text { No. }\end{array}$} & \multirow{2}{*}{$\begin{array}{c}\text { Total } \\
\text { affected } \\
(\%)\end{array}$} & \multirow{2}{*}{$\begin{array}{c}\text { Total } \\
\text { No. of } \\
\text { workers }\end{array}$} \\
\hline & & in hospital & on site & $\%$ & & & \\
\hline $1^{\text {st }}$ & 8 & 2 & - & 6.5 & 21 & 32 & 31 \\
\hline $2^{\text {nd }}$ & 0 & 1 & 2 & 17 & 15 & 17 & 18 \\
\hline $3^{\mathrm{rd}}$ & 15 & 1 & 1 & 5 & 22 & 44 & 39 \\
\hline $4^{\text {th }}$ & 13 & 2 & 5 & 15 & 27 & 43 & 47 \\
\hline Total & 36 & 6 & 8 & 10 & 85 & 37 & 135 \\
\hline
\end{tabular}




\subsubsection{Applying the QRMF to the Imperial Sugar refinery}

The brief descriptions above clearly show that the Imperial Sugar refinery lacked effective risk management and the knowledge of how to deal with dust hazards. Use of this case study shows the effectiveness of the QRMF in reducing the hazard of explosion. The following sections describe the framework steps as applied to the Imperial sugar refinery.

\section{Identify hazard}

The CSB (2009) report identified the hazardous material as icing and granulated sugar dust. Two bags of regular icing and granulated sugar were considered as samples to be tested. The sugar characteristics have been defined experimentally, as described in Chapter 4.

\section{Understand hazard}

The CSB investigators' scenario was simulated by DESC to find the explosion pressure (severity of consequences) inside the refinery's work areas. The probability of occurrence was determined by the FTA technique and by using Relex software. The risk calculations and risk evaluation are explained in detail in the following sub-sections.

\section{i) Consequence analysis}

\section{- DESC simulation}

As some details, such as the exact locations of the workers, machines, and various structures at the moment of the explosion, are not available, they are simulated on a 'best estimate' basis. Likewise, as the destructive static pressure values of the building walls and windows are also not available, a fixed value is given for each item. In the built geometry of DESC, the wall destruction has been simulated as gates (openings) in the walls. Figure 5.3 and Figure 5.4 show these gates as groups (i.e., groups 1 to 7). Additionally, there are single gates that have been covered by pressure relief panels (PP), which open at a certain pressure. They are distributed on the bottom tunnel (PP1 - PP4, 


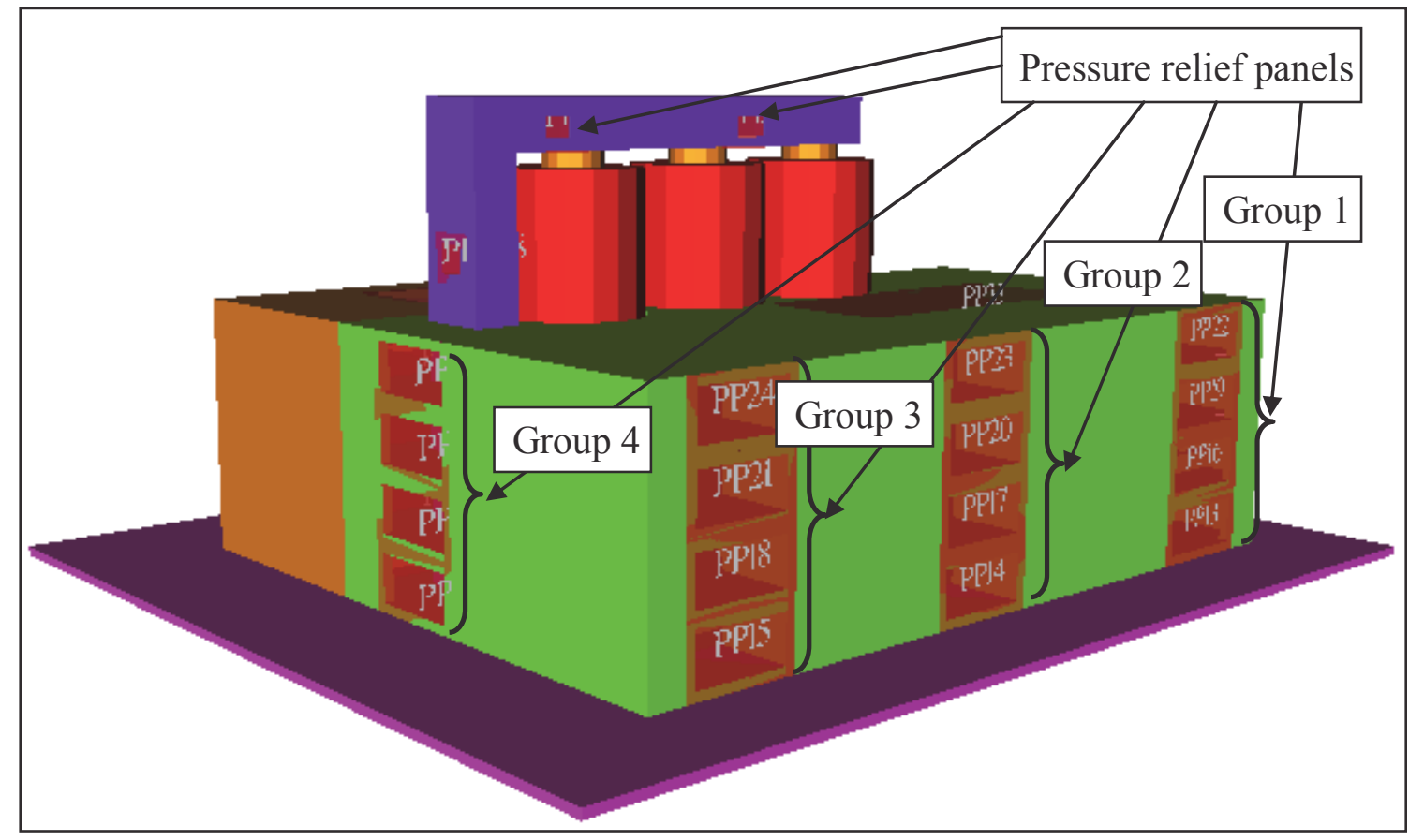

Figure 5.3 CASD image (3D front view) of the Imperial Sugar refinery with the pressure relief panels (PPs).

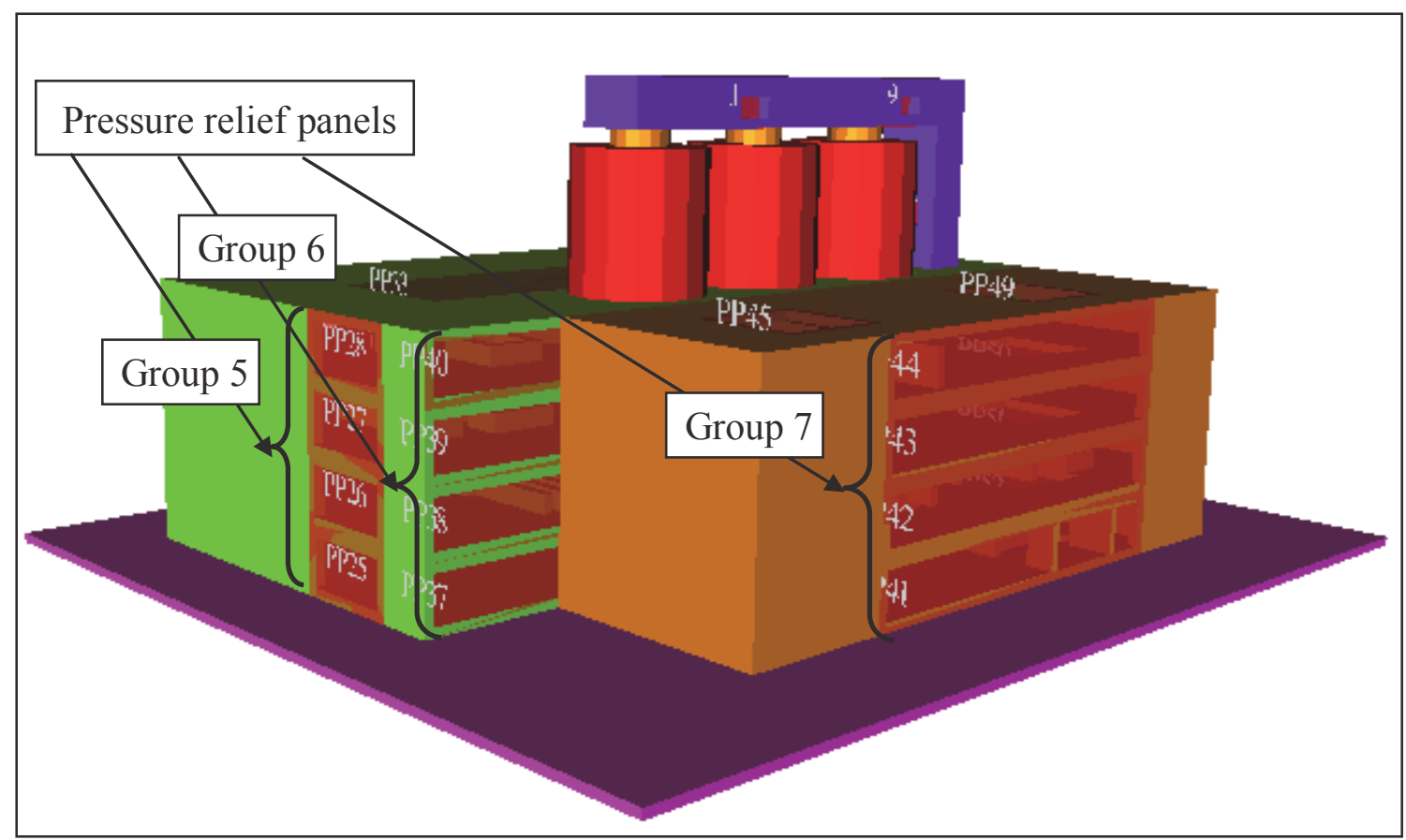

Figure 5.4 CASD image (3D back view) of the Imperial Sugar refinery with the pressure relief panels (PPs). 
PP58, and PP57), on each side of the vertical riser tunnel (PP5 - PP8 \& PP53 - PP56), and on the upper tunnel (PP9 - PP12). These gates and groups were used as safety pressure panels and have been distributed to release any explosion pressure efficiently.

Figure 5.5 shows a side view of the working floors as well as module distribution in the Imperial Sugar refinery geometery.

Research shows that a static overpressure value ranging from 7 to $70 \mathrm{kPa}$ can cause complete unit destruction (Cozzani \& Salzano, 2004). Therefore, the pressure panels were adjusted to be within the destructive overpressure at 10,20, and $30 \mathrm{kPa}$ to represent different strengths of the wall components, as represented in Table 5.2.

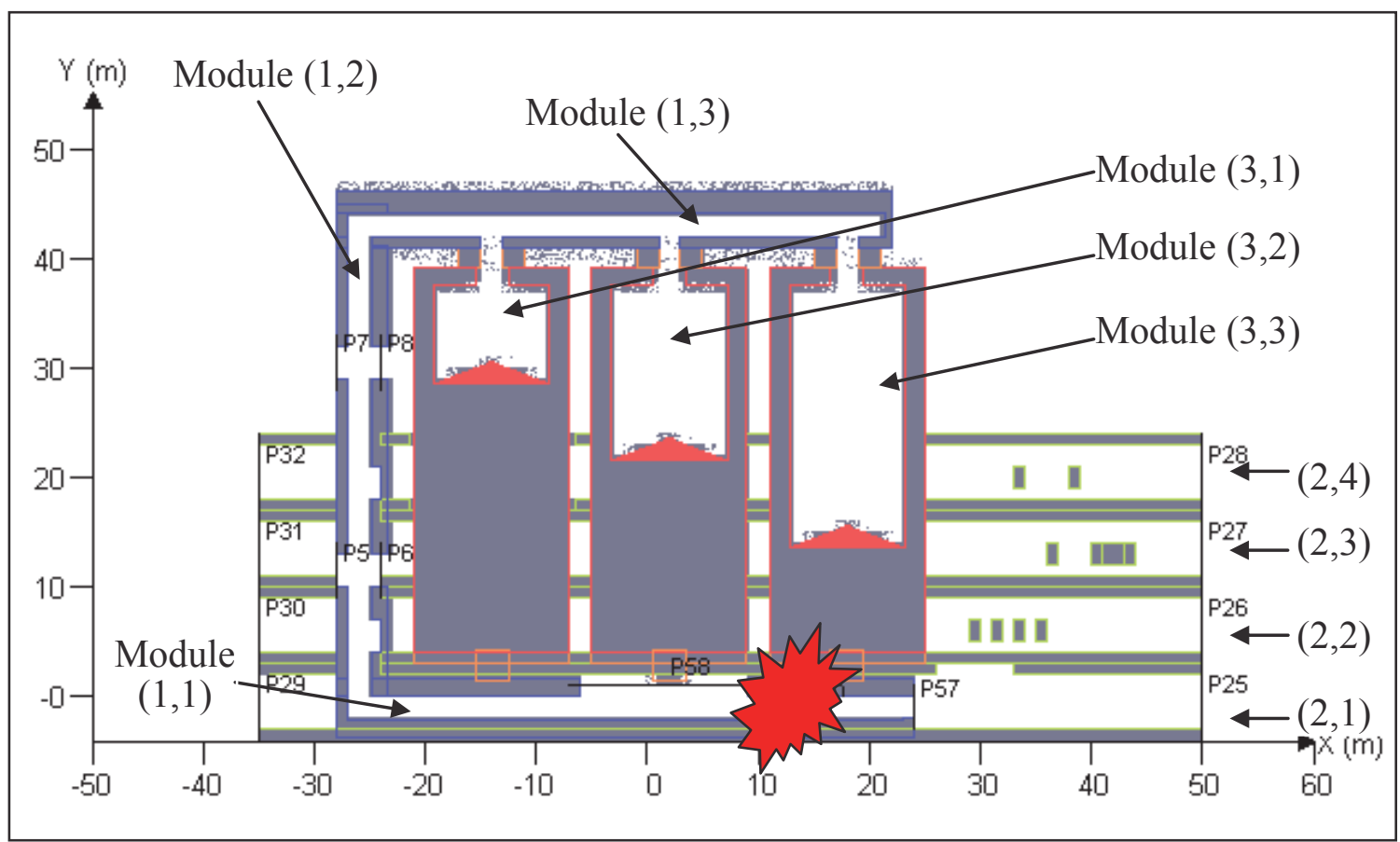

Figure 5.5 Side view of the module distributions of the Imperial Sugar refinery geometry. 
Table 5.2 Opening pressure values of pressure panels and their sizes in the Imperial Sugar refinery.

\begin{tabular}{|l|c|c|}
\hline $\begin{array}{c}\text { Pressure Panel } \\
\text { No. }\end{array}$ & $\begin{array}{c}\text { Opening Pressure } \\
(\mathbf{~ k P a ~})\end{array}$ & $\begin{array}{c}\text { Size } \\
\left(\mathbf{~ m}^{\mathbf{2}}\right)\end{array}$ \\
\hline PP1 - PP4 & 30 & 68 \\
P58 & 30 & 85 \\
P57 & 30 & 20 \\
\hline PP5 - PP8 & 30 & 25 \\
PP53 - PP56 & 30 & 20 \\
\hline PP9 - PP12 & 30 & 40 \\
\hline Group 1 & 20 & 84 \\
\hline Group 2 & 30 & 84 \\
\hline Group 3 & 20 & 84 \\
\hline Group 4 & 20 & 84 \\
\hline Group 5 & 10 & 84 \\
\hline Group 6 & 20 & 112 \\
\hline Group 7 & 30 & 294 \\
\hline
\end{tabular}

In Figure 5.6, M1 to M80 represent DESC pressure monitoring points. Also, simulation volume size, dust concentration, pressure relief panels, fuel properties, and ignition energy have been defined and adjusted according to the available data. Table 5.3 presents some important required data for the simulation.

\section{- $\quad$ Structure damage:}

No one was killed in the refinery from the explosion impact or explosion shock waves. However, four workers were fatally burned when trapped under the falling floor, four workers died at the scene when surrounded by fire and unable to escape, six workers died at the hospital due to serious burns, and 36 workers had various kinds of injuries (13 were severely injured and 23 had minor injuries); 85 workers remained uninjured during the incident (CSB, 2009). Nevertheless, the spectacular explosions, numerous fatalities, and extensive damage prompted widespread reports of the accident. 


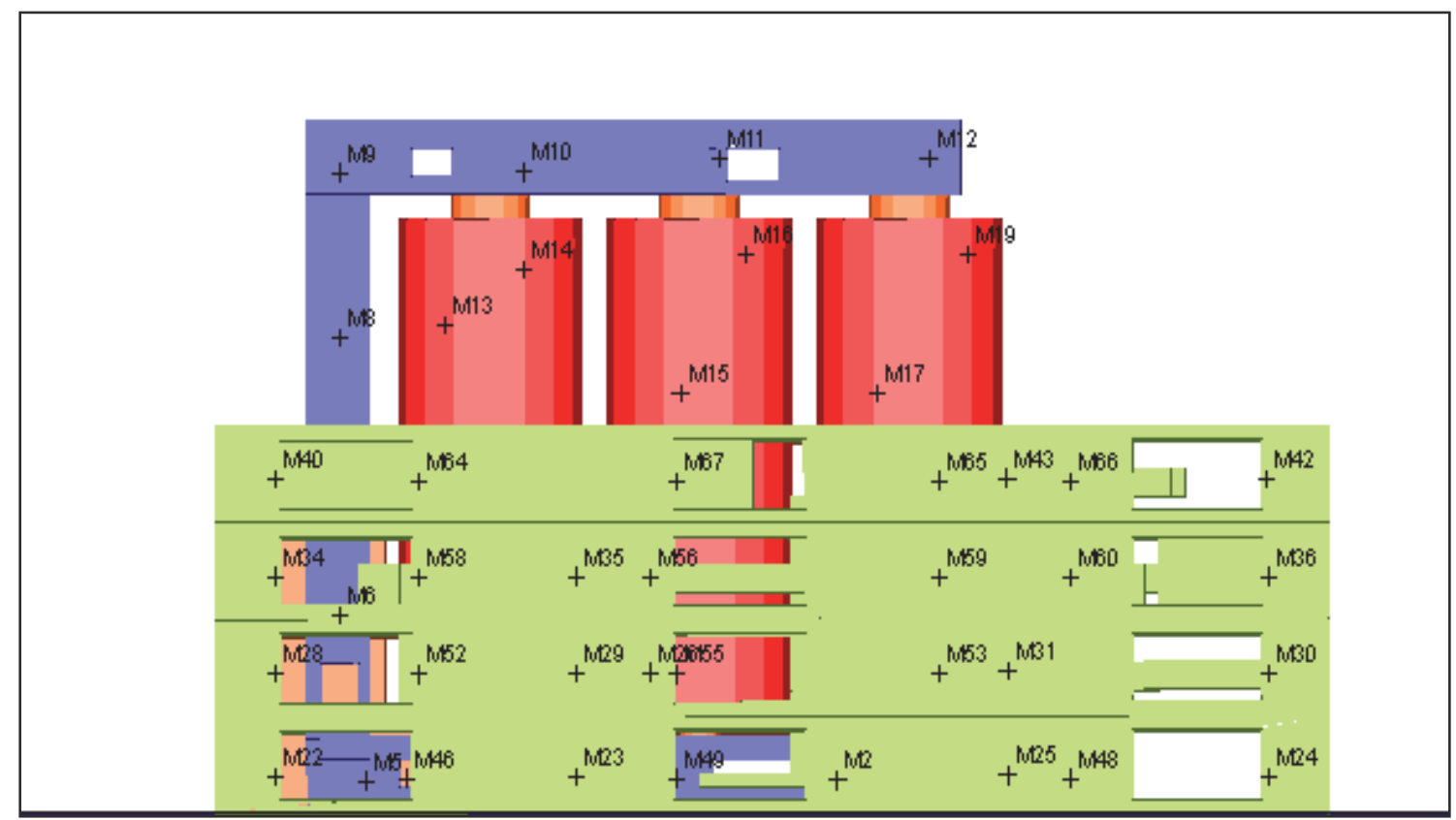

Figure 5.6 DESC representation of interconnected $3700-\mathrm{m}^{3}$ silos and the monitoring points (M1 - M80) at the Imperial Sugar refinery.

Table 5.3 DESC scenario input data for Imperial Sugar refinery geometry.

\begin{tabular}{|c|l|}
\hline No. & \multicolumn{1}{|c|}{ DESC scenario input data } \\
\hline 1 & Simulation volume size $(\mathrm{x}, \mathrm{y}, \mathrm{z})=(110 \mathrm{~m}, 70 \mathrm{~m}, 95 \mathrm{~m})$ \\
\hline 2 & Geometry size $(\mathrm{x}, \mathrm{y}, \mathrm{z})=(85 \mathrm{~m}, 50 \mathrm{~m}, 70 \mathrm{~m})$ \\
\hline 3 & Fuel name is "Icing Sugar" \\
\hline 4 & Dust concentration $=500 \mathrm{~g} / \mathrm{m}^{3}$ \\
\hline 5 & Number of monitor points $=80$ \\
\hline 6 & Number of pressure panels $(\mathrm{PP})=58$ \\
\hline 7 & Ignition energy $=10 \mathrm{~kJ}$ \\
\hline
\end{tabular}

Using the Probit equation 3.2, the damage which occurred as a result of the maximum pressure obtained from DESC can be estimated. using Table D.1 and Table D.2 in Appendix D, with the structural damage and its causative variables $\left(\mathrm{K}_{1}, \mathrm{~K}_{2}\right)$, the equation will be: $Y=-23.8+2.92 * \ln \left(P_{\text {ovr }}\right)$. 
Figures 5.7 to 5.10 show top views of the working floors. DESC pressure simulations of each work area revealed that the maximum explosion pressure $\left(\mathrm{P}_{\max }\right)$ reached inside the working areas during the simulation was $25 \mathrm{kPa}$, which was attained at $2.6 \mathrm{~s}$ of the simulation time. The top-view figures below define the pressure distribution at each floor. The areas are bounded with contour lines to designate various pressure zones $(A-R)$. Each zone has a different color to indicate pressure magnitude.

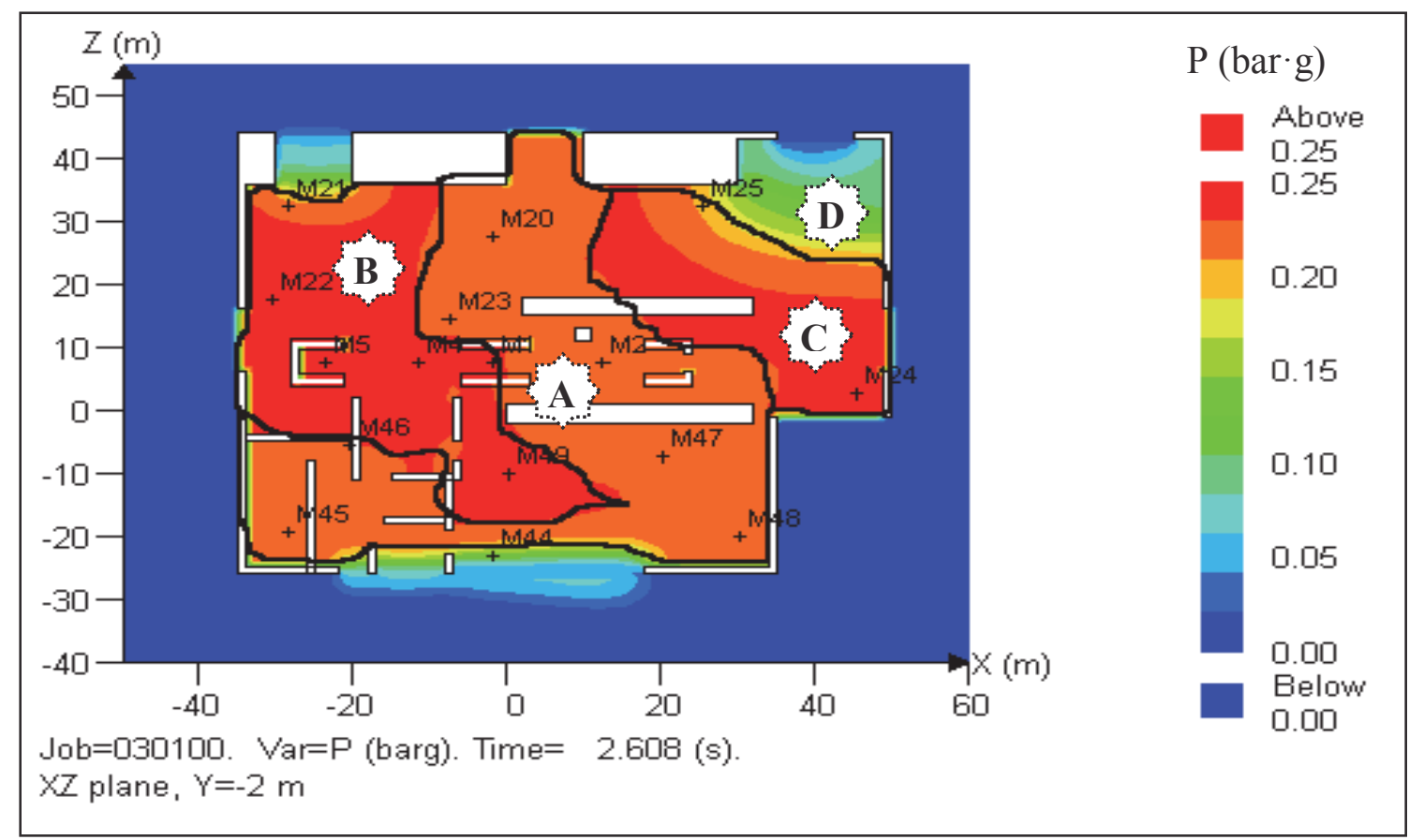

Figure 5.7 DESC pressure simulation from a plane view of the first floor, Module $(2,1)$ of the Imperial Sugar refinery explosion. 


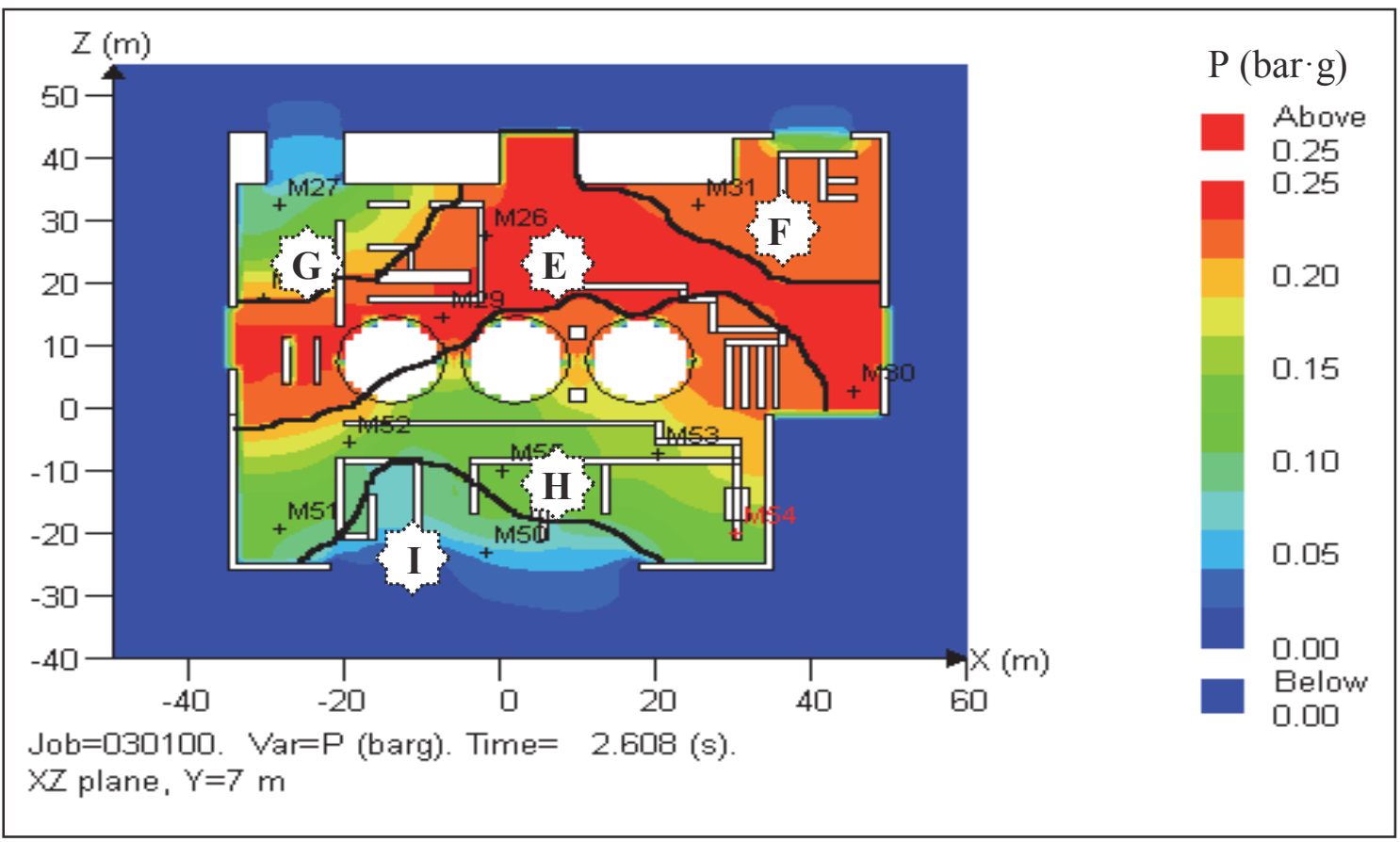

Figure 5.8 DESC pressure simulation from a plane view of the second floor, Module $(2,2)$ of the Imperial Sugar refinery explosion.

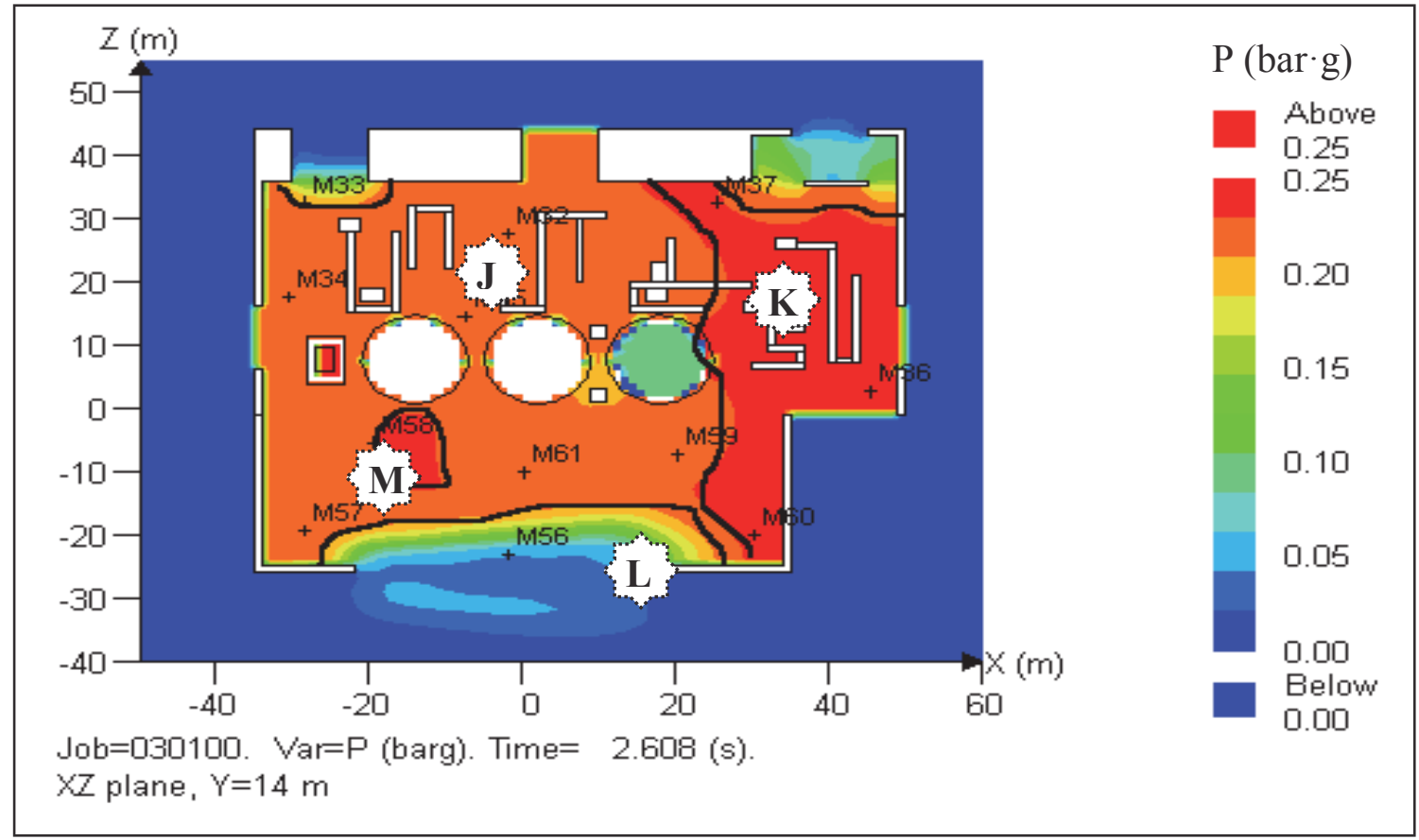

Figure 5.9 DESC pressure simulation from a plane view of the third floor, Module $(2,3)$ of the Imperial Sugar refinery explosion. 


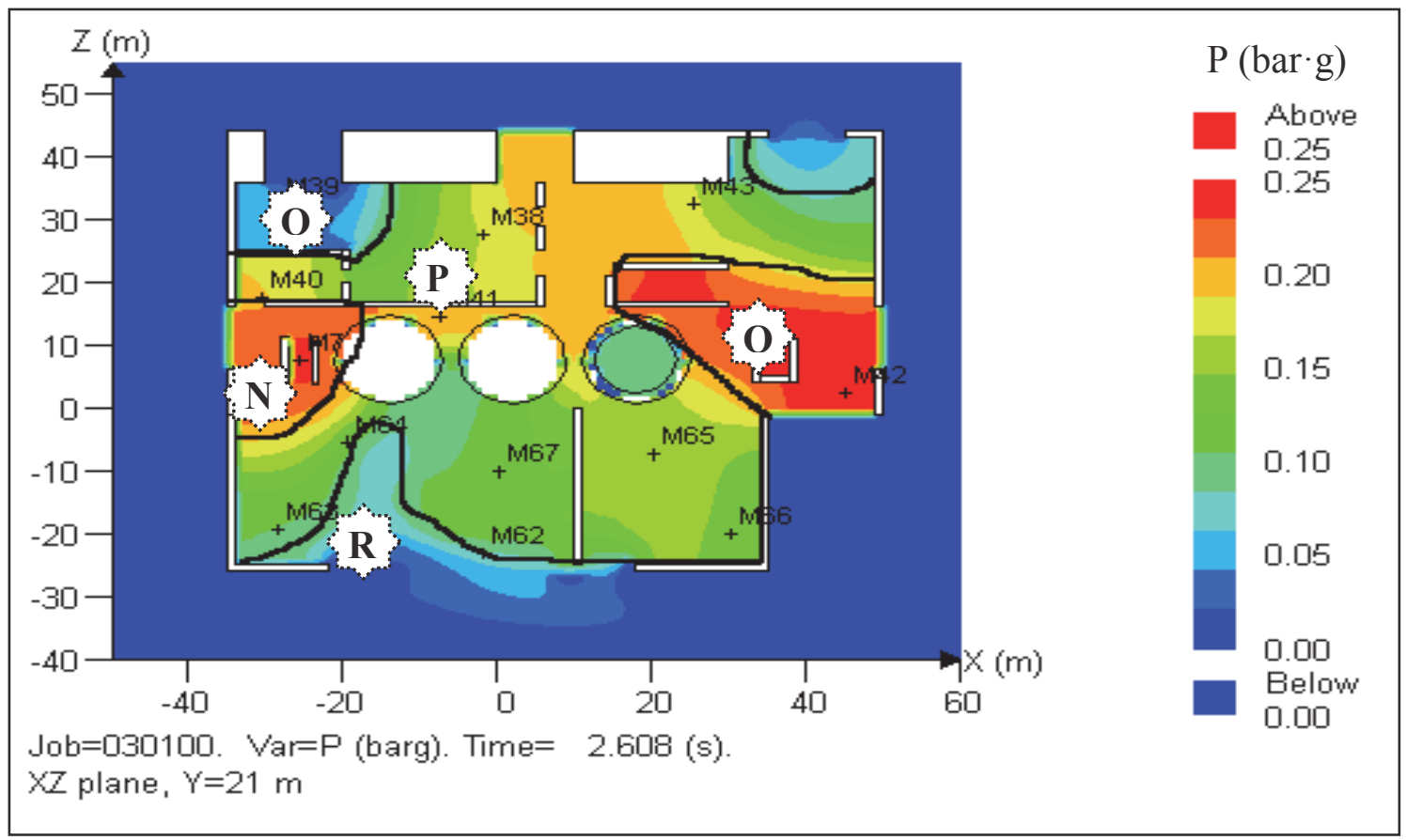

Figure 5.10 DESC pressure simulation from a plane view of the fourth floor, Module $(2,4)$ of the Imperial Sugar refinery explosion.

Figures 5.11 to 5.14 show the development of the explosion pressure, measured by the monitor points (M1 - M67), with respect to time on each floor. Figure 5.11 shows two explosion pressure peaks, which represent the primary explosion pressure inside the enclosure and the secondary explosion pressure on the first floor, respectively. At $1.2 \mathrm{~s}$, the explosion pressure in the enclosure reached $0.3 \mathrm{bar}(\mathrm{g})(30 \mathrm{kPa})$, which is the adjusted relief pressure of the vents that represent the enclosure walls' strength. Then, the pressure suddenly decreased to nearly zero bar(g) because the pressure had been released into the refinery's first floor area, which was much larger than the enclosure. Shortly thereafter, at $1.7 \mathrm{~s}$, the secondary explosion started as a result of the pre-explosion conditions existing on the first floor. The secondary explosion pressure then increased until it reached 0.2 $\operatorname{bar}(\mathrm{g})$, which was the panels' opening pressure on the refinery walls. The pressure continued to increase for a few milliseconds longer, reaching $0.25 \mathrm{bar}(\mathrm{g})$ at $2.4 \mathrm{~s}$, as the explosion pressure rate was significantly higher than the pressure releasing rate (venting). 


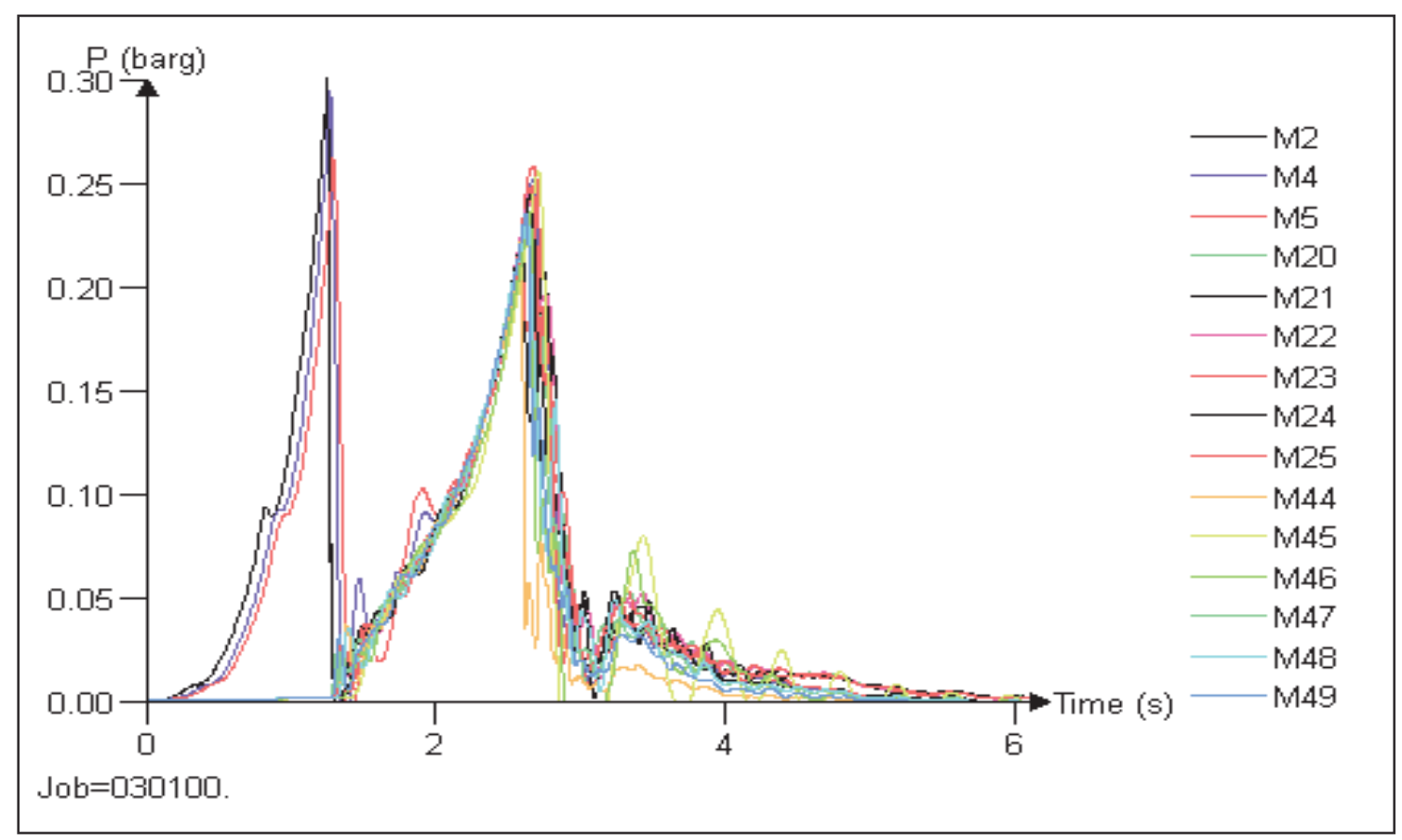

Figure 5.11 DESC pressure/time simulation at the monitor points on the first floor, Module $(2,1)$ of the Imperial Sugar refinery explosion.

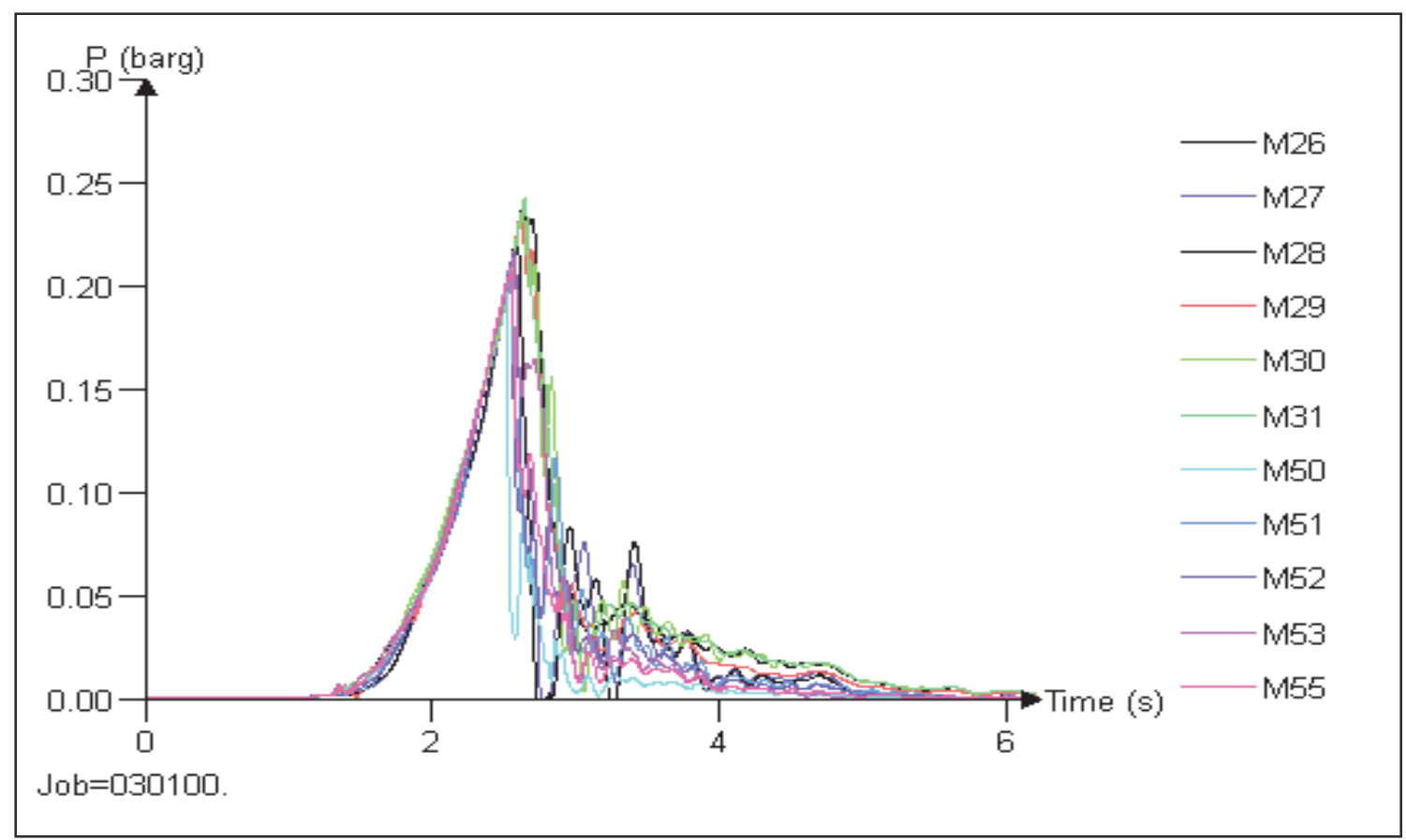

Figure 5.12 DESC pressure/time simulation at the monitor points on the second floor, Module $(2,2)$ of the Imperial Sugar refinery explosion. 


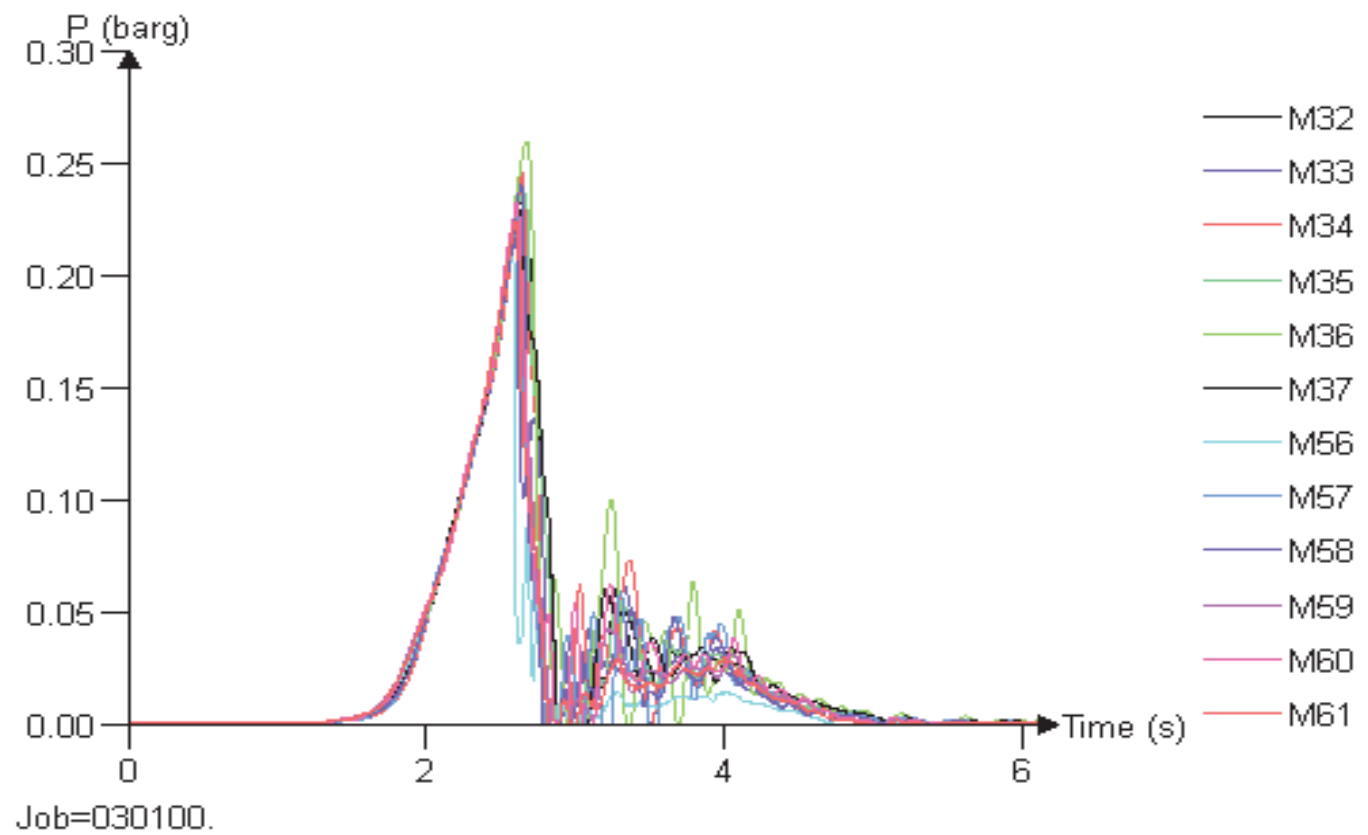

Figure 5.13 DESC pressure/time simulation at the monitor points on the third floor, Module $(2,3)$ of the Imperial Sugar refinery explosion.

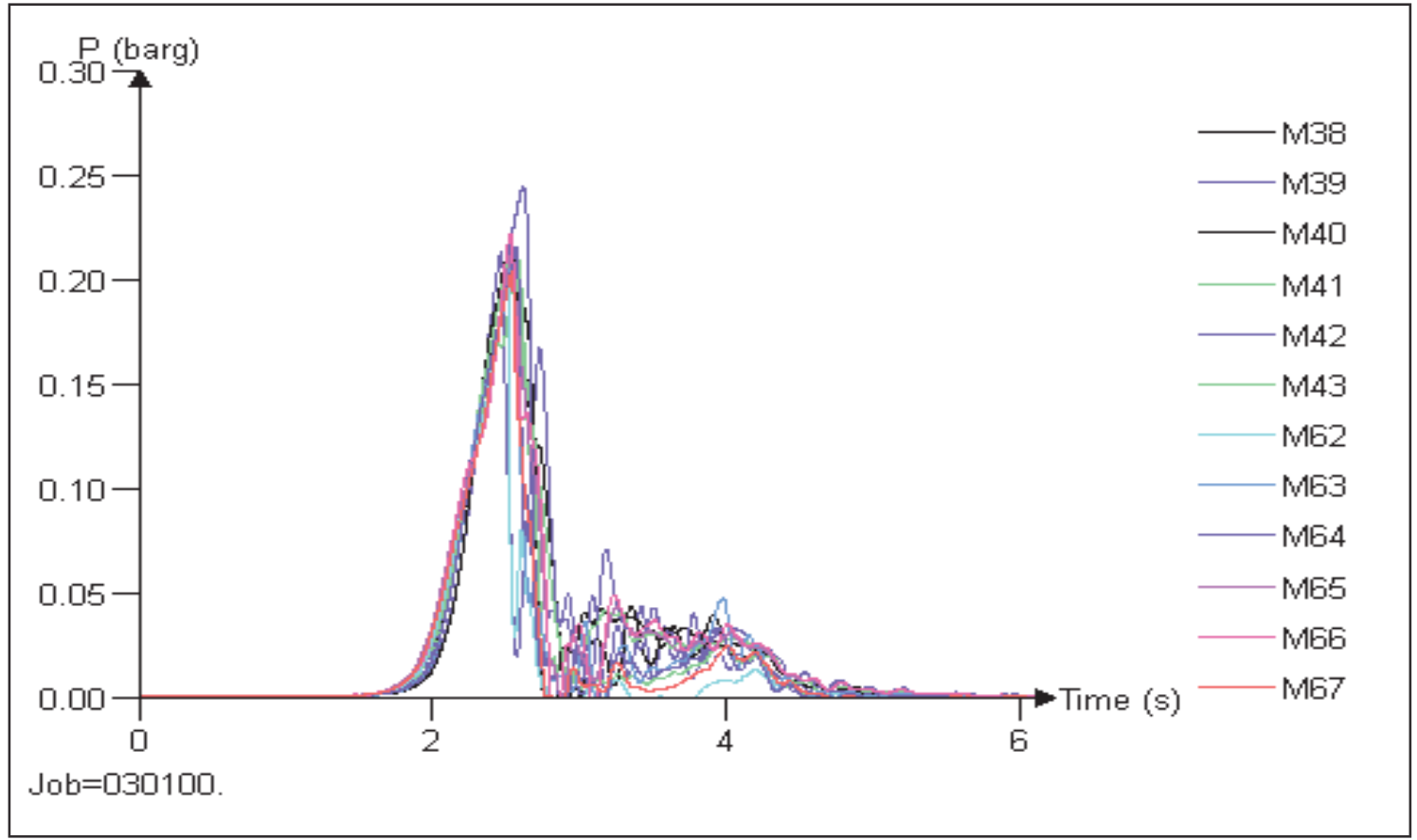

Figure 5.14 DESC pressure/time simulation at the monitor points on the fourth floor, Module $(2,4)$ of the Imperial Sugar refinery explosion. 
Then, the pressure curve dropped off rapidly when the pressure was fully released. At 3.1 $\mathrm{s}$, the pressure fluctuated for a few seconds (due to some remaining compressed zones inside the floor) until it completely released at $6 \mathrm{~s}$. Figures 5.12 to 5.14 show the explosion pressure peaks for the second, third, and fourth floors, all three of which had nearly identical pressure development during the same explosion time (6 s).

The Probit equation and the transformation table shown in Appendix D determined the structural damage at each zone as a damage percentage. Considering the fire effects on the workers who were trapped at the most damaged areas, the zones' danger degrees took the same damage percentages (i.e., any zone with $25 \%, 22 \%$, or $16 \%$ damage will have the same value of fatalities). Explosion pressure, along with its corresponding Probit value and the damage percentage for each zone in the work areas, can be seen in Tables 5.4 to 5.7 .

Table 5.4 Estimated Probit damage percentages caused by explosion overpressure of incident outcome cases at Module $(2,1)$.

\begin{tabular}{|c|c|c|c|}
\hline $\begin{array}{c}\text { Incident } \\
\text { outcome case }\end{array}$ & $\begin{array}{c}\mathbf{P}_{\max } \\
{[\mathbf{b a r}(\mathbf{g})]}\end{array}$ & $\mathbf{Y}$ & $\begin{array}{c}\text { Damage } \\
\text { percentage (\%) }\end{array}$ \\
\hline A & 0.22 & 5.39 & 65 \\
\hline B & 0.25 & 5.77 & 78 \\
\hline C & 0.23 & 5.52 & 70 \\
\hline D & 0.16 & 4.47 & 30 \\
\hline
\end{tabular}


Table 5.5 Estimated Probit damage percentages caused by explosion overpressure of incident outcome cases at Module $(2,2)$.

\begin{tabular}{|c|c|c|c|}
\hline $\begin{array}{c}\text { Incident } \\
\text { outcome case }\end{array}$ & $\begin{array}{c}\mathbf{P}_{\max } \\
{[\mathbf{b a r}(\mathbf{g})]}\end{array}$ & $\mathbf{Y}$ & $\begin{array}{c}\text { Damage } \\
\text { percentage (\%) }\end{array}$ \\
\hline E & 0.25 & 5.77 & 78 \\
\hline F & 0.22 & 5.39 & 65 \\
\hline G & 0.16 & 4.47 & 30 \\
\hline H & 0.16 & 4.47 & 30 \\
\hline I & 0.10 & 3.10 & 03 \\
\hline
\end{tabular}

Table 5.6 Estimated Probit damage percentages caused by explosion overpressure of incident outcome cases at Module $(2,3)$.

\begin{tabular}{|c|c|c|c|}
\hline $\begin{array}{c}\text { Incident } \\
\text { outcome case }\end{array}$ & $\begin{array}{c}\mathbf{P}_{\max } \\
{[\mathbf{b a r}(\mathbf{g})]}\end{array}$ & $\mathbf{Y}$ & $\begin{array}{c}\text { Damage } \\
\text { percentage (\%) }\end{array}$ \\
\hline $\mathrm{J}$ & 0.22 & 5.39 & 65 \\
\hline $\mathrm{K}$ & 0.25 & 5.77 & 78 \\
\hline $\mathrm{L}$ & 0.16 & 4.47 & 30 \\
\hline $\mathrm{M}$ & 0.25 & 5.39 & 78 \\
\hline
\end{tabular}

Table 5.7 Estimated Probit damage percentages caused by explosion overpressure of incident outcome cases at Module $(2,4)$.

\begin{tabular}{|c|c|c|c|}
\hline $\begin{array}{c}\text { Incident } \\
\text { outcome case }\end{array}$ & $\begin{array}{c}\mathbf{P}_{\max } \\
(\mathbf{b a r}(\mathbf{g}))\end{array}$ & $\mathbf{Y}$ & $\begin{array}{c}\text { Damage } \\
\text { percentage (\%) }\end{array}$ \\
\hline $\mathrm{N}$ & 0.22 & 5.39 & 65 \\
\hline $\mathrm{O}$ & 0.25 & 5.77 & 78 \\
\hline $\mathrm{P}$ & 0.16 & 4.47 & 30 \\
\hline $\mathrm{Q}$ & 0.04 & 0.42 & 0 \\
\hline $\mathrm{R}$ & 0.07 & 2.06 & 01 \\
\hline
\end{tabular}




\section{ii) Likelihood calculations}

As mentioned, historical information for at least ten years is required to obtain a reliable likelihood assessment. The basic events data of the refinery-developed FTA have been generated from Equation 2.5 (the best guess method) and Equation 2.6 (the confidence limit method), as recommended by Freeman (2011) for explosion initiation test estimates. As no historical data is available for the refinery, $k=1 / 3$ and $n=t=10$ years have been used for basic events such as bagging and filling FIBCs and transfer units. However, Equation 2.7 has been used for events that were expected to have a significantly larger contribution to probability for explosion initiation, such as dust collecting receivers, ignition sources, shock waves, and belt conveyors. Due to the generally unsafe conditions under which the sugar refinery operated, the failure probabilities of the units that had a large effect on the explosion are estimated as follows:

- The confinement, the dust concentration, and the combustible material probabilities were 0.99 ; the first two probabilities were due to the enclosure covering the conveyor belt, and the third probability was due to the sugar material.

- As the explosion occurred at normal atmosphere inside the enclosure, the oxidant concentration probability (to be above the LOC) was 0.8 .

- Rationally, the practical size probability was 0.25 because at least $25 \%$ of the airborne dust sugar was less than the non-explosible diameter.

- The probability that the transport system (belt conveyors, elevators, and screw conveyors) contributed to the complete dust mixing is 0.25 because they were the type of machines (in relatively constant movement) that could raise the sugar dust into the air.

Table 5.8 summarizes the calculated probabilities of occurrence for the basic events at the Imperial Sugar refinery prior to the explosion. The failure rates $\left(M_{i}=\lambda\right)$ for basic events were calculated using Equations 2.5 and 2.7; then failure probability was calculated using Equation 2.8. Other probabilities, such as dust concentration, belt conveyors, mechanical impact sparks, etc., were estimated as explained in the previous paragraph. 
Table 5.8 Failure rates of the explosion basic events at the Imperial Sugar refinery.

\begin{tabular}{|c|c|c|c|c|c|c|c|}
\hline No. & \multicolumn{3}{|c|}{ Event (Gate) } & \multicolumn{2}{|c|}{ Basic event } & \multirow{2}{*}{$\begin{array}{c}\text { Failure rate } \\
(\boldsymbol{\lambda})\end{array}$} & \multirow{2}{*}{$\begin{array}{c}\text { Probability } \\
\qquad \boldsymbol{P}[(\boldsymbol{t})] \\
0.0325\end{array}$} \\
\hline 1 & \multirow{23}{*}{ 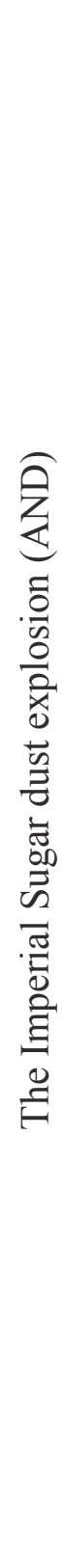 } & \multirow{16}{*}{ 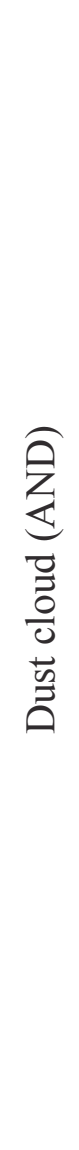 } & \multirow{10}{*}{ 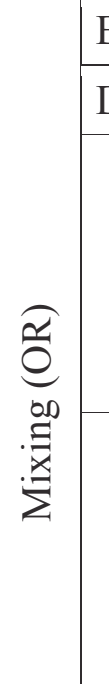 } & \multicolumn{2}{|c|}{ Bagging and filling / FIBCs } & & \\
\hline 2 & & & & \multicolumn{2}{|c|}{ Dust collecting receivers } & 0.067 & 0.0650 \\
\hline 3 & & & & \multirow{4}{*}{ 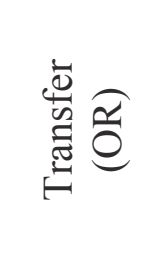 } & Silos and bins & 0.033 & 0.0325 \\
\hline 4 & & & & & Cartridge & 0.033 & 0.0325 \\
\hline 5 & & & & & Bag houses & 0.033 & 0.0325 \\
\hline 6 & & & & & Others & - & 0.0010 \\
\hline 7 & & & & \multirow{4}{*}{ 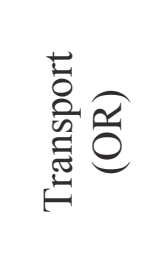 } & Belt conveyors & - & 0.2500 \\
\hline 8 & & & & & Elevators & - & 0.2500 \\
\hline 9 & & & & & Screw conveyors & - & 0.2500 \\
\hline 10 & & & & & Others & - & 0.0010 \\
\hline 11 & & & & \multicolumn{2}{|c|}{ Shock waves } & 0.067 & 0.0650 \\
\hline 12 & & & & \multicolumn{2}{|l|}{ Others } & - & 0.0010 \\
\hline 13 & & & & \multicolumn{2}{|c|}{ Combustible material } & - & 0.9900 \\
\hline 14 & & & 。 & \multicolumn{2}{|c|}{ Concentration $>\mathrm{MEC}$} & - & 0.9900 \\
\hline 15 & & & & \multicolumn{2}{|c|}{$\begin{array}{l}\text { Particle size }<\text { non- } \\
\text { explosible diameter }\end{array}$} & - & 0.2500 \\
\hline 16 & & & \multicolumn{3}{|c|}{ Oxidant concentration $>$ LOC } & - & 0.8000 \\
\hline 17 & & \multirow{6}{*}{ 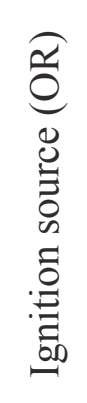 } & \multicolumn{3}{|c|}{ Mechanical impact sparks } & - & 0.0650 \\
\hline 18 & & & \multicolumn{3}{|c|}{ Friction sparks } & - & 0.0650 \\
\hline 19 & & & \multicolumn{3}{|c|}{ Flames and direct heat } & 0.067 & 0.0650 \\
\hline 20 & & & \multicolumn{3}{|c|}{ Electrical sparks } & 0.067 & 0.0650 \\
\hline 21 & & & \multicolumn{3}{|c|}{ Static electricity } & 0.067 & 0.0650 \\
\hline 22 & & & \multicolumn{3}{|c|}{ Others } & - & 0.0010 \\
\hline 23 & & \multicolumn{4}{|c|}{ Total confinement } & - & 0.9900 \\
\hline
\end{tabular}


The general dust explosion fault tree flowchart has been modified to address the Imperial Sugar explosion, and the FTA in Figure 5.15 has been extracted from Figure 3.2 to address the possible events that could contribute to the disaster. Some non-existing events have been removed, such as hybrid mixture, dryers, separators, pneumatic conveyors, and lightning events, as they did not exist for the Imperial Sugar explosion.

\section{Risk estimation}

Risk estimation is a combination of the severity of consequences and the likelihood of occurrence. Risk criteria might be one or more of the following: individual risk, societal risk, and/or risk indices.

\section{- Individual risk}

Individual risk has been calculated for the four floors of the working area, which are represented as Module (2, i), where $\mathrm{i}=1,2,3,4$.

The fault tree analysis finds the probability $(P)$ of the Imperial Sugar refinery incident is $3.8 * 10^{-2}$ per year. The probability has been assumed to be the same for all four floors because the explosion occurred on the lower floor of the interconnected building, and any explosion that occurred on the first floor would spread upwards to all other floors. The following risk estimation measures show the quantitative risk values in the work areas.

Tables 5.9 to 5.12 show frequency of incident outcome at case $\mathrm{i}\left(\mathrm{f}_{\mathrm{i}}\right)$, the probability of fatality $\left(P_{f, i}\right)$, the total risk $\left(\mathrm{f}_{\mathrm{i}} * P_{f, i}\right)$, the number of workers, and the estimated number of fatalities $(\mathrm{N})\left(\mathrm{N}=\mathrm{P}_{\mathrm{f}, \mathrm{i}} *\right.$ No. of workers) at each defined explosion pressure zone $(\mathrm{A}-\mathrm{R})$. 


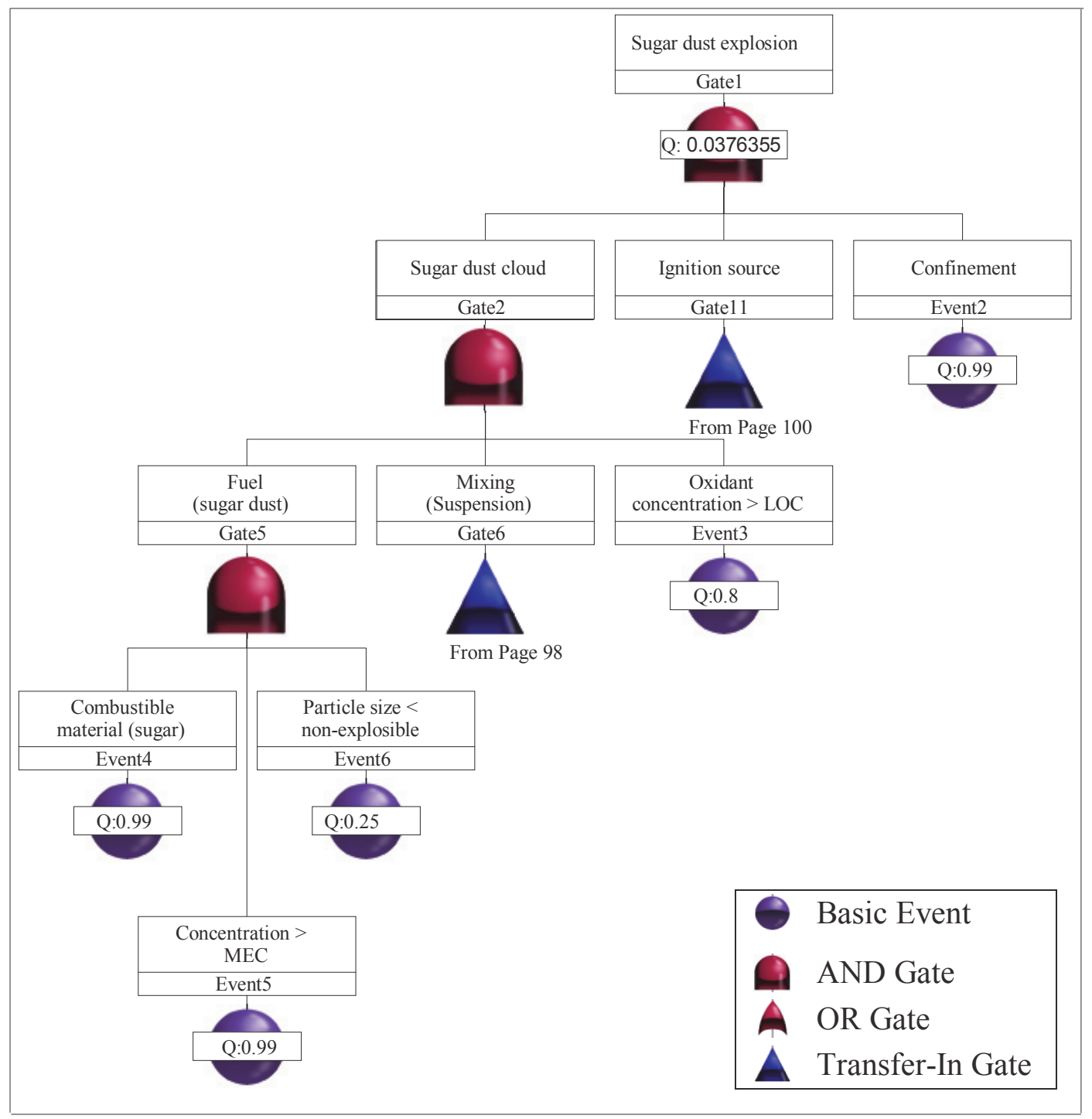

Figure 5.15 Fault Tree Analysis flowchart of the Imperial Sugar refinery explosion. 


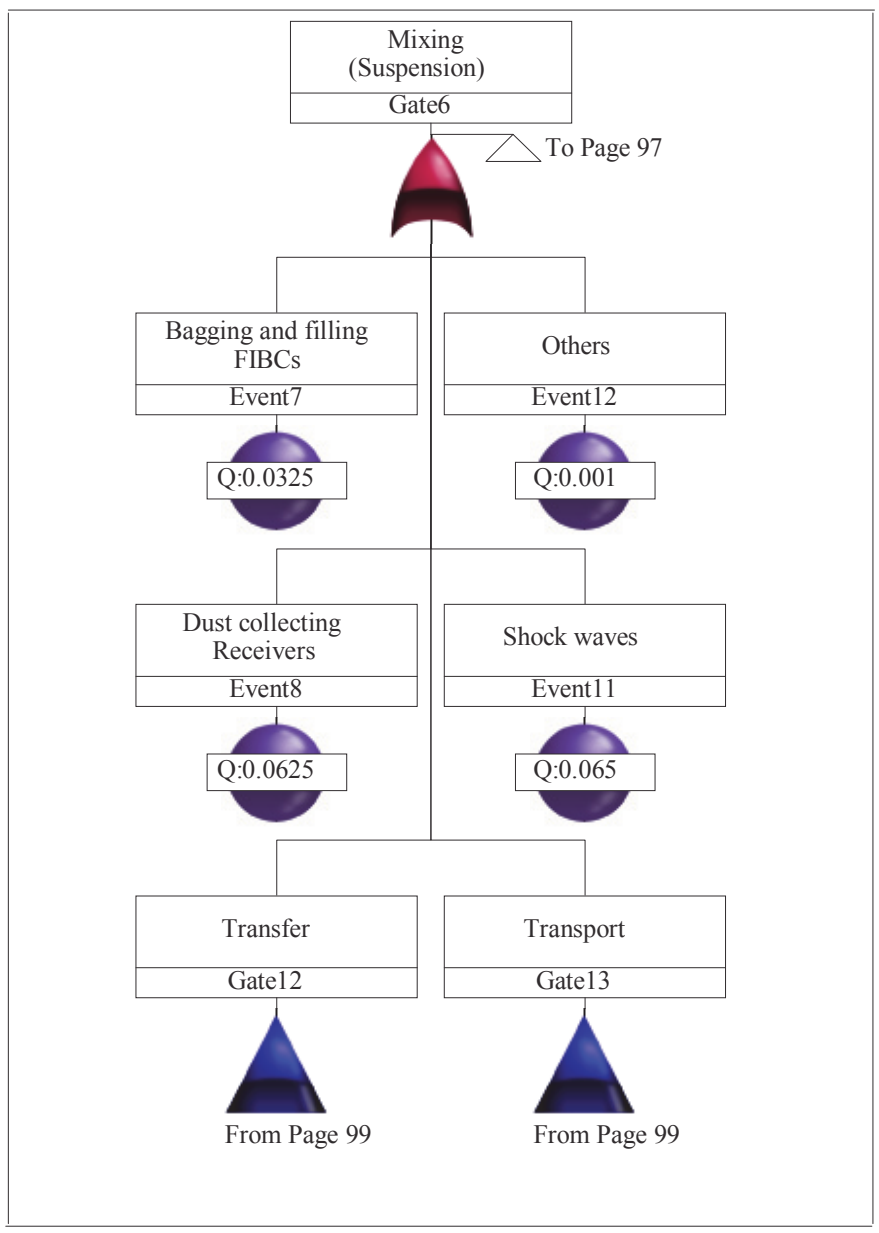



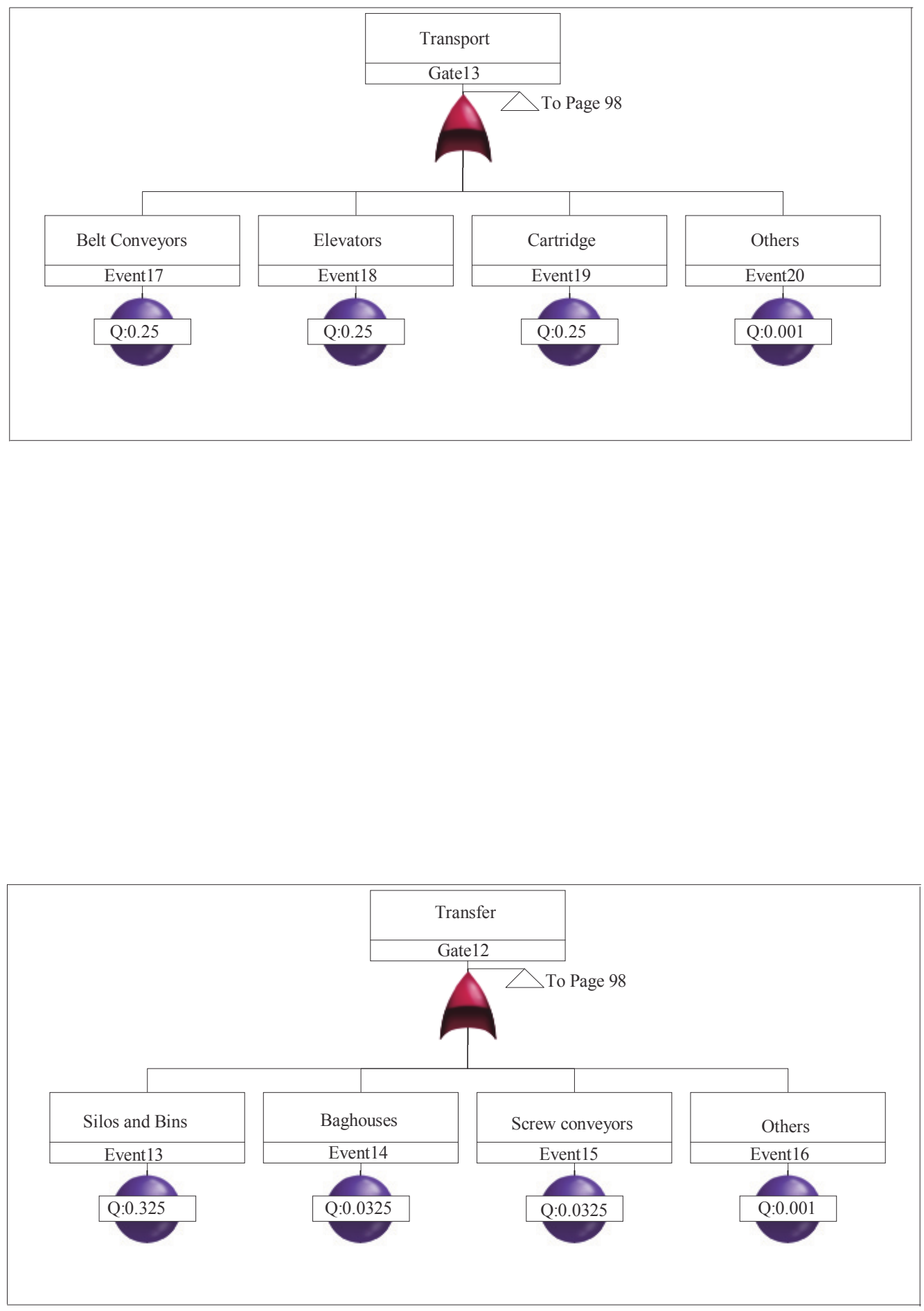


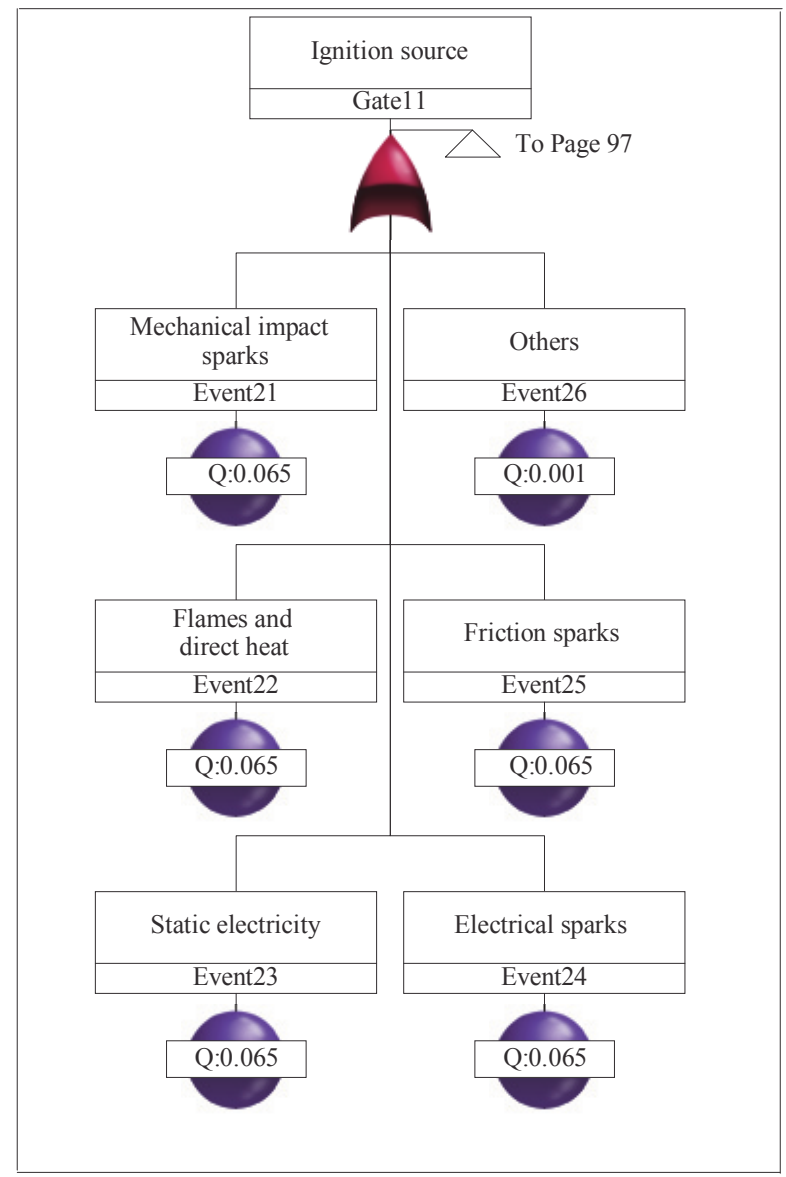

Table 5.9 Individual risk calculations for the first floor, Module $(2,1)$.

\begin{tabular}{|c|c|c|c|c|c|}
\hline $\begin{array}{c}\text { Incident } \\
\text { outcome case }\end{array}$ & $\begin{array}{c}\mathbf{f}_{\mathbf{i}} \\
(\mathbf{p e r} \text { year) }\end{array}$ & $\mathbf{P}_{\mathbf{f , i}}$ & $\mathbf{f}_{\mathbf{i}} * \mathbf{P}_{\mathbf{f , i}}$ & $\begin{array}{c}\text { No. of } \\
\text { workers }\end{array}$ & $\begin{array}{c}\text { Estimated no. } \\
\text { of fatalities (N) }\end{array}$ \\
\hline $\mathrm{A}$ & $3.8 * 10^{-2}$ & 0.65 & $2.5 * 10^{-2}$ & 15 & 10 \\
\hline $\mathrm{B}$ & $3.8 * 10^{-2}$ & 0.78 & $2.9 * 10^{-2}$ & 6 & 5 \\
\hline $\mathrm{C}$ & $3.8 * 10^{-2}$ & 0.70 & $2.6 * 10^{-2}$ & 6 & 4 \\
\hline $\mathrm{D}$ & $3.8 * 10^{-2}$ & 0.30 & $1.1 * 10^{-2}$ & 4 & 1 \\
\hline
\end{tabular}

Average individual risk on the first floor, calculated using equation 3.9:

$I R \operatorname{avg} 1=$

$$
\begin{gathered}
\frac{(15) * 2.5 * 10^{-2}+(6) * 2.9 * 10^{-2}+(6) * 2.6 * 10^{-2}+(4) * 1.1 * 10^{-3}}{31} \\
=2.3 * 10^{-2}
\end{gathered}
$$


Table 5.10 Individual risk calculations for the second floor, Module $(2,2)$.

\begin{tabular}{|c|c|c|c|c|c|}
\hline $\begin{array}{c}\text { Incident } \\
\text { outcome case }\end{array}$ & $\begin{array}{c}\mathbf{f}_{\mathbf{i}} \\
\text { (per year) }\end{array}$ & $\mathbf{P}_{\mathbf{f}, \mathbf{i}}$ & $\mathbf{f}_{\mathbf{i}} * \mathbf{P}_{\mathbf{f}, \mathbf{i}}$ & $\begin{array}{c}\text { No. of } \\
\text { workers }\end{array}$ & $\begin{array}{c}\text { Estimated no. } \\
\text { of fatalities (N) }\end{array}$ \\
\hline $\mathrm{E}$ & $3.8 * 10^{-2}$ & 0.78 & $2.9 * 10^{-2}$ & 4 & 3 \\
\hline $\mathrm{F}$ & $3.8 * 10^{-2}$ & 0.65 & $2.5 * 10^{-2}$ & 2 & 1 \\
\hline $\mathrm{G}$ & $3.8 * 10^{-2}$ & 0.30 & $1.1 * 10^{-2}$ & 1 & 0 \\
\hline $\mathrm{H}$ & $3.8 * 10^{-2}$ & 0.30 & $1.1 * 10^{-2}$ & 8 & 2 \\
\hline $\mathrm{I}$ & $3.8 * 10^{-2}$ & 0.03 & $1.1 * 10^{-3}$ & 3 & 0 \\
\hline Average individual risk on the second floor, calculated using Equation 3.9: \\
IRavg $=$ \\
$(4) * 2.9 * 10^{-2}+(2) * 2.5 * 10^{-2}+(1+8) * 1.1 * 10^{-2}+(3) * 1.1 * 10^{-3}$ \\
\hline
\end{tabular}

Table 5.11 Individual risk calculations for the third floor, Module $(2,3)$.

\begin{tabular}{|c|c|c|c|c|c|}
\hline $\begin{array}{c}\text { Incident } \\
\text { outcome case }\end{array}$ & $\begin{array}{c}\mathbf{f}_{\mathbf{i}} \\
(\text { per year) }\end{array}$ & $\mathbf{P}_{\mathbf{f}, \mathbf{i}}$ & $\mathbf{f}_{\mathbf{i}} * \mathbf{P}_{\mathbf{f}, \mathbf{i}}$ & $\begin{array}{c}\text { No. of } \\
\text { workers }\end{array}$ & $\begin{array}{c}\text { Estimated no. of } \\
\text { fatalities (N) }\end{array}$ \\
\hline $\mathrm{J}$ & $3.8 * 10^{-2}$ & 0.65 & $2.5 * 10^{-2}$ & 21 & 14 \\
\hline $\mathrm{K}$ & $3.8 * 10^{-2}$ & 0.78 & $2.9 * 10^{-2}$ & 12 & 9 \\
\hline $\mathrm{L}$ & $3.8 * 10^{-2}$ & 0.30 & $1.1 * 10^{-2}$ & 4 & 1 \\
\hline $\mathrm{M}$ & $3.8 * 10^{-2}$ & 0.78 & $2.9 * 10^{-2}$ & 2 & 2 \\
\hline & Average individual risk on the third floor, calculated using Equation 3.9: \\
IR avg $3=$ \\
$\quad(21) * 2.5 * 10^{-2}+(12) * 2.9 * 10^{-2}+(4) * 1.1 * 10^{-2}+(2) * 2.9 * 10^{-2}$ \\
\hline
\end{tabular}


Table 5.12 Individual risk calculations for the fourth floor, Module $(2,4)$.

\begin{tabular}{|c|c|c|c|c|c|}
\hline $\begin{array}{c}\text { Incident } \\
\text { outcome case }\end{array}$ & $\begin{array}{c}\mathbf{f}_{\mathbf{i}} \\
(\mathbf{p e r} \text { year})\end{array}$ & $\mathbf{P}_{\mathbf{f}, \mathbf{i}}$ & $\mathbf{f}_{\mathbf{i}} * \mathbf{P}_{\mathbf{f}, \mathbf{i}}$ & $\begin{array}{c}\text { No. of } \\
\text { workers }\end{array}$ & $\begin{array}{c}\text { Estimated no. } \\
\text { of fatalities (N) }\end{array}$ \\
\hline $\mathrm{N}$ & $3.8 * 10^{-2}$ & 0.22 & $8.3 * 10^{-3}$ & 5 & 1 \\
\hline $\mathrm{O}$ & $3.8 * 10^{-2}$ & 0.25 & $9.4 * 10^{-3}$ & 10 & 3 \\
\hline $\mathrm{P}$ & $3.8 * 10^{-2}$ & 0.16 & $6.0 * 10^{-3}$ & 25 & 4 \\
\hline $\mathrm{Q}$ & $3.8 * 10^{-2}$ & 0.04 & $1.5 * 10^{-3}$ & 3 & 0 \\
\hline $\mathrm{R}$ & $3.8 * 10^{-2}$ & 0.07 & $2.6 * 10^{-3}$ & 4 & 0 \\
\hline Average individual risk on the fourth floor calculated using Equation $3.9:$ \\
\\
$I R_{\text {avg } 4}=\left\{(5) * 8.3 * 10^{-3}+(10) * 9.4 * 10^{-3}+(25) * 6.0 * 10^{-3}+(3)\right.$ \\
\end{tabular}

The average individual risk for the entire refinery is:

$$
\begin{aligned}
I R_{\text {avgT }}=\{(15 & +2+21) * 2.5 * 10^{-2}+(6+4+12+2) * 2.9 * 10^{-2} \\
& +(6) * 2.6 * 10^{-2}+(4+1+8+3+4) * 1.1 * 10^{-3}+(5) \\
& * 8.3 * 10^{-3}+(10) * 9.4 * 10^{-3}+(25) * 6.0 * 10^{-3}+(3) \\
& \left.* 1.5 * 10^{-3}+(4) * 2.6 * 10^{-3}\right\} / 135 \\
& =0.931+0.706+0.158+0.0226+0.0414+0.0941+0.1505 \\
& +0.00453+0.01052 / 135=0.016
\end{aligned}
$$

- Location-specific individual risk (LSIR)

The LSIR for each floor has been calculated from Equation 3.5 to identify the hypothetical risk at each location.

$$
\begin{aligned}
& \operatorname{LSIR}_{1}=2.5 * 10^{-2}+2.9 * 10^{-2}+2.6 * 10^{-2}+1.1 * 10^{-2}=9.2 * 10^{-2} \\
& \operatorname{LSIR}_{2}=2.9 * 10^{-2}+2.5 * 10^{-2}+1.1 * 10^{-2}+1.1 * 10^{-2}+1.1 * 10^{-3}=7.8 * 10^{-2} \\
& \operatorname{LSIR}_{3}=2.5 * 10^{-2}+2.9 * 10^{-2}+1.1 * 10^{-2}+2.9 * 10^{-2}=9.5 * 10^{-2} \\
& \operatorname{LSIR}_{4}=8.3 * 10^{-3}+9.4 * 10^{-3}+6.0 * 10^{-3}+1.5 * 10^{-3}+2.6 * 10^{-3}=2.8 * 10^{-2}
\end{aligned}
$$

The total LSIR is calculated as:

$$
\operatorname{LSIR}_{\mathrm{T}}=9.2 * 10^{-2}+7.8 * 10^{-2}+9.5 * 10^{-2}+2.8^{*} 10^{-2}=0.30
$$


- Individual-specific individual risk (ISIR)

The ISIR for each floor has been calculated from Equation 3.7 to identify the risk at different locations, taking into account employee working time.

$\operatorname{ISIR}_{1}=9.2 * 10^{-2} * 8 / 24=0.0305$

$\operatorname{ISIR}_{2}=7.8 * 10^{-2} * 8 / 24=0.026$

$\operatorname{ISIR}_{3}=9.5 * 10^{-2} * 8 / 24=0.032$

$\mathrm{ISIR}_{4}=2.8 * 10^{-2} * 8 / 24=0.0093$

The total individual-specific individual risk (ISIR) is:

$I S I R_{T}=\operatorname{LSIR}_{T} * P_{L}=0.3 * \frac{8}{24}=0.1$

- Fatal accident rate (FAR)

FAR is calculated from the average individual risk for the exposed employee population from Equation 3.3.

Fatal accident rate $(\mathrm{FAR})=\operatorname{ISIR}_{\mathrm{T}} * 10^{8} / H=0.1 * 10^{8} /(135 * 2000)=36$

fatalities $/ 10^{8}$ man-hours of exposure

- Group (societal) risks

- F-N Curve:

The estimated numbers of fatalities at each incident outcome (zone) have been arranged in decreasing order, as presented in Table 5.13.

Table 5.14 expresses the F-N data in the requisite form, showing cumulative frequencies beginning with the top value (i.e., starting from the highest value of N).

Figure 5.16 shows the F-N curve, which presents the cumulative frequencies versus the number of fatalities tabulated in Table 5.14. Figure 5.16 and Table 5.15 with ALARP prove that the refinery had been at risk before the explosion occurred, as the plotted data are in the unacceptable risk range. 
Table 5.13 Estimated number of fatalities at each frequency of the incident outcome cases.

\begin{tabular}{|c|c|c|}
\hline $\begin{array}{c}\text { Estimated number } \\
\text { of fatalities } \mathbf{N}\end{array}$ & $\begin{array}{c}\text { Incident outcome cases } \\
\text { included }\end{array}$ & $\begin{array}{c}\text { Total frequency } \\
\left(\mathbf{F}_{\mathbf{N}}\right) \text { (per year) }\end{array}$ \\
\hline 14 & $\mathrm{~J}$ & $3.8 * 10^{-2}$ \\
\hline 10 & $\mathrm{~A}$ & $3.8 * 10^{-2}$ \\
\hline 9 & $\mathrm{~K}$ & $3.8 * 10^{-2}$ \\
\hline 5 & $\mathrm{~B}$ & $3.8 * 10^{-2}$ \\
\hline 4 & $\mathrm{C}, \mathrm{P}$ & $3.8 * 10^{-2}$ \\
\hline 3 & $\mathrm{E}, \mathrm{O}$ & $3.8 * 10^{-2}$ \\
\hline 2 & $\mathrm{H}, \mathrm{M}$ & $3.8 * 10^{-2}$ \\
\hline 1 & $\mathrm{D}, \mathrm{F}, \mathrm{L}, \mathrm{N}$ & $3.8 * 10^{-2}$ \\
\hline 0 & $\mathrm{G}, \mathrm{I}, \mathrm{Q}, \mathrm{R}$ & $3.8 * 10^{-2}$ \\
\hline
\end{tabular}

Table 5.14 Cumulative frequency data for F-N curve of the Imperial Sugar refinery explosion.

\begin{tabular}{|c|c|c|}
\hline $\begin{array}{c}\text { Estimated number } \\
\text { of fatalities } \mathbf{~}\end{array}$ & Incident outcome cases included & $\begin{array}{c}\text { Total frequency } \\
\mathbf{F}_{\mathbf{N}} \text { (per year) }\end{array}$ \\
\hline 14 & $\mathrm{~J}$ & $3.8 * 10^{-2}$ \\
\hline 10 & $\mathrm{~A}, \mathrm{~J}$ & $7.5 * 10^{-2}$ \\
\hline 9 & $\mathrm{~A}, \mathrm{~J}, \mathrm{~K}$ & $1.1 * 10^{-1}$ \\
\hline 5 & $\mathrm{~A}, \mathrm{~B}, \mathrm{~J}, \mathrm{~K}$ & $1.5 * 10^{-1}$ \\
\hline 4 & $\mathrm{~A}, \mathrm{~B}, \mathrm{C}, \mathrm{J}, \mathrm{K}, \mathrm{P}$ & $1.9 * 10^{-1}$ \\
\hline 3 & $\mathrm{~A}, \mathrm{~B}, \mathrm{C}, \mathrm{E}, \mathrm{J}, \mathrm{K}, \mathrm{O}, \mathrm{P}$ & $2.3 * 10^{-1}$ \\
\hline 2 & $\mathrm{~A}, \mathrm{~B}, \mathrm{C}, \mathrm{E}, \mathrm{H}, \mathrm{J}, \mathrm{K}, \mathrm{M}, \mathrm{O}, \mathrm{P}$ & $2.6 * 10^{-1}$ \\
\hline 1 & $\mathrm{~A}, \mathrm{~B}, \mathrm{C}, \mathrm{D}, \mathrm{E}, \mathrm{F}, \mathrm{H}, \mathrm{J}, \mathrm{K}, \mathrm{L}, \mathrm{M}, \mathrm{N}, \mathrm{O}, \mathrm{P}$ & $3.0 * 10^{-1}$ \\
\hline 0 & A,B,C,D,E,F,G,H,I,J,K,L,M,N,O,P,Q,R & $3.4 * 10^{-1}$ \\
\hline
\end{tabular}




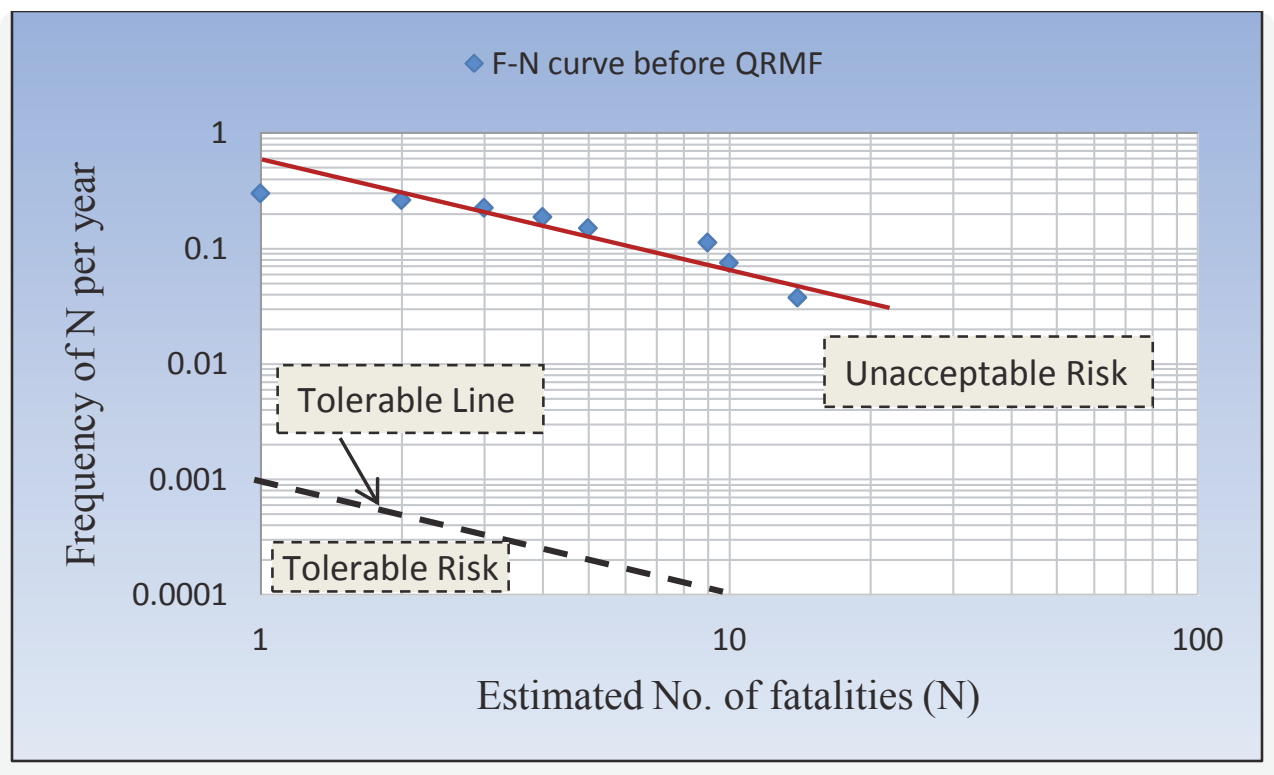

Figure 5.16 The estimated social risk F-N curve for the Imperial Sugar refinery before the explosion.

Table 5.15 Summary of the individual risk results for the Imperial Sugar refinery explosion, before applying the QRMF.

\begin{tabular}{|c|c|c|c|}
\hline $\begin{array}{c}\mathbf{I R}_{\text {avgT }} \\
\left(\mathbf{y r}^{-\mathbf{1}}\right)\end{array}$ & LSIR & ISIR & $\begin{array}{c}\text { FAR } \\
\text { Fatalties } / \\
\left(\mathbf{1 0}^{\mathbf{8}} \text { hours of exposure }\right)\end{array}$ \\
\hline $1.6 * 10^{-2}$ & 0.3 & 0.1 & 36 \\
\hline
\end{tabular}

\section{Risk evaluation}

As mentioned in section 3.1.3, and according to UK Health and Safety Executive guidelines, the maximum acceptable individual risk range in the industry is $5 * 10^{-5}$ $5 * 10^{-6}$. However, the maximum acceptable public individual risk range is $5 * 10^{-3}-$ $1 * 10^{-4}$. 


\section{Identify units and unsafe procedures that could contribute significantly to probability of top event:}

- the new stainless steel panels that covered the conveyor belts below the tall silos,

- using compressed air to clean the packaging machines,

- spilled sugar around the working machines, and

- insufficient pressure relief vents to release explosion pressure safely.

\section{Apply the risk controls}

Responding to the identified units and wrong actions, the QRMF controls should be applied to minimize the risk to be at least tolerable.

a) Inherent safety

Inherent safety principles (minimization, simplification, substitution) have been applied in recommended sequence to control the expected main causes of the Imperial Sugar refinery explosion, as seen in Table 5.16.

b) Engineered safety

- Passive engineered safety: Add sufficient explosion relief vents that can open to release sudden explosion pressure.

- Active engineered safety: Add an automatic explosion suppression system that able to control explosion fire.

c) Procedural safety: If any modification has been applied to the process units or to the work area cleaning procedures, review procedure for the entire refinery design. Review and apply certain safety maintenance procedures to reduce any possible ignition source. Also, review, revise, create, and apply safety procedures for emergency plans and periodic training procedures regarding safety issues for workers. 
Table 5.16 Applying inherent safety principles on the units, and wrong actions that contributed to the Imperial Sugar refinery explosion.

\begin{tabular}{|l|l|l|}
\hline $\begin{array}{c}\text { Units or actions } \\
\text { contributing to } \\
\text { the explosion } \\
\text { event }\end{array}$ & $\begin{array}{c}\text { Inherent } \\
\text { safety } \\
\text { principle }\end{array}$ & Action \\
\hline $\begin{array}{l}\text { Spilled sugar } \\
\text { around the working } \\
\text { machines }\end{array}$ & Minimization & $\begin{array}{l}\text { - Good housekeeping (dust removal/cleaning) to } \\
\text { mitigate secondary dust explosion and/or } \\
\text { prevent primary dust explosion. } \\
\text { - Keeping dust concentrations outside explosible } \\
\text { range (Amyotte \& Eckhoff, 2010). }\end{array}$ \\
\hline $\begin{array}{l}\text { Stainless steel } \\
\text { panels to cover the } \\
\text { conveyor belts } \\
\text { below the tall silos }\end{array}$ & Simplification & $\begin{array}{l}\text { Eliminate opportunities for errors by eliminating } \\
\text { excessive add-on safety features and protective } \\
\text { devices by removing the new stainless steel } \\
\text { panels that cover the conveyor belts below the } \\
\text { tall silos. }\end{array}$ \\
\hline $\begin{array}{l}\text { Using compressed } \\
\text { air to clean the } \\
\text { packaging } \\
\text { machines }\end{array}$ & Substitution & $\begin{array}{l}\text { Replace the hazardous cleaning procedure (using } \\
\text { compressed air to clean the packaging machines) } \\
\text { with one that is less hazardous, e.g. using dust } \\
\text { vacuum cleaners }\end{array}$ \\
\hline
\end{tabular}

\section{Understand the residual hazard}

i) Consequence analysis

- DESC simulation

Based on the risk controls, detailed in section 5.1.4 at step 6, new DESC simulations were run on the refinery geometry. Table 5.17 shows the simulation parameters that were changed to achieve safer operations. The pressure panels at the steel enclosure, Module $(1,1)$ have been adjusted to open at zero bar(g) to represent enclosure removal. Module $(1,2)$ and Module $(1,3)$ pressure panels were unchanged because they cover the transportation system outside the building. However, pressure panels in groups 1, 3, 4, 5, and 7 were adjusted to open at $0.05 \mathrm{bar}(\mathrm{g})(5 \mathrm{kPa})$. 
Table 5.17 Opening pressure values of pressure panels and their sizes in the Imperial Sugar refinery, after applying the QRMF.

\begin{tabular}{|l|c|c|}
\hline $\begin{array}{c}\text { Pressure panel } \\
\text { no. }\end{array}$ & $\begin{array}{c}\text { Opening pressure } \\
(\mathbf{~ k P a ~})\end{array}$ & $\begin{array}{c}\text { Size } \\
\left(\mathbf{~ m}^{\mathbf{2}}\right)\end{array}$ \\
\hline PP1 - PP4 & 0 & 68 \\
P58 & 0 & 85 \\
P57 & 0 & 20 \\
\hline PP5 - PP8 & 30 & 25 \\
PP53 - PP56 & 30 & 20 \\
\hline PP9 - PP12 & 30 & 40 \\
\hline Group 1 & 5 & 84 \\
\hline Group 2 & 30 & 84 \\
\hline Group 3 & 5 & 84 \\
\hline Group 4 & 5 & 84 \\
\hline Group 5 & 5 & 84 \\
\hline Group 6 & 30 & 112 \\
\hline Group 7 & 5 & 294 \\
\hline
\end{tabular}

The simulations showed that the pressure panels, shown in Table 5.17, at the adjusted opening pressure, are able to release any explosion pressure inside the refinery before it causes significant damage. Also, the dust concentration was adjusted to $250 \mathrm{~g} / \mathrm{m}^{3}$, which can be achieved by applying the inherent safety principle of minimization (i.e., good housekeeping).

The various colors in Figures 5.17 to 5.20 demonstrate the maximum explosion pressure reached during the DESC simulations. The simulations show that the pressure distribution is almost the same inside the buildings during the explosion. However, when the venting relief pressure value is reached, different pressure areas (colored zones) arise, indicated by different shapes and colors. These areas are the consequence of both pressure release and explosion reaction continuation. 


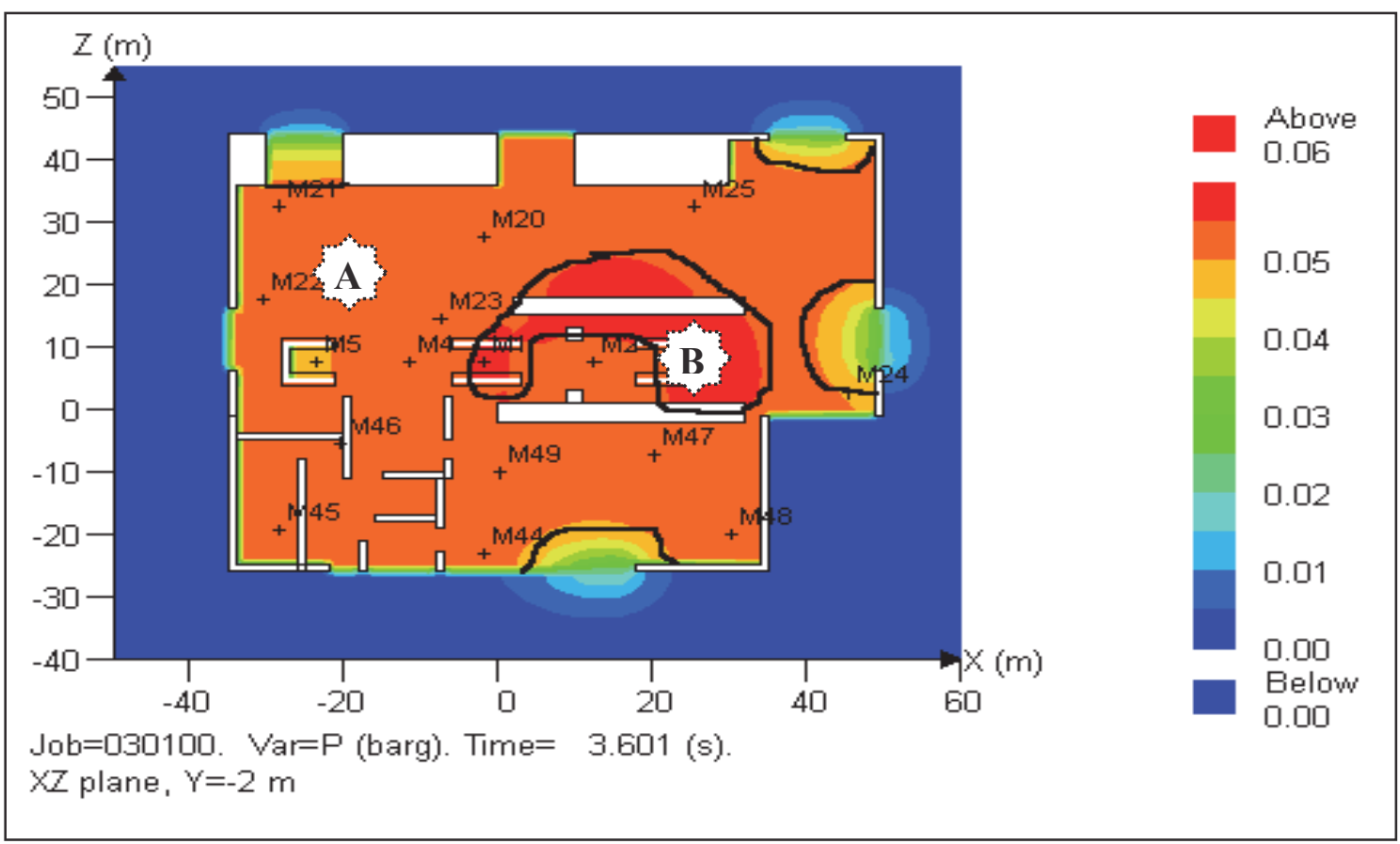

Figure 5.17 DESC pressure simulation from a plane view of the first floor, Module $(2,1)$, of the Imperial Sugar refinery explosion, after applying the QRMF.

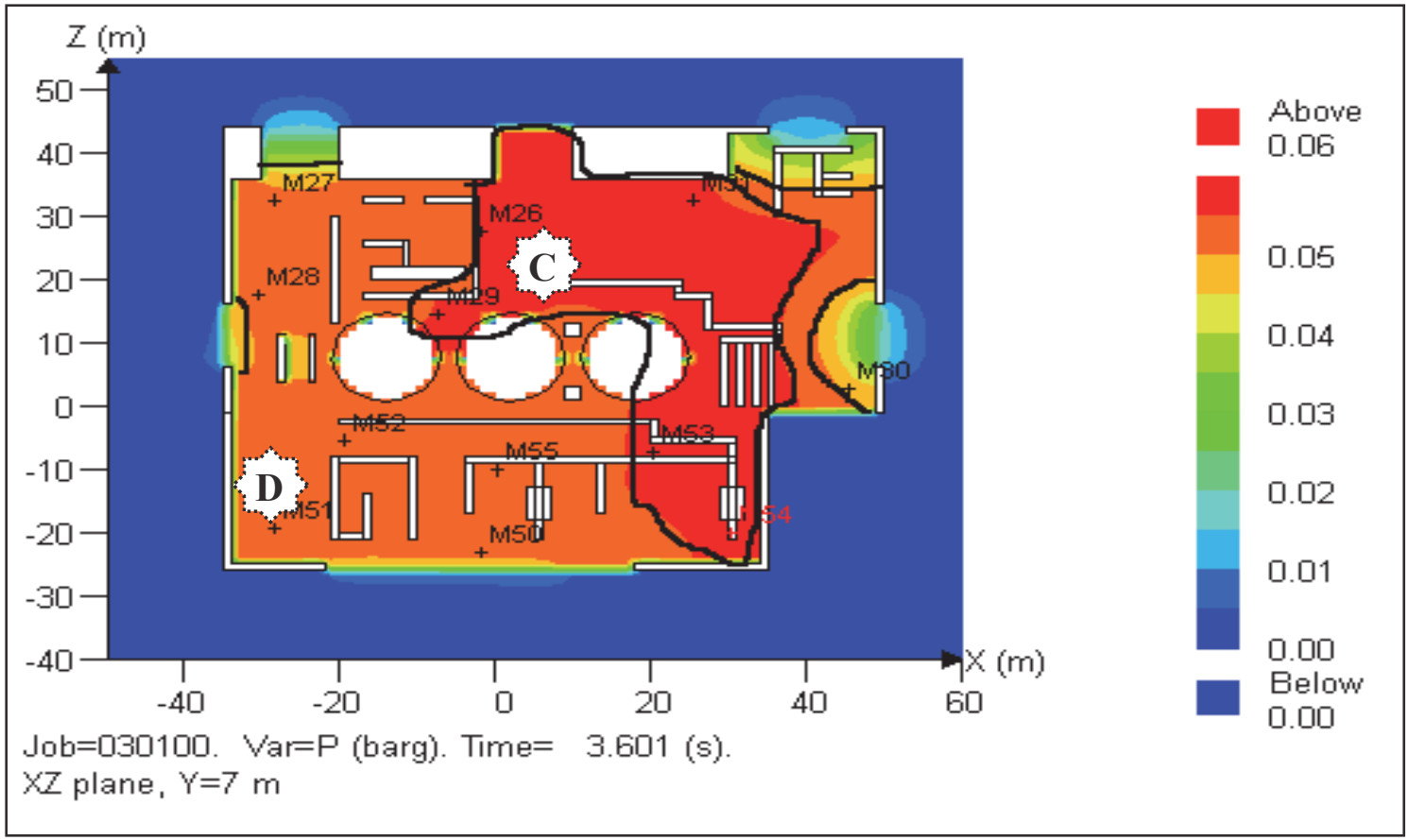

Figure 5.18 DESC pressure simulation from a plane view of the second floor, Module $(2,2)$, of the Imperial Sugar refinery explosion, after applying the QRMF. 


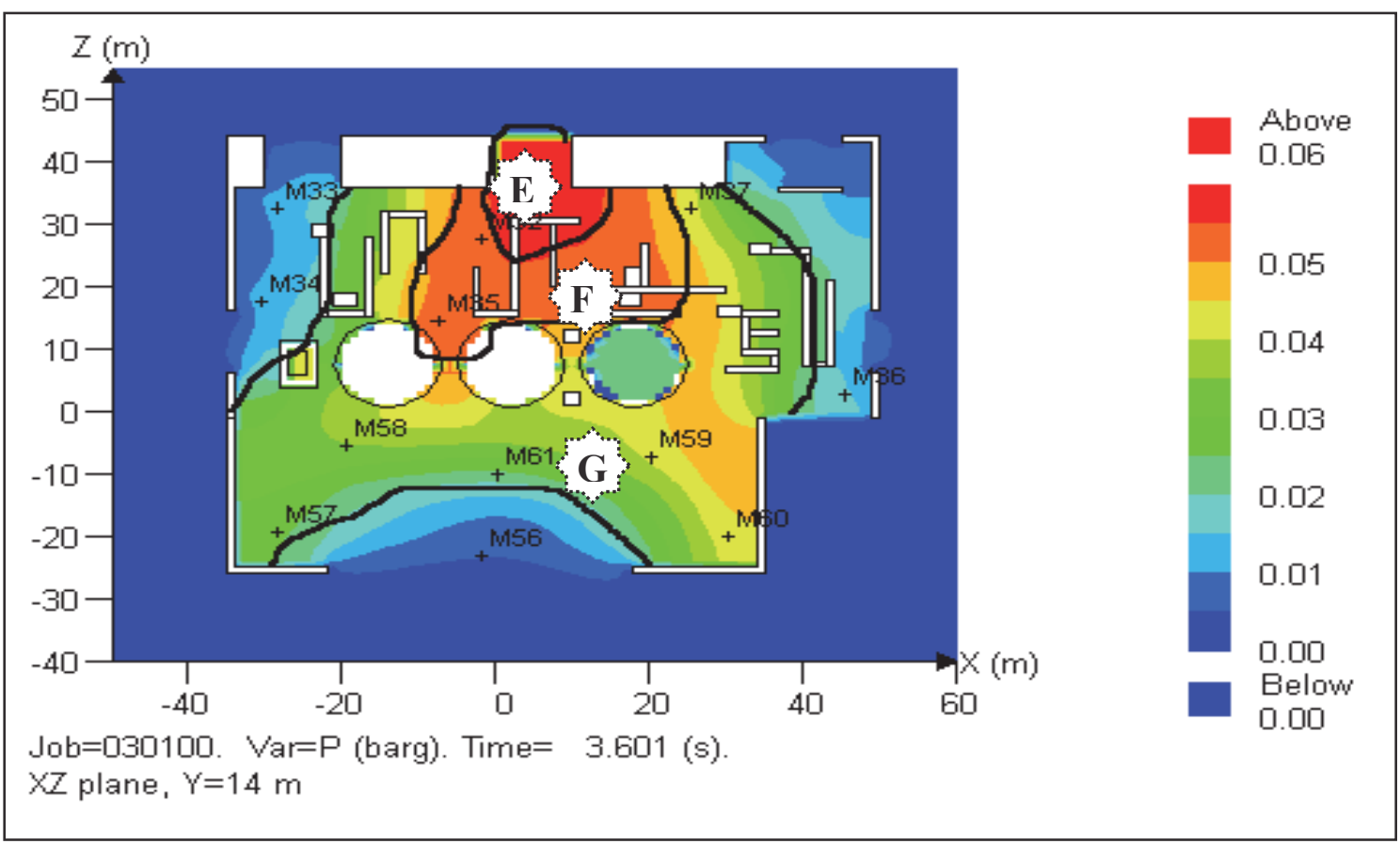

Figure 5.19 DESC pressure simulation from a plane view of the third floor, Module $(2,3)$, of the Imperial Sugar refinery explosion, after applying the QRMF.

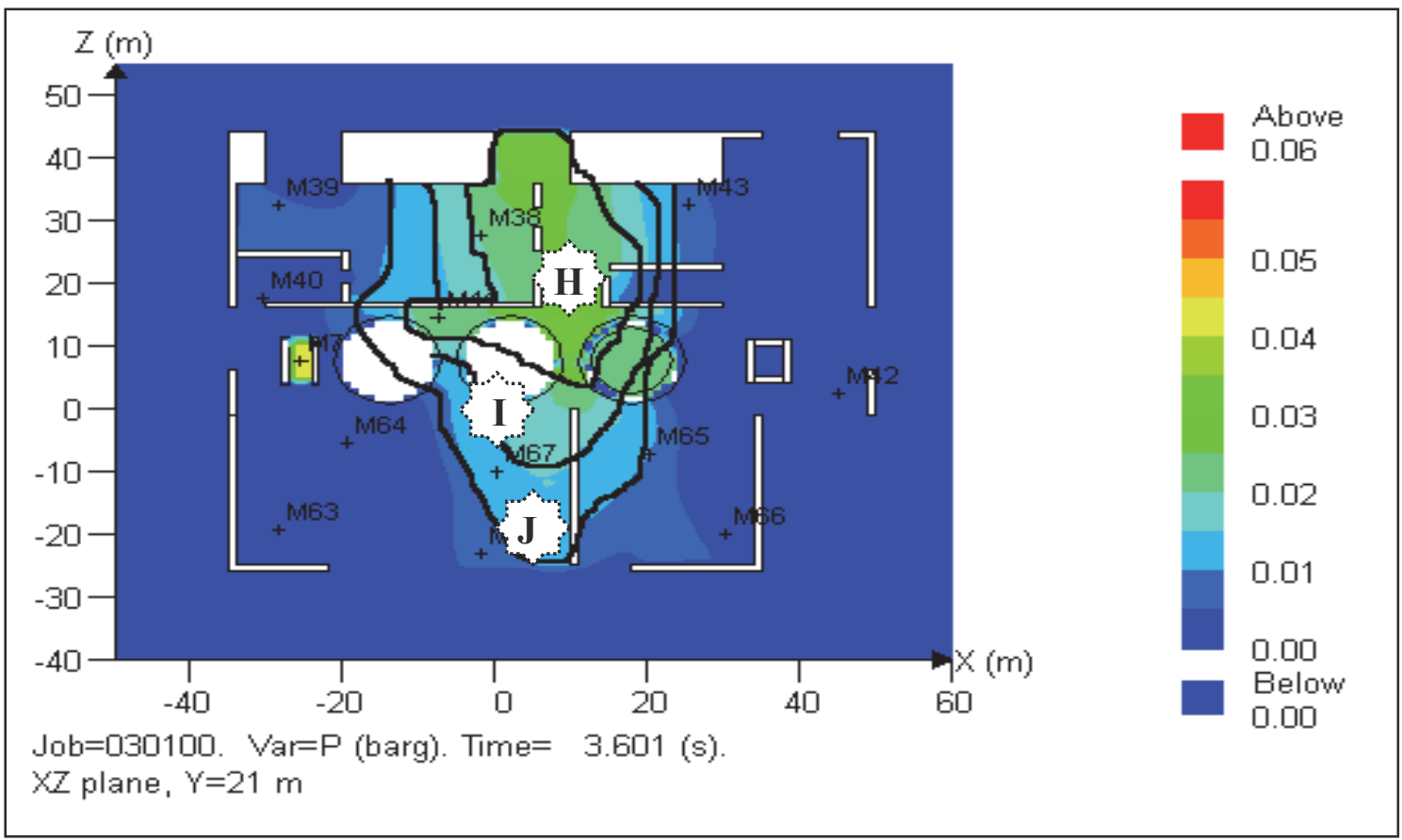

Figure 5.20 DESC pressure simulation on a plane view of the fourth floor, Module $(2,4)$, of the Imperial Sugar refinery explosion, after applying the QRMF. 
Figures 5.21 to 5.24 are plotted in DESC to show the pressure development during the explosion time. The pressure/time simulations were recorded by the local monitoring points (M2 - M66) and reflect Figures 5.17 to 5.20, respectively. The explosion started and ended nearly at the same time (an $8 \mathrm{~s}$ duration) across all four floors, as can be seen in the Figures 5.21 to 5.24. The maximum explosion pressure exceeded the opening panels' pressure, $0.05 \operatorname{bar}(\mathrm{g})$, to reach $0.06 \operatorname{bar}(\mathrm{g})$ because of the relatively high $\mathrm{K}_{\text {St. }}$ value with respect to the venting areas. However, the $\mathrm{P}_{\max }$ was still under the destruction pressure value of $0.07-7.0 \mathrm{bar}(\mathrm{g})$. The pressure took about $5 \mathrm{~s}$ to entirely release.

Figures 5.21 to 5.24 also show that the explosion took longer to start and had a longer duration compared to the explosion before applying the QRMF because of the effect of the decreased dust concentration (from $500 \mathrm{~g} / \mathrm{m}^{3}$ to $250 \mathrm{~g} / \mathrm{m}^{3}$ ) and the lower wall vent relief pressure, from $0.2 \operatorname{bar}(\mathrm{g})$ to $0.05 \mathrm{bar}(\mathrm{g})$.

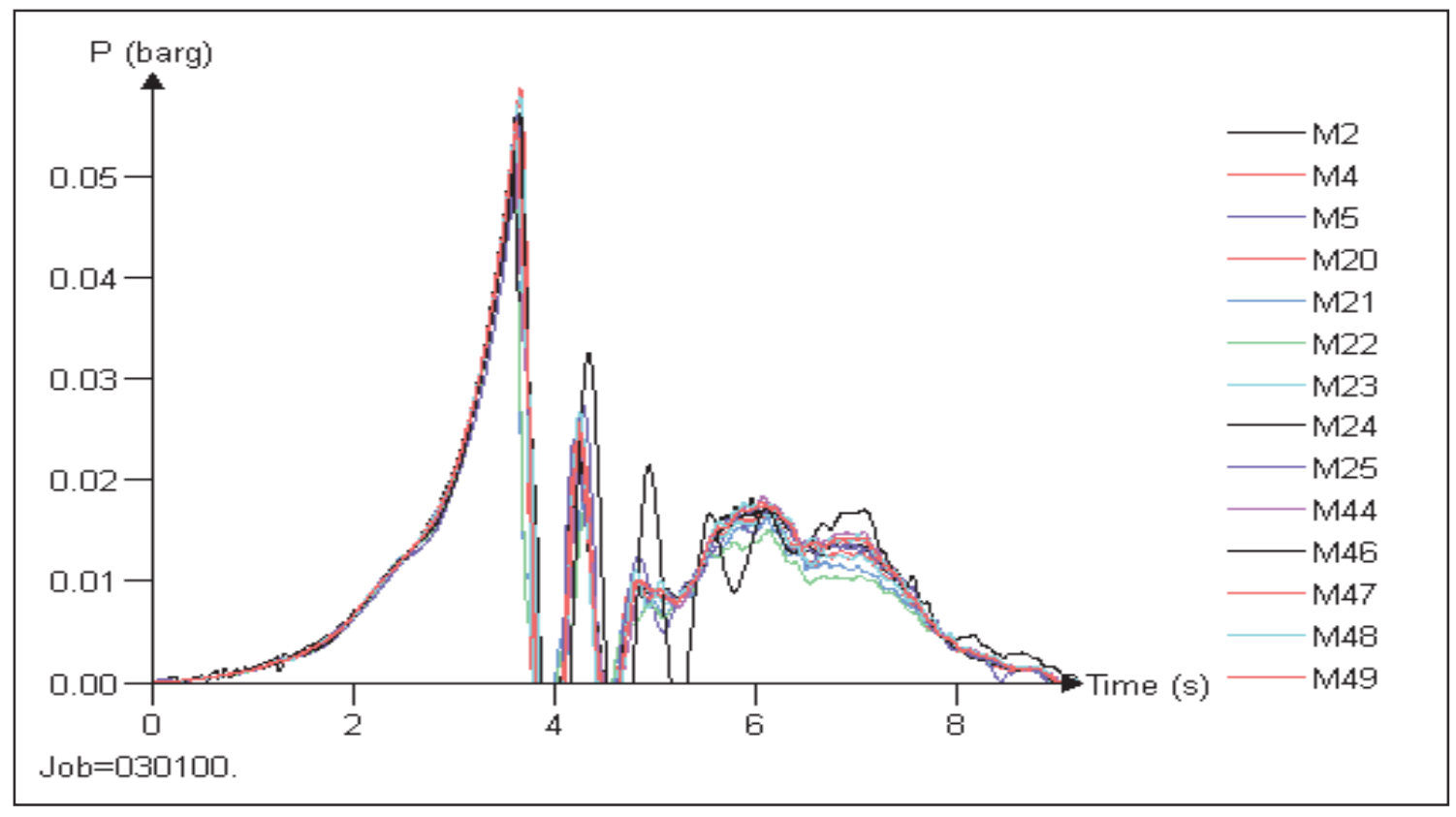

Figure 5.21 DESC pressure/time simulation at monitor points on the first floor, Module $(2,1)$, of the Imperial Sugar refinery explosion, after applying the QRMF. 


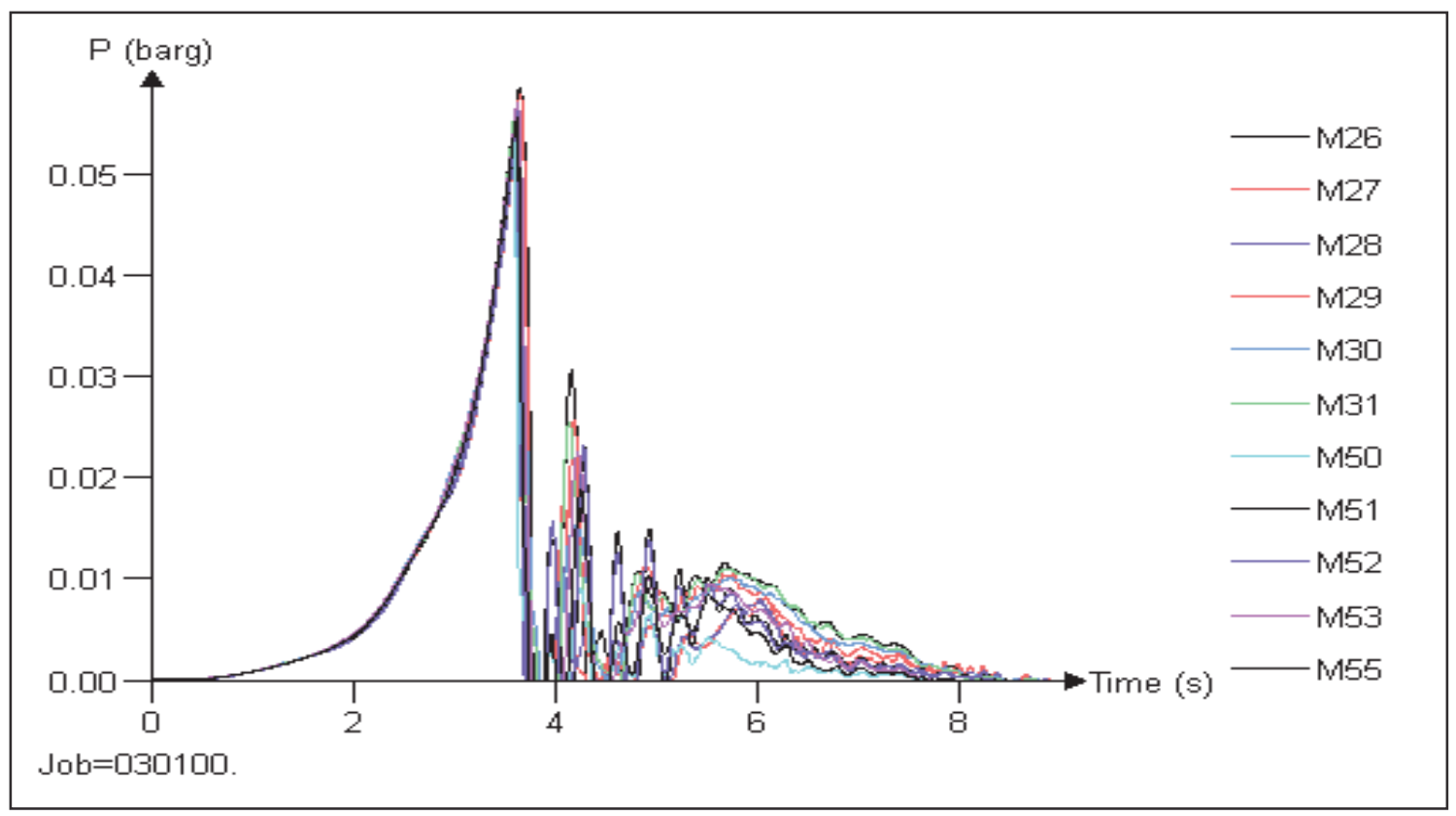

Figure 5.22 DESC pressure/time simulation at monitor points on the second floor, Module $(2,2)$, of the Imperial Sugar refinery explosion, after applying the QRMF.

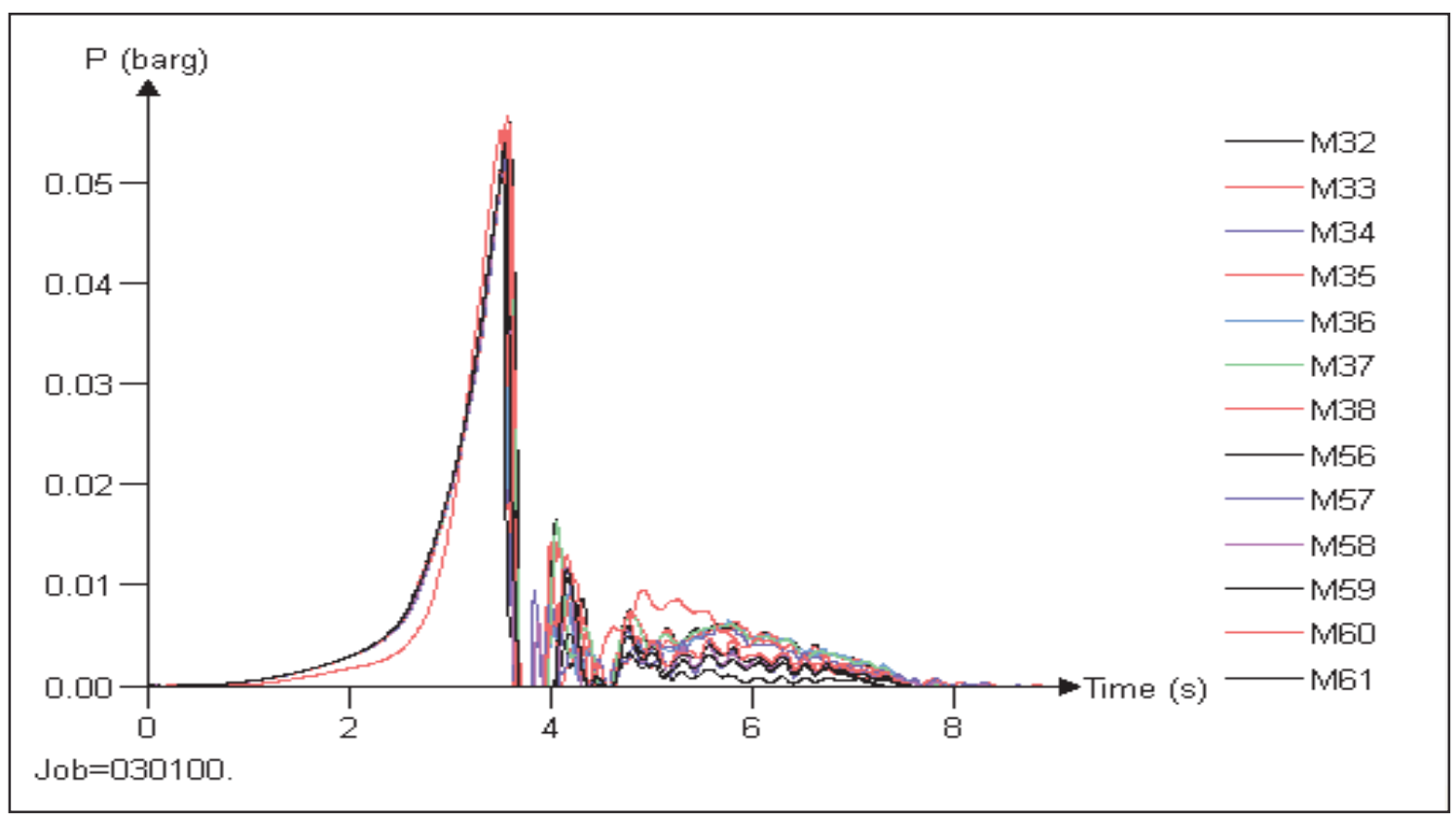

Figure 5.23 DESC pressure/time simulation at the monitor points on the third floor, Module $(2,3)$, of the Imperial Sugar refinery explosion, after applying the QRMF. 


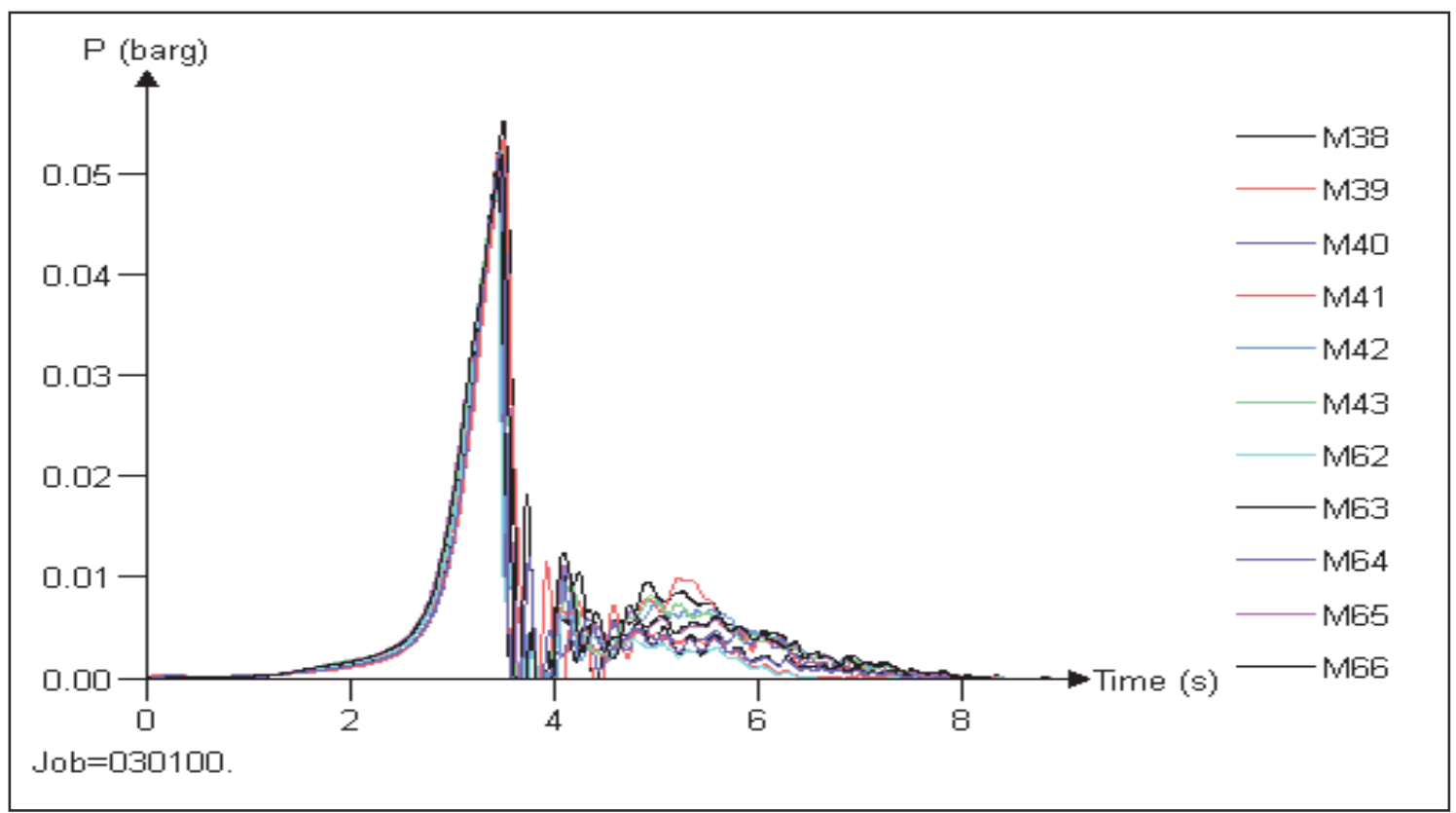

Figure 5.24 DESC pressure/time simulation at monitor points on the fourth floor, Module $(2,4)$, of the Imperial Sugar refinery explosion, after applying the QRMF.

Explosion pressure, the corresponding Probit value (Y), and the damage percentage for each zone after applying the QRMF are presented in Table 5.18. Table 5.18 shows slight damage occurred after the risk controls were applied, which clearly indicates the framework's validity in assessing and reducing the potential impact of dust and hybrid mixture explosions. 
Table 5.18 Estimated Probit damage percentages caused by explosion overpressure of incident outcome cases in the simulated refinery.

\begin{tabular}{|c|c|c|c|}
\hline $\begin{array}{c}\text { Incident } \\
\text { outcome case }\end{array}$ & $\begin{array}{c}\mathbf{P}_{\max } \\
{[\mathbf{b a r}(\mathbf{g})]}\end{array}$ & $\mathbf{Y}$ & $\begin{array}{c}\text { Damage } \\
\text { percentage (\%) }\end{array}$ \\
\hline A & 0.055 & 1.35 & $1.31 * 10^{-2}$ \\
\hline B & 0.060 & 1.60 & $3.37 * 10^{-2}$ \\
\hline C & 0.060 & 1.60 & $3.37 * 10^{-2}$ \\
\hline D & 0.055 & 1.35 & $1.31 * 10^{-2}$ \\
\hline E & 0.060 & 1.60 & $3.37 * 10^{-2}$ \\
\hline F & 0.055 & 1.35 & $1.31 * 10^{-2}$ \\
\hline G & 0.040 & 0.42 & $2.33 * 10^{-4}$ \\
\hline H & 0.030 & 0 & No likely damage \\
\hline I & 0.020 & 0 & No likely damage \\
\hline J & 0.015 & 0 & No likely damage \\
\hline
\end{tabular}

\section{ii) Likelihood calculations}

Table 5.19 compares the probabilities of occurrence of the basic events of the Imperial Sugar refinery explosion before and after applying the QRMF. Some of the basic events in the Imperial Sugar fault tree flowchart (Figure 5.15) have been recalculated to address the applied safety controls. Figure 5.25 showed the estimated probability of the dust explosion in the refinery after applying the QRMF, reducing the probability of occurrence of some basic events. The modified basic events were generated according to the following reasoning:

- When the dust concentration probability is minimized to 0.0325 , the dust collection receivers will collect less dust, and airborne dust particles will also be minimal.

- Removing the steel cover (the enclosure) will reduce the primary explosion risk and shock-wave probability, and minimize the total confinement probability.

- Applying detailed and written procedural safety (in writing), such as creating checklist, routinely evaluating dust accumulation in hidden areas, applying 
Table 5.19 The estimated failure rate of the explosion's basic events at the Imperial Sugar refinery before and after applying the QRMF.

\begin{tabular}{|c|c|c|c|c|c|c|c|c|}
\hline \multirow[b]{2}{*}{ No } & \multirow{2}{*}{\multicolumn{3}{|c|}{ Event (Gate) }} & \multirow{2}{*}{\multicolumn{2}{|c|}{ Basic event }} & \multirow{3}{*}{$\begin{array}{c}\begin{array}{c}\text { failure } \\
\text { rate } \\
(\lambda)\end{array} \\
0.033 \\
\end{array}$} & \multicolumn{2}{|c|}{ Probability $[P(t)]$} \\
\hline & & & & & & & \multirow{2}{*}{$\begin{array}{c}\begin{array}{c}\text { Before } \\
\text { applying } \\
\text { QRMF }\end{array} \\
0.0325\end{array}$} & \multirow{2}{*}{$\begin{array}{c}\begin{array}{c}\text { After } \\
\text { applying } \\
\text { QRMF }\end{array} \\
0.0325\end{array}$} \\
\hline 1 & \multirow{23}{*}{ 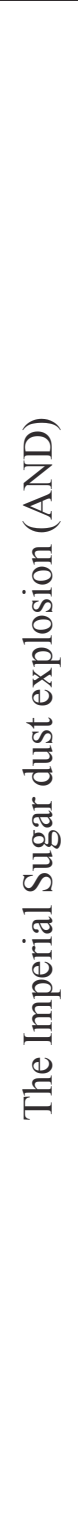 } & \multirow{16}{*}{ 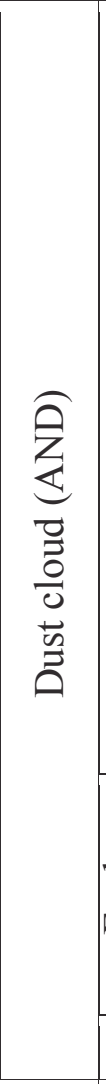 } & \multirow{12}{*}{ 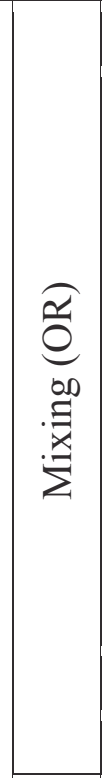 } & \multicolumn{2}{|c|}{ Bagging and filling / FIBCs } & & & \\
\hline 2 & & & & \multicolumn{2}{|c|}{ Dust collecting receivers } & 0.067 & 0.0650 & 0.0325 \\
\hline 3 & & & & \multirow{4}{*}{ 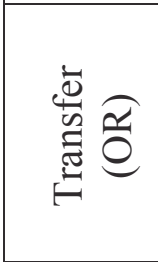 } & Silos and bins & 0.033 & 0.0325 & 0.0325 \\
\hline 4 & & & & & Cartridge & 0.033 & 0.0325 & 0.0325 \\
\hline 5 & & & & & Bag houses & 0.033 & 0.0325 & 0.0325 \\
\hline 6 & & & & & Others & - & 0.0010 & 0.0010 \\
\hline 7 & & & & \multirow{4}{*}{ 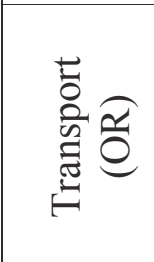 } & Belt conveyors & - & 0.2500 & 0.2500 \\
\hline 8 & & & & & Elevators & - & 0.2500 & 0.2500 \\
\hline 9 & & & & & Screw conveyors & - & 0.2500 & 0.2500 \\
\hline 10 & & & & & Others & - & 0.0010 & 0.0010 \\
\hline 11 & & & & \multicolumn{2}{|c|}{ Shock waves } & 0.067 & 0.0650 & 0.0325 \\
\hline 12 & & & & \multicolumn{2}{|r|}{ Others } & - & 0.0010 & 0.0010 \\
\hline 13 & & & \multirow{3}{*}{ 氞 } & \multicolumn{2}{|c|}{ Combustible material } & - & 0.9900 & 0.9900 \\
\hline 14 & & & & Conce & ntration $>$ MEC & - & 0.9900 & 0.0325 \\
\hline 15 & & & & $\begin{array}{l}\text { Part } \\
\text { expl }\end{array}$ & $\begin{array}{l}\text { le size < non- } \\
\text { sible diameter }\end{array}$ & - & 0.2500 & 0.0325 \\
\hline 16 & & & \multicolumn{3}{|c|}{ Oxidant concentration $>$ LOC } & - & 0.8000 & 0.8000 \\
\hline 17 & & \multirow{6}{*}{ 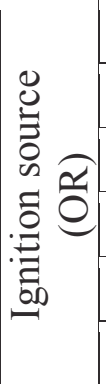 } & \multicolumn{3}{|c|}{ Mechanical impact sparks } & - & 0.0650 & 0.0325 \\
\hline 18 & & & \multicolumn{3}{|c|}{ Friction sparks } & - & 0.0650 & 0.0650 \\
\hline 19 & & & \multicolumn{3}{|c|}{ Flames and direct heat } & 0.067 & 0.0650 & 0.0325 \\
\hline 20 & & & \multicolumn{3}{|c|}{ Electrical sparks } & 0.067 & 0.0650 & 0.0650 \\
\hline 21 & & & \multicolumn{3}{|c|}{ Static electricity } & 0.067 & 0.0650 & 0.0325 \\
\hline 22 & & & \multicolumn{3}{|c|}{ Others } & - & 0.0010 & 0.0010 \\
\hline 23 & & \multicolumn{4}{|c|}{ Total confinement } & - & 0.9900 & 0.2500 \\
\hline & & & & plocion & Ohbility ( oftan & vin & ORMF & $4 * 10^{-5}$ \\
\hline
\end{tabular}




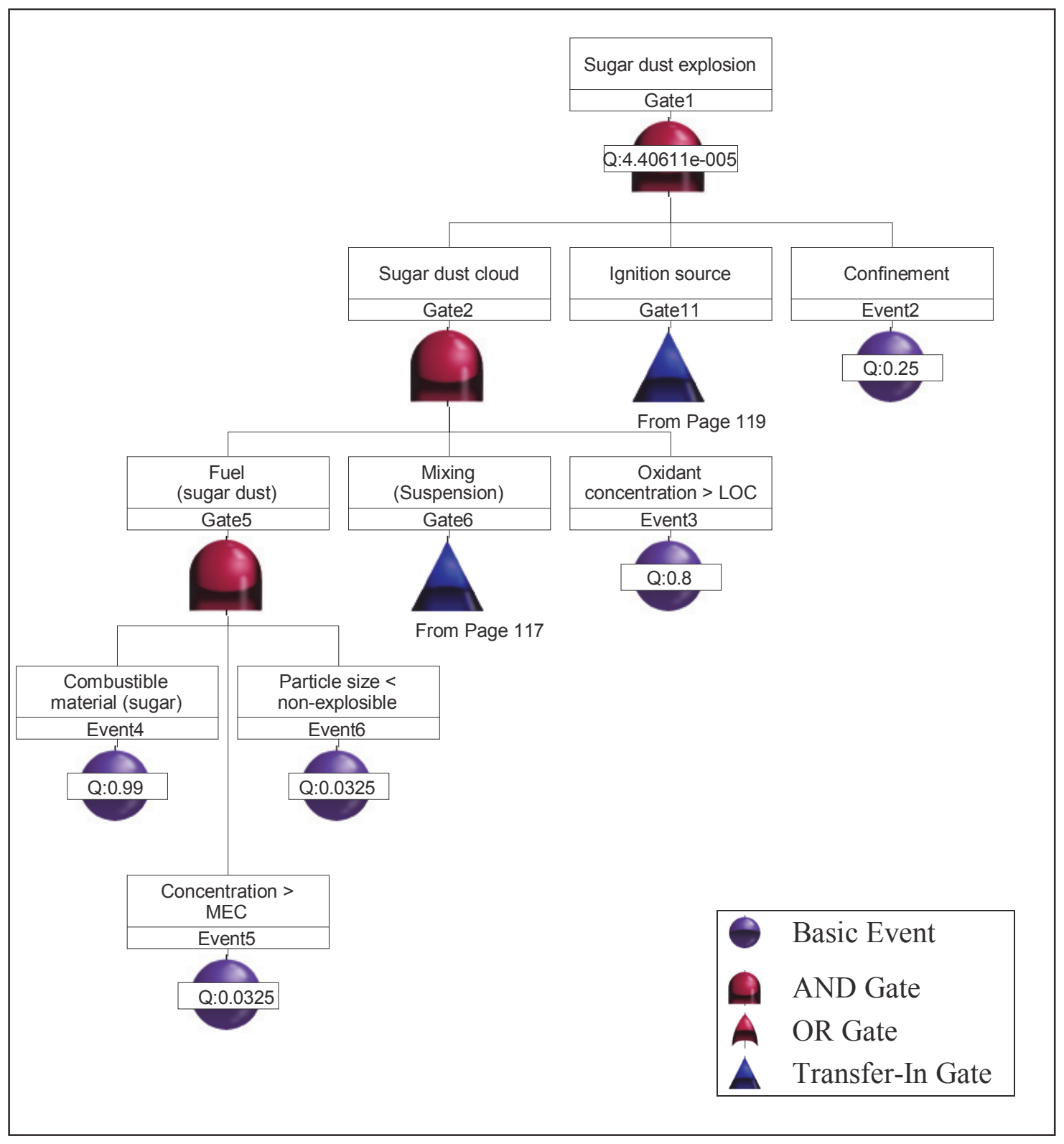

Figure 5.25 Fault Tree Analysis flowchart of the Imperial Sugar refinery explosion. 


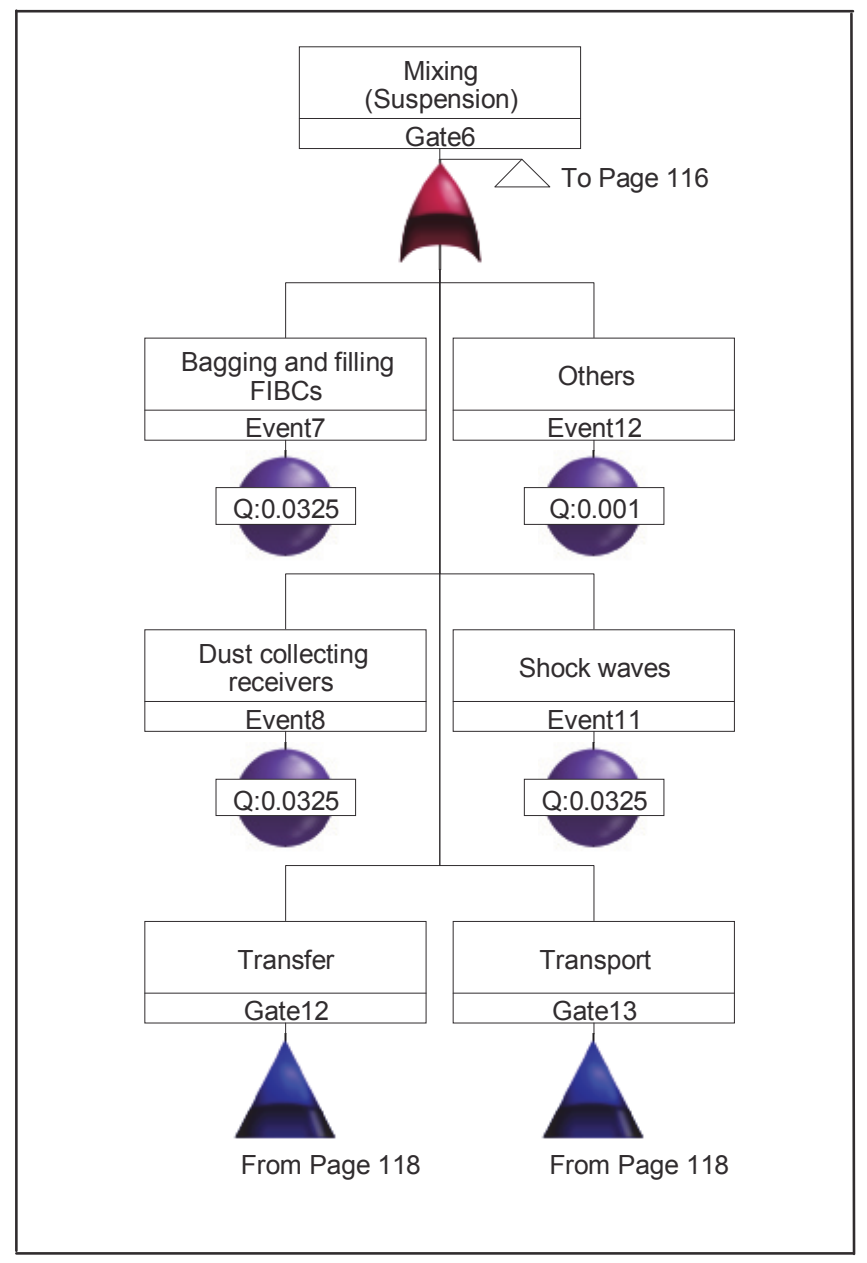



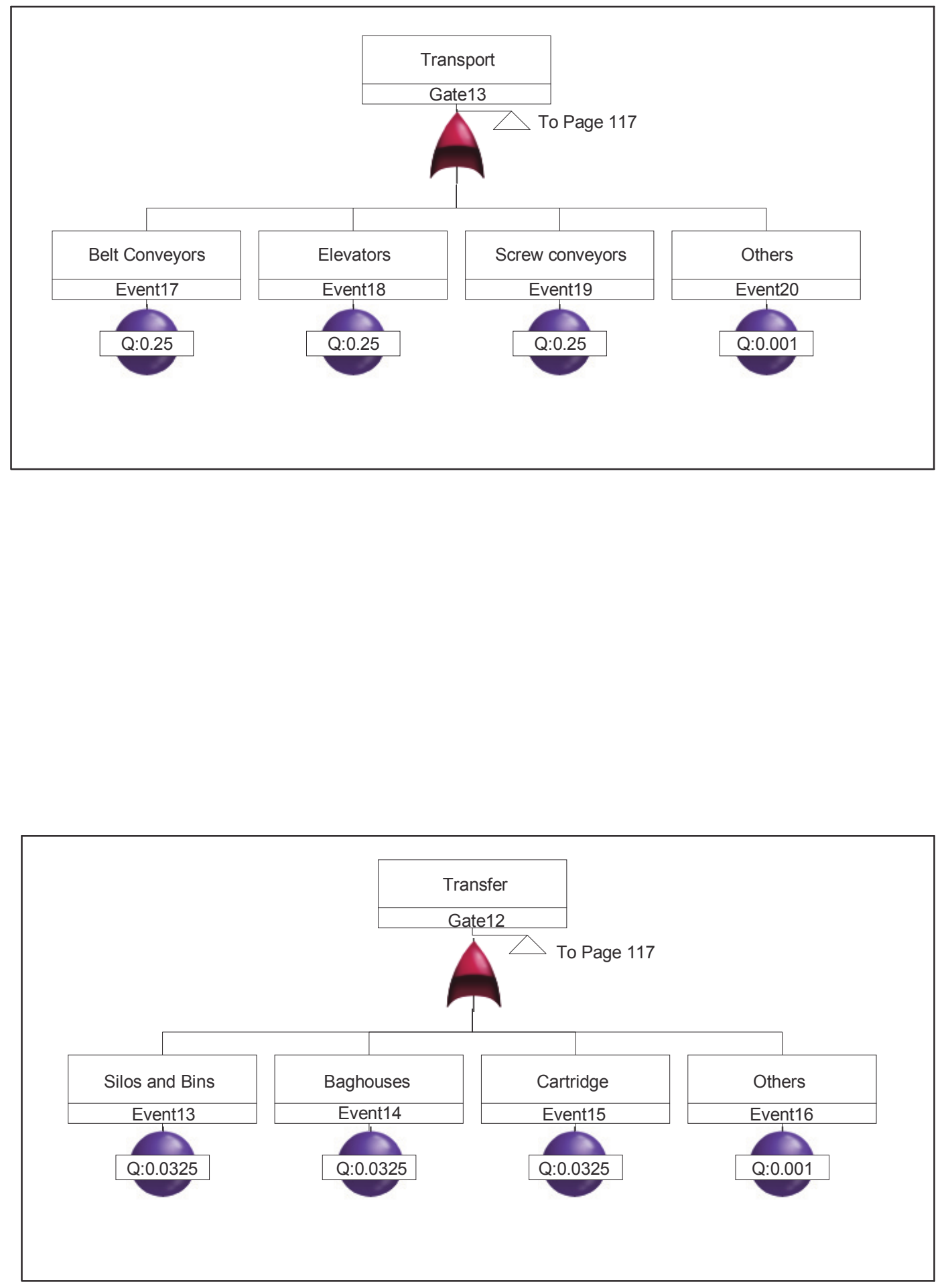


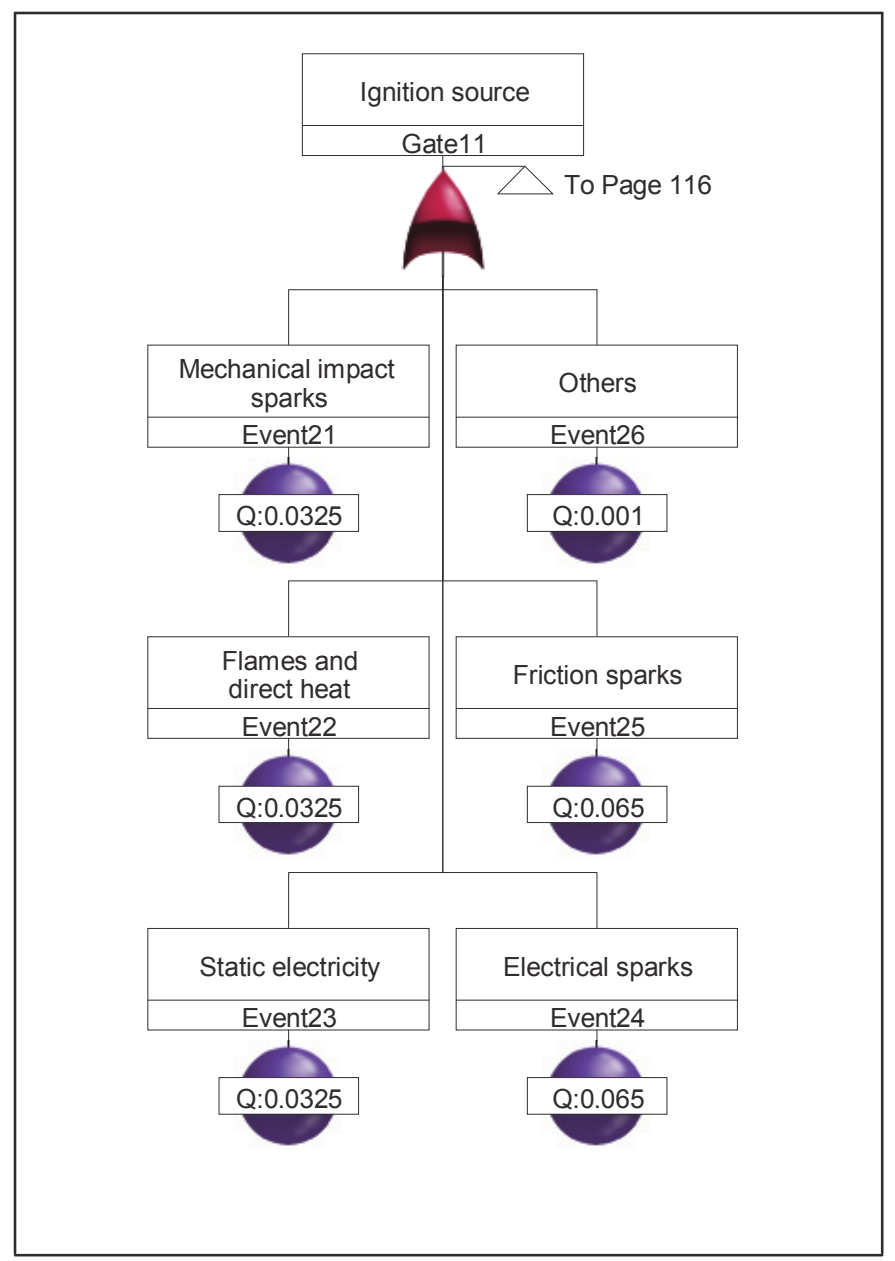


frequently and proper cleaning method, ensuring equipment grounding are in places, hot permit, flames and direct heat, etc.

\section{Risk estimation}

Risk estimation is a function of the severity of consequences and the probability of occurrence, as defined in Equation 3.1. As Table 5.18 shows, slight damage occurred after the QRMF was applied, and thus the risk estimation (individual and societal risks) is insignificant.

The probability of occurrence is also very low, at $4.4 * 10^{-5}$ per year. This means that a dust explosion might occur once every 22,727 years, which is an acceptable probability of occurrence.

- Individual risk

Individual risk re-calculated for the four floors (Module $(2, i)$, where $i=1,2,3,4)$, to estimate the QRMF's effect on the refinary.

Tables 5.20 to 5.23 show the estimated number of fatalities at each defined explosion pressure zone $(\mathrm{A}-\mathrm{R})$, and the average individual risk at each floor.

Table 5.20 Individual risk calculations after applying the QRMF for the first floor.

\begin{tabular}{|c|c|c|c|c|c|}
\hline $\begin{array}{c}\text { Incident } \\
\text { outcome case }\end{array}$ & $\begin{array}{c}\mathbf{f}_{\mathbf{i}} \\
\text { (per year) }\end{array}$ & $\mathbf{P}_{\mathbf{f}, \mathbf{i}}$ & $\mathbf{f}_{\mathbf{i}} * \mathbf{P}_{\mathbf{f}, \mathbf{i}}$ & $\begin{array}{c}\text { No. of } \\
\text { workers }\end{array}$ & $\begin{array}{l}\text { Estimated no. } \\
\text { of fatalities }(\mathrm{N})\end{array}$ \\
\hline A & $4.4 * 10^{-5}$ & $1.31 * 10^{-4}$ & $5.76 * 10^{-9}$ & 25 & 0 \\
\hline $\mathrm{B}$ & $4.4 * 10^{-5}$ & $3.37 * 10^{-4}$ & $1.48 * 10^{-8}$ & 6 & 0 \\
\hline \multicolumn{6}{|c|}{ Average individual risk on the first floor, calculated using equation 3.9: } \\
\hline \multicolumn{6}{|c|}{$\underline{(25) * 5.76 * 10^{-9}+(6) * 1.48 * 10^{-8}}$} \\
\hline
\end{tabular}


Table 5.21 Individual risk calculations after applying the QRMF for the second floor.

\begin{tabular}{|c|c|c|c|c|c|}
\hline $\begin{array}{c}\text { Incident } \\
\text { outcome case }\end{array}$ & $\begin{array}{c}\mathbf{f}_{\mathbf{i}} \\
(\text { per year) }\end{array}$ & $\mathbf{P}_{\mathrm{f}, \mathbf{i}}$ & $\mathbf{f}_{\mathbf{i}} * \mathbf{P}_{\mathbf{f}, \mathbf{i}}$ & $\begin{array}{c}\text { No. of } \\
\text { workers }\end{array}$ & $\begin{array}{c}\text { Estimated no. } \\
\text { of fatalities (N) }\end{array}$ \\
\hline $\mathrm{C}$ & $4.4 * 10^{-5}$ & $3.37 * 10^{-4}$ & $1.48 * 10^{-8}$ & 5 & 0 \\
\hline $\mathrm{D}$ & $4.4 * 10^{-5}$ & $1.31 * 10^{-4}$ & $5.76 * 10^{-9}$ & 13 & 0 \\
\hline
\end{tabular}

Average individual risk on the second floor, calculated using Equation 3.9:

$I \operatorname{Ravg} 2=$

$$
\frac{(5) * 1.48 * 10^{-8}+(13) * 5.76 * 10^{-9}}{18}=8.3 * 10^{-9}
$$

Table 5.22 Individual risk calculations after applying the QRMF for the third floor

\begin{tabular}{|c|c|c|c|c|c|}
\hline $\begin{array}{c}\text { Incident } \\
\text { outcome case }\end{array}$ & $\begin{array}{c}\mathbf{f}_{\mathbf{i}} \\
\text { (per year) }\end{array}$ & $\mathbf{P}_{\mathbf{f}, \mathbf{i}}$ & $\mathbf{f}_{\mathbf{i}} * \mathbf{P}_{\mathbf{f}, \mathbf{i}}$ & $\begin{array}{c}\text { No. of } \\
\text { workers }\end{array}$ & $\begin{array}{c}\text { Estimated no. of } \\
\text { fatalities (N) }\end{array}$ \\
\hline $\mathrm{E}$ & $4.4 * 10^{-5}$ & $3.37 * 10^{-4}$ & $1.48 * 10^{-8}$ & 3 & 0 \\
\hline $\mathrm{F}$ & $4.4 * 10^{-5}$ & $1.31 * 10^{-4}$ & $5.76 * 10^{-9}$ & 10 & 0 \\
\hline $\mathrm{G}$ & $4.4 * 10^{-5}$ & $2.33 * 10^{-6}$ & $1.03 * 10^{-10}$ & 26 & 0 \\
\hline
\end{tabular}

Average individual risk on the third floor, calculated using Equation 3.9:

IRavg $=$

$$
\frac{(3) * 1.48 * 10^{-8}+(10) * 5.76 * 10^{-9}+(26) * 1.03 * 10^{-10}}{39}=2.7 * 10^{-9}
$$


Table 5.23 Individual risk calculations after applying the QRMF for the fourth floor

\begin{tabular}{|c|c|c|c|c|c|}
\hline $\begin{array}{c}\text { Incident } \\
\text { outcome case }\end{array}$ & $\begin{array}{c}\mathbf{f}_{\mathbf{i}} \\
\text { (per year) }\end{array}$ & $\mathbf{P}_{\mathbf{f}, \mathbf{i}}$ & $\mathbf{f}_{\mathbf{i}} * \mathbf{P}_{\mathbf{f}, \mathbf{i}}$ & $\begin{array}{c}\text { No. of } \\
\text { workers }\end{array}$ & $\begin{array}{c}\text { Estimated no. } \\
\text { of fatalities (N) }\end{array}$ \\
\hline $\mathrm{H}$ & $4.4 * 10^{-5}$ & 0 & 0 & 5 & 0 \\
\hline $\mathrm{I}$ & $4.4 * 10^{-5}$ & 0 & 0 & 10 & 0 \\
\hline $\mathrm{J}$ & $4.4 * 10^{-5}$ & 0 & 0 & 25 & 0 \\
\hline
\end{tabular}

The average individual risk for the entire refinery, after QRMF, is:

$$
\begin{aligned}
& I R_{\text {avg } T} \\
& =\frac{\left\{(6+5+3) * 1.48 * 10^{-8}+(25+13+10) * 5.76 * 10^{-9}+(26) * 1.03 * 10^{-10}\right\}}{135} \\
& =3.6 * 10^{-9}
\end{aligned}
$$

- Location-specific individual risk (LSIR)

The LSIR for each floor has been re-calculated from Equation 3.5 to identify the hypothetical risk, after applying the QRMF, at each location.

$$
\begin{aligned}
& \operatorname{LSIR}_{1}=1.48 * 10^{-8}+5.76 * 10^{-9}=2.06 * 10^{-8} \\
& \operatorname{LSIR}_{2}=1.48 * 10^{-8}+5.76 * 10^{-9}=2.06 * 10^{-8} \\
& \operatorname{LSIR}_{3}=1.48 * 10^{-8}+5.76 * 10^{-9}+1.03 * 10^{-10}=2.07 * 10^{-8} \\
& \mathrm{LSIR}_{4}=0.0
\end{aligned}
$$

The total LSIR is re-calculated as:

$$
\operatorname{LSIR}_{\mathrm{T}}=2.06 * 10^{-8}+2.06 * 10^{-8}+2.07 * 10^{-8}=6.2 * 10^{-8}
$$


- Individual - specific individual risk (ISIR)

The ISIR for each floor has been calculated from Equation 3.7 to identify the risk at different locations, after applying the QRMF, taking into account employee working time.

$\mathrm{ISIR}_{1}=2.06 * 10^{-8} * 8 / 24=0.69 * 10^{-8}$

$\operatorname{ISIR}_{2}=2.06 * 10^{-8} * 8 / 24=0.69 * 10^{-8}$

$\mathrm{ISIR}_{3}=2.07 * 10^{-8} * 8 / 24=0.69 * 10^{-8}$

$\mathrm{ISIR}_{4}=0$

The total individual-specific individual risk (ISIR) is:

$I S I R_{T}=\operatorname{LSIR}_{T} * P_{L}=6.2 * 10^{-8} * \frac{8}{24}=2.07 * 10^{-8}$

- Fatal accident rate (FAR)

FAR is re-calculated, as well, from the average individual risk for the exposed employee population from Equation 3.3.

Fatal accident rate $(\mathrm{FAR})=\operatorname{ISIR}_{\mathrm{T}} * 10^{8} / H=2.07 * 10^{-8} * 10^{8} /(135 * 2000)=7.7 *$ $10^{-6}$ fatalities $/ 10^{8}$ man-hours of exposure

- $A L A R P$

As shown in Figure 5.26, and according to the HSE (Health and Safety Executive), ALARP (as low as reasonably practicable) range is from $1 * 10^{-6}$ to $1 * 10^{-3}$. The acceptable risk to the public per year is in the region of $1 * 10^{-6}$ to $1 * 10^{-4}$. Therefore, the value of $1.6 * 10^{-2}$ per year, which is the individual risk (IR) of the Imperial Sugar refinery before applying the conceptual framework, was within the unacceptable range. However, the individual and societal risks of the given case study after applying the safety controls are completely acceptable with IR equal to $3.6 * 10^{-9}$. These values show a significant reduction of the dust explosion probability, with the refinery becoming substantially safer with the new applied controls. 
Table 5.24 compares the risk measure results obtained before and after applying the QRMF controls. The numbers show that the total risk has been reduced for each single measure: the probability of occurrence has been reduced, along with the IR, the LSIR, the ISIR, and the FAR, which are completely safe.

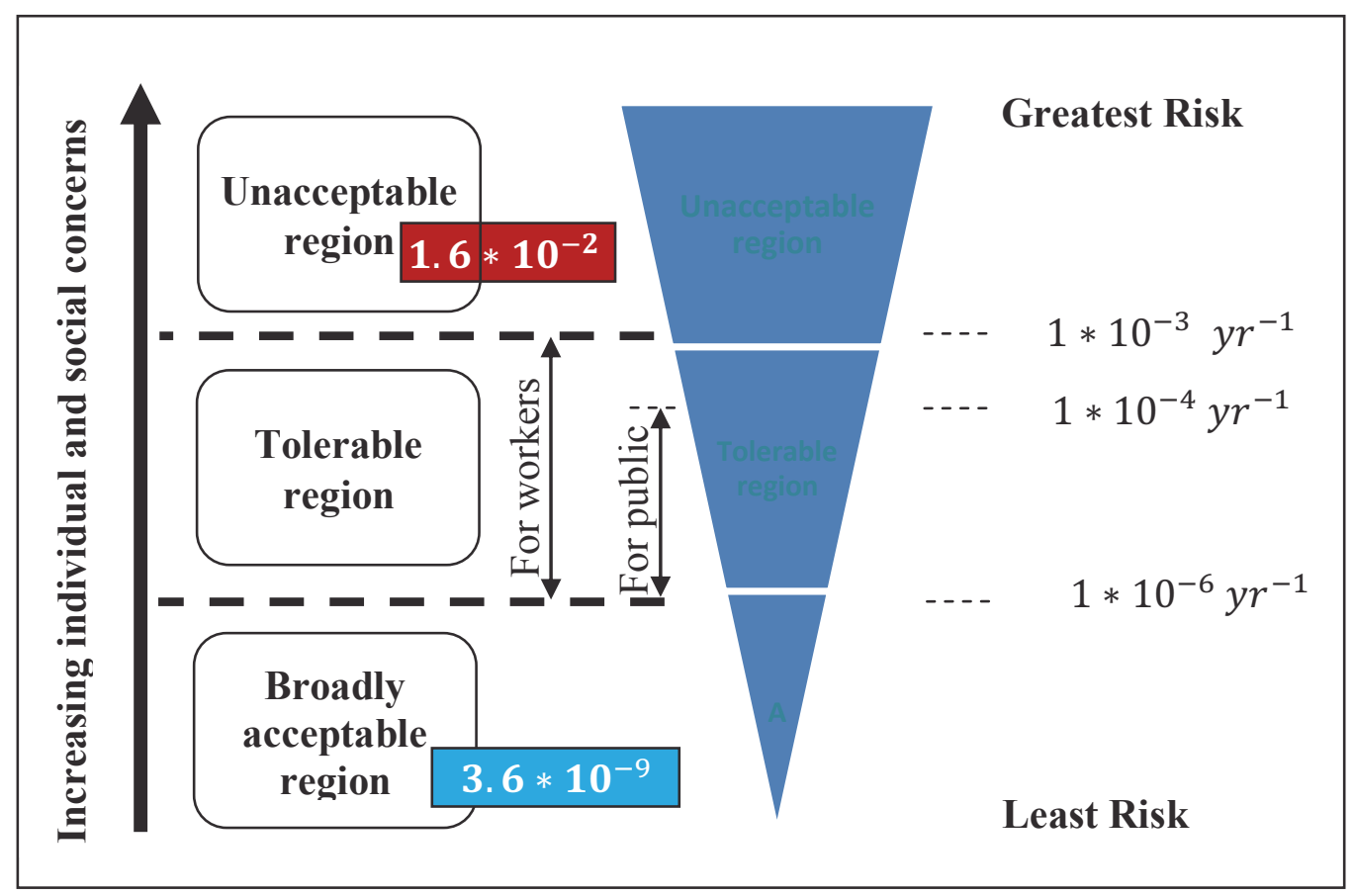

Figure 5.26 HSE frameworks for tolerability of risk (after IET, 2010).

Table 5.24 Summary of the individual risk results for the Imperial Sugar refinery explosion.

\begin{tabular}{|c|c|c|c|c|c|}
\hline & $\begin{array}{c}\text { Probability } \\
\text { of } \\
\text { occurrence }\end{array}$ & $\boldsymbol{I R}_{\text {avg }}$ & $\boldsymbol{L S I R}$ & $\boldsymbol{I S I R}$ & $\begin{array}{c}\boldsymbol{F A R} \\
\left(\boldsymbol{y r}^{-\mathbf{1}}\right)\end{array}$ \\
$\begin{array}{c}\text { (Fatalities/10 } \\
\text { of exposure } \mathbf{~ h r s}\end{array}$ \\
\hline $\begin{array}{c}\text { Before applying } \\
\text { QRMF }\end{array}$ & $3.8 * 10^{-2}$ & $1.6 * 10^{-2}$ & $3.0 * 10^{-1}$ & $1.0 * 10^{-1}$ & 36 \\
\hline $\begin{array}{c}\text { After applying } \\
\text { QRMF }\end{array}$ & $4.4 * 10^{-5}$ & $3.6 * 10^{-9}$ & $6.2 * 10^{-8}$ & $2.07 * 10^{-8}$ & $7.7 * 10^{-6}$ \\
\hline
\end{tabular}




\subsection{Semabla Grain Storage Hybrid Mixture Explosion}

\subsubsection{Semabla installation description}

Semabla boasted the largest grain storage installations in France. The complex was located in the port area of Blaye and consisted of vertical silo units with a capacity of 40,000 ton, along with some nearby warehouse buildings with a 90,000-ton capacity, as shown in Figure 5.27. The number of workers at the site was 21, and the silo facility was surrounded by a low wall at a distance of $25 \mathrm{~m}$ (Masson, 1998).

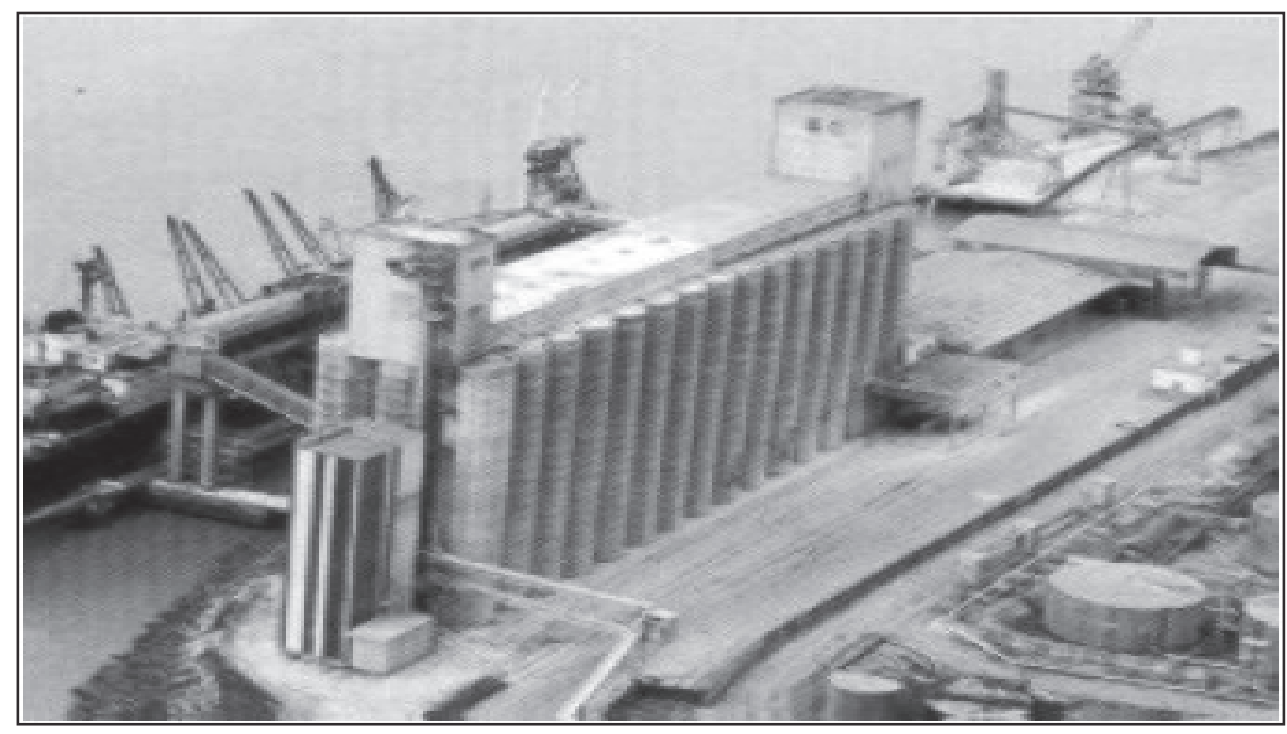

Figure 5.27 View of the Semabla cells and warehouse-A storage units before the explosion (Masson, 1998).

The storage silo installation was divided into two groups of concrete cells. The first group consisted of 20 cells, and the second group of 24 cells. They were arranged in three rows, as shown in Figure 5.28. Each cylindrical cell was $6.20 \mathrm{~m}$ in diameter and $33 \mathrm{~m}$ in height. The interspaces between the cells were also used to store grain and were kept open, except for the two interspaces between the two groups of cells (Masson, 1998). 


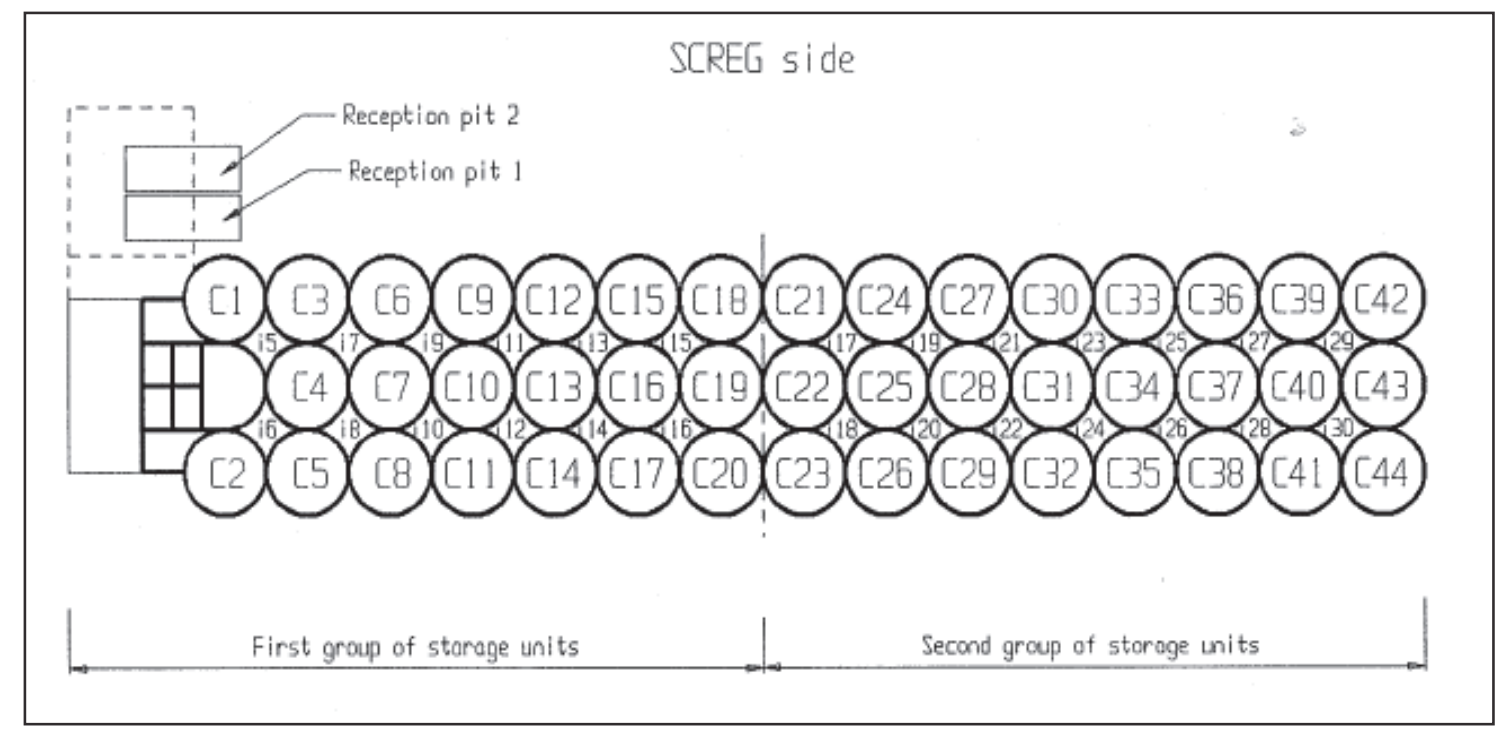

Figure 5.28 The Semabla identification of storage cells (Masson, 1998).

In addition, there were two vertical towers at the ends of the silo for the grading system and cleaner separators. They were connected to each other by a gallery located above the cells. An additional metal-framed tower, close to the cells, was used for maize dryers. A series of conveyors inside the underground gallery connected the gallery with underground storage pits and transfer elevators. While there was a dust removal system (fans, filters, and a dust chamber), there were no protective devices for the workers to wear should an explosion or fire occur inside the facility (Masson, 1998).

\subsubsection{Explosion causes}

The investigation report by Masson (1998) suggested two possible causes: combustible gases from fermentation, and a dust-air explosion in the dust removal circuit. However, the report could not pinpoint the explosion's ignition source. Possible sources include an electric spark, friction, mechanical impact, and self-ignition (Masson, 1998). 


\subsubsection{Explosion event}

On August 20, 1997, an ignition spark reached a hybrid mixture cloud in a confined place (likely the top of the handling tower), causing an explosion (Masson, 1998).

In his report, Masson (1998) stated that some witnesses were certain that the explosion began at the top of the handling tower, propagated through the gallery on top of the silo, and then went downwards, as a flame jet, through the open interspaces between the two groups of cells to the working area. The flame jet also propagated inside warehouse-A. The first explosion possibly raised settled dust, including maize dust, which was handled in one of the towers, and other maize material that was being unloaded from a truck at the time of the explosion. The airborne dust caused a second explosion, leading to major destruction of the facilities, as seen in Figure 5.29.

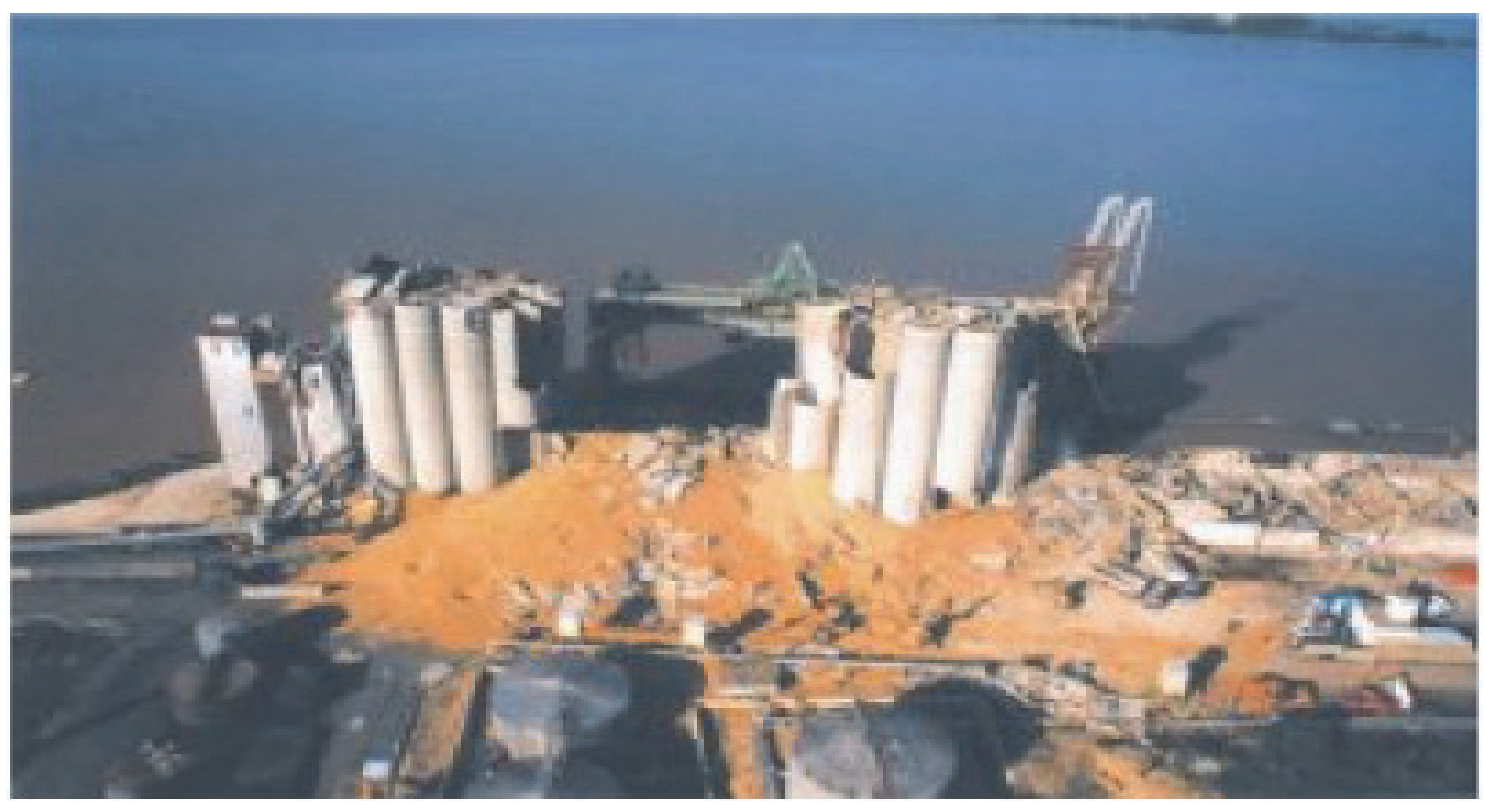

Figure 5.29 A view of the Semabla silo and warehouse-A storage facilities after the explosion (van der Voort et al., 2007). 


\subsubsection{Explosion consequences}

The explosion killed 11 people, injured one, and destroyed the storage cells at the centre and northern end of the silos. The bodies of ten workers were found in the buildings under the silo; the eleventh victim, a fisherman, was found outside the silo fence a few days after the explosion, buried under projected debris. Table 5.25 summarizes the human toll of injured, uninjured, and killed, along with their location. The stored grain spilled out over the $25 \mathrm{~m}$ space to the fence wall, while the projected debris reached more than $50 \mathrm{~m}$ (Masson, 1998). The total effect of the spilled grain and debris increased the probability of fatality in the surrounding area of the silo (within $25 \mathrm{~m}$ ) to $100 \%$, and the death probability beyond the silo boundary wall (within $50 \mathrm{~m}$ ) to $25 \%$.

Table 5.25 The number of injured, deceased, and uninjured people at the storage grain silo explosion (Masson, 1998).

\begin{tabular}{|l|c|c|c|c|}
\hline Location & Injured & Deceased & Uninjured & $\begin{array}{c}\text { Total no. of } \\
\text { people }\end{array}$ \\
\hline $\begin{array}{l}\text { Inside the } \\
\text { facility }\end{array}$ & 1 & 10 & 10 & 21 \\
\hline $\begin{array}{l}\text { Outside the } \\
\text { facility }\end{array}$ & 0 & 1 & 0 & 1 \\
\hline Total & 1 & 11 & 10 & 22 \\
\hline
\end{tabular}

\subsubsection{Applying the QRMF to the Semabla grain storage silo}

According to the accident consequences, the grain facility was at high risk due to a lack of safety management. This case study shows the severity of consequences that could occur in a similar storage facility, especially the high probability of existing hybrid mixture. For this reason, this facility was chosen as a case study to apply the QRMF to prevent/mitigate such explosions.

The following section describes the framework steps for the Semabla grain facility. 


\section{Identify hazard}

The Masson (1998) report identified the hazardous dust material as barley, wheat and maize, which were mixed with a fermented flammable gas. The maize characteristics have been identified experimentally, as given in Table F.4. (Appendix F) Maize starch has the most reactivity compared with wheat and barley, so it was chosen in the simulation as the worst explosion scenario that could occur.

\section{Understand hazard}

The explosion scenario was simulated using DESC software to find the explosion pressure zones (severity of consequences). FTA was used to calculate the probability of occurrence by using Relex software, risk calculations were done, and the risk evaluation obtained, as explained in detail in the following sections.

\section{iii) Consequences analysis}

\section{- DESC simulation}

Some details about the Semabla storage silo structure are not publicly available, such as information about emergency exit doors, worker areas, safety procedures, etc., due to company privacy rules. Thus, in DESC, the Semabla geometry and its facilities were built using 'best estimates'. Figure 5.30 shows the silo geometry built by DESC and the wall destruction openings. Figure 5.31 shows the side view of the Semabla silo installation and the modules' distribution on the silo geometery. Table 5.26 lists the wall openings covered by pressure relief panels (PPs) and their adjusted opening pressure. Figure 5.32 and Figure 5.33 indicate, by color, the explosion pressure zones at the top and side views, respectively. The red color represents the maximum pressure $\left(\mathrm{P}_{\max }\right)$ reached inside the work areas during the simulation. As indicated, the pressure reached $0.35 \mathrm{bar}(\mathrm{g})(3.5 *$ $10^{4} \mathrm{~Pa}$ ), which is very destructive. 


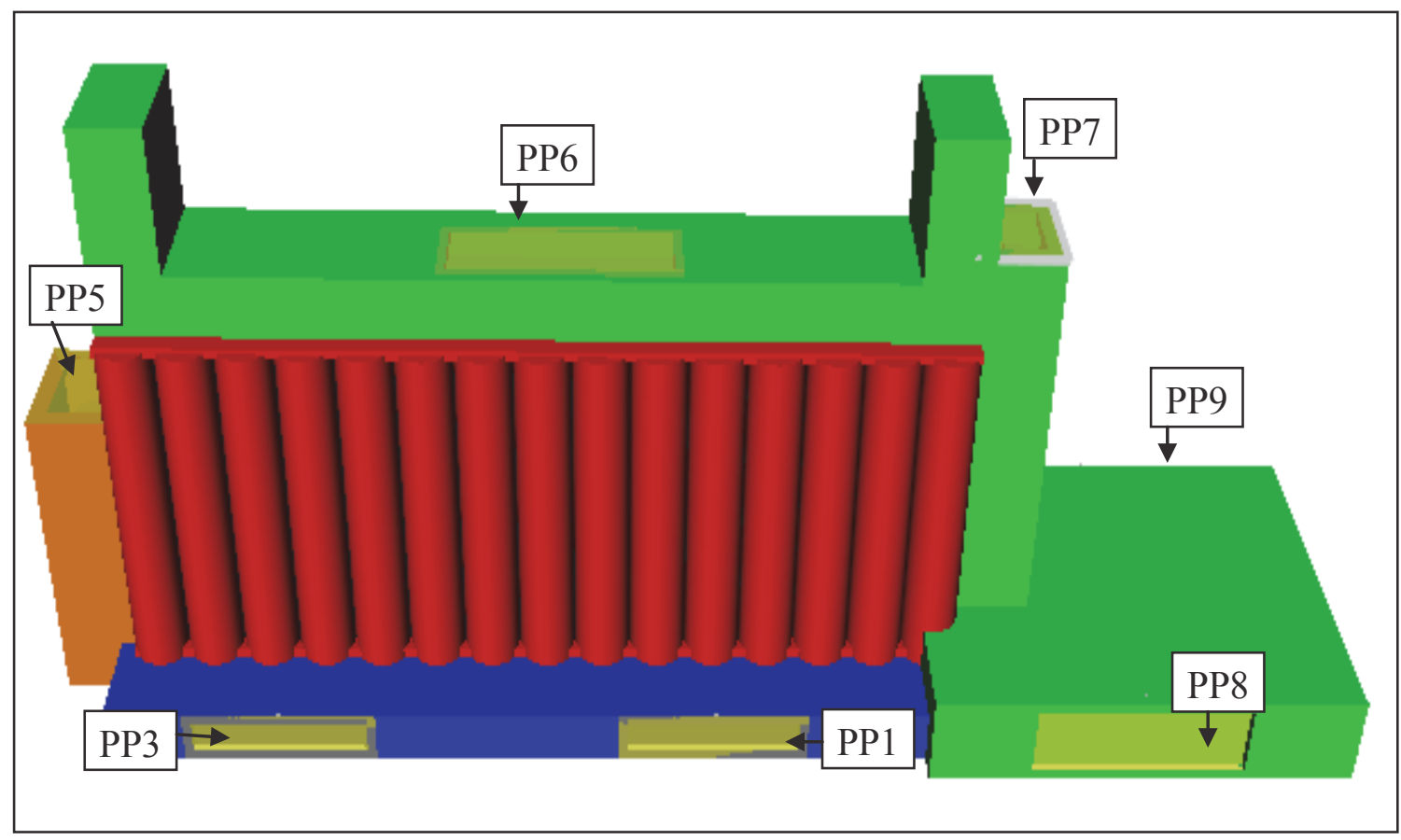

Figure 5.30 CASD image (3D view) of the Semabla storage silo with the pressure relief panels (PPs).

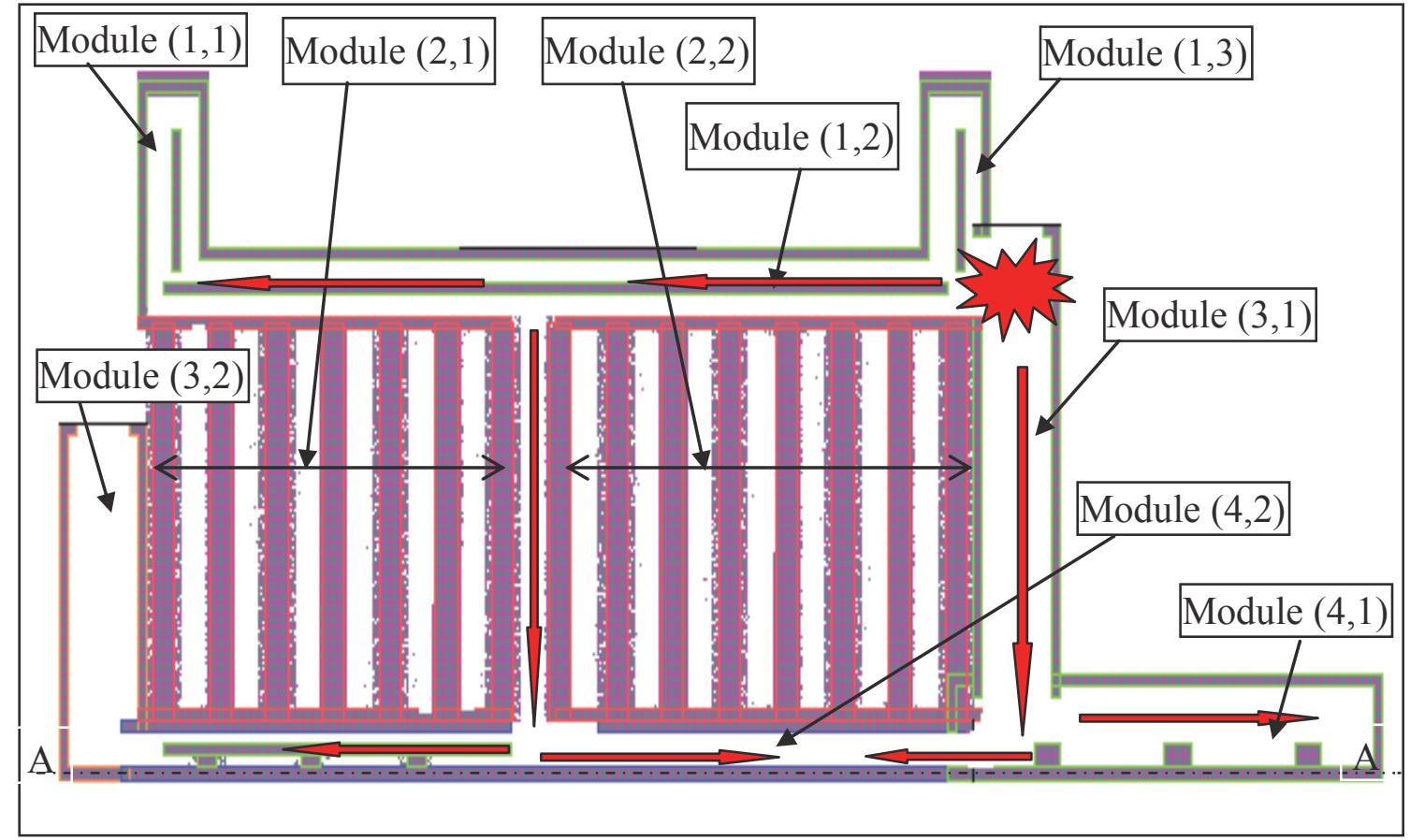

Figure 5.31 Module distribution: a side view of the Semabla silo geometry. 
Table 5.26 Opening pressure value of pressure panels and their sizes in the Semabla storage silo.

\begin{tabular}{|l|c|c|}
\hline Pressure panel no. & $\begin{array}{c}\text { Opening pressure } \\
(\mathbf{~ k P a})\end{array}$ & $\begin{array}{c}\text { Size } \\
\mathbf{( ~ m}^{\mathbf{2}} \mathbf{)}\end{array}$ \\
\hline $\begin{array}{l}\text { Module (4,2) } \\
\text { PP1 - PP4 }\end{array}$ & 30 & 60 \\
\hline $\begin{array}{l}\text { Module (3,2) } \\
\text { PP5 }\end{array}$ & 30 & 54 \\
\hline $\begin{array}{l}\text { Module (1,2) } \\
\text { PP6 }\end{array}$ & 30 & 42 \\
\hline $\begin{array}{l}\text { Module (3,1) } \\
\text { PP7 }\end{array}$ & 30 & 175 \\
\hline $\begin{array}{l}\text { Module (4,1) } \\
\text { PP8 - PP9 }\end{array}$ & 20 & 42 \\
\hline
\end{tabular}

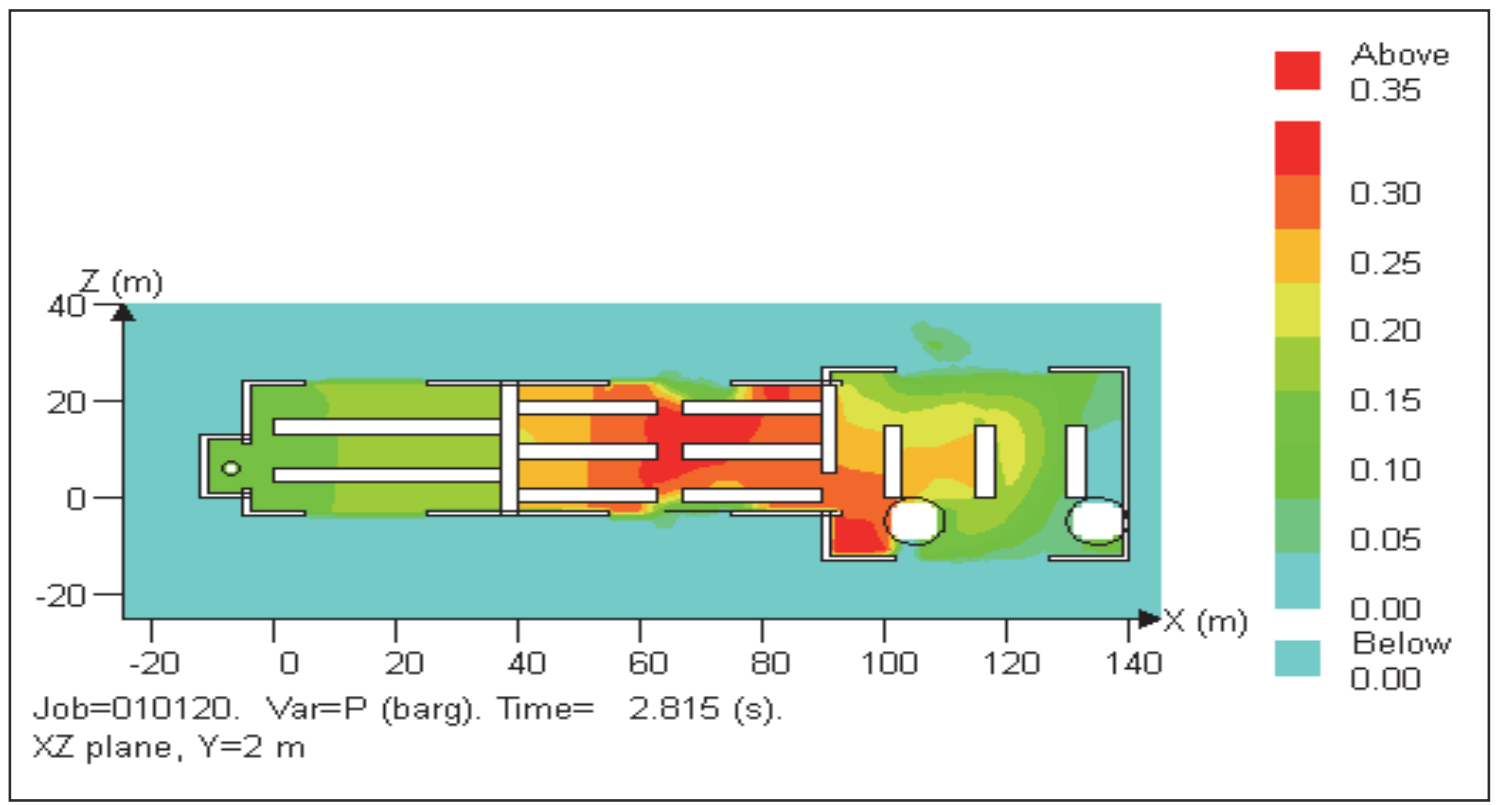

Figure 5.32 DESC pressure simulation of the Semabla silo explosion geometry (top view). 


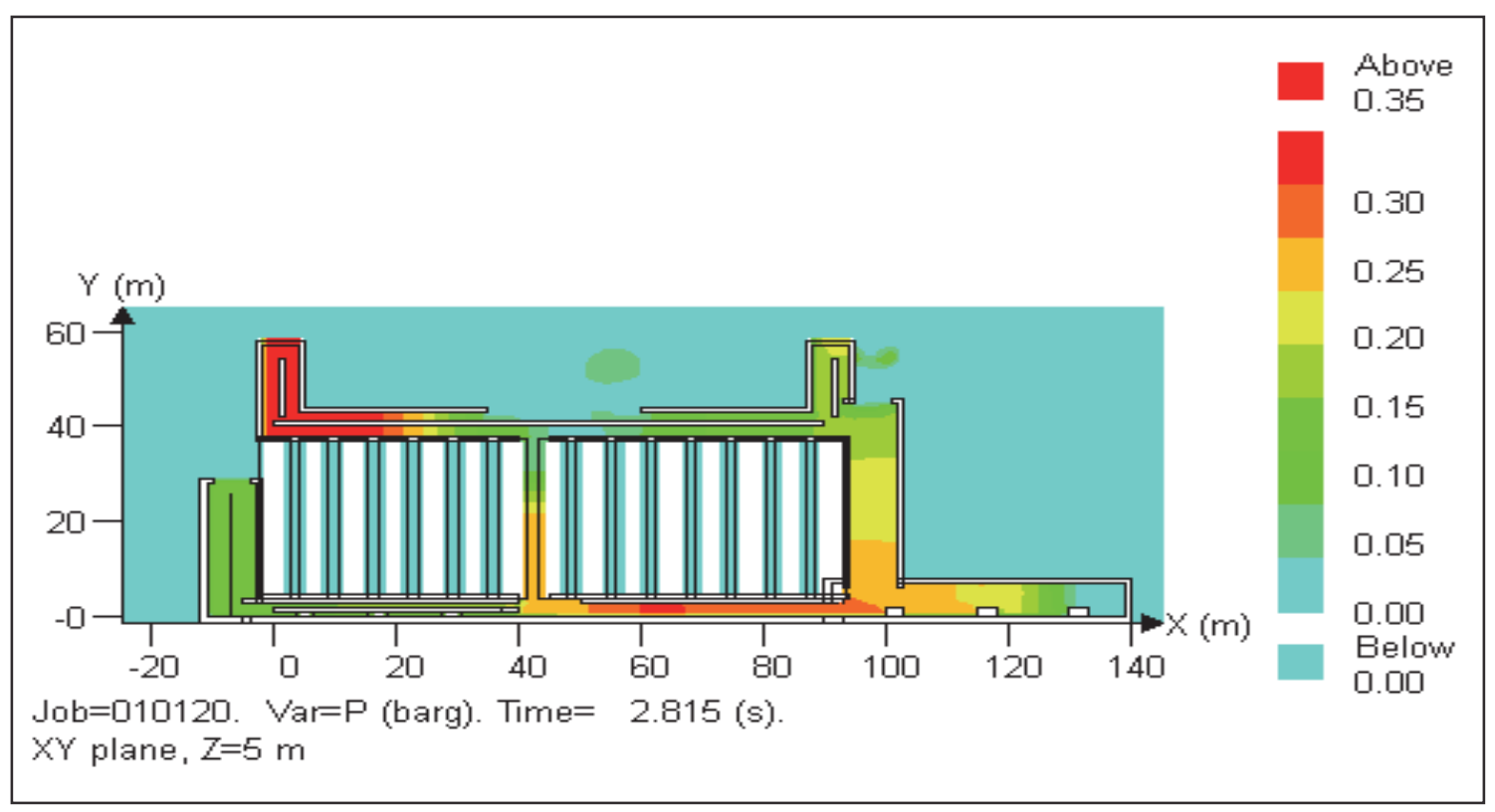

Figure 5.33 DESC pressure simulation of the Semabla silo explosion geometry (side view).

Table 5.27 summarizes some important data required in the Semabla simulation. The fuel used in the simulation was maize starch, which is considered the main fuel, with its explosibility characteristics shown in Table F.4 (Appendix F). However, wheat and barley also contributed to the extreme severity of the explosion that spread to the entire silo facility and nearby buildings over a short period of time.

\section{- Structure damage}

As mentioned in Chapter 3, the Probit Equation 3.2 can determine the structural damage that occurred as a result of the explosion maximum pressure. Using the transformation tables in Appendix D, the structural damage equation and its causative variables $\left(\mathrm{K}_{1}, \mathrm{~K}_{2}\right)$ are: $Y=-23.8+2.92 * \ln \left(\mathrm{P}_{\mathrm{ovr}}\right)$. The reason for choosing this equation is that the fatalities resulted from structural damage consequences (grain overflow and debris).

DESC simulated the pressure profile during the explosion inside the silo building. Figure 5.34 is a plane view of the refinery at the cut line A-A in Figure 5.31. Figure 5.34 also demonstrates the pressure simulation in colors, with the red color representing the highest 
Table 5.27 DESC scenario input data for Semabla silo geometry.

\begin{tabular}{|c|l|}
\hline No. & \multicolumn{1}{|c|}{ DESC scenario input data } \\
\hline 1 & Simulation volume size $(\mathrm{x}, \mathrm{y}, \mathrm{z})=(170 \mathrm{~m}, 66 \mathrm{~m}, 65 \mathrm{~m})$ \\
\hline 2 & Geometry size $(\mathrm{x}, \mathrm{y}, \mathrm{z})=(150 \mathrm{~m}, 58 \mathrm{~m}, 35 \mathrm{~m})$ \\
\hline 3 & Fuel name is "Maize starch" \\
\hline 4 & Dust concentration $=500 \mathrm{~g} / \mathrm{m}^{3}$ \\
\hline 5 & Number of monitor points $=40$ \\
\hline 6 & Number of pressure panels $(\mathrm{PP})=9$ \\
\hline 7 & Ignition energy $=10 \mathrm{~kJ}$ \\
\hline
\end{tabular}

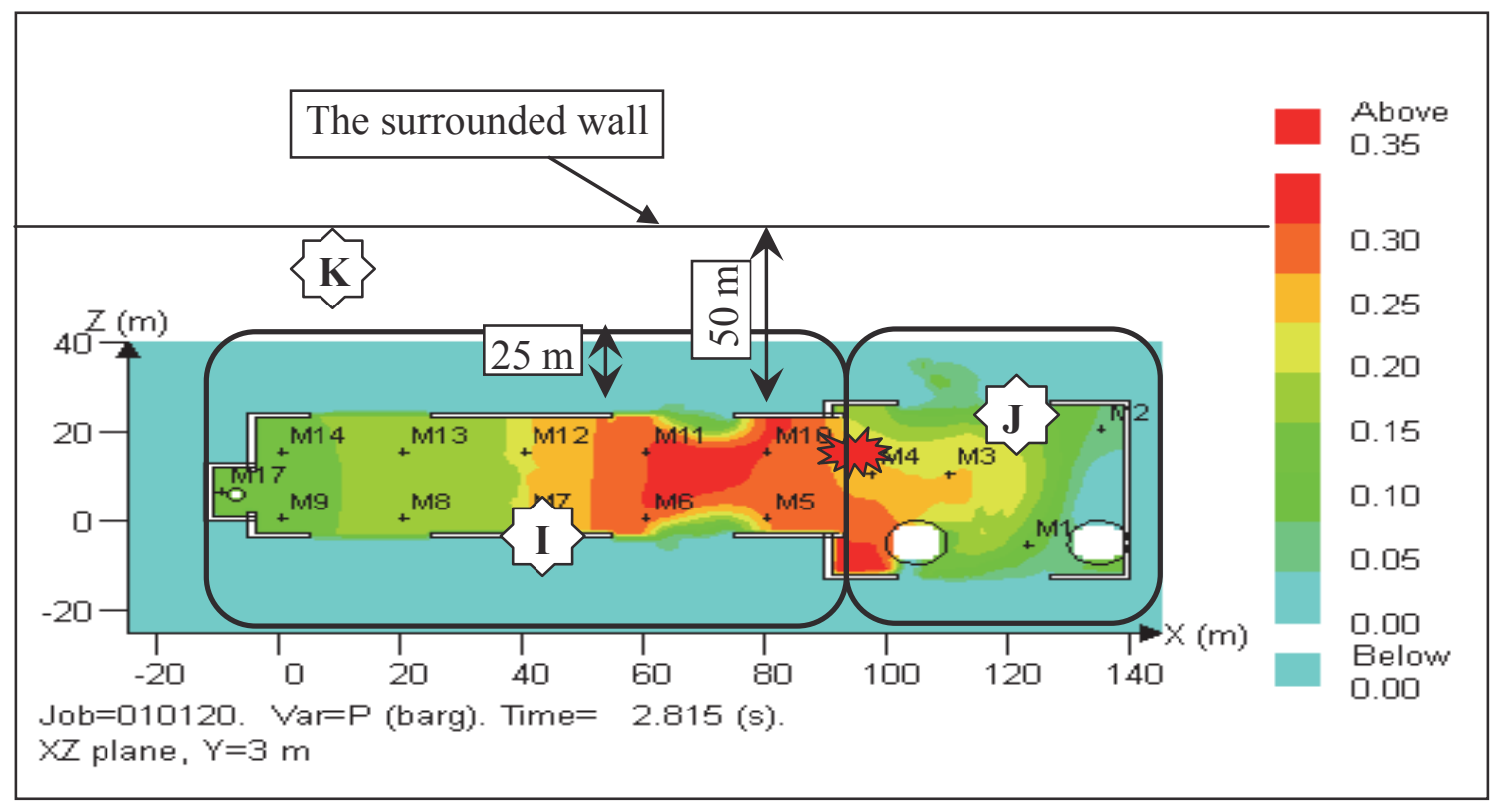

Figure 5.34 A plane view of the Semabla silo geometry in Blaye, France.

pressure, $0.35 \operatorname{bar}(\mathrm{g})$, and the blue color representing the lowest pressure, zero bar(g). Figure 5.34 also shows the most dangerous area in the installation (I), which had the highest pressure value, and the lower-risk area $(\mathrm{K})$, which had the lowest pressure value. In addition, the pressure simulation, Figure 5.35, shows that the explosion pressure was sufficiently high to destroy the facility. In addition, the spilled grains and projected debris 


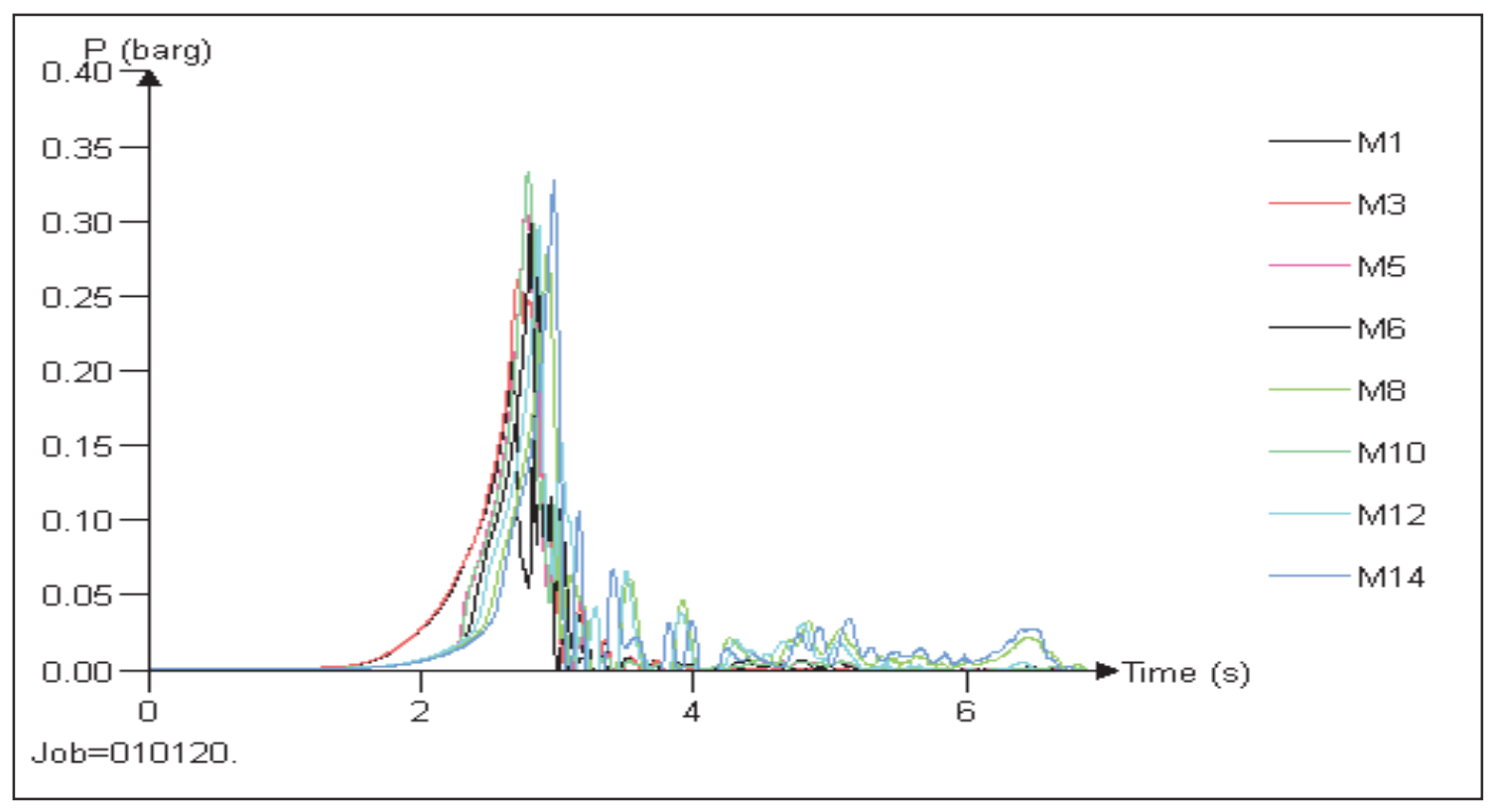

Figure 5.35 DESC pressure/time simulation at monitor points in Modules $(4,1)$ and $(4,2)$ of the Semabla storage silo explosion.

caused by the explosion were also threats.

The Probit equation and the transformation table, Appendix D, have determined the structural damage at each zone in terms of damage percentage. Outcomes for three areas are shown in Table 5.28.

Table 5.28 Estimated Probit damage percentages caused by explosion overpressure of incident outcome cases at Module $(2,1)$.

\begin{tabular}{|c|c|c|c|}
\hline $\begin{array}{c}\text { Incident } \\
\text { outcome case }\end{array}$ & $\begin{array}{c}\mathbf{P}_{\max } \\
{[\mathbf{b a r}(\mathbf{g})]}\end{array}$ & $\mathbf{Y}$ & $\begin{array}{c}\text { Damage percentage } \\
\mathbf{( \% )}\end{array}$ \\
\hline $\mathrm{I}$ & 0.35 & 6.75 & 96 \\
\hline $\mathrm{J}$ & 0.19 & 5.00 & 50 \\
\hline $\mathrm{K}$ & 0.00 & 0.00 & No likely damage \\
\hline
\end{tabular}




\section{iv) Likelihood calculations}

The probability of occurrence of the FTA basic events at Semabla has been generated from Freeman's (2011) equations. Equations 2.5 and 2.7 were recommended by Freeman for such incidents. Due to the generally unsafe conditions under which the silo operated, the failure probabilities of the units that had significant effects on the explosion are as follows:

- The confinement was $75 \%$ because the explosion occurred inside the tower, which was open to other buildings.

- The dust concentration was $25 \%$, as it was not managed safely.

- The probability of existing combustible material was $99 \%$ because all materials (wheat, barley and maize) were combustible.

- The probability of the oxidant concentration above the LOC was considered $80 \%$, as the explosion occurred at normal conditions.

- Rationally, at least $25 \%$ of the airborne material was less than or equal the nonexplosible diameter i.e. the existing of the explosible practical size probability was also $25 \%$.

- One of the strongest expectations was the existence of flammable gases mixed with airborne dust; the probability of the gas existence was $75 \%$.

The general dust explosion fault tree flow chart has been modified to address the Semabla silo explosion. Figure 5.36 provides the FTA of the silo and the probabilities of the elements that led to the explosion. 


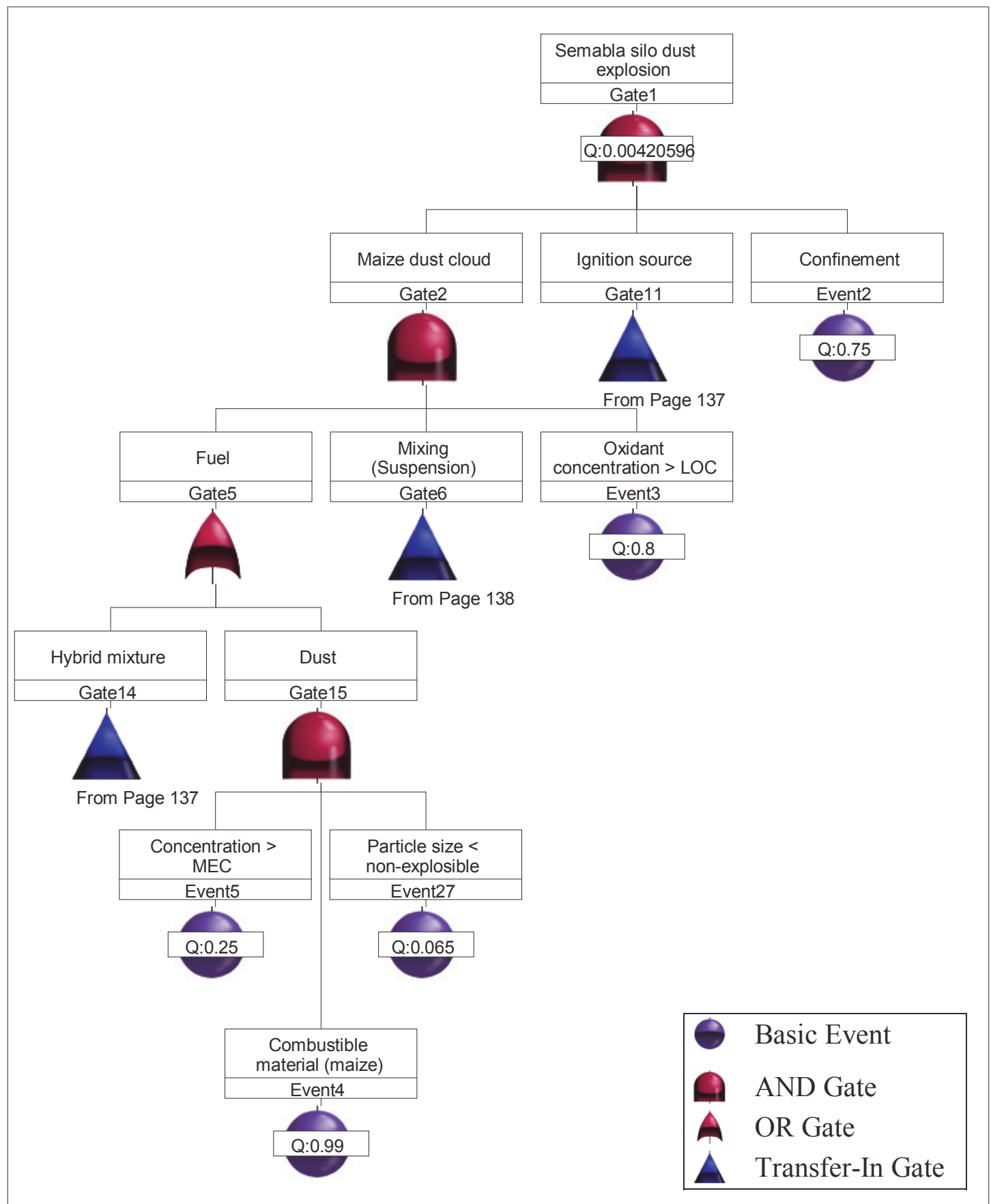

Figure 5.36 Fault Tree Analysis flowchart of the Semabla silo explosion. 


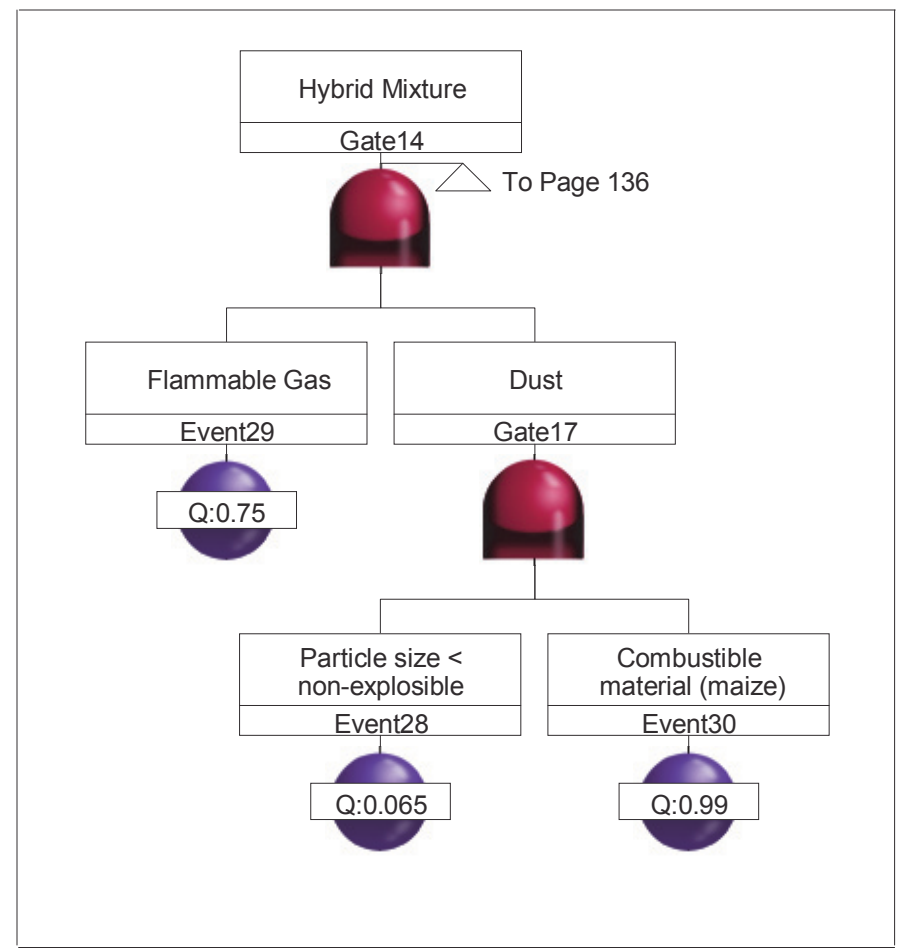




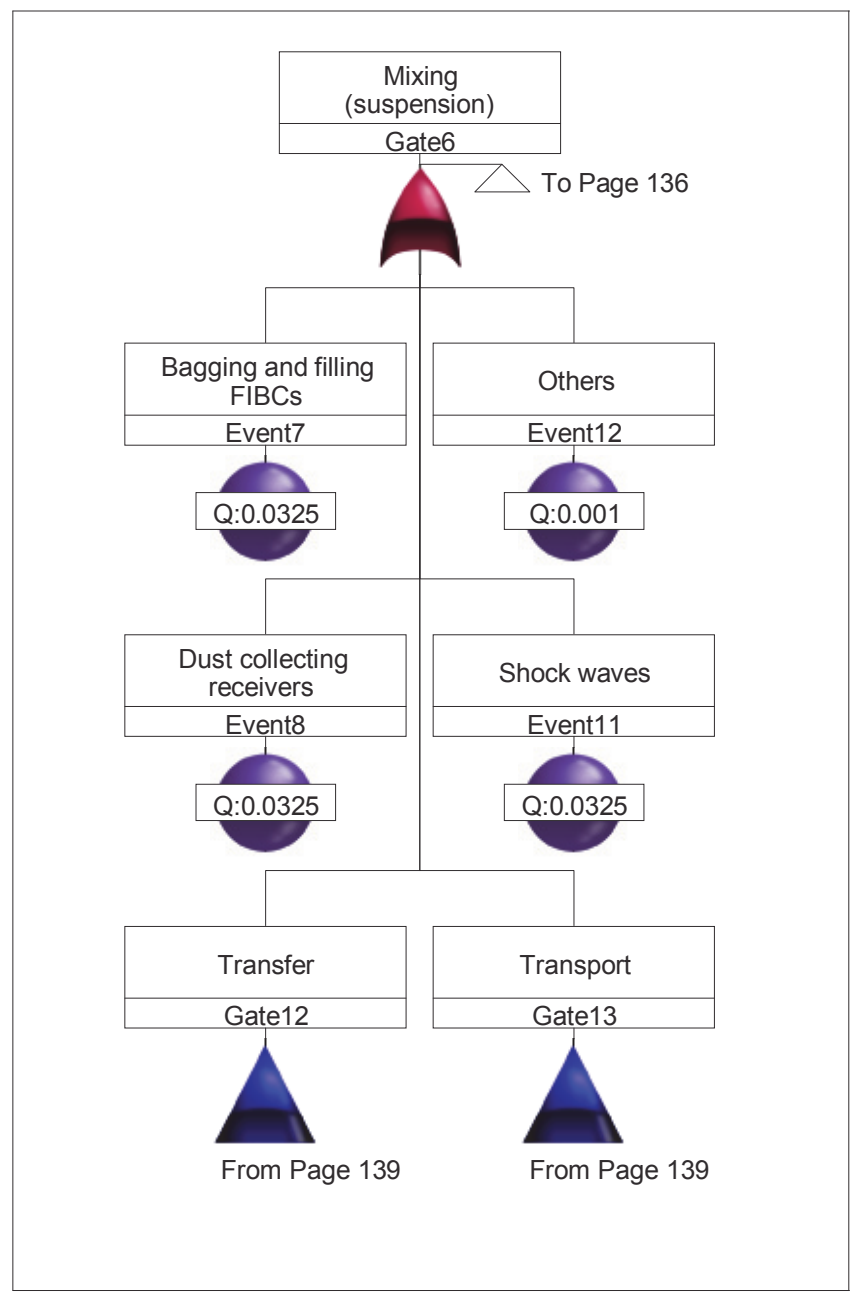



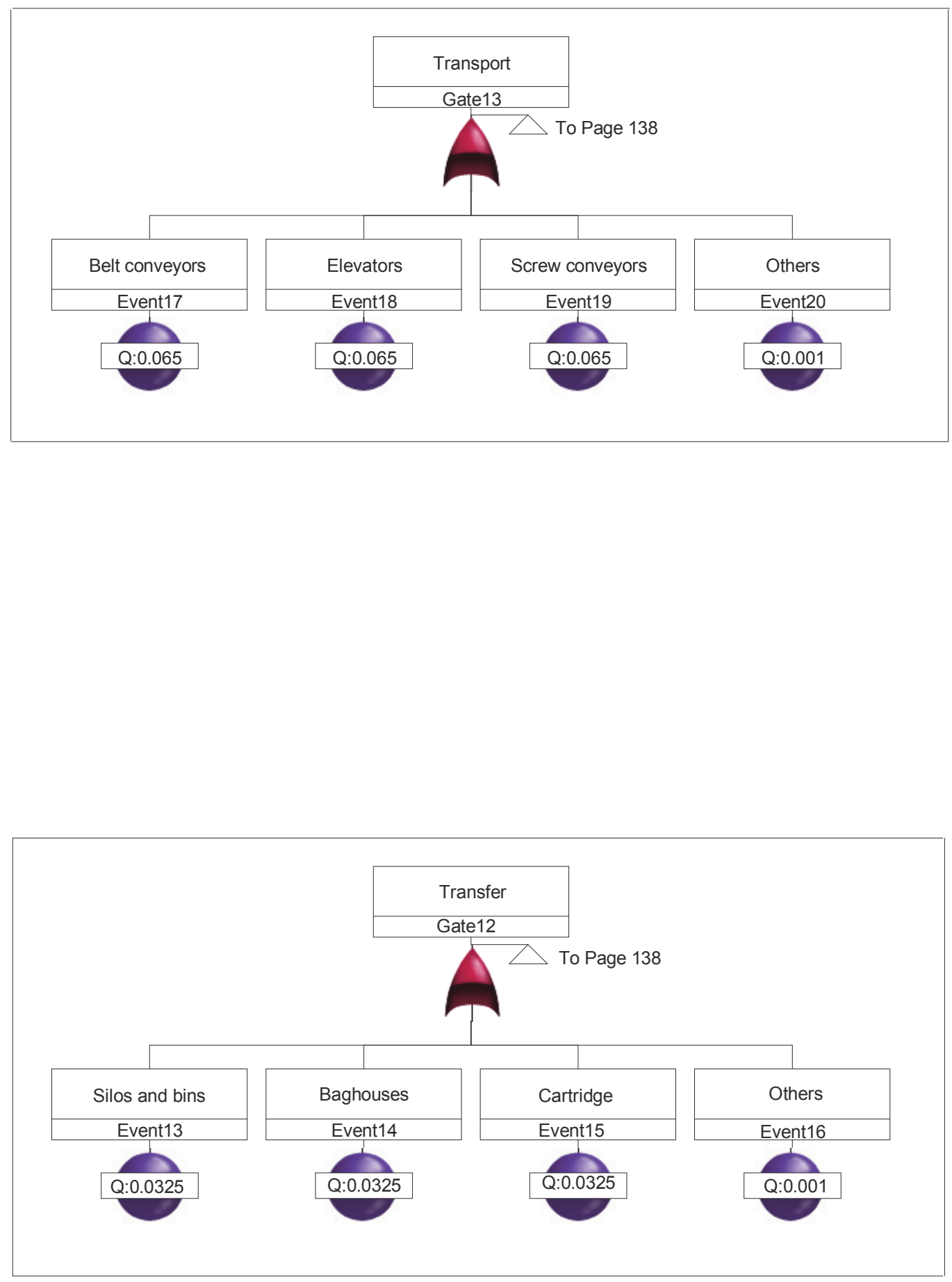


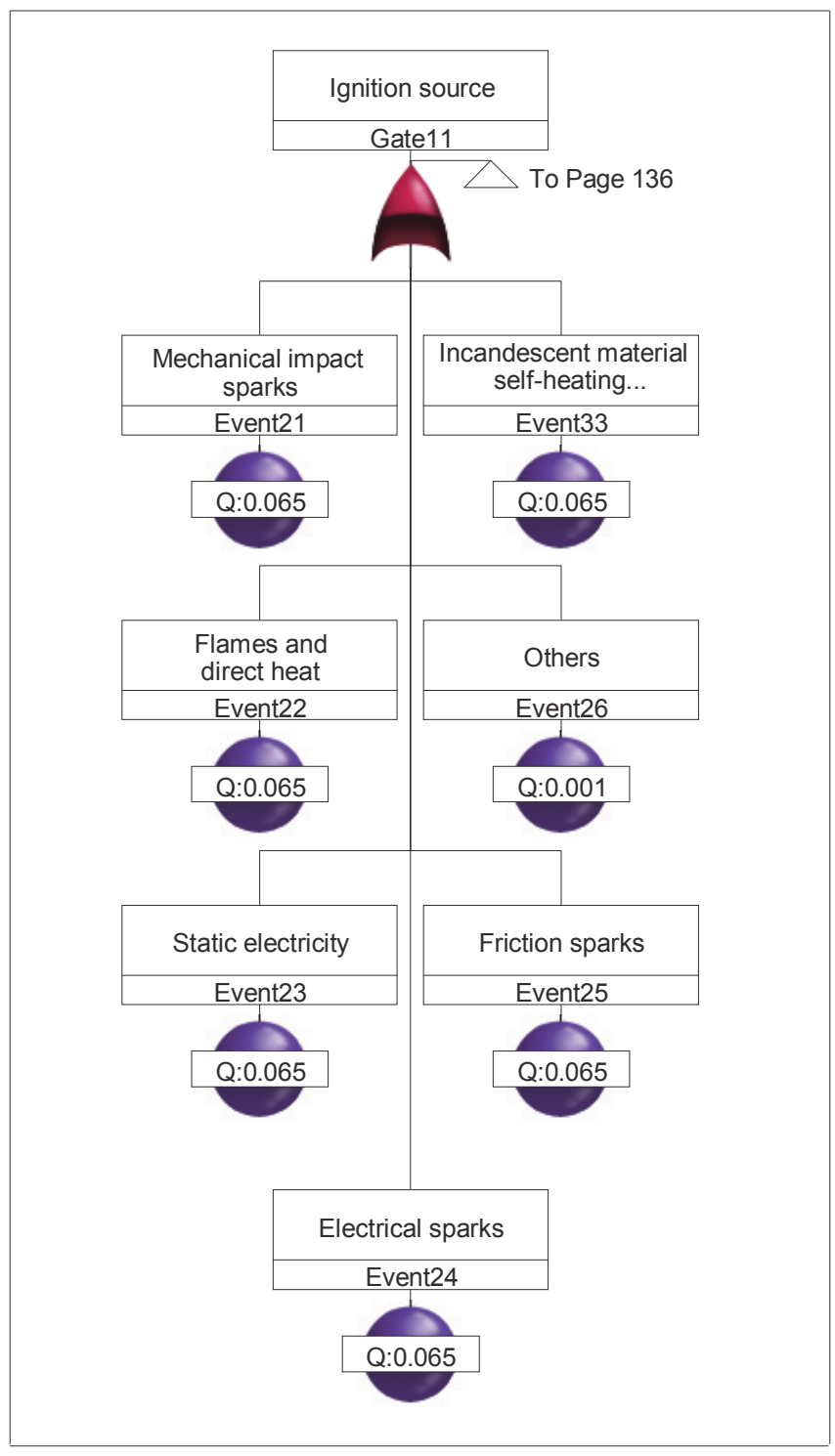




\section{Risk estimation}

Analysis of the severity of consequences and likelihood of occurrence results in risk estimation. The combination of these factors is represented in the risk criterion, as follows:

\section{i) Individual risk}

Most of the victims in the silo were killed because of the collapse that occurred in the silo cells and the overflow of bulk grain onto the work areas at the foot of the silo. Individual risk has been calculated in the work areas, Module $(4,1)$ and Module $(4,2)$, as shown in Figure 5.31. The fault tree calculations found the probability (f) of the silo explosion as $4.21 * 10^{-3}$ per year.

Table 5.29 shows the probability of fatality $\left(\mathrm{P}_{\mathrm{f}, \mathrm{i}}\right)$ for each zone. The $\mathrm{P}_{\mathrm{f}, \mathrm{i}}$ of zone $\mathrm{I}$ is 1.0 $(100 \%)$ due to the $96 \%$ wall destruction plus the grain overflow. The $\mathrm{P}_{\mathrm{f}, \mathrm{i}}$ of zone $\mathrm{K}$ is $0.25(25 \%)$ because of the projected debris. Table 5.29 shows the estimated total risk after multiplying the incident frequency $\left(\mathrm{f}_{\mathrm{i}}\right)$ by $\mathrm{P}_{\mathrm{f}, \mathrm{i}}$, the number of workers, and the estimated number of fatalities at each defined zone (I, J, K). The estimated number of fatalities is calculated by multiplying the $\mathrm{P}_{\mathrm{f}, \mathrm{i}}$ by the number of workers.

Table 5.29 Individual risk calculations for the Semabla silo, Module $(4,1)$.

\begin{tabular}{|c|c|c|c|c|c|}
\hline $\begin{array}{c}\text { Incident } \\
\text { outcome case }\end{array}$ & $\begin{array}{c}\mathbf{f}_{\mathbf{i}} \\
\text { (per year) }\end{array}$ & $\mathbf{P}_{\mathbf{f}, \mathbf{i}}$ & $\mathbf{f}_{\mathbf{i}} * \mathbf{P}_{\mathbf{f}, \mathbf{i}}$ & $\begin{array}{c}\text { No. of } \\
\text { workers }\end{array}$ & $\begin{array}{c}\text { Estimated no. } \\
\text { of Fatalities }\end{array}$ \\
\hline $\mathrm{I}$ & $4.2 * 10^{-3}$ & 1.0 & $4.2 * 10^{-3}$ & 10 & 10 \\
\hline $\mathrm{J}$ & $4.2 * 10^{-3}$ & 0.50 & $2.1 * 10^{-3}$ & 11 & 6 \\
\hline $\mathrm{K}$ & $4.2 * 10^{-3}$ & 0.25 & $1.1 * 10^{-3}$ & 1 & 1 \\
\hline Average individual risk \\
$I R_{\text {avg }}=\frac{(10) * 4.2 * 10^{-3}+(11) * 2.1 * 10^{-3}+(1) * 1.1 * 10^{-3}}{2}=3.0 * 10^{-3}$ \\
\hline
\end{tabular}




$$
\begin{aligned}
& \operatorname{LSIR}_{\mathrm{T}}=4.2 * 10^{-3}+2.1 * 10^{-3}+1.1 * 10^{-3}=7.3 * 10^{-3} \\
& I S I R=\operatorname{LSIR} * P_{L}=7.3 * 10^{-3} * \frac{8}{24}=2.43 * 10^{-3}
\end{aligned}
$$

- Fatal accident rate (FAR)

The FAR is calculated from the average individual risk for the exposed employee population from Equation 3.10.

Fatal accident rate $(F A R)=I S I R * 10^{8} / H=2.43 * 10^{-3} * 10^{8} /(22 * 2000)=$

5.5 Fatalities $/ 10^{8}$ man-hours of exposure

ii) Group (societal) risks

- F-N Curve

Table 5.30 lists the number of fatalities and the frequency of each incident zone.

Table 5.31 expresses the F-N data, showing cumulative frequencies from the lowest to the highest value of fatalities.

Figure 5.37 presents the cumulative frequencies versus number of fatalities, as shown in Table 5.31.

Table 5.30 Cumulative frequency data for the F-N curve of the Semabla explosion.

\begin{tabular}{|c|c|c|}
\hline $\begin{array}{c}\text { Estimated number } \\
\text { of fatalities (N) }\end{array}$ & $\begin{array}{c}\text { Incident outcome cases } \\
\text { included }\end{array}$ & $\begin{array}{c}\text { Total frequency } \\
\mathbf{( F}_{\mathbf{N}} \text { (per year) }\end{array}$ \\
\hline 10 & $\mathrm{I}$ & $4.2 * 10^{-3}$ \\
\hline 6 & $\mathrm{~J}$ & $4.2 * 10^{-3}$ \\
\hline 1 & $\mathrm{~K}$ & $4.2 * 10^{-3}$ \\
\hline
\end{tabular}


Table 5.31 Cumulative frequency data for F-N curve of the Semabla explosion.

\begin{tabular}{|c|c|c|}
\hline $\begin{array}{c}\text { Estimated number } \\
\text { of fatalities }(\mathbf{N})\end{array}$ & Incident outcome cases included & $\begin{array}{c}\text { Total frequency } \\
\left(\mathbf{F}_{\mathbf{N}}\right)(\mathbf{p e r} \text { year) }\end{array}$ \\
\hline $10+$ & $\mathrm{I}$ & $4.2 * 10^{-3}$ \\
\hline $6+$ & $\mathrm{I}, \mathrm{J}$ & $8.4 * 10^{-3}$ \\
\hline $1+$ & $\mathrm{I}, \mathrm{J}, \mathrm{K}$ & $1.3 * 10^{-2}$ \\
\hline
\end{tabular}

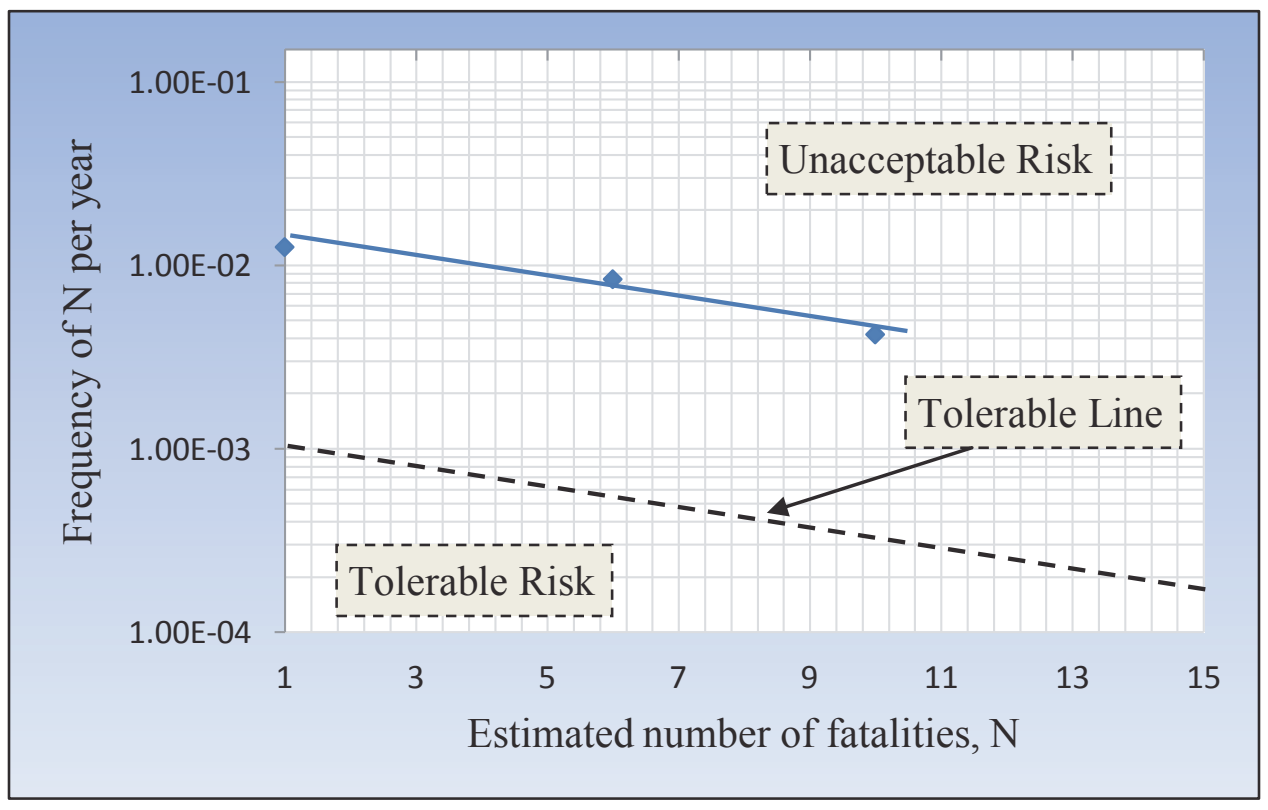

Figure 5.37 Social risk F-N curves for the Semabla explosion.

\section{Risk evaluation}

Table 5.32 summarizes the risk calculations for the Semabla silo explosion, showing that the risk was unacceptable. Figure 5.37, also indicates that the refinery was at risk, and that the F-N curve is in the unacceptable risk range, quite far away from the tolerable line. 
Table 5.32 Summary of the individual risk results for the Semabla explosion, before applying the QRMF.

\begin{tabular}{|c|c|c|c|}
\hline $\begin{array}{c}\mathbf{I R}_{\text {avgT }} \\
\left(\mathbf{y r}^{-\mathbf{1}}\right)\end{array}$ & LSIR & ISIR & $\begin{array}{c}\text { FAR } \\
\text { Fatalties } / \\
\left(\mathbf{1 0}^{\mathbf{8}} \text { hours of exposure }\right)\end{array}$ \\
\hline $3.0 * 10^{-3}$ & $7.3 * 10^{-3}$ & $2.43 * 10^{-3}$ & 5.5 \\
\hline
\end{tabular}

\section{Identify units and unsafe procedures that contribute significantly to probability of top event}

The following contributed to the probability of an explosion at Blaye:

- the existence of combustible gases from fermentation,

- the occurrence of hybrid mixture explosion in the dust removal circuit,

- the open interspaces between the two groups of cells,

- the existence of maize dryers,

- the maintenance and truck-unloading procedures, and

- lack of smoke detectors.

\section{Apply the risk controls}

Responding to the identified units and unsafe procedures actions, the QRMF controls should be applied to minimize the risk to be at least tolerable.

- Inherent safety

Inherent safety principles (minimization, substitution, moderation) were applied in recommended sequence to control the expected main causes of the Semabla silo explosion, as seen in Table 5.33.

- Engineered safety

- Passive engineered safety: Add sufficient explosion relief vents that are able to release explosion pressure on time, and add smoke detectors. 
Table 5.33 Applying inherent safety principles to the units and wrong actions that contributed to the Semabla explosion.

\begin{tabular}{|l|l|l|}
\hline $\begin{array}{l}\text { Units or actions } \\
\text { contributing to the } \\
\text { explosion event }\end{array}$ & $\begin{array}{c}\text { Inherent } \\
\text { safety } \\
\text { principle }\end{array}$ & \multicolumn{1}{c|}{ The Action } \\
\hline $\begin{array}{l}\text { Dust-air explosion } \\
\text { occurred in the dust } \\
\text { removal circuit }\end{array}$ & Minimization & $\begin{array}{l}\text { - Good housekeeping (dust removal/cleaning). } \\
\text { - Keeping dust concentration outside } \\
\text { explosible range (Amyotte \& Eckhoff, 2010). }\end{array}$ \\
\cline { 3 - 3 } $\begin{array}{l}\text { The open interspaces } \\
\text { between the two } \\
\text { groups of cells }\end{array}$ & $\begin{array}{l}\text { Minimize dust cloud volume by filling the } \\
\text { opened interspaces with grain or sealing them } \\
\text { tightly. }\end{array}$ \\
\hline $\begin{array}{l}\text { Unloading of maize } \\
\text { and dryers procedure }\end{array}$ & Substitution & $\begin{array}{l}\text { Replace the hazardous unloading and drying } \\
\text { procedures with others that are less hazardous } \\
\text { (Amyotte et al., 2009). }\end{array}$ \\
\hline $\begin{array}{l}\text { Existence of } \\
\text { combustible gases } \\
\text { from fermentation }\end{array}$ & Moderation & $\begin{array}{l}\text { Identify processing (storage) options that } \\
\text { involve less severe processing conditions e.g. } \\
\text { efficient add-on (ventilation) system. }\end{array}$ \\
\hline
\end{tabular}

- Active engineered safety: Add an automatic explosion suppression system by inerting dust cloud.

\section{- Procedural safety:}

Apply safe truck-unloading procedures. Also, review procedures for the entire installation design, if any modification has been applied to the process units or to the working areas' cleaning procedure. Review and apply safety maintenance procedures to reduce any possible ignition source. Also, create, modify, and/or apply safety procedures for emergency plans as well as periodic training procedures regarding safety issues for workers.

\section{Understand the residual hazard}

\section{i) Consequence analysis}

Similar to the procedure used at the Imperial Sugar refinery, new DESC simulations were conducted after applying possible risk controls that suggested the above. Table 5.34 
provides the new opening values of the pressure relief panels for achieving safe operations. Dust concentration was reduced to $250 \mathrm{~g} / \mathrm{m}^{3}$, which is $50 \%$ of the previous concentration. The flammable gas formed from the fermentation process was also reduced by the add-on system.

Table 5.34 Opening pressure values of pressure panels and their sizes in the Semabla storage silo.

\begin{tabular}{|l|c|c|}
\hline Pressure panel no. & $\begin{array}{c}\text { Opening pressure } \\
(\mathbf{~ k P a})\end{array}$ & $\begin{array}{c}\text { Size } \\
\mathbf{( ~ \mathbf { ~ m }}^{\mathbf{2}} \mathbf{)}\end{array}$ \\
\hline PP1 - PP4 & 5 & 60 \\
\hline PP5 & 5 & 54 \\
\hline PP6 & 20 & 175 \\
\hline PP7 & 5 & 42 \\
\hline PP8 - PP9 & 5 & 175 \\
\hline
\end{tabular}

During the simulation, the explosion pressure distribution was virtually the same inside the buildings until it reached the venting relief pressure value ( $5 \mathrm{kPa}$, or $0.05 \mathrm{bar}(\mathrm{g}))$, after which different pressure regions started forming with different shapes and colors, indicating pressure release through the panels and continuity of the explosion reaction.

Through the use of different colored areas, Figure 5.38 and Figure 5.39 show the maximum explosion pressures reached during the DESC simulation. Figure 5.38 indicates that the maximum explosion pressure reached was $0.05 \mathrm{bar}(\mathrm{g})$ at $3.4 \mathrm{~s}$ in Module $(4,1)$. The explosion then propagated through open interspaces between the two groups of cells to the work area, Module $(4,2)$, where the pressure rose again to 0.05 $\operatorname{bar}(\mathrm{g})$ at $12.4 \mathrm{~s}$, as shown at Figure 5.39. 


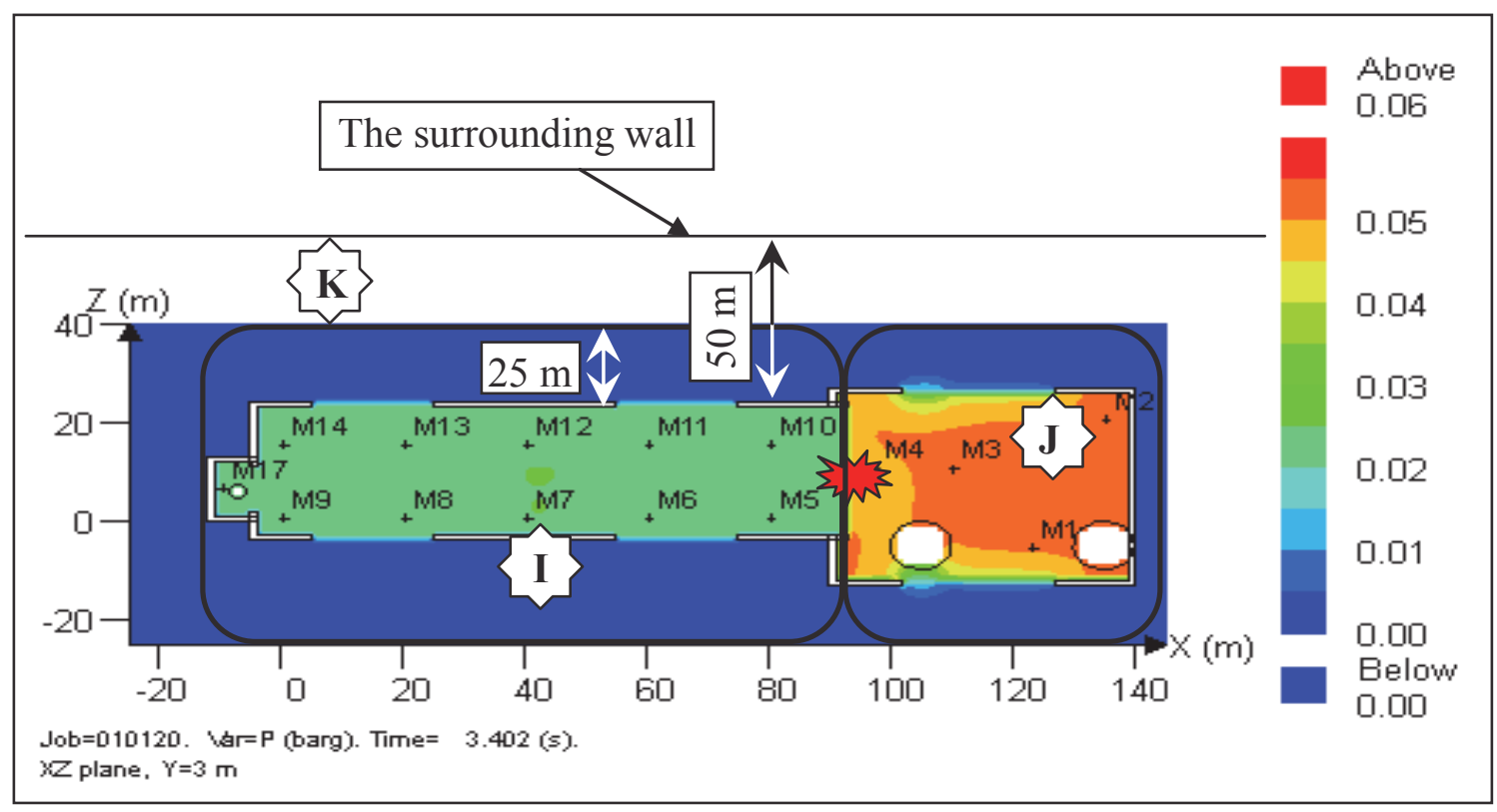

Figure 5.38 DESC pressure simulation from a plane view of the Semabla storage silo explosion, after applying the QRMF at $3.4 \mathrm{~s}$.

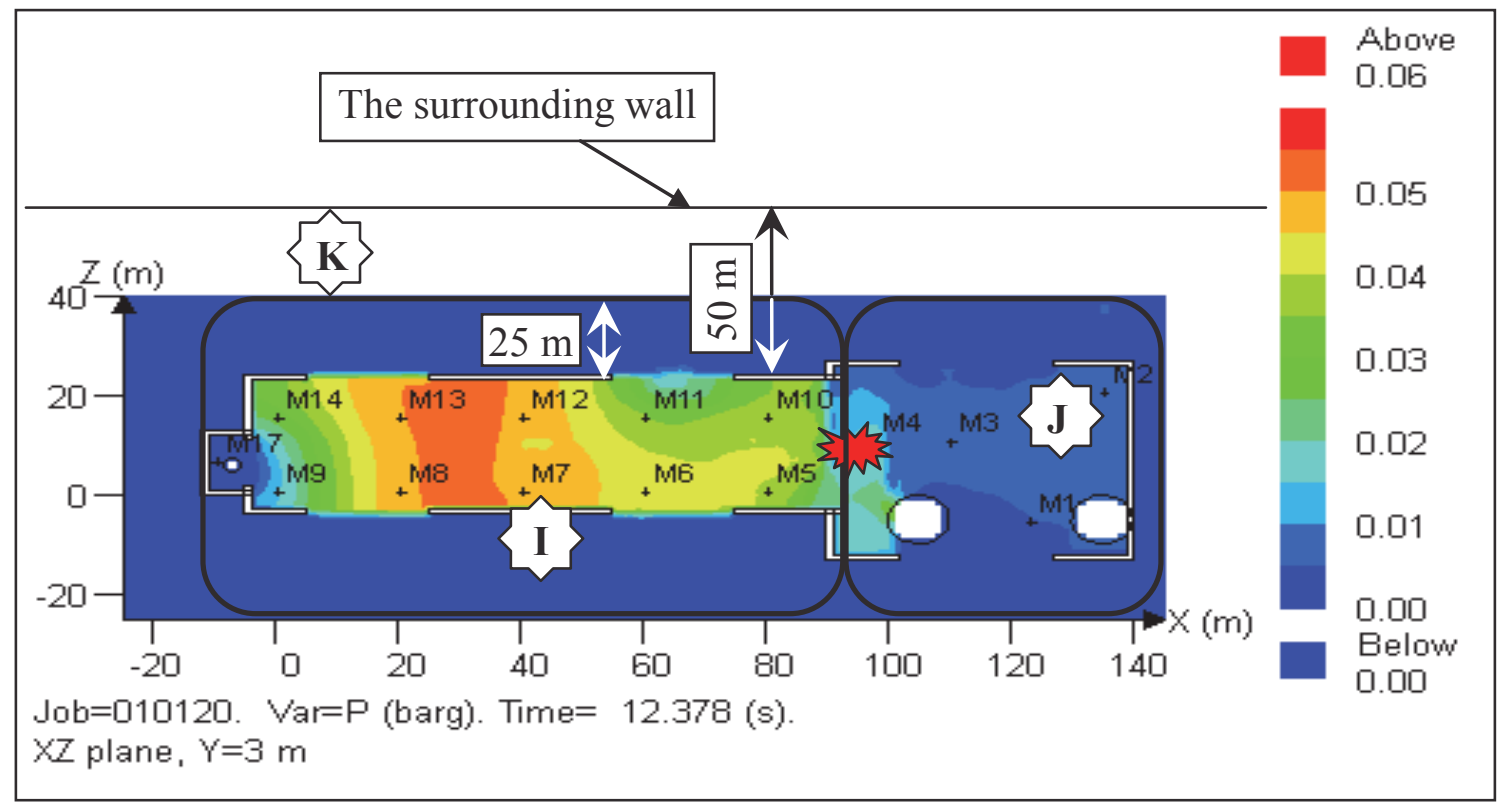

Figure 5.39 DESC pressure simulation from a plane view of the Semabla storage silo explosion, after applying the QRMF at $12.3 \mathrm{~s}$. 
Figure 5.40 expresses the pressure simulation of Figures 5.38 and 5.39, showing the pressure developments at monitor points M3, M8, and M11. The first peak, at $3.4 \mathrm{~s}$, recorded by M3, indicates the maximum explosion pressure, $0.05 \operatorname{bar}(\mathrm{g})$, in Module $(4,1)$, and the second peak, at $12.4 \mathrm{~s}$, recorded by M8 and M11, indicates the maximum pressure, $0.05 \operatorname{bar}(\mathrm{g})$, in Module (4,2). The total explosion time of $14 \mathrm{~s}$ is also shown in Figure 5.40.

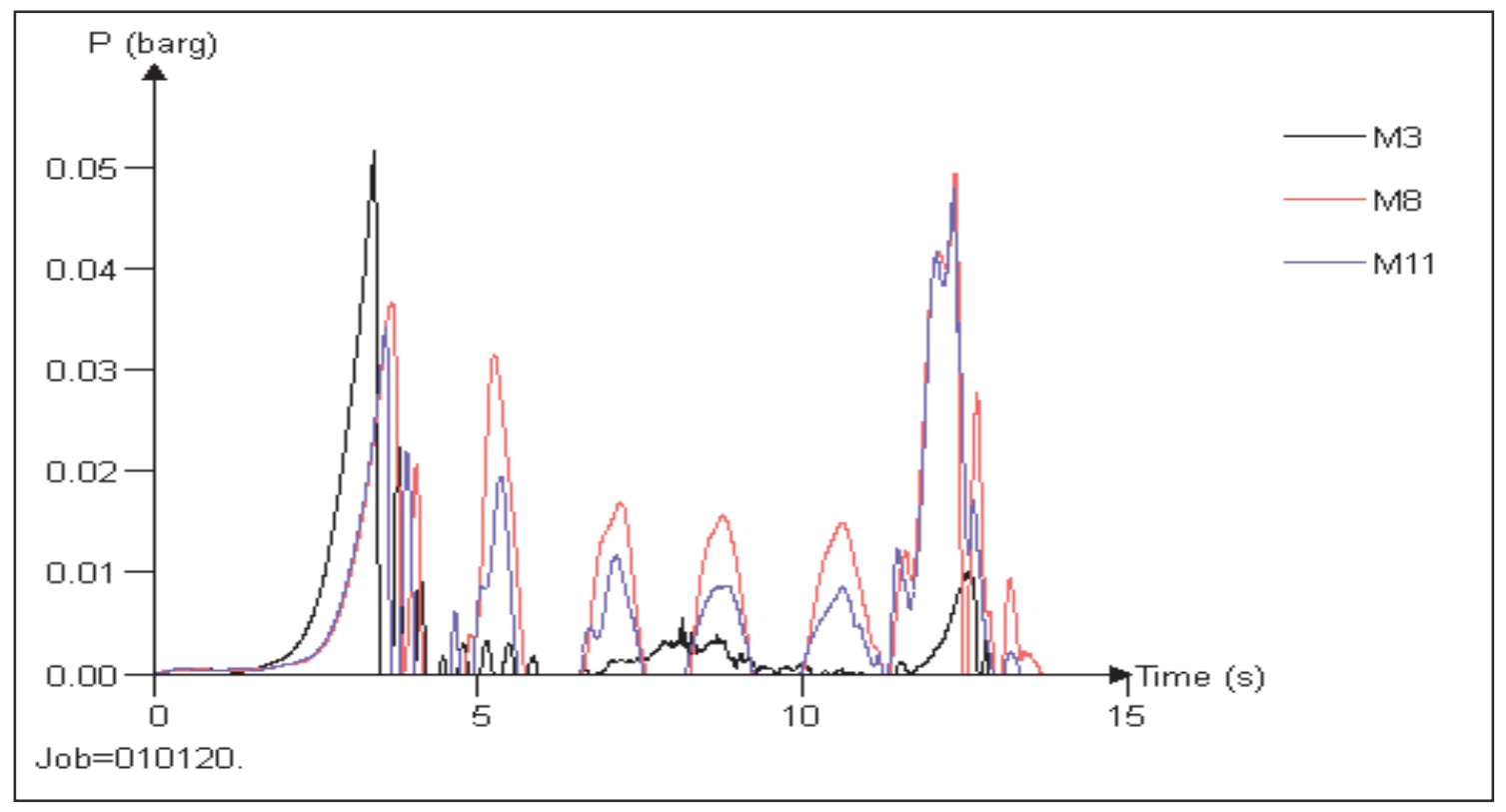

Figure 5.40 DESC pressure/time simulation at the monitor points in Modules $(4,1)$ and $(4,2)$ of the Semabla storage silo explosion, after applying the QRMF.

Table 5.35 lists the maximum explosion pressure, corresponding Probit value, and insignificant damage percentage for each explosion zone, after applying the QRMF, which shows significant protection to the Semabla case study. 
Table 5.35 Estimated Probit damage percentages caused by explosion overpressure of incident outcome cases in the simulated Semabla grain silo, after applying the QRMF.

\begin{tabular}{|c|c|c|c|}
\hline $\begin{array}{c}\text { Incident } \\
\text { outcome case }\end{array}$ & $\begin{array}{c}\mathbf{P}_{\max } \\
(\mathbf{b a r}(\mathbf{g}))\end{array}$ & $\mathbf{Y}$ & $\begin{array}{c}\text { Damage } \\
\text { percentage }(\mathbf{\%})\end{array}$ \\
\hline $\mathrm{I}$ & 0.052 & 1.19 & $6.95^{*} 10^{-3}$ \\
\hline $\mathrm{J}$ & 0.055 & 1.35 & $1.31 * 10^{-2}$ \\
\hline $\mathrm{K}$ & 0 & 0 & No likely damage \\
\hline
\end{tabular}

\section{ii) Likelihood calculations}

Table 5.36 compares the probabilities of occurrence of the Semabla explosion, before and after applying the QRMF. Using Equation 2.5 (the 'best guess' method), some basic events in the Semabla fault tree flowchart are recalculated, with $k=1 / 3$ and $n=t=10$ years. This resulted in a basic event probability value of 0.0325 , and addresses the applied safety controls, as follows:

- As the probability of dust concentration (which must be greater than or equal to MEC) is minimized to 0.0325 , the existing of airborne dust particles will likewise be reduced to 0.0325 .

- Applying procedural safety measures such as hot permit, frequently mechanical and electrical maintenance, and check equipment grounding will reduce the probability of mechanical impact sparks, flames and direct heat, or static electricity to 0.0325 .

- A new safety procedure for organic grain storage and a proper ventilation system will reduce incandescent material ignition sources to 0.0325 and mitigate the presence of flammable gas.

Figure 5.41 is the FTA flowchart of the Semabla grain silo explosion. Figure 5.41 estimates the probability of the dust explosion in Semabla after applying the QRMF, reducing the probability of occurrence of the most significant causes of the basic events. 
Table 5.36 Estimated failure rate of the explosion's basic events at Semabla, before and after applying the QRMF.

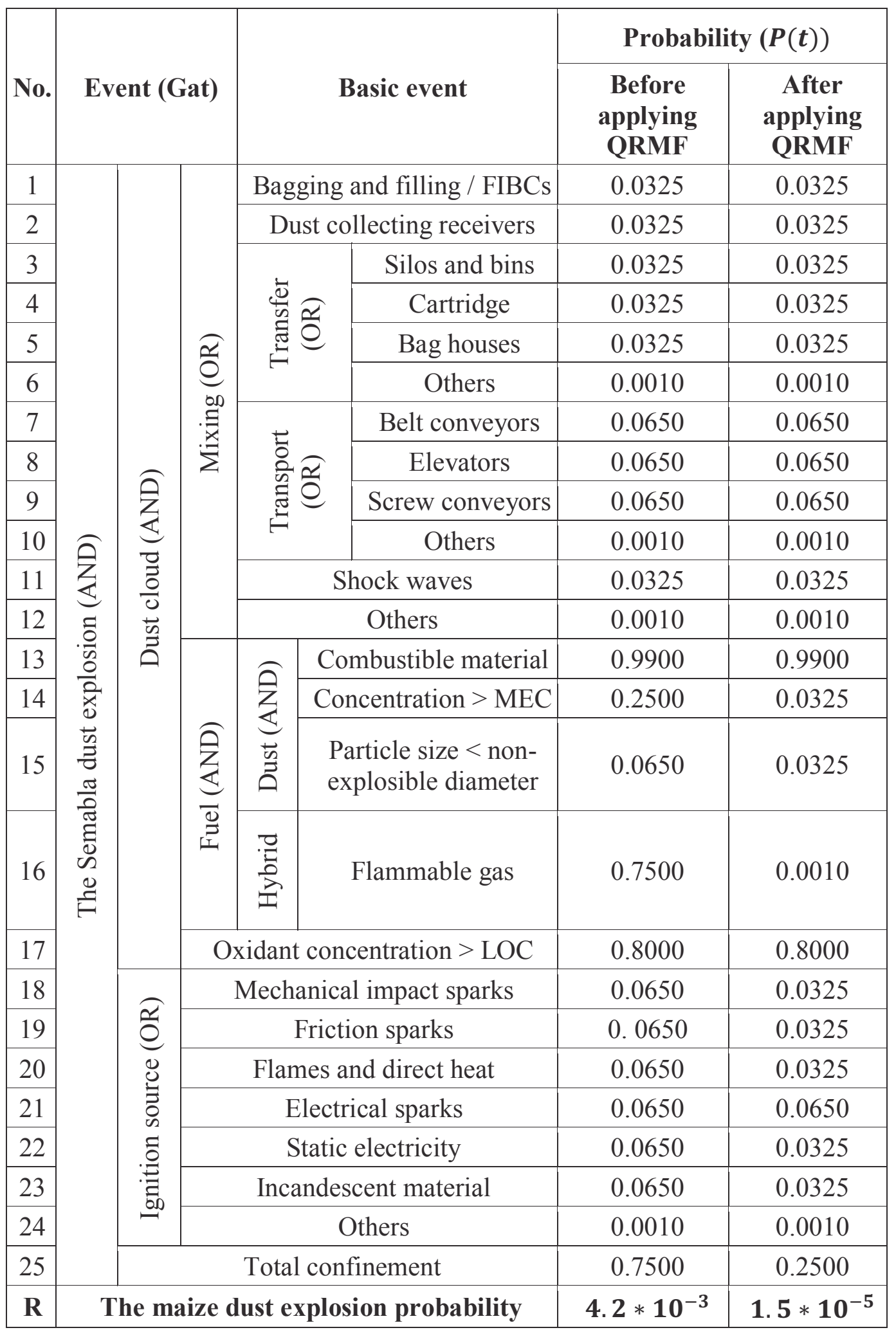




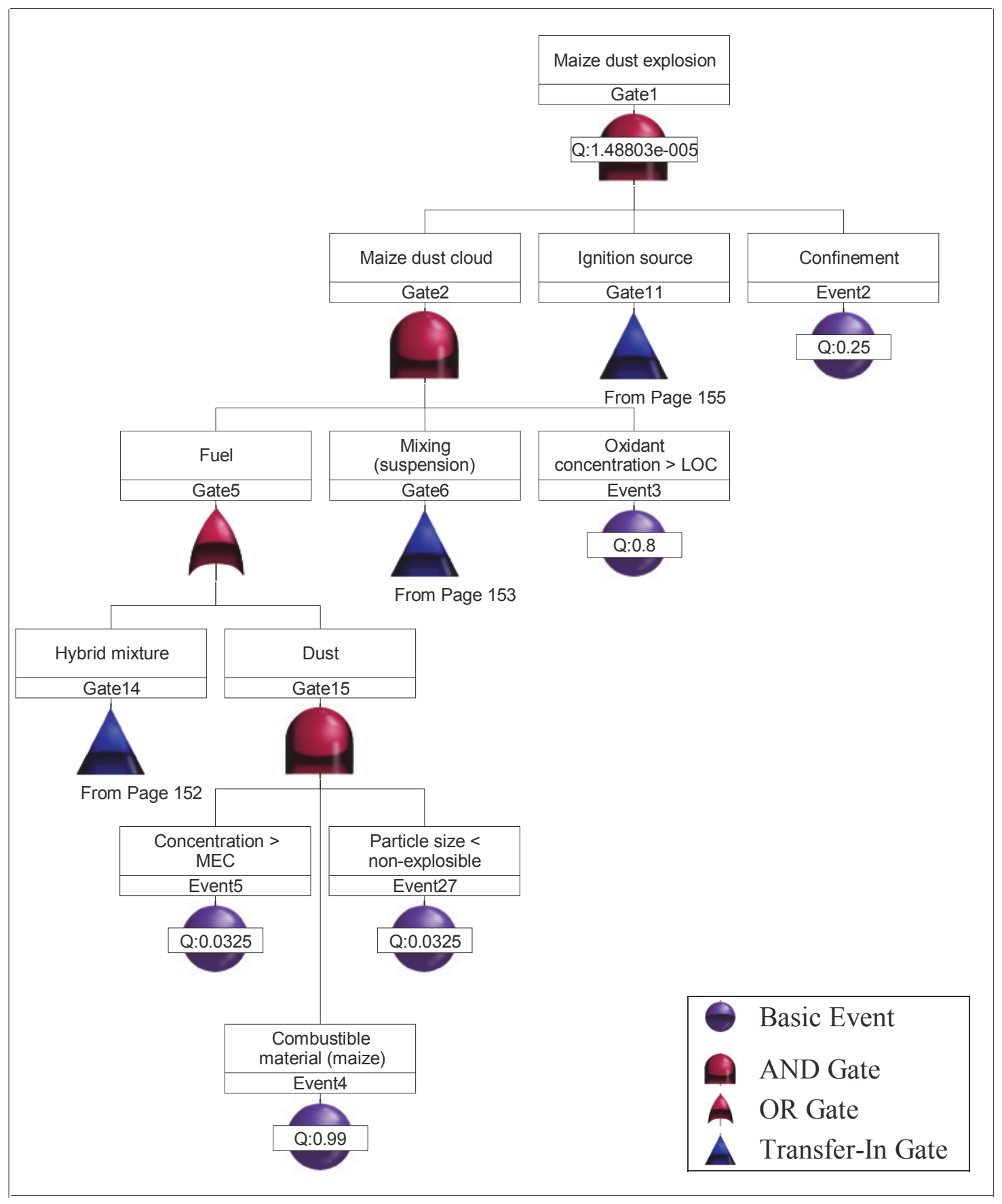

Figure 5.41 Fault Tree Analysis flowchart of the Semabla explosion after application of the QRMF. 


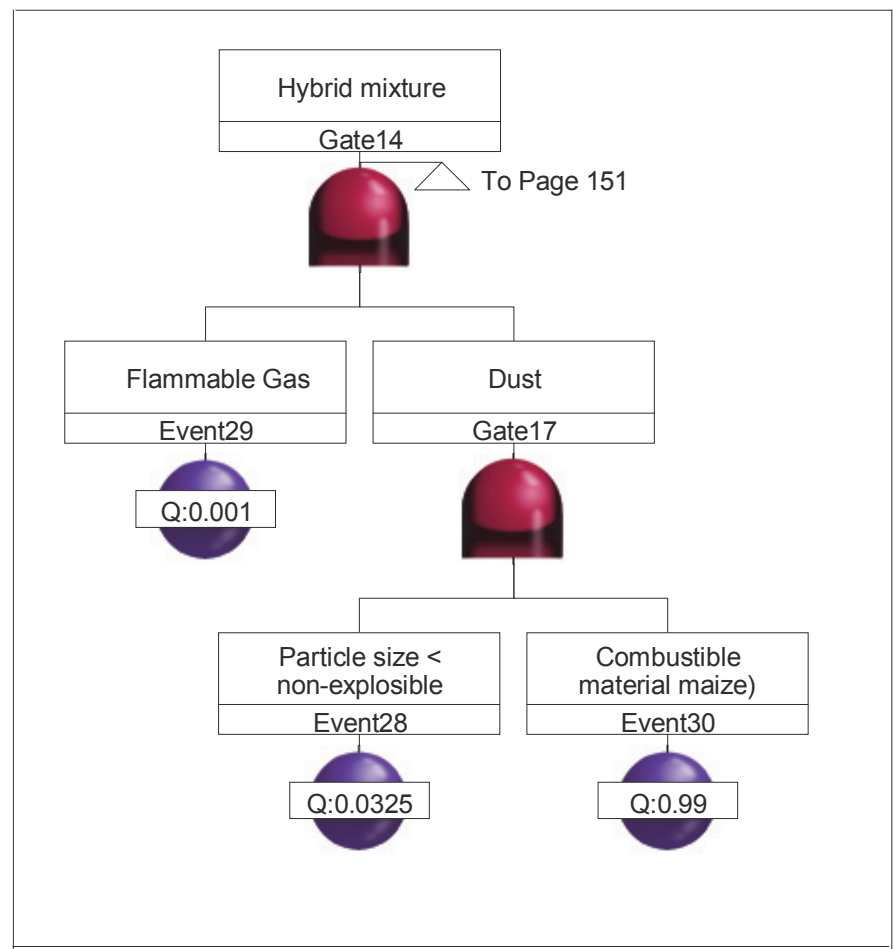




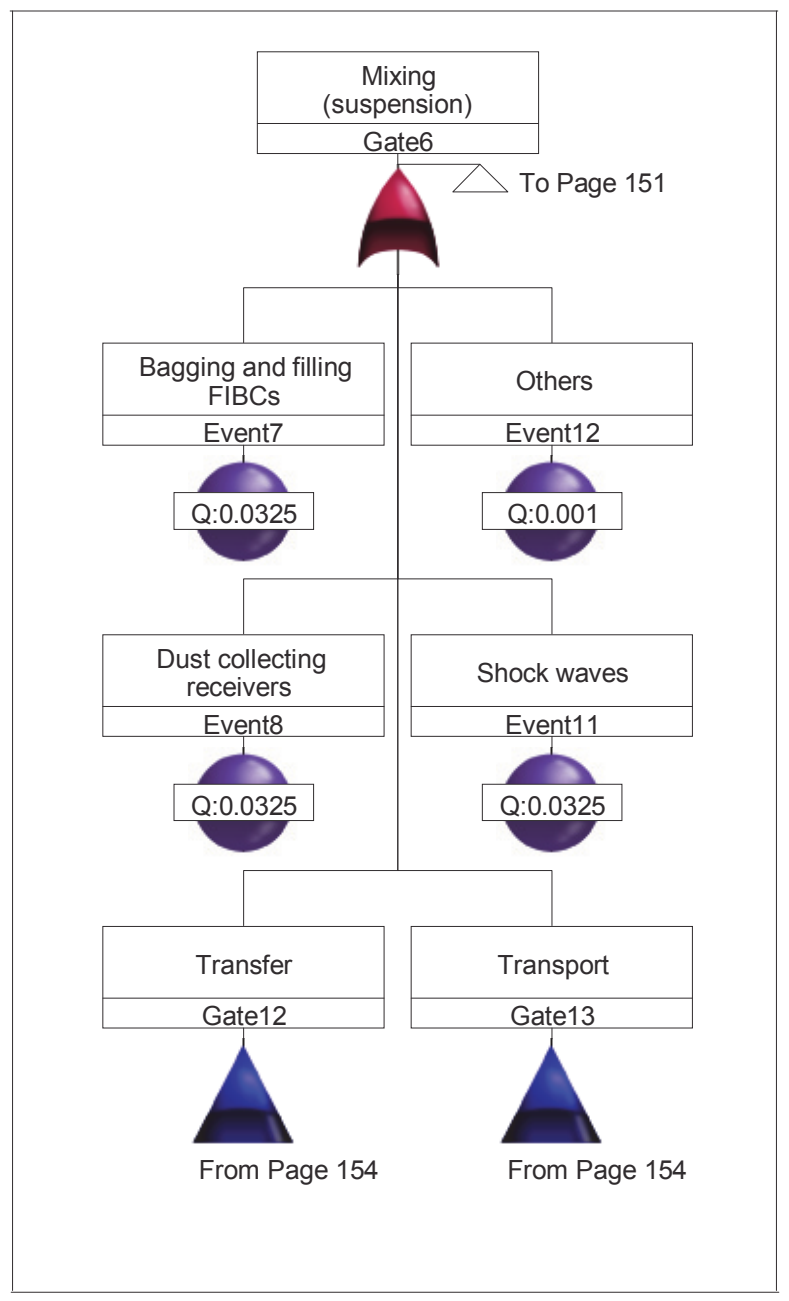



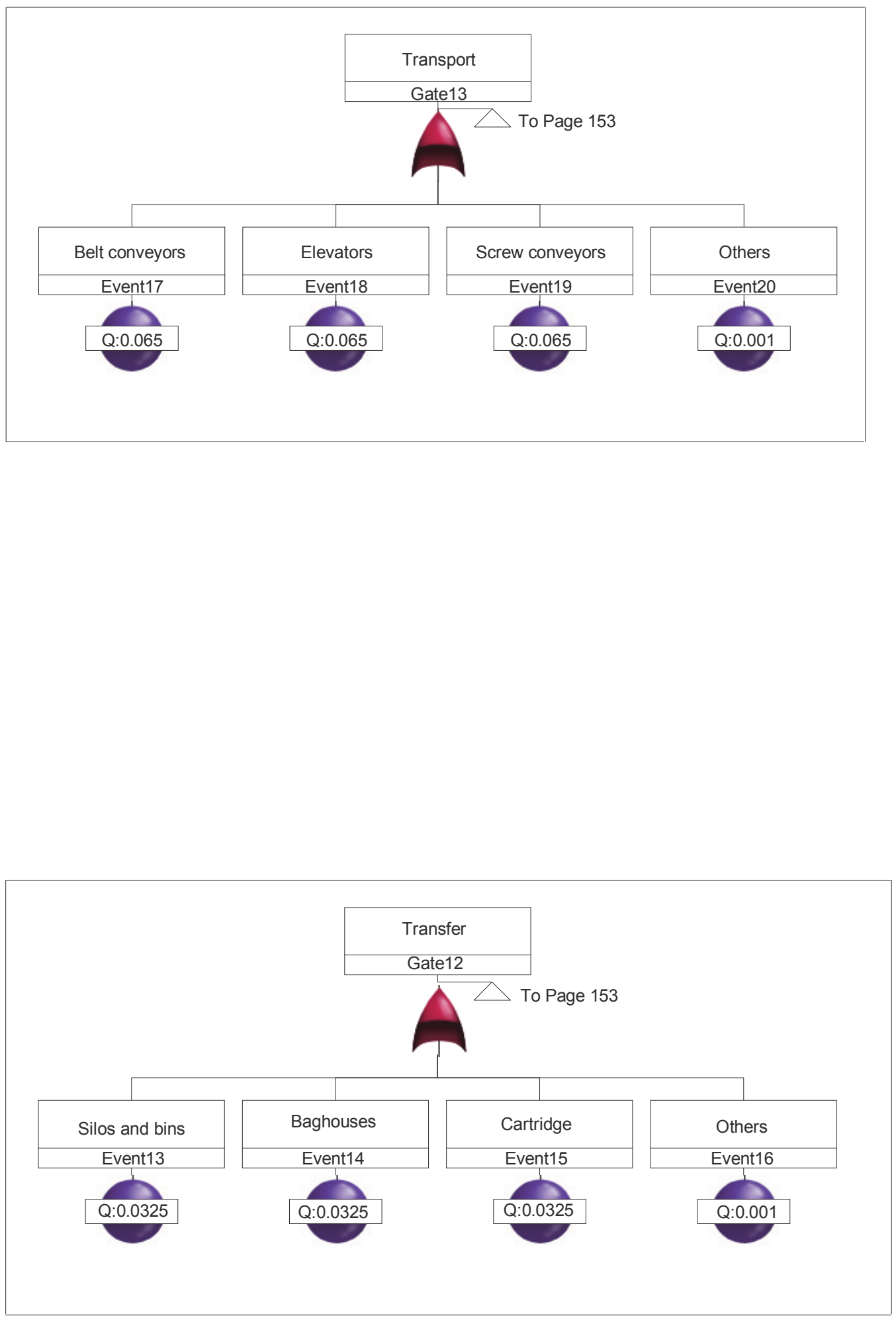


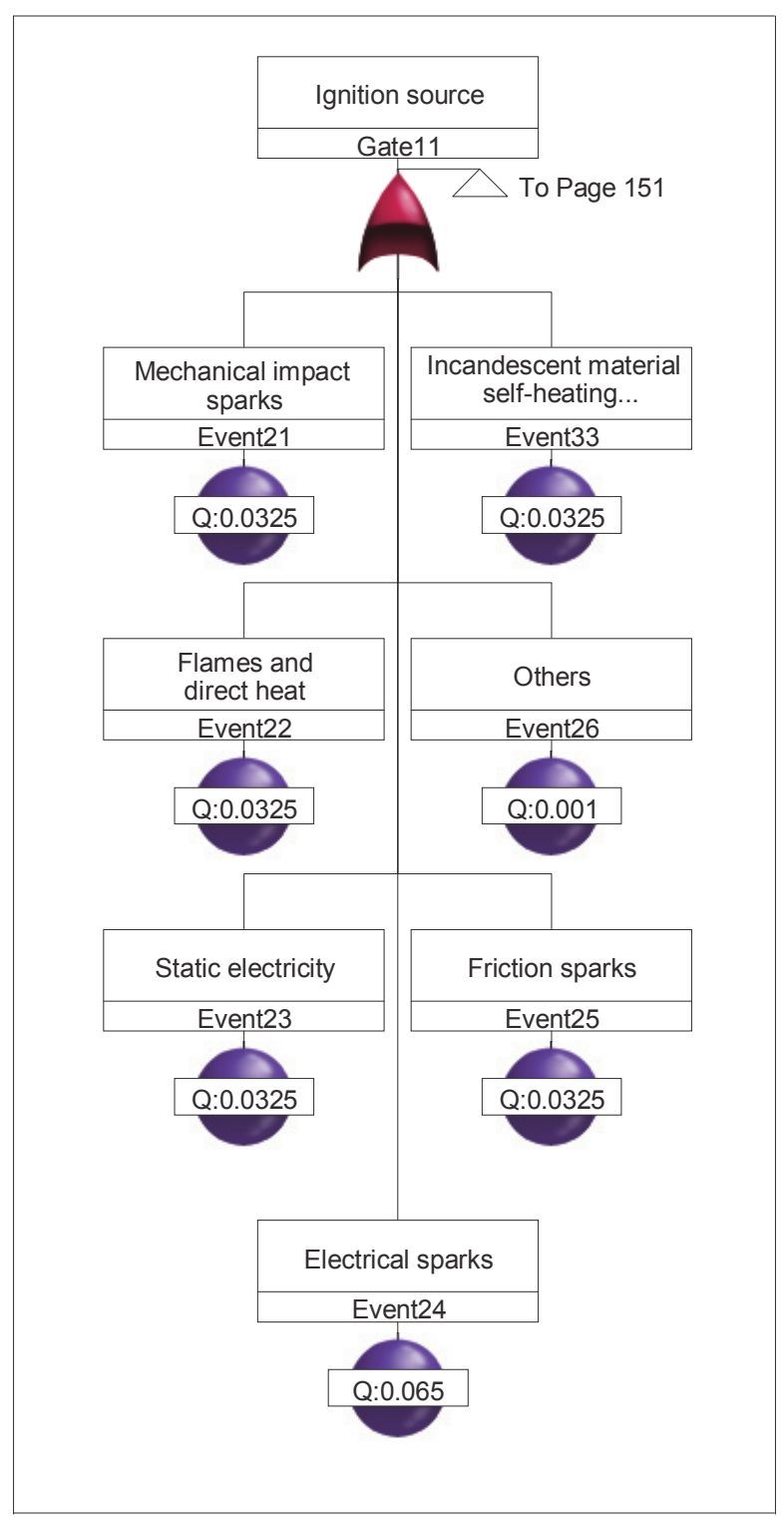

\section{Risk estimation}

The previous simulations and calculations that were achieved after applying the QRMF showed the validation of the framework. Table 5.35 shows remaining consequences of the hybrid mixture explosion, which is very low as can be seen in Table 5.37, and the probability of occurrence was reduced to $1.5 * 10^{-5}$ per year, as can be seen in Figure 5.41 . 
Table 5.37 Individual risk calculations for the Semabla silo, Module $(4,1)$.

\begin{tabular}{|c|c|c|c|c|c|}
\hline $\begin{array}{c}\text { Incident } \\
\text { outcome case }\end{array}$ & $\begin{array}{c}\mathbf{f}_{\mathbf{i}} \\
\text { (per year) }\end{array}$ & $\mathbf{P}_{\mathbf{f}, \mathbf{i}}$ & $\mathbf{f}_{\mathbf{i}} * \mathbf{P}_{\mathbf{f}, \mathbf{i}}$ & $\begin{array}{c}\text { No. of } \\
\text { workers }\end{array}$ & $\begin{array}{l}\text { Estimated no. } \\
\text { of Fatalities }\end{array}$ \\
\hline $\mathrm{I}$ & $1.5 * 10^{-5}$ & $6.95 * 10^{-5}$ & $1.04 * 10^{-9}$ & 10 & 0 \\
\hline $\mathrm{J}$ & $1.5 * 10^{-5}$ & $1.31 * 10^{-4}$ & $1.97 * 10^{-9}$ & 11 & 0 \\
\hline $\mathrm{K}$ & $1.5 * 10^{-5}$ & 0 & 0 & 1 & 0 \\
\hline Average individual risk \\
$\qquad R_{\text {avg }}=\frac{(10) * 1.04 * 10^{-9}+(11) * 1.97 * 10^{-9}+0}{22}=1.5 * 10^{-9}$ \\
\hline
\end{tabular}

$$
\begin{aligned}
& \operatorname{LSIR}_{\mathrm{T}}=1.04 * 10^{-9}+1.97 * 10^{-9}+0=3.0 * 10^{-9} \\
& I S I R=L S I R * P_{L}=3.01 * 10^{-9} * \frac{8}{24}=1.0 * 10^{-9}
\end{aligned}
$$

- Fatal accident rate (FAR)

The FAR is calculated from the average individual risk for the exposed employee population from Equation 3.10.

Fatal accident rate $(F A R)=I S I R * 10^{8} / H=1.0 * 10^{-9} * 10^{8} /(22 * 2000)=$ $2.3 * 10^{-6}$ Fatalities $/ 10^{8}$ man-hours of exposure

- $A L A R P$

Figure 5.42 shows the individual risks at the Semabla grain silo, plotted on an ALARP graph, before and after the QRMF was applied. The individual and societal risk of a dust/hybrid mixture explosion was at first unacceptable $\left(3.0 * 10^{-3}\right)$, but was then reduced to $1.9 * 10^{-9}$, indicating (in theory) a very safe process. This analysis concerns structural destruction, but additional risks persist, such as pressure safety vents that do not open properly, fire, fragments from the explosion, structural weakness in some working areas, etc. 


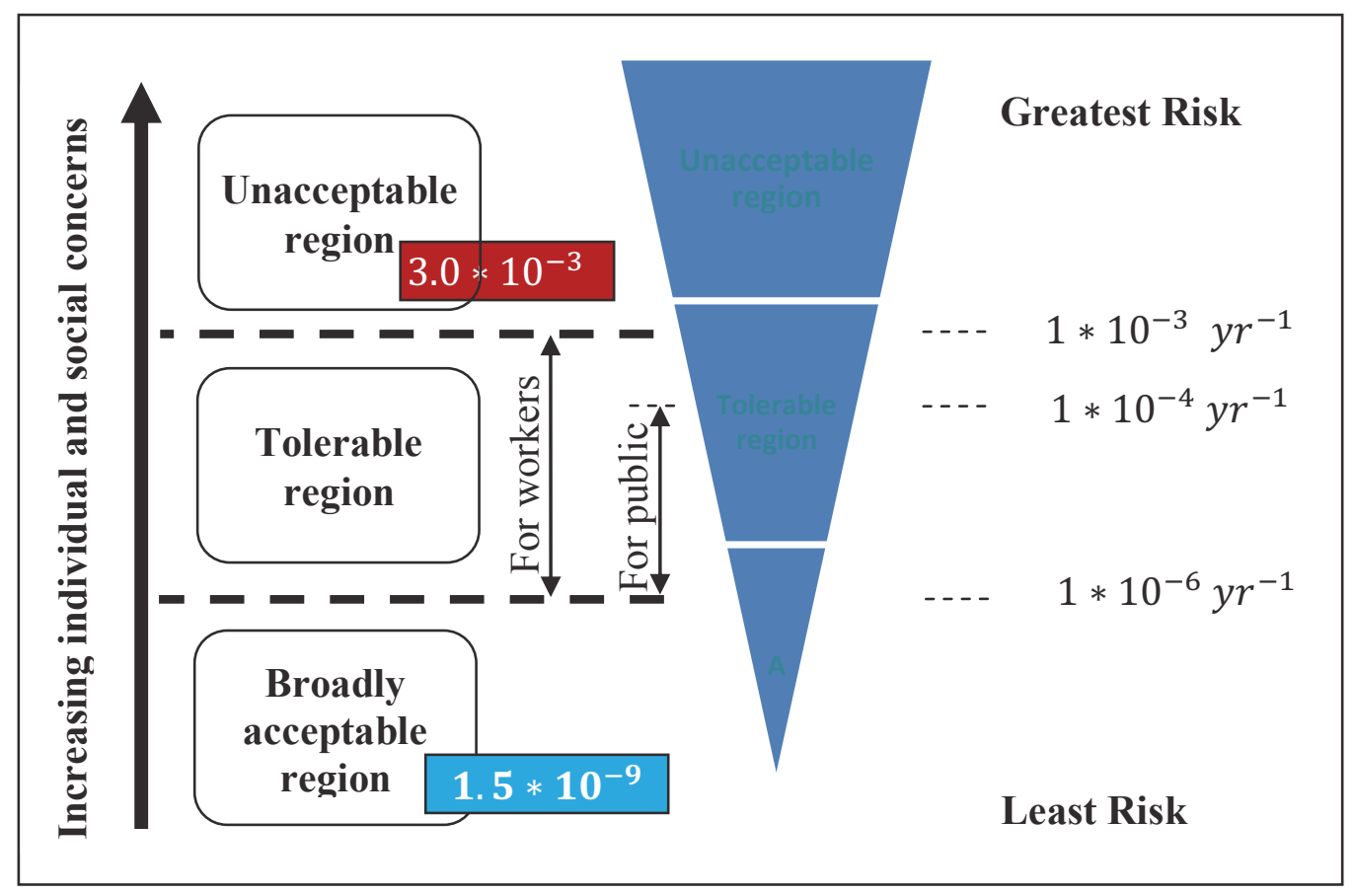

Figure 5.42 HSE frameworks for tolerability of risk (after IET, 2010).

Table 5.38 compares the risk measure results obtained before and after applying the QRMF controls. The numbers show that the total risk has been reduced for each single measure: the probability of occurrence has been reduced, and the IR, LSIR, ISIR and FAR, are very acceptable.

Table 5.38 Summary of the individual risk results for the Semabla storage silo explosion.

\begin{tabular}{|c|c|c|c|c|c|}
\hline & $\begin{array}{c}\text { Probability } \\
\text { of } \\
\text { occurrence }\end{array}$ & $\begin{array}{c}\boldsymbol{I} \boldsymbol{R}_{\text {avg }} \\
\left(\boldsymbol{y} \boldsymbol{r}^{-\mathbf{1}}\right)\end{array}$ & $\boldsymbol{L S I R}$ & $\boldsymbol{I S I R}$ & $\begin{array}{c}\boldsymbol{F A R} \\
\left(\begin{array}{c}\text { Fatalities } / \mathbf{1 0}^{\mathbf{8}} \mathbf{h r s} \\
\text { of exposure }\end{array}\right.\end{array}$ \\
\hline $\begin{array}{c}\text { Before applying } \\
\text { QRMF }\end{array}$ & $4.2 * 10^{-3}$ & $3.0 * 10^{-3}$ & $7.3 * 10^{-3}$ & $2.43 * 10^{-3}$ & 5.5 \\
\hline $\begin{array}{c}\text { After applying } \\
\text { QRMF }\end{array}$ & $1.5 * 10^{-5}$ & $1.5 * 10^{-9}$ & $3.0 * 10^{-9}$ & $1.0 * 10^{-9}$ & $2.3 * 10^{-6}$ \\
\hline
\end{tabular}




\subsection{Hypothetical 400-M³ Polyethylene Storage Silo Dust EXPLOSION ${ }^{2}$}

As mentioned previously, the current work is interested in the QRMF's ability to reduce dust and hybrid mixture explosion risks for industrial-scale process units. One example of this would be the arrangement of storage silos at a polyethylene production facility. Of concern is the maximum explosion pressure to be expected for various combinations of parameters such as explosible dust concentrations, flammable gas percentages, and ignition source locations.

Consequence analysis by means of CFD modeling using DESC was performed for a case study involving a typical industrial-scale $400-\mathrm{m}^{3}$ polyethylene storage silo. The silo has a number of proprietary explosion panels set to open at a pressure well below the maximum overpressure the silo could sustain without damage.

As previously described, DESC requires explosibility data for the material under consideration as would be determined in standardized 20 -L testing. Table 5.39 provides details on the potential dust explosion scenarios considered. All simulations were run at

Table 5.39 Potential dust explosion scenarios for case study.

\begin{tabular}{|c|c|c|c|c|}
\hline $\begin{array}{c}\text { Scenario } \\
\text { No. }\end{array}$ & $\begin{array}{c}\text { Sample No. } \\
\text { from Table 4.1 }\end{array}$ & $\begin{array}{c}\text { Dust } \\
\text { Concentration } \\
\left(\mathbf{g} / \mathbf{m}^{\mathbf{3}}\right)\end{array}$ & $\begin{array}{c}\text { Volume of Dust } \\
\text { Cloud } \\
\mathbf{( m}^{\mathbf{3}} \mathbf{)}\end{array}$ & $\begin{array}{c}\text { Area of } \\
\text { Explosion } \\
\text { Panels }\end{array}$ \\
\hline 1 & A & 500 & 400 & Normal \\
\hline 2 & B & 500 & 400 & Normal \\
\hline 3 & B & 500 & 200 & Normal \\
\hline 4 & B & 250 & 200 & Normal \\
\hline 5 & C & 500 & 400 & Normal \\
\hline 6 & C & 500 & 400 & $\begin{array}{c}\text { Five-fold } \\
\text { Increase }\end{array}$ \\
\hline
\end{tabular}

${ }^{2}$ This case study is part of a published paper referenced as Abuswer et al. (2011). 
consistent operating conditions (excess oxygen, homogeneous dust cloud, complete confinement, etc.) and with a bottom-end ignition source of 10-kJ energy (Abuswer et al., 2011).

The combination of sample characteristics and scenario conditions shown in Tables 4.1 and 5.39, respectively, yields examples of applications that involve both inherently safer design and passive engineered safety. The results of the DESC simulations for the six scenarios given in Table 5.39 are shown in Figures 5.43 to 5.48.

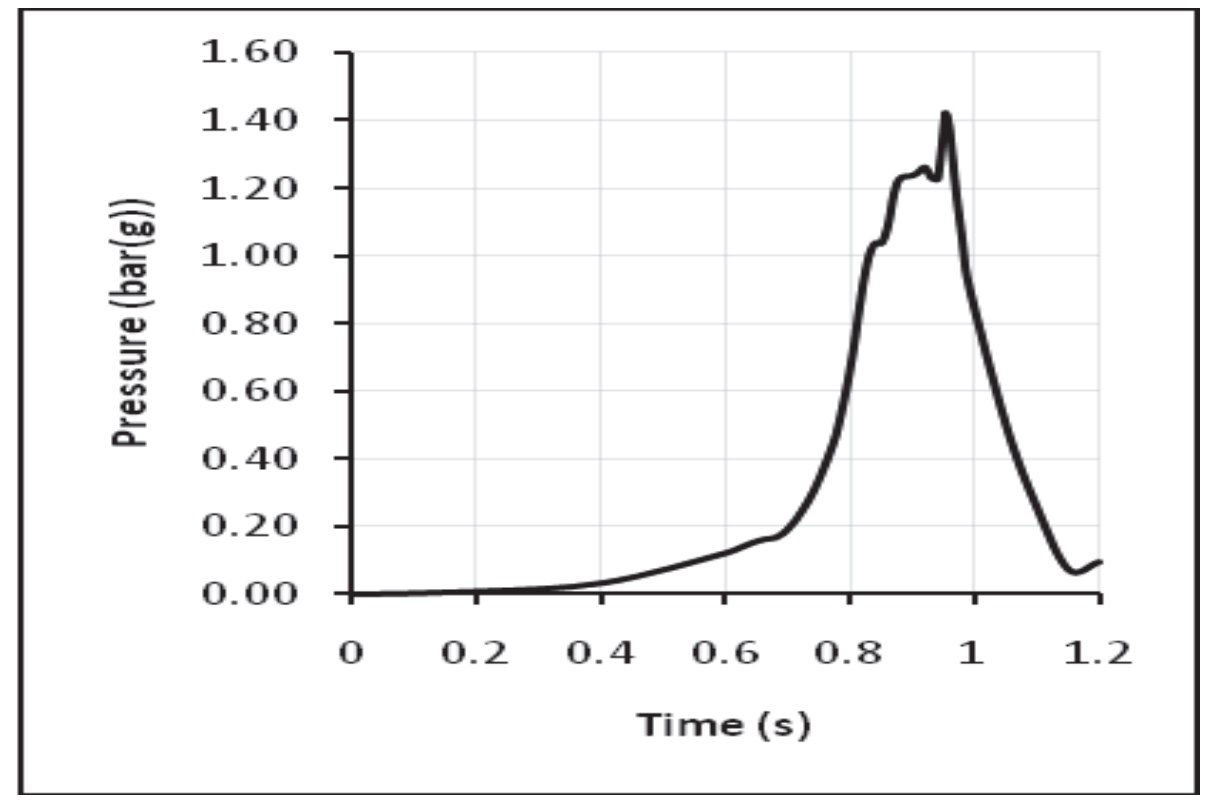

Figure 5.43 DESC simulation of Scenario 1. 


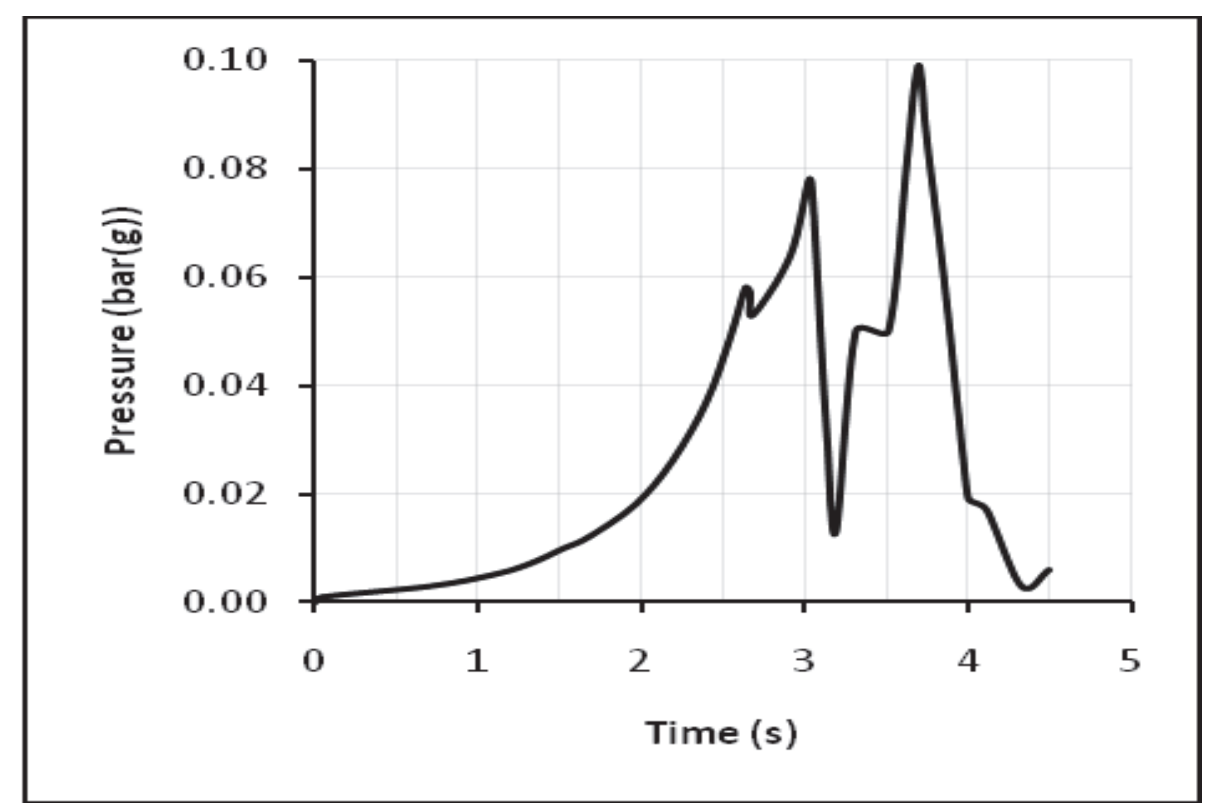

Figure 5.44 DESC simulation of Scenario 2.

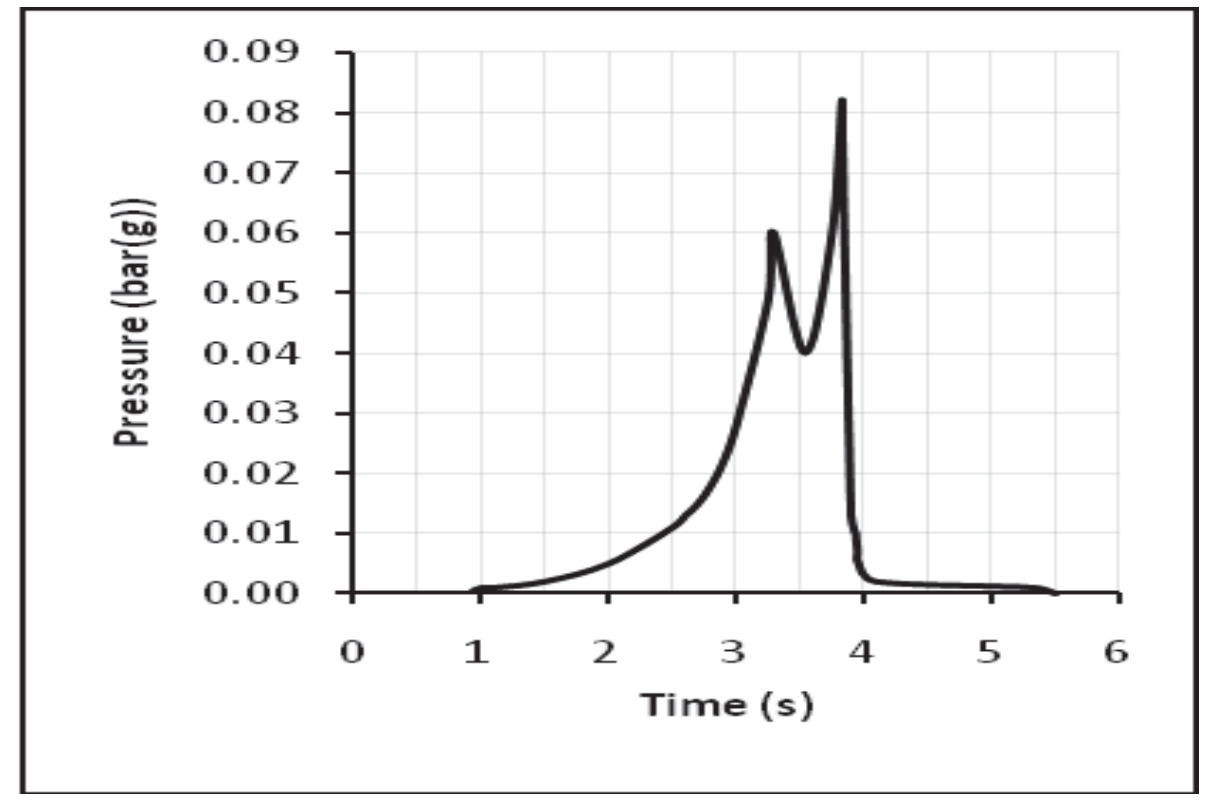

Figure 5.45 DESC simulation of Scenario 3. 


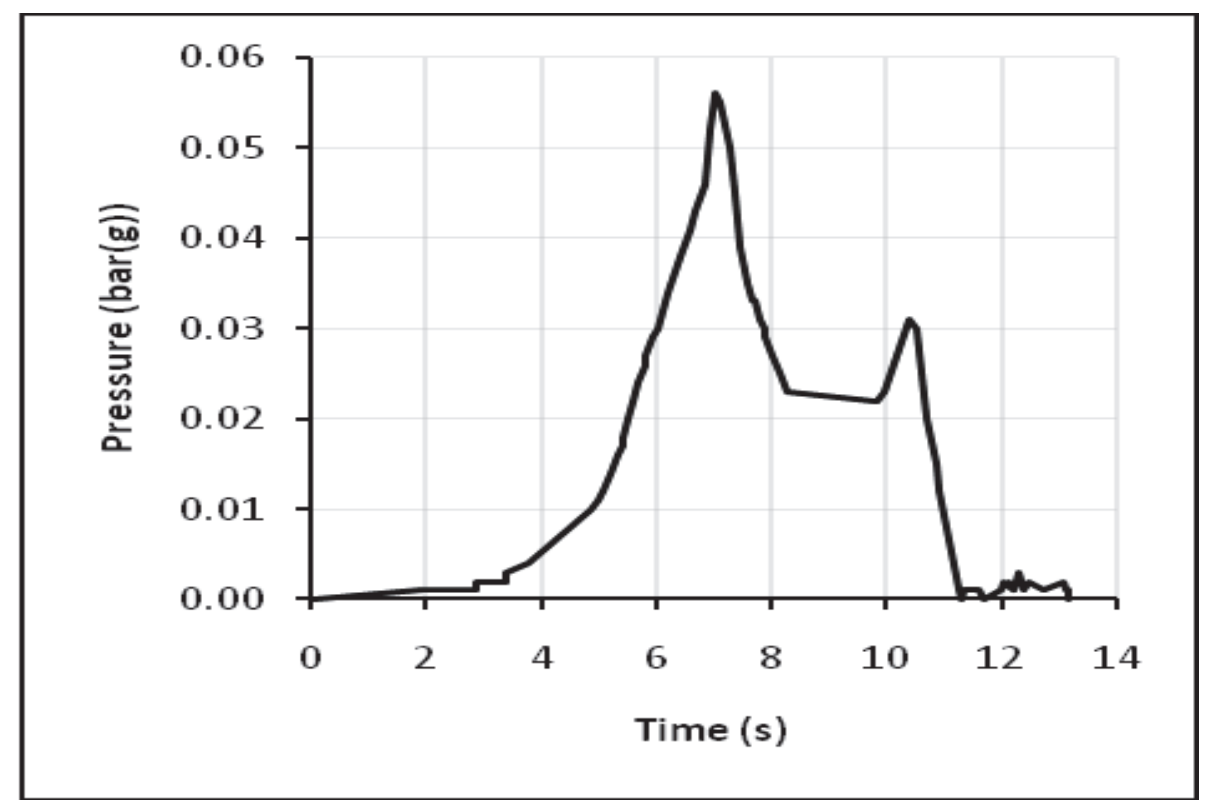

Figure 5.46 DESC simulation of Scenario 4.

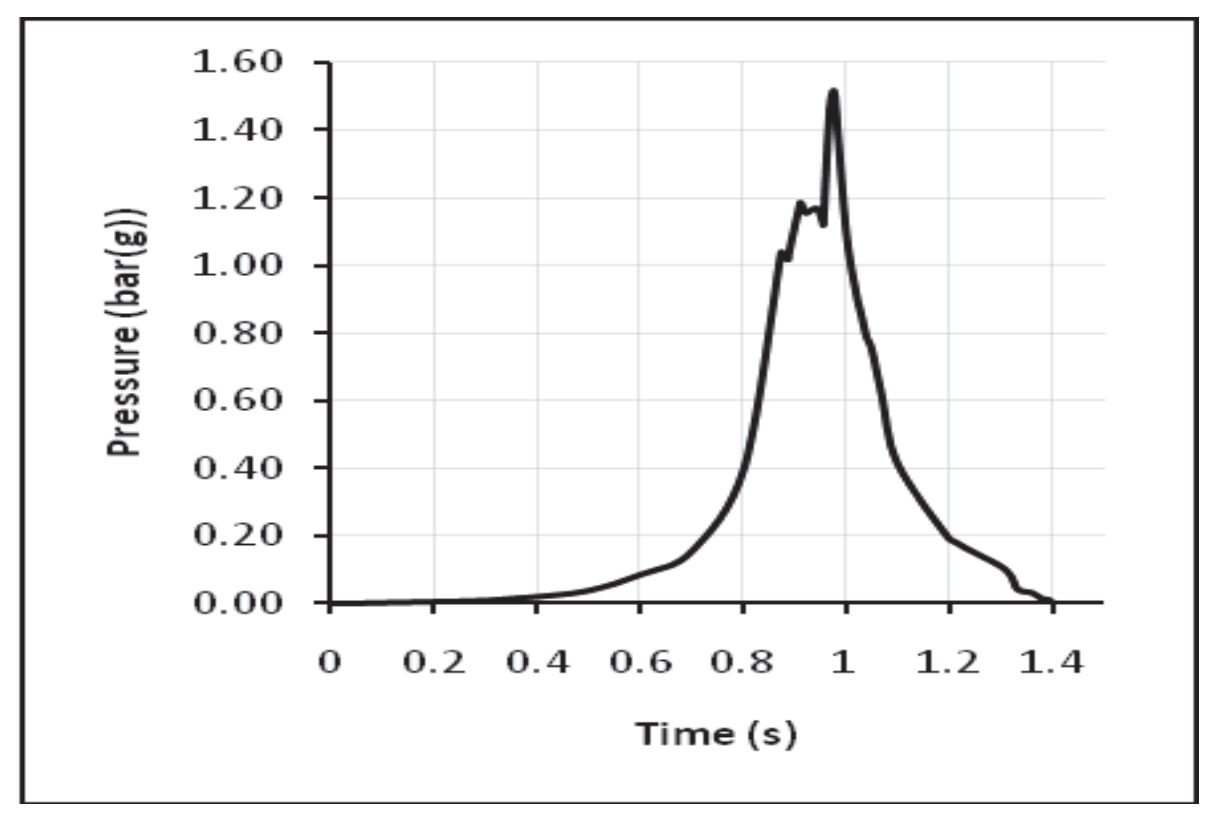

Figure 5.47 DESC simulation of Scenario 5. 


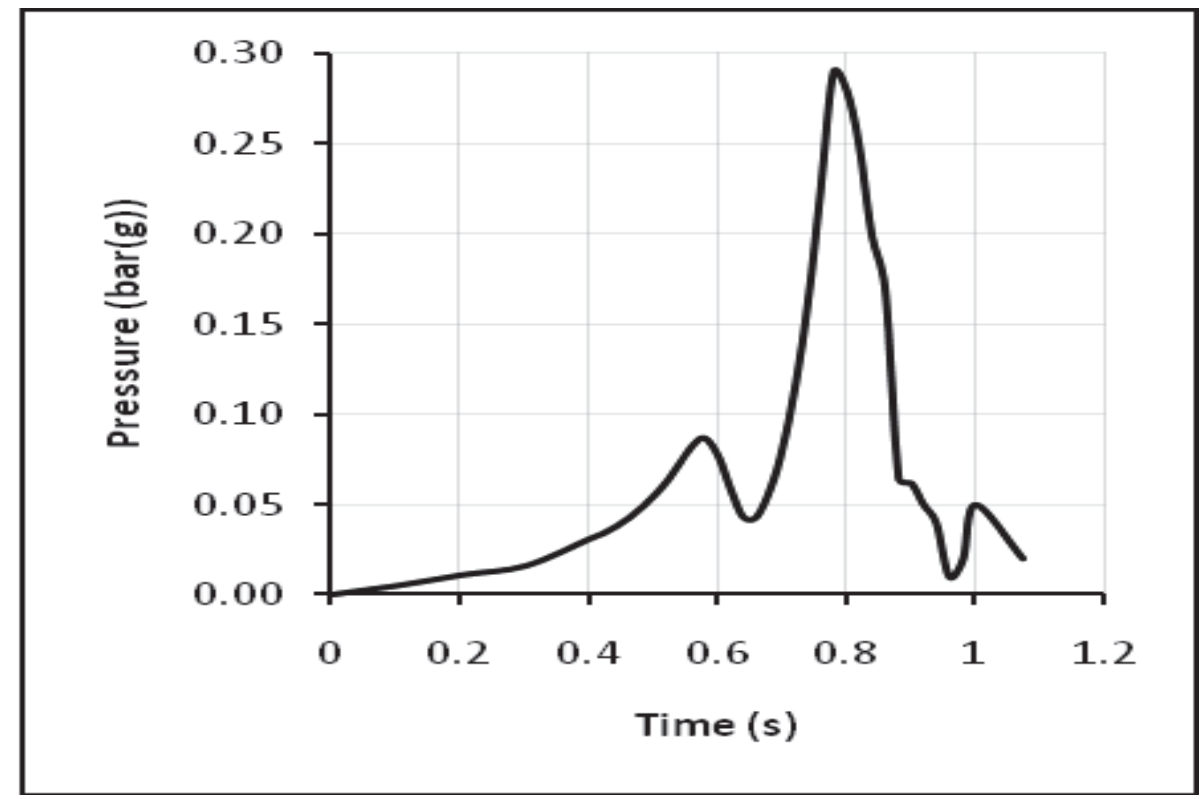

Figure 5.48 DESC simulation of Scenario 6.

Figure 5.43 (Scenario No. 1) shows a full-volume explosion of 48- $\mu \mathrm{m}$ polyethylene for which an overpressure higher than the maximum allowable silo pressure is attained. With application of the inherently safer design principle of moderation, achieved by means of an increase in particle diameter, the overpressure is reduced to a level that will not cause damage to the silo (Figure 5.44 for Scenario No. 2). Comparison of Figures 5.44 and 5.45 (Scenarios No. 2 and 3, respectively) further illustrates the positive impact of inherent safety - in this case, via minimization of the dust cloud volume for a fixed dust concentration. The same trend can be observed in Figures 5.45 and 5.46 (Scenarios No. 3 and 4, respectively), which show the effect of minimization when dust concentration is lowered for a fixed dust cloud volume.

Scenario No. 5, as depicted in Figure 5.47, is the case of a hybrid mixture of $48-\mu \mathrm{m}$ polyethylene with 1-volume \% admixed hexane, explosibility data in Table F.3 (Appendix F). A comparison of Figures 5.43 and 5.47 illustrates the importance of avoiding the formation of hybrid mixtures of combustible dust and flammable gas (a further application of the inherent safety principle of moderation). The decrease in peak 
overpressure in moving from the hybrid-mixture scenario (Figure 5.47) to the dust-only scenario (Figure 5.43) is not, however, significant in this case. A more pronounced overpressure reduction can be achieved with the increased use of passive engineered safety by means of an increase in vent area, as shown in Figure 5.48 (Scenario No. 6). 


\section{CHAPTER 6 CONCLUSIONS AND RECOMMENDATIONS}

\subsection{Conclusions}

Developing a safety management protocol is urgently required to protect industries that involve dust/hybrid mixtures in at least one of their stages. This chapter concludes the work done in this research and summarizes the main idea of each tool that leads to the development of the Quantitative Risk Management Framework (QRMF), which is based in part on the tools developed for process risk reduction.

1. The SCAP algorithm methodology for safety management developed by Khan et al. (2001), envisages the quantitative risk analysis principles as hazard identification, possible accident scenarios, consequence analysis, probability analysis, and risk estimation and evaluation. SCAP is the main methodology on which the QRMF is based. The original contribution is the reformulation of the tool in a general form that can be used for any dust or hybrid mixture explosion prevention or mitigation purpose.

2. The QRA tool for the external safety of industrial plants with a dust explosion hazard that was provided by van der Vort et al. (2007) has been used as a guide to identify external safety scenarios by dividing any given case study into groups of modules.

3. The present research has made a contribution by developing a general Fault Tree Analysis flowchart for dust and hybrid mixture explosion analysis. The QRMF uses FTA through Relex software to calculate dust/hybrid mixture explosion frequencies and their cut sets.

4. DESC makes a significant contribution by simulating different kinds of accident scenarios. It calculates explosion pressure, temperature, velocity, and fuel consumption at each grid cell in the given geometry, thus enabling it to predict the consequence potential of dust/hybrid mixture explosions in industry. DESC is expected to be the future tool for dust explosion simulations (Eckhoff, 2005). The use of this software as a part of the QRMF to assess dust and hybrid mixtures risks is 
novel in the dust explosion prevention/mitigation area.

5. The dust explosion prevention/mitigation approach based on inherent safety that was developed by Amyotte et al. (2003) is used as a main template for the developed QRMF; the current authors' approach, principles, and steps have extended it to include QRA for dust and hybrid mixtures. Additionally, the combination of DESC and Relex software makes a valuable contribution by precisely assessing dust/hybrid mixture explosion risks.

The studies above have, in part, been reformulated to conduct dust and hybrid mixture risk assessment. In conjunction with the DESC and Relex software, they showed effective safety management to mitigate and prevent dust and hybrid mixture explosions, as several case studies in industrial processes have proven. The sequence of the safety management framework elements as the following: identify and characterize hazards theoretically and experimentally, understand hazards by developing possible scenarios, conduct risk estimation, conduct risk evaluation, identify units and incorrect actions that contribute significantly to the probability of a top event, and apply the hierarchy of controls (inherent, engineered, and procedural), has minimized cost and time of risk analysis, and it maximize the QRMF benefits by trying to prevent or mitigate threats inherently. Also the developed implementation flowchart of the conceptual framework facilitates the framework steps.

Several dust explosion tests, for icing and granulated sugar, that were performed in a 20L Siwek chamber for DESC validation and DESC fuel file have given good confidence to the QRMF results; the maximum pressures $\left(\mathrm{P}_{\max }\right)$ of the tests were compared with $\mathrm{P}_{\max }$ values from DESC simulations, with errors found to be less that 5\%. Also, the newly developed FTA for dust and hybrid mixture explosions has worked effectively to determine the explosion probabilities of the top event in the case studies.

The three distinct case studies that have been selected to examine the developed QRMF and the dust explosion FTA: the Imperial Sugar refinery explosion in 2008 in USA, the Semabla grain storage explosion in 1997 in France, and a hypothetical 400- $\mathrm{m}^{3}$ cylindrical 
silo polyethylene dust explosion, can be considered another contribution because they demonstrated practically the QRMF steps. The case studies have reflected the dust and hybrid mixture risks that might threat process industries. DESC has facilitates risk analysis in QRMF; DESC simulated the explosion scenarios, in terms of maximum pressure of each area where the simulations show the explosion pressure zones that led to the destruction of the given process industries. Then the structural damage percentage at each zone was determined by a Probit equation. Risk estimation (risk indices, individual risk, and societal risk) was calculated for the three cases, before and after the framework was applied, with the QRMF showing significant risk reductions in each case.

The QRMF presented in this work can help prevent/mitigate dust and hybrid mixture explosions in process industries, provide an optimal safety level by applying the hierarchy of controls, and present a complete picture of dust and hybrid mixture explosion risks. The value of arranging the safety controls in a hierarchy is minimizing the safety application cost by attempting to prevent explosions through the application of inherent safety standards and procedures. If the risk is still unacceptable, then engineered safety and certain procedural safety measures can be applied to mitigate explosion consequences. 


\subsection{ReCOMMENDATIONS}

Additional work should be undertaken to further develop various aspects of dust and hybrid mixture explosion risk quantification. As new kinds of dust, such as nanomaterials, start to be used in industry, the adoption of safety methodologies involving new technologies is crucial from the outset of a plant's life if explosions are to be avoided. Thus, it is imperative from both a research and safety perspective to:

1. validate the QRMF by using different CFD software and other hazard identification techniques (HAZOP, Dow Relative Ranking, FMEA, or SWIFT (Structured What If Technique), as well as frequency analysis techniques, such as ETA (Event Tree Analysis),

2. develop more precise FTA by considering data uncertainty of the basic causes of explosions,

3. compare DESC with other CFD explosion tools for more validation,

4. use more up-to-date consequence effect models than the Probit model,

5. extend the developed QRMF to prevent/mitigate nanomaterial explosions,

6. extend severity of consequences calculations to include burn deaths from flash fire, deaths, and injuries from impact, and death and injuries from flying fragments, and

7. determine the sizes and locations of pressure relief vents in future case studies in order to achieve maximum protection at minimal cost. 


\section{REFERENCES}

Abbasi, T., \& Abbasi, S. A. (2007). Dust explosions-Cases, causes, consequences, and control. Journal of Hazardous Materials, 140(1-2), 7-44.

Abuswer, M., Amyotte, P. R., \& Khan, F. (2011). A quantitative risk management framework for dust and hybrid mixture explosions, Journal of Loss Prevention in the Process Industries (2011), doi:10.1016/j.jlp.2011.08.010.

Amyotte, P. R. (2010). Dust explosions happen because we believe in unicorns. Paper presented at the Mary Kay O'Connor, Process Safety Centre, Texas A\&M University, USA.

Amyotte, P. R., Goraya, A. U., Hendershot, D. C., \& Khan, F. I. (2007). Incorporation of inherent safety principles in process safety management. Process Safety Progress, 26(4), 333-346.

Amyotte, P., Abuswer, M., Di Benedetto, A., \& Russo, P. (2010). Determination of hybrid mixture explosion severity. 13th International Symposium on Loss Prevention and Safety Promotion in the Process Industries, Brugge, Belgium. , 02, 149-156.

Amyotte, P., Kahn, F., \& Dastidar, A. G. (2003). Reduce dust explosions the inherently safer way. Chemical Engineering Progress, 99(10), 36-43.

Amyotte, P. R., \& Eckhoff, R. K. (2010). Dust explosion causation, prevention and mitigation: An overview. Journal of Chemical Health and Safety, 17(1), 15-28.

Amyotte, P. R., \& McCutcheon, D. J. (2006). Risk management an area of knowledge for all engineers. Discussion paper Research Committee of the Canadian Council of Professional Engineers. 
Amyotte, P. R., Pegg, M. J., \& Khan, F. I. (2009). Application of inherent safety principles to dust explosion prevention and mitigation. Process Safety and Environmental Protection, 87(1), 35-39. doi: 10.1016/j.psep.2008.06.007.

Attwood, D., Khan, F., \& Veitch, B. (2006). Offshore oil and gas occupational accidents - What is important? Journal of Loss Prevention in the Process Industries, 19(5), 386-398.

Bernatik, A., \& Libisova, M. (2004). Loss prevention in heavy industry: Risk assessment of large gasholders. Journal of Loss Prevention in the Process Industries, 17(4), 271 278.

Cameron, I., \& Raman, R. (2005). Process systems risk management. (1st ed.). Burlington, USA: Elsevier.

CCOHS. (2011). OH\&S legislation in Canada - introduction. Retrieved from http://www.ccohs.ca/oshanswers/legisl/intro.html

CCPS. (2000). Guidelines for chemical process quantitative risk analysis. $2^{\text {nd }}$ Edition ed. NY, USA: Center for Chemical Process Safety/AIChE.

CCPS. (2009). Guidelines for developing quantitative safety risk criteria. USA: American Institute of Chemical Engineers, Center for Chemical Process Safety.

Cesana, C., \& Siwek, R. (1998). Operating instructions, 20-L-apparatus. No. B000_053). Switzerland: Kuhner AG. doi:23.04.01 CC.

Cozzani, V., \& Salzano, E. (2004). The quantitative assessment of domino effects caused by overpressure: Part I. Probit models. Journal of Hazardous Materials, 107(3), 6780. doi:10.1016/j.jhazmat.2003.09.013.

Crowl, D., A., \& Louvar, J., F. (Eds.). (2007). Chemical process safety: Fundamentals with applications. 2nd ed. U.S.A.: Prentice Hall, Inc. 
CSB. (2004). West pharmaceutical services dust explosion and fire. No. REPORT NO. 2003-07-I-NC). Washington, DC: U.S. CHEMICAL SAFETY AND HAZARD INVESTIGATION BOARD.

CSB. (2005). Combustible dust fire and explosions - CTA acoustics, inc. No. Report No. 2003-09-I-ky). Corbin, Kentucky: U.S. Chemical Safety and Hazard Investigation Board.

CSB. (2009). Imperial sugar company dust explosion and fire. Retrieved from http://www.csb.gov/investigations/detail.aspx?SID =6

Dastidar, A. G., Nalda-Reyes, B., \& Dahn, J. (2005). Evaluation of dust and hybrid mixture explosion potential in process plants. American Institute of Chemical Engineers, Process Safety Progress, 24(04), 294-298.

Denkevits, A., \& Dorofeev, S. (2004). Dust explosion experiments. No. TW3-TSSSEA5.2. Karisruhe, Germany: Forschungszentrum Karlsruhe GmbH.

Ekhoff R., K. (2003). Dust explosions in the process industries (Third Edition ed.) Gulf Professional Publishing.

Eckhoff, R. K. (2005). Current status and expected future trends in dust explosion research. Journal of Loss Prevention in the Process Industries, 18(4-6), 225-237.

Frank, W. L. (2004). Dust explosion prevention and the critical importance of housekeeping.23(3), 175-184. doi:doi: 10.1002/prs.10033.

Freeman, R. (2011). What to do when nothing has happened. American Institute of Chemical Engineers, Process Safety Progress, 30(3), 204-211.

DOI: $10.1002 /$ prs. 10463.

GexCon. (2009). Global explosion consultants - experts on gas and dust explosions. Retrieved 08/05/2009 from http://www.gexcon.com/DESC. 
Gowland, R. (2006). The accidental risk assessment methodology for industries (ARAMIS)/layer of protection analysis (LOPA) methodology: A step forward towards convergent practices in risk assessment? Journal of Hazardous Materials, 130(3), 307-310.

Groen, F. J., Smidts, C., \& Mosleh, A. (2006). QRAS—-the Quantitative Risk Assessment system. Reliability Engineering \& System Safety, 91(3), 292-304.

Grossel, S. S. (2001). Guidelines for chemical process quantitative risk analysis. Journal of Loss Prevention in the Process Industries, 14(5), 438-439. doi: 10.1016/S09504230(01)00002-X.

Institute of Engineering and Technology (IET). (2010). Determining the acceptability of risk. No. 36. Michael Faraday House, Stevenage, Herts, UK: Health and Safety Policy Advisory Group Secretary, Institute of Engineering and Technology.

James, N. (2007). Qualitative versus quantitative research: Key points in a classic debate. Retrieved 7/4/2007, 2007, from http://wilderdom.com/research/QualitativeVersus QuantitativeResearch.html\#Features).

Kauer, R., Fabbri, L., Giribone, R., \& Heerings, J. (2002). Risk acceptance criteria and regulatory aspects. Operation Maintenance and Material Issues (OMMI), European Technology Development, UK, 1(2).

Khan, F. I., \& Abbasi, S. A. (1998a). MAXCRED - a new software package for rapid risk assessment in chemical process industries. Environmental Modelling and Software, 14(1), 11-25.

Khan, F. I., \& Abbasi, S. A. (1998b). Rapid Quantitative Risk Assessment of a petrochemical industry using a new software package MAXCRED. Journal of Cleaner Production, 6(1), 9-22. 
Khan, F. I., \& Abbasi, S. A. (2000). TORAP - a new tool for conducting rapid riskassessments in petroleum refineries and petrochemical industries. Applied Energy, 65(1-4), 187-210.

Khan, F. (2008). Risk calculations and presentation . Retrieved 12/27 from http://www.engr.mun.ca/ fkhan/EN-6601/risk\%20calc.doc

Khan, F., I., \& Husain, T. (2001). Risk assessment and safety evaluation using probabilistic fault tree analysis. Human and Ecological Risk Assessment, 7(7), 19091927.

Khan, F., I., Iqbal, A., Ramesh, N., \& Abbasi, S. A. (2001). SCAP: A new methodology for safety management based on feedback from credible accident-probabilistic fault tree analysis system. Journal of Hazardous Materials, 87(1-3), 23-56.

Kletz, T. A., \& Amyotte, P. (2010). Process plants : A handbook for inherently safer design. 2nd ed. Boca Raton, FL, USA: CRC Press/Taylor \& Francis Group.

Mannan, S. (2005). Lees' loss prevention in the process industries, volume 1 (3rd Edition ed.). USA: Elsevier.

Marhavilas, P. K., \& Koulouriotis, D. E. (2008). A risk-estimation methodological framework using quantitative assessment techniques and real accidents' data: Application in an aluminum extrusion industry. Journal of Loss Prevention in the Process Industries, 21(6), 596-603.

Marhavilas, P. K., Koulouriotis, D., \& Gemeni, V. (2011). Risk analysis and assessment methodologies in the work sites: On a review, classification and comparative study of the scientific literature of the period 2000-2009. Journal of Loss Prevention in the Process Industries, doi:DOI: 10.1016/j.jlp.2011.03.004.

Markowski, A. S. (2007). exLOPA for explosion risks assessment. Journal of Hazardous Materials, 142(3), 669-676. 
Masson, F. (1998). Explosion of a grain silo, blaye (france) summary report. [France]: Ministry for National and Regional Development and the Environment. ID: 50774149.

Misra, K. (2008). Handbook of performability engineering (1st ed.). UK: Springer Verlag London Limited. doi:10.1007/978-84800-131-2

NFPA. (2011). National fire protection association. Retrieved from http://www.nfpa.org/index.asp?cookie\%5Ftest=1

NOHSAC. (2007). National profile of Occupational Health and Safety in New Zealand : Report to the minister of labour. Retrieved from http://www.nohsac.govt.nz/national_profile/index.php?section=sec5:s1:p018:

OSHA. (2007). Combustible dust national emphasis program. No. CPL 03-00-006). Washington, DC, U.S.A.: U.S. Department of Labor.

OSHA. (2011). Combustible dust national emphasis program. Retrieved from http://www.osha.gov/pls/oshaweb/owadisp.show_document?p_table=DIRECTIVES $\& p \_i d=3729$

Papazoglou, I. A., Bellamy, L. J., Hale, A. R., Aneziris, O. N., Ale, B. J. M., Post, J. G., \& Oh, J. I. H. (2003). I-risk: Development of an integrated technical and management risk methodology for chemical installations. Journal of Loss Prevention in the Process Industries, 16(6), 575-591.

Pula, R., Khan, F. I., Veitch, B., \& Amyotte, P. R. (2005). Revised fire consequence models for offshore Quantitative Risk Assessment. Journal of Loss Prevention in the Process Industries, 18(4-6), 443-454. 
Rogers, R. L. 2000. Methodolgy for the risk assessment of unit operations and equipment for use in potentially explosive atmospheres. INBUREX, Germany: The RASE project (Risk Assessment of Unit Operations and Equipment) / EU Commission project.

Skjold, T. (2007). Review of the DESC project. Journal of Loss Prevention in the Process Industries, 20(4-6), 291-302.

Tweeddale, M. (2003). Managing risk and reliability of process plants. USA: Gulf Professional Pub., Elsevier Science.

van der Voort, M. M., Klein, A. J. J., deMaaijer, M., van den Berg, A. C., van Deursen, J. R., \& Versloot, N. H. A. (2007). A Quantitative Risk Assessment tool for the external safety of industrial plants with a dust explosion hazard. Journal of Loss Prevention in the Process Industries, 20(4-6), 375-386.

Wilson, L., \& McCutcheon, D. (Eds.). (2003). Industrial safety and risk management. T6G 2E1. Faculty of Engineering, University of Alberta, Edmonton.

Woodruff, J. M. (2005). Consequence and likelihood in risk estimation: A matter of balance in UK health and safety risk assessment practice. Safety Science, 43(5-6), 345-353. doi: 10.1016/j.ssci.2005.07.003. 
Appendix A Industries with combustible dusts 
Table A.1 Industries with more frequent and/or high consequence combustible dust explosions/fires (OSHA, 2007).

\begin{tabular}{|c|l|c|}
\hline SICS* & \multicolumn{1}{|c|}{ Industry } & NAICS** \\
\hline 2046 & Wet Corn Milling & 311221 \\
\hline 4911 & $\begin{array}{l}\text { Electric Services --Establishments engaged in the generation, } \\
\text { transmission, and/or distribution of electric energy for sale }\end{array}$ & 221112 \\
\hline 2041 & Flour and Other Grain Mill Products & 311211 \\
\hline 2493 & Reconstituted Wood Products & 321219 \\
\hline 2899 & Chemicals and Chemical Preparations, Not Elsewhere Classified & 325510, \\
\hline 2099 & $\begin{array}{l}\text { Prepared Foods and Miscellaneous Food Specialties, not } \\
\text { Elsewhere Classified }\end{array}$ & 311212 \\
\hline 3471 & Electroplating, Plating, Polishing, Anodizing, and Coloring & 332813 \\
\hline 3341 & Secondary Smelting and Refining of Nonferrous Metals & 331314 \\
\hline 2834 & Pharmaceutical Preparations & 325412 \\
\hline 2499 & Wood Products, Not Elsewhere Classified & 321920, \\
\hline 2421 & Sawmills and Planing Mills, General & 321219 \\
\hline 2062 & Cane Sugar Refining & 321113 \\
\hline 2063 & $\begin{array}{l}\text { Beet Sugar (Establishments Primarily Engaged in Manufacturing } \\
\text { Sugar From Sugar Beets. }\end{array}$ & 311313 \\
\hline 3061 & Molded, Extruded, and Lathe-Cut Mechanical Rubber Goods & 326291 \\
\hline 3714 & Motor Vehicle Parts and Accessories & 336322 \\
\hline 3365 & Aluminum Foundries & 331524 \\
\hline
\end{tabular}

* The Standard Industrial Classification

** North American Industry Classification System 
Table A.2 Industries that may have combustible dusts (OSHA, 2007)

\begin{tabular}{|c|c|c|}
\hline SICS & Industry & NAICS \\
\hline 0723 & Crop Preparation Services for Market, Except Cotton Ginning & $\begin{array}{l}115114 \\
115111\end{array}$ \\
\hline 2052 & $\begin{array}{l}\text { Fresh cookies, crackers, pretzels, and similar "dry" bakery } \\
\text { products. }\end{array}$ & 311821 \\
\hline 2062 & Refining purchased raw cane sugar and sugar syrup. & 311312 \\
\hline 2087 & $\begin{array}{l}\text { Flavoring extracts, syrups, powders, and related products, not } \\
\text { elsewhere classified. }\end{array}$ & 311930 \\
\hline 2099 & $\begin{array}{l}\text { Prepared foods and miscellaneous food specialties, not elsewhere } \\
\text { classified. }\end{array}$ & 311212 \\
\hline 2221 & Broadwoven Fabric Mills, Manmade Fiber and Silk & 313210 \\
\hline 2262 & Finishers of Broadwoven Fabrics of Manmade Fiber and Silk & 313311 \\
\hline 2299 & Textile Goods, Not Elsewhere Classified & 313111 \\
\hline 2421 & Sawmills and Planing Mills, General & 321113 \\
\hline 2431 & Millwork & 321911 \\
\hline 2434 & Wood Kitchen Cabinets & 33711 \\
\hline 2439 & Structural Wood Members, Not Elsewhere Classified & $\begin{array}{l}321213, \\
321214 \\
\end{array}$ \\
\hline 2452 & Prefabricated Wood Buildings and Components & 321992 \\
\hline 2493 & Reconstituted Wood Products & 321219 \\
\hline 2499 & Wood Products, Not Elsewhere Classified & $\begin{array}{l}321920, \\
321219\end{array}$ \\
\hline 2511 & Wood Household Furniture, Except Upholstered & 337122 \\
\hline 2591 & Drapery Hardware and Window Blinds and Shades & 337920 \\
\hline 2819 & Industrial Inorganic Chemicals, Not Elsewhere Classified & $\begin{array}{l}325188, \\
325998, \\
331311 \\
\end{array}$ \\
\hline 2821 & $\begin{array}{l}\text { Plastic Materials, Synthetic Resins, and Nonvulcanizable } \\
\text { Elastomers }\end{array}$ & 325211 \\
\hline 2823 & Cellulosic Manmade Fibers & 325221 \\
\hline 2834 & Pharmaceutical Preparations & 325412 \\
\hline 2841 & Soap and Other Detergents, Except Specialty Cleaners & 325611 \\
\hline
\end{tabular}




\begin{tabular}{|c|c|c|}
\hline SICS & Industry & NAICS \\
\hline 2851 & Paints, Varnishes, Lacquers, Enamels, and Allied Products & 32551 \\
\hline 2861 & Gum and Wood Chemicals & 325191 \\
\hline 2899 & Chemicals and Chemical Preparations, Not Elsewhere Classified & $\begin{array}{l}325510, \\
325998\end{array}$ \\
\hline 3011 & Tires And Inner Tubes & 326211 \\
\hline 3061 & Molded, Extruded, and Lathe-Cut Mechanical Rubber Goods & 326291 \\
\hline 3069 & Fabricated Rubber Products, Not Elsewhere Classified & 326299 \\
\hline 3081 & Unsupported Plastics Film and Sheet & 326113 \\
\hline 3082 & Unsupported Plastics Profile Shapes & 326121 \\
\hline 3086 & Plastics Foam Products & $\begin{array}{l}326140, \\
326150\end{array}$ \\
\hline 3087 & Custom Compounding of Purchased Plastics Resins & 325991 \\
\hline 3089 & Plastics Products, Not Elsewhere Classified & 326199 \\
\hline 3291 & Abrasive Products & 327910 \\
\hline 3313 & Alumina and Aluminum Production and Processing & 331312 \\
\hline 3334 & Primary Production of Aluminum & 331312 \\
\hline 3341 & Secondary Smelting and Refining of Nonferrous Metals & 331314 \\
\hline 3354 & Aluminum Extruded Products & 331316 \\
\hline 3363 & Aluminum Die-Castings & 331521 \\
\hline 3365 & Aluminum Foundries & 331524 \\
\hline 3369 & Nonferrous Foundries, Except Aluminum and Copper & 331528 \\
\hline 3398 & Metal Heat Treating & 332811 \\
\hline 3441 & Metal Cans & 332431 \\
\hline 3469 & Metal Stampings, Not Elsewhere Classified & 332116 \\
\hline 3471 & Electroplating, Plating, Polishing, Anodizing, and Coloring & 332813 \\
\hline 3479 & Coating, Engraving, and Allied Services, Not Elsewhere Classified & 332812 \\
\hline 3496 & Miscellaneous Fabricated Wire Products & 332618 \\
\hline 3499 & Fabricated Metal Products, Not Elsewhere Classified & 332999 \\
\hline 3548 & Lighting Equipment, Not Elsewhere Classified & 335129 \\
\hline 3644 & Noncurrent-Carrying Wiring Devices & 335932 \\
\hline
\end{tabular}




\begin{tabular}{|l|l|c|}
\hline SICS & \multicolumn{1}{|c|}{ Industry } & NAICS \\
\hline 3714 & Motor Vehicle Parts and Accessories & 336322 \\
\hline 3761 & Guided Missiles and Space Vehicles & 336414 \\
\hline 3799 & Transportation Equipment, Not Elsewhere Classified & 333924 \\
\hline 3995 & Burial Caskets & 339995 \\
\hline \multirow{2}{*}{3999} & Manufacturing Industries, Not Elsewhere Classified & 321999, \\
& & 325998, \\
\hline 4221 & Farm product warehousing and storage & 493130 \\
\hline 4911 & $\begin{array}{l}\text { Electric Services Establishments engaged in the generation, } \\
\text { transmission, and/or distribution of electric energy for sale. }\end{array}$ & 221112 \\
\hline 4952 & Sanitary treatment facilities & 221320 \\
\hline 4953 & Refuse Systems & 562920 \\
\hline 5093 & Scrap and waste materials & 423930 \\
\hline 5162 & Plastics materials and basic forms and shapes & 424610 \\
\hline
\end{tabular}


Appendix B Examples of dust explosion incidents 
Table B.1 Illustrative examples of dust explosion incidents, 1911-2004 (OSHA, 2007)

\begin{tabular}{|c|c|c|c|c|}
\hline Date & Location & Material & Plant / building & Dead / injured \\
\hline 1785 & Turin, Italy & Wheat flour & Bakery & $2 \mathrm{i}$ \\
\hline 1807 & $\begin{array}{l}\text { Leiden, The } \\
\text { Netherlands }\end{array}$ & Black powder & Ship & $151 \mathrm{~d} / 2000 \mathrm{i}$ \\
\hline 1911 & Glascow, UK & $\mathrm{a}$ & $\mathrm{a}$ & $5 \mathrm{~d} / 8 \mathrm{i}$ \\
\hline 1911 & Liverpool, UK & a & a & $37 \mathrm{~d} / 100 \mathrm{i}$ \\
\hline 1911 & Manchester, UK & $\mathrm{a}$ & a & $3 \mathrm{~d} / 5 \mathrm{i}$ \\
\hline 1913 & Manchester, UK & a & a & $3 \mathrm{~d} / 5 \mathrm{i}$ \\
\hline 1916 & Duluth, MN & Grain & Steel bin & - \\
\hline 1919 & Cedar Rapids, IA & Corn starch & Starch plant & $43 \mathrm{~d}$ \\
\hline 1924 & Peking, IL & Corn starch & Starch plant & $42 d$ \\
\hline 1924 & USA & Sulphide dust & a & $1 \mathrm{~d} / 6 \mathrm{i}$ \\
\hline 1924 & USA & Sulphide dust & a & $1 \mathrm{~d} / 1 \mathrm{i}$ \\
\hline 1924 & USA & Sulphide dust & a & $2 \mathrm{~d} / 1 \mathrm{i}$ \\
\hline 1926 & USA & Sulphide dust & $\mathrm{a}$ & $3 \mathrm{~d} / 1 \mathrm{i}$ \\
\hline 1930 & Liverpool, UK & a & a & $11 \mathrm{~d} / 32 \mathrm{i}$ \\
\hline 1944 & Kansas City, KS & Grain dust & a & a \\
\hline 1949 & Port Colbourne, CA & Grain & Steel bin & - \\
\hline 1952 & Bound Brook, NJ & $\begin{array}{c}\text { Phenolic resin } \\
\text { dust }\end{array}$ & Hammer mill & $5 \mathrm{~d} / 21 \mathrm{i}$ \\
\hline 1952 & Saskatchewan & Grain dust & Shipping bin & $6 \mathrm{~d} / 14 \mathrm{i}$ \\
\hline 1955 & Waynesboro, GA & Grain dust & Feed plant & $3 \mathrm{~d} / 13 \mathrm{i}$ \\
\hline 1956 & South Chicago & Grain dust & Elevator & - \\
\hline 1958 & Kansas City & Grain dust & Elevator & - \\
\hline 1960 & Canada & Sulphide dust & a & $2 \mathrm{~d} /-$ \\
\hline 1960 & Albern, Vienna & Grain dust & a & - \\
\hline 1962 & St. Louis, MO & Grain dust & Feed plant & $3 \mathrm{~d} / 13 \mathrm{i}$ \\
\hline 1964 & Paisley, UK & a & a & $2 \mathrm{~d} / 34 \mathrm{i}$ \\
\hline 1965 & London, UK & Flour & Flour mill & $4 d / 37 i$ \\
\hline 1969 & Sweden & Sulphide dust & a & $2 \mathrm{~d} / 1 \mathrm{i}$ \\
\hline 1970 & Kiel, FRG & Grain dust & Grain silo & $6 \mathrm{~d} / 18 \mathrm{i}$ \\
\hline 1970 & Germany & Grain dust & $\begin{array}{c}\text { Silos on shipping } \\
\text { canal }\end{array}$ & $\begin{array}{c}6 \mathrm{~d} / 17 \mathrm{i}, \text { loss } \$ 10 \\
\text { million }\end{array}$ \\
\hline
\end{tabular}




\begin{tabular}{|c|c|c|c|c|}
\hline 1970 & Norway & Wheat grain dust & Silo & $\mathrm{a}$ \\
\hline 1971 & New Orleans & Bushel & Elevator & a \\
\hline 1972 & Norway & Silicon & Milling section & $5 \mathrm{~d} / 4 \mathrm{i}$ \\
\hline 1973 & Norway & Aluminum & Mixing vessel & $5 \mathrm{~d} / 2 \mathrm{i}$ \\
\hline 1974 & Canada & Sulphide dust & Fox mines & $\mathrm{a}$ \\
\hline 1974 & Preska, South Africa & Sulphide dust & Mines & a \\
\hline 1975 & Norway & Fish meal & $\begin{array}{l}\text { Fish meal } \\
\text { grinding plant }\end{array}$ & $1 \mathrm{~d} / 1 \mathrm{i}$ \\
\hline 1976 & Norway & Barley/oats dust & Silo & - \\
\hline 1976 & Oslo, Norway & $\begin{array}{c}\text { Malted barley } \\
\text { dust }\end{array}$ & Silo & - \\
\hline 1977 & Galvesto, TX & Grain dust & Grain silo & $15 \mathrm{~d}$ \\
\hline 1977 & Westwego, Louisiana & Grain dust & Grain silo & $36 \mathrm{~d} / 10 \mathrm{i}$ \\
\hline 1979 & Lerida, Spain & Grain dust & Grain silo & $7 \mathrm{~d}$ \\
\hline 1979 & Canada & Sulphide dust & Ruttan mines & $\mathrm{a}$ \\
\hline 1980 & Germany & Coal & Cement factory & - \\
\hline 1980 & Iowa, USA & Corn dust & Bucket elevator & - \\
\hline 1980 & Minnesota, USA & Grain dust & $\begin{array}{l}\text { Cross tunnel, } \\
\text { bucket elevators }\end{array}$ & $13 \mathrm{i}$ \\
\hline 1980 & Naples, Italy & Grain dust & Grain silo & $8 \mathrm{i}$ \\
\hline 1980 & Ohama, NE, USA & Grain dust & Head house & Loss $\$ 3,300,000$ \\
\hline 1980 & St. Joseph, MO, USA & Grain dust & Shipping bin & $\begin{array}{l}1 \mathrm{~d} / 4 \mathrm{i}, \text { loss } \\
\$ 2,000,000\end{array}$ \\
\hline 1981 & Canada & Sulphide dust & Mattabi mines & a \\
\hline 1981 & Corpus Christi, TX & Grain dust & Bucket elevator & $9 \mathrm{~d} / 30 \mathrm{i}$ \\
\hline 1981 & Bellwood, NE, USA & Grain dust & Bucket elevator & Loss $\$ 6,400,000$ \\
\hline 1981 & Germany & Coal & $\begin{array}{l}\text { Coal dust burner } \\
\text { plant, cement } \\
\text { works }\end{array}$ & - \\
\hline 1982 & $\begin{array}{l}\text { British Columbia, } \\
\text { Canada }\end{array}$ & Coal & Silo & - \\
\hline 1983 & Anglesey, UK & Aluminum & $\begin{array}{l}\text { Aluminum } \\
\text { powder } \\
\text { production }\end{array}$ & $2 \mathrm{i}$ \\
\hline 1984 & USA & Caol & Silo & - \\
\hline 1985 & Australia & Sulphide dust & Elura mines & $\mathrm{a}$ \\
\hline
\end{tabular}




\begin{tabular}{|c|c|c|c|c|}
\hline 1985 & Canada & Sulphide dust & Lynn lake & $\mathrm{a}$ \\
\hline 1985 & Germany & Coal & Silo & $1 \mathrm{i}$ \\
\hline 1985 & Norway & $\begin{array}{l}\text { Rape seed flour } \\
\text { pellets }\end{array}$ & Silo & - \\
\hline 1986 & Canada & Sulphide dust & Brunswick mines & a \\
\hline 1986 & Sweden & Sulphide dust & Langsele mines & a \\
\hline 1986 & Canada & Sulphide dust & Dumugami mines & a \\
\hline 1986 & Australia & Sulphide dust & Woodlawn & $\mathrm{a}$ \\
\hline 1987 & Canada & Sulphide dust & GECO mines & a \\
\hline 1987 & China & Textile dust & $\begin{array}{l}\text { Dust collection } \\
\text { system }\end{array}$ & $58 \mathrm{~d} / 177 \mathrm{i}$ \\
\hline 1987 & Oslo, Norway & $\begin{array}{c}\text { Malted barley } \\
\text { dust }\end{array}$ & Silo & - \\
\hline 1988 & Norway & Wheat grain dust & Silo & - \\
\hline 1988 & Sweden & Coal & Silo & - \\
\hline 1989 & Sweden & $\begin{array}{l}\text { Palletized wheat } \\
\text { bran }\end{array}$ & Silo & - \\
\hline 1990 & Japan & Benzoylperoxide & Storage & $9 \mathrm{~d} / 17 \mathrm{i}$ \\
\hline 1992 & Moriya, Japan & $\begin{array}{l}\text { Potassium } \\
\text { chlorate and } \\
\text { aluminum dust }\end{array}$ & Mixing operation & $3 \mathrm{~d} / 58 \mathrm{i}$ \\
\hline 1994 & Okaharu, Japan & Cotton waste & Textile mill & a \\
\hline 1994 & Tokyo, Japan & Rubber waste & Shoe factory & $5 \mathrm{~d} / 22 \mathrm{i}$ \\
\hline 1997 & Japan & Tantalum dust & a & $1 \mathrm{~d} / 1 \mathrm{i}$ \\
\hline 1997 & Blaye, France & Grain & Storage & $11 \mathrm{~d}$ \\
\hline 1999 & Michigan & $\begin{array}{l}\text { Coal dust (cause } \\
\text { for secondary } \\
\text { explosion) }\end{array}$ & Powerhouse & $6 \mathrm{~d} / 14 \mathrm{i}$ \\
\hline 1999 & Massachusetts & Resin & Oven & $3 \mathrm{~d} / 12 \mathrm{i}$ \\
\hline 2000 & Japan & $\mathrm{Mg}-\mathrm{Al}$ alloy & & $1 \mathrm{~d} / 1 \mathrm{i}$ \\
\hline 2000 & Modesto California & Aluminum dust & a & $\mathrm{a}$ \\
\hline 2002 & Mississippi & Rubber & Recycling plant & $5 \mathrm{~d} / /^{\mathrm{a}}$ \\
\hline 2003 & Kentucky & Resin & Production line & $7 d$ \\
\hline 2003 & Kinston, NC & Polyethylene & $\begin{array}{l}\text { Pharmaceutical } \\
\text { plant }\end{array}$ & $6 \mathrm{~d} / 38 \mathrm{i}$ \\
\hline 2004 & Avon, $\mathrm{OH}$ & Lacquer dust & a & a \\
\hline
\end{tabular}

a : Details not available. 
Appendix C Process Safety Management elements 
Table C.1 Process Safety Management elements (Crowl \& Louvar, 2007)

\begin{tabular}{|c|l|}
\hline No. & Process Safety Management elements \\
\hline 1 & Process Safety Information \\
\hline 2 & Process Hazard Analysis \\
\hline 3 & Operating Procedures \\
\hline 4 & Employee participation \\
\hline 5 & Training \\
\hline 6 & Contractors \\
\hline 7 & Pre-Startup Safety Review \\
\hline 8 & Mechanical Integrity \\
\hline 9 & Hot Work \\
\hline 10 & Management of Change \\
\hline 11 & Incident Investigation \\
\hline 12 & Emergency Planning and Response \\
\hline 13 & Compliance Audits \\
\hline 14 & Trade Secrets \\
\hline
\end{tabular}


Appendix D Probit correlations for a variety of explosions and their transformation 
Table D.1 Probit correlations for a variety of exposures (the causative variable is representative of the magnitude of the exposure) (Crowl \& Louvar, 2007).

\begin{tabular}{|l|c|c|}
\hline \multicolumn{1}{|c|}{ Type of injury or damage } & \multicolumn{2}{c|}{ Probit } \\
\cline { 2 - 3 } & $\mathbf{K}_{\mathbf{1}}$ & $\mathbf{K}_{\mathbf{2}}$ \\
\hline Fire & & \\
Burn deaths from flash fire & -14.9 & 2.56 \\
Burn deaths from pool burning & -14.9 & 2.56 \\
\hline Explosion & & \\
Deaths from lung hemorrhage & -77.1 & 6.91 \\
Eardrum ruptures & -15.5 & 1.93 \\
Deaths from impact & -46.1 & 4.82 \\
Injuries from impact & -39.1 & 4.45 \\
Structural damage & -23.8 & 2.92 \\
Glass breakage & -18.1 & 2.79 \\
\hline Toxic release & & \\
\hline Ammonia deaths & -35.90 & 1.86 \\
Carbon monoxide deaths & -37.98 & 3.70 \\
Chlorine deaths & -08.29 & 0.92 \\
Ethylene oxide deaths & -06.19 & 1.00 \\
Hydrogen chloride deaths & -16.85 & 2.00 \\
Nitrogen dioxide deaths & -13.79 & 1.40 \\
Phosgene deaths & -19.27 & 3.69 \\
Propylene oxide deaths & -07.42 & 0.51 \\
Sulfur dioxide deaths & -15.67 & 1.00 \\
Toluene. & -06.79 & 0.41 \\
\hline
\end{tabular}


Table D.2 Transformation from percentages to Probits (Crowl \& Louvar, 2007).

\begin{tabular}{|c|c|c|c|c|c|c|c|c|c|c|}
\hline $\mathbf{0}$ & $\mathbf{0}$ & $\mathbf{1}$ & $\mathbf{2}$ & $\mathbf{3}$ & $\mathbf{4}$ & $\mathbf{5}$ & $\mathbf{6}$ & $\mathbf{7}$ & $\mathbf{8}$ & $\mathbf{9}$ \\
\hline $\mathbf{0}$ & - & 2.67 & 2.95 & 3.12 & 3.25 & 3.36 & 3.45 & 3.52 & 3.59 & 3.66 \\
\hline $\mathbf{1 0}$ & 3.72 & 3.77 & 3.82 & 3.87 & 3.92 & 3.96 & 4.01 & 4.05 & 4.08 & 4.12 \\
\hline $\mathbf{2 0}$ & 4.16 & 4.19 & 4.23 & 4.26 & 4.29 & 4.33 & 4.36 & 4.39 & 4.42 & 4.45 \\
\hline $\mathbf{3 0}$ & 4.48 & 4.50 & 4.53 & 4.56 & 4.59 & 4.61 & 4.64 & 4.67 & 4.69 & 4.72 \\
\hline $\mathbf{4 0}$ & 4.75 & 4.77 & 4.80 & 4.82 & 4.85 & 4.87 & 4.90 & 4.92 & 4.95 & 4.97 \\
\hline $\mathbf{5 0}$ & 5.00 & 5.03 & 5.05 & 5.08 & 5.10 & 5.13 & 5.15 & 5.18 & 5.20 & 5.23 \\
\hline $\mathbf{6 0}$ & 5.25 & 5.28 & 5.31 & 5.33 & 5.36 & 5.39 & 5.41 & 5.44 & 5.47 & 5.50 \\
\hline $\mathbf{7 0}$ & 5.52 & 5.55 & 5.58 & 5.61 & 5.64 & 5.67 & 5.71 & 5.74 & 5.77 & 5.81 \\
\hline $\mathbf{8 0}$ & 5.84 & 5.88 & 5.92 & 5.95 & 5.99 & 6.04 & 6.08 & 6.13 & 6.18 & 6.23 \\
\hline $\mathbf{9 0}$ & 6.28 & 6.34 & 6.41 & 6.48 & 6.55 & 6.64 & 6.75 & 6.88 & 7.05 & 7.33 \\
\hline $\mathbf{9}$ & $\mathbf{0 . 0}$ & $\mathbf{0 . 1}$ & $\mathbf{0 . 2}$ & $\mathbf{0 . 3}$ & $\mathbf{0 . 4}$ & $\mathbf{0 . 5}$ & $\mathbf{0 . 6}$ & $\mathbf{0 . 7}$ & $\mathbf{0 . 8}$ & $\mathbf{0 . 9}$ \\
\hline $\mathbf{9 9}$ & 7.33 & 7.37 & 7.41 & 7.46 & 7.51 & 7.58 & 7.65 & 7.75 & 7.88 & 8.09 \\
\hline
\end{tabular}


Appendix E Severity of consequences and hazard probability ratings 
Table E.1 Criticality rating (or severity of consequences ratings) for the decision matrix risk assessment technique (Marhavilas \& Koulouriotis, 2008).

\begin{tabular}{|c|c|l|}
\hline \multicolumn{3}{|c|}{ Severity of consequences ratings (S) } \\
\hline Category & Descriptive word & \multicolumn{1}{c|}{ Description } \\
\hline 6 & Super-catastrophe & $\begin{array}{l}\text { Massive deaths damage and production loss } \\
>1,000,000 €\end{array}$ \\
\hline 5 & Catastrophe & $\begin{array}{l}\text { Multiple deaths damage and production loss } \\
>100,000 €\end{array}$ \\
\hline 4 & Critical & $\begin{array}{l}\text { Death or multiple injuries damage and production } \\
\text { loss between } 10,000 \text { and } 100,000 €\end{array}$ \\
\hline 3 & Hazardous & $\begin{array}{l}\text { Time loss or permanent injury damage and } \\
\text { production loss between } 1000 \text { and } 10,000 €\end{array}$ \\
\hline 2 & Marginal & $\begin{array}{l}\text { Single injury damage and production loss between } \\
100 \text { and } 1000 €\end{array}$ \\
\hline 1 & Negligible & $\begin{array}{l}\text { Slight or no injury damage and production loss }< \\
100 €\end{array}$ \\
\hline
\end{tabular}

Table E.2 Frequency rating (or hazard probability ratings) for the decision matrix risk assessment technique (Marhavilas \& Koulouriotis, 2008).

\begin{tabular}{|c|l|l|}
\hline \multicolumn{3}{|c|}{ Hazard probability ratings (P) } \\
\hline Category & Descriptive word & \multicolumn{1}{|c|}{ Frequency of event occurring } \\
\hline 6 & Frequent & 1 event during a time period of $\Delta \mathrm{t}<10^{3} \mathrm{~h}$ \\
\hline 5 & Probable & 1 event during a time period of $10^{3}<\Delta \mathrm{t}<10^{4} \mathrm{~h}$ \\
\hline 4 & Occasional & 1 event during a time period of $10^{4}<\Delta \mathrm{t}<10^{5} \mathrm{~h}$ \\
\hline 3 & Remote & 1 event during a time period of $10^{5}<\Delta \mathrm{t}<10^{6} \mathrm{~h}$ \\
\hline 2 & Improbable & 1 event during a time period of $10^{6}<\Delta \mathrm{t}<10^{7} \mathrm{~h}$ \\
\hline 1 & Impossible & 1 event during a time period of $\Delta \mathrm{t}>10^{7} \mathrm{~h}$ \\
\hline
\end{tabular}


Appendix $\mathrm{F}$ Explosibility parameters of different dust materials, used in DESC simulations 
Table F.1 Explosibility parameters of polyethylene dust, -200 mesh (Sample no. A).

\begin{tabular}{|c|c|c|c|c|c|c|}
\hline $\begin{array}{c}\text { Test } \\
\text { No. }\end{array}$ & $\begin{array}{c}\text { Concentration } \\
{\left[\mathbf{g} / \mathbf{m}^{\mathbf{3}}\right]}\end{array}$ & $\begin{array}{c}\mathbf{P}_{\mathbf{m}} * \\
{[\mathbf{b a r}(\mathbf{g})]}\end{array}$ & $\begin{array}{c}\mathbf{P}_{\mathbf{m}} * * \\
{[\mathbf{b a r}(\mathbf{g})]}\end{array}$ & $\begin{array}{c}(\mathbf{d P} / \mathbf{d t})_{\mathbf{m}} * \\
{[\mathbf{b a r} / \mathbf{s}]}\end{array}$ & $\begin{array}{c}(\mathbf{d P} / \mathbf{d t})_{\mathbf{m}} * * \\
{[\mathbf{b a r} / \mathbf{s}]}\end{array}$ & $\begin{array}{c}\mathbf{K}_{\mathbf{S}}{ }^{* *} \\
(\mathbf{b a r} \cdot \mathbf{m} / \mathbf{s})\end{array}$ \\
\hline 1 & 125 & 6.4 & 6.3 & 207 & 207 & 56 \\
\hline 2 & 250 & 6.5 & 6.4 & 216 & 235 & 64 \\
\hline 3 & 500 & 6.8 & 6.6 & 278 & 278 & 75 \\
\hline 4 & 750 & 6.4 & 6.7 & 286 & 320 & 87 \\
\hline 5 & 1000 & 6.4 & 6.6 & 374 & 360 & 98 \\
\hline 6 & 1250 & 6.3 & 6.2 & 331 & 340 & 92 \\
\hline 7 & 1500 & 5.9 & 5.8 & 284 & 312 & 85 \\
\hline 8 & 2000 & - & 4.5 & - & 260 & 71 \\
\hline
\end{tabular}

* Average experimental data

** Smoothed experimental data for DESC

Table F.2 Explosibility parameters of polyethylene dust, -70 mesh (Sample no. B).

\begin{tabular}{|c|c|c|c|c|c|c|}
\hline $\begin{array}{c}\text { Test } \\
\text { No. }\end{array}$ & $\begin{array}{c}\text { Concentration } \\
{\left[\mathbf{g} / \mathbf{m}^{\mathbf{3}}\right]}\end{array}$ & $\begin{array}{c}\mathbf{P}_{\mathbf{m}} * \\
{[\mathbf{b a r}(\mathbf{g})]}\end{array}$ & $\begin{array}{c}\mathbf{P}_{\mathbf{m}} * * \\
{[\mathbf{b a r}(\mathbf{g})]}\end{array}$ & $\begin{array}{c}(\mathbf{d P} / \mathbf{d t})_{\mathbf{m}} * \\
{[\mathbf{b a r} / \mathbf{s}]}\end{array}$ & $\begin{array}{c}\mathbf{( d P / d t})_{\mathbf{m}} * * \\
{[\mathbf{b a r} / \mathbf{s}]}\end{array}$ & $\begin{array}{c}\mathbf{K}_{\mathbf{S t}} * * \\
(\mathbf{b a r} \bullet \mathbf{m} / \mathbf{s})\end{array}$ \\
\hline 1 & 125 & - & 1 & - & 4 & 1 \\
\hline 2 & 250 & 0 & 2.5 & 0 & 18 & 5 \\
\hline 3 & 500 & 6.2 & 6.4 & 41 & 55 & 15 \\
\hline 4 & 750 & 5.9 & 5 & 36 & 48 & 13 \\
\hline 5 & 1000 & 5.4 & 4 & 42 & 33 & 9 \\
\hline 6 & 1250 & 5.2 & 3.5 & 48 & 22 & 6 \\
\hline 7 & 1500 & - & 3 & - & 15 & 4 \\
\hline 8 & 2000 & - & 2 & - & 4 & 1 \\
\hline
\end{tabular}

* Average experimental data

** Smoothed experimental data for DESC 
Table F.3 Explosibility parameters of polyethylene dust, -200 mesh $+1 \%$ hexane (Sample no. C).

\begin{tabular}{|c|c|c|c|c|c|c|}
\hline $\begin{array}{c}\text { Test } \\
\text { No. }\end{array}$ & $\begin{array}{c}\text { Concentration } \\
{\left[\mathbf{g} / \mathbf{m}^{\mathbf{3}}\right]}\end{array}$ & $\begin{array}{c}\mathbf{P}_{\mathbf{m}} * \\
{[\mathbf{b a r}(\mathbf{g})]}\end{array}$ & $\begin{array}{c}\mathbf{P}_{\mathbf{m}} * * \\
{[\mathbf{b a r}(\mathbf{g})]}\end{array}$ & $\begin{array}{c}(\mathbf{d P} / \mathbf{d t})_{\mathbf{m}} * \\
{[\mathbf{b a r} / \mathbf{s}]}\end{array}$ & $\begin{array}{c}(\mathbf{d P} / \mathbf{d t})_{\mathbf{m}} * * \\
{[\mathbf{b a r} / \mathbf{s}]}\end{array}$ & $\begin{array}{c}\mathbf{K}_{\mathbf{S t}} * * \\
(\mathbf{b a r} \cdot \mathbf{m} / \mathbf{s})\end{array}$ \\
\hline 1 & 125 & 7.2 & 7.2 & 312 & 276 & 75 \\
\hline 2 & 250 & 7.3 & 7.3 & 466 & 460 & 125 \\
\hline 3 & 500 & 6.8 & 6.8 & 479 & 512 & 139 \\
\hline 4 & 750 & 5.9 & 6.1 & 352 & 401 & 109 \\
\hline 5 & 1000 & - & 5.4 & - & 276 & 75 \\
\hline 6 & 1250 & - & 4.5 & - & 147 & 40 \\
\hline
\end{tabular}

* Average experimental data

** Smoothed experimental data for DESC

Table F.4 Explosibility parameters of corn starch (maize) dust (provided by GexCon).

\begin{tabular}{|c|c|c|c|c|}
\hline $\begin{array}{c}\text { Test } \\
\text { No. }\end{array}$ & $\begin{array}{c}\text { Concentration } \\
{\left[\mathbf{g} / \mathbf{m}^{3}\right]}\end{array}$ & $\begin{array}{c}\mathbf{P}_{\mathbf{m}}{ }^{*} \\
(\mathbf{b a r}(\mathbf{g}) \mathbf{)}\end{array}$ & $\begin{array}{c}(\mathbf{d P} / \mathbf{d t})_{\mathbf{m}} * * \\
(\mathbf{b a r} / \mathbf{s})\end{array}$ & $\begin{array}{c}\mathbf{K}_{\mathbf{S t}}{ }^{*} \\
(\mathbf{b a r} \bullet \mathbf{m} / \mathbf{s})\end{array}$ \\
\hline 1 & 30 & 1.2 & 16 & 4 \\
\hline 2 & 60 & 2.8 & 150 & 41 \\
\hline 3 & 125 & 6.2 & 328 & 89 \\
\hline 4 & 250 & 9.6 & 692 & 188 \\
\hline 5 & 500 & 8.7 & 1187 & 322 \\
\hline 6 & 750 & 7.8 & 1072 & 291 \\
\hline 7 & 1000 & 7.0 & 850 & 231 \\
\hline 8 & 1500 & 5.5 & 475 & 129 \\
\hline
\end{tabular}

* Smoothed experimental data for DESC 
Appendix G Elsevier license, terms and conditions. 


\section{ELSEVIER LICENSE TERMS AND CONDITIONS}

This is a License Agreement between Meftah Abuswer ("You") and Elsevier ("Elsevier") provided by Copyright Clearance Center ("CCC"). The license consists of your order details, the terms and conditions provided by Elsevier, and the payment terms and conditions.

\section{All payments must be made in full to CCC. For payment instructions, please see information listed at the bottom of this form.}

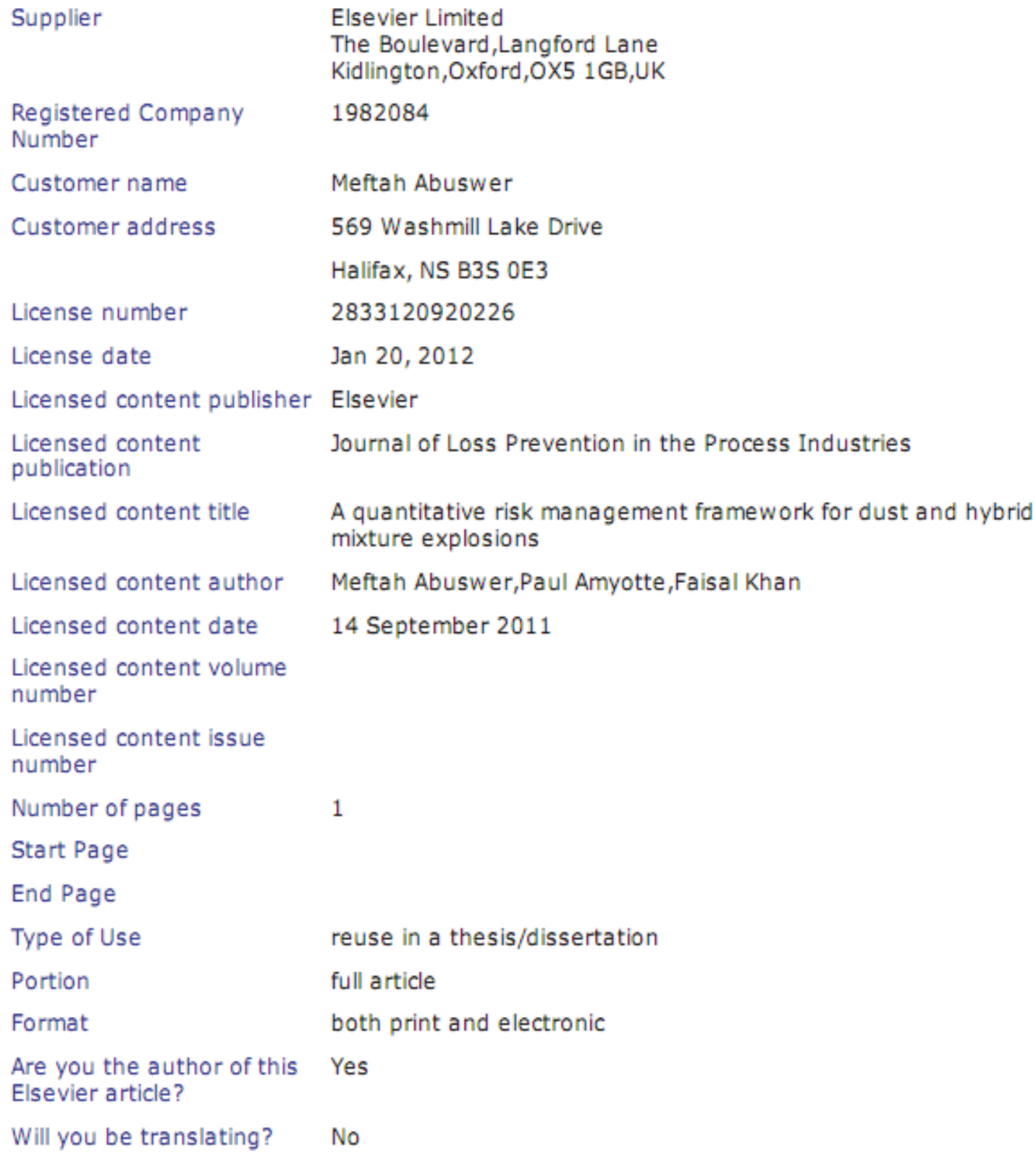
mixture explosions

Start Page

End Page

Type of Use

reuse in a thesis/dissertation

Portion

full article

Format

both print and electronic

Are you the author of this Yes

Elsevier article?

Will you be translating? No 
Order reference number

Title of your

thesis/dissertation

Expected completion date

Estimated size (number of pages)

Elsevier VAT number

Permissions price

VAT/Local Sales Tax

Total

Terms and Conditions
A QUANTITATIVE RISK MANAGEMENT FRAMEWORK FOR DUST AND HYBRID MIXTURE EXPLOSION PREVENTION

Mar 2012

170

GB 494627212

0.00 USD

0.00 USD / GBP

0.00 USD

\section{INTRODUCTION}

1. The publisher for this copyrighted material is Elsevier. By clicking "accept" in connection with completing this licensing transaction, you agree that the following terms and conditions apply to this transaction (along with the Billing and Payment terms and conditions established by Copyright Clearance Center, Inc. ("CCC"), at the time that you opened your Rightslink account and that are available at any time at http://myaccount.copyright.com).

\section{GENERAL TERMS}

2. Elsevier hereby grants you permission to reproduce the aforementioned material subject to the terms and conditions indicated.

3. Acknowledgement: If any part of the material to be used (for example, figures) has appeared in our publication with credit or acknowledgement to another source, permission must also be sought from that source. If such permission is not obtained then that material may not be included in your publication/copies. Suitable acknowledgement to the source must be made, either as a footnote or in a reference list at the end of your publication, as follows:

"Reprinted from Publication title, Vol/edition number, Author(s), Title of article / title of chapter, Pages No., Copyright (Year), with permission from Elsevier [OR APPLICABLE SOCIETY COPYRIGHT OWNER]." Also Lancet special credit - "Reprinted from The Lancet, Vol. number, Author(s), Title of article, Pages No., Copyright (Year), with permission from Elsevier."

4. Reproduction of this material is confined to the purpose and/or media for which permission is hereby given.

5. Altering/Modifying Material: Not Permitted. However figures and illustrations may be altered/adapted minimally to serve your work. Any other abbreviations, additions, deletions and/or any other alterations shall be made only with prior written authorization of Elsevier Ltd. (Please contact Elsevier at permissions@elsevier.com)

6. If the permission fee for the requested use of our material is waived in this instance, please be advised that your future requests for Elsevier materials may attract a fee. 
7. Reservation of Rights: Publisher reserves all rights not specifically granted in the combination of (i) the license details provided by you and accepted in the course of this licensing transaction, (ii) these terms and conditions and (iii) CCC's Billing and Payment terms and conditions.

8. License Contingent Upon Payment: While you may exercise the rights licensed immediately upon issuance of the license at the end of the licensing process for the transaction, provided that you have disclosed complete and accurate details of your proposed use, no license is finally effective unless and until full payment is received from you (either by publisher or by $\mathrm{CCC}$ ) as provided in CCC's Billing and Payment terms and conditions. If full payment is not received on a timely basis, then any license preliminarily granted shall be deemed automatically revoked and shall be void as if never granted. Further, in the event that you breach any of these terms and conditions or any of CCC's Billing and Payment terms and conditions, the license is automatically revoked and shall be void as if never granted. Use of materials as described in a revoked license, as well as any use of the materials beyond the scope of an unrevoked license, may constitute copyright infringement and publisher reserves the right to take any and all action to protect its copyright in the materials.

9. Warranties: Publisher makes no representations or warranties with respect to the licensed material.

10. Indemnity: You hereby indemnify and agree to hold harmless publisher and $\mathrm{CCC}$, and their respective officers, directors, employees and agents, from and against any and all claims arising out of your use of the licensed material other than as specifically authorized pursuant to this license.

11. No Transfer of License: This license is personal to you and may not be sublicensed, assigned, or transferred by you to any other person without publisher's written permission.

12. No Amendment Except in Writing: This license may not be amended except in a writing signed by both parties (or, in the case of publisher, by CCC on publisher's behalf).

13. Objection to Contrary Terms: Publisher hereby objects to any terms contained in any purchase order, acknowledgment, check endorsement or other writing prepared by you, which terms are inconsistent with these terms and conditions or CCC's Billing and Payment terms and conditions. These terms and conditions, together with CCC's Billing and Payment terms and conditions (which are incorporated herein), comprise the entire agreement between you and publisher (and CCC) concerning this licensing transaction. In the event of any conflict between your obligations established by these terms and conditions and those established by $\mathrm{CCC}$ 's Billing and Payment terms and conditions, these terms and conditions shall control.

14. Revocation: Elsevier or Copyright Clearance Center may deny the permissions described in this License at their sole discretion, for any reason or no reason, with a full refund payable to you. Notice of such denial will be made using the contact information provided by you. Failure to receive such notice will not alter or invalidate the denial. In no event will Elsevier or Copyright Clearance Center be responsible or liable for any costs, expenses or damage incurred by you as a result of a denial of your permission request, other than a refund of the amount(s) paid by you to Elsevier and/or Copyright Clearance Center for denied permissions.

\section{LIMITED LICENSE}


The following terms and conditions apply only to specific license types:

15. Translation: This permission is granted for non-exclusive world English rights only unless your license was granted for translation rights. If you licensed translation rights you may only translate this content into the languages you requested. A professional translator must perform all translations and reproduce the content word for word preserving the integrity of the article. If this license is to re-use 1 or 2 figures then permission is granted for non-exclusive world rights in all languages.

16. Website: The following terms and conditions apply to electronic reserve and author websites: Electronic reserve: If licensed material is to be posted to website, the web site is to be password-protected and made available only to bona fide students registered on a relevant course if:

This license was made in connection with a course, This permission is granted for 1 year only. You may obtain a license for future website posting, All content posted to the web site must maintain the copyright information line on the bottom of each image,

A hyper-text must be included to the Homepage of the journal from which you are licensing at http://www.sciencedirect.com/science/journal/xxxxx or the Elsevier homepage for books at http://www.elsevier.com, and

Central Storage: This license does not include permission for a scanned version of the material to be stored in a central repository such as that provided by Heron/XanEdu.

17. Author website for journals with the following additional clauses:

All content posted to the web site must maintain the copyright information line on the bottom of each image, and the permission granted is limited to the personal version of your paper. You are not allowed to download and post the published electronic version of your article (whether PDF or HTML, proof or final version), nor may you scan the printed edition to create an electronic version. A hyper-text must be included to the Homepage of the journal from which you are licensing at http://www.sciencedirect.com/science/journal/xxxxx . As part of our normal production process, you will receive an e-mail notice when your article appears on Elsevier's online service ScienceDirect (www.sciencedirect.com). That e-mail will include the article's Digital Object Identifier (DOI). This number provides the electronic link to the published article and should be included in the posting of your personal version. We ask that you wait until you receive this e-mail and have the DOI to do any posting.

Central Storage: This license does not include permission for a scanned version of the material to be stored in a central repository such as that provided by Heron/XanEdu.

18. Author website for books with the following additional clauses:

Authors are permitted to place a brief summary of their work online only. A hyper-text must be included to the Elsevier homepage at http $/ /$ www.elsevier.com. All content posted to the web site must maintain the copyright information line on the bottom of each image. You are not allowed to download and post the published electronic version of your chapter, nor may you scan the printed edition to create an electronic version. 
Central Storage: This license does not include permission for a scanned version of the material to be stored in a central repository such as that provided by Heron/XanEdu.

19. Website (regular and for author): A hyper-text must be included to the Homepage of the journal from which you are licensing at http $/ /$ www.sciencedirect.com $/$ science $/ j o u r n a l / x x x x x$. or for books to the Elsevier homepage at http://www.elsevier.com

20. Thesis/Dissertation: If your license is for use in a thesis/dissertation your thesis may be submitted to your institution in either print or electronic form. Should your thesis be published commercially, please reapply for permission. These requirements include permission for the Library and Archives of Canada to supply single copies, on demand, of the complete thesis and include permission for UMI to supply single copies, on demand, of the complete thesis. Should your thesis be published commercially, please reapply for permission.

21. Other Conditions: Please note that as one of the Authors of this article, you retain the right to include the journal article, in full or in part, in a thesis or dissertation. You do not require permission to do so.

v1.6

If you would like to pay for this license now, please remit this license along with your payment made payable to "COPYRIGHT CLEARANCE CENTER" otherwise you will be invoiced within 48 hours of the license date. Payment should be in the form of a check or money order referencing your account number and this invoice number RLNK500703146. Once you receive your invoice for this order, you may pay your invoice by credit card. Please follow instructions provided at that time.

Make Payment To:

Copyright Clearance Center

Dept 001

P.O. Box 843006

Boston, MA 02284-3006

For suggestions or comments regarding this order, contact RightsLink Customer Support: customercare@copyright.com or +1-877-622-5543 (toll free in the US) or +1-978-6462777.

Gratis licenses (referencing $\$ 0$ in the Total field) are free. Please retain this printable license for your reference. No payment is required. 